UNIVERSIDADE DE SÃO PAULO

ESCOLA DE ENFERMAGEM DE RIBEIRÃO PRETO

Simone de Oliveira Pileggi

VALIDAÇÃO CLÍNICA DO DIAGNÓSTICO DE ENFERMAGEM DESOBSTRUÇÃO INEFICAZ DE VIAS AÉREAS DE CRIANÇAS E ADOLESCENTES SUBMETIDOS À CORREÇÃO CIRÚRGICA DE CARDIOPATIA CONGÊNITA 
Simone de Oliveira Pileggi

\title{
VALIDAÇÃO CLÍNICA DO DIAGNÓSTICO DE ENFERMAGEM DESOBSTRUÇÃO INEFICAZ DE VIAS AÉREAS DE CRIANÇAS E ADOLESCENTES SUBMETIDOS À CORREÇÃO CIRÚRGICA DE CARDIOPATIA CONGÊNITA
}

\begin{abstract}
Dissertação apresentada ao Programa de Pós-Graduação em Enfermagem Fundamental da Escola de Enfermagem de Ribeirão Preto da Universidade de São Paulo para obtenção do título de Mestre em Enfermagem

Linha de pesquisa: Fundamentação teórica, metodológica e tecnológica do processo de cuidar em enfermagem

Orientadora: Maria Célia Barcellos Dalri
\end{abstract}


AUTORIZO A REPRODUÇÃO E DIVULGAÇÃO TOTAL OU PARCIAL DESTE TRABALHO, POR QUALQUER MEIO CONVENCIONAL OU ELETRÔNICO, PARA FINS DE ESTUDO E PESQUISA, DESDE QUE CITADA A FONTE.

Ficha catalográfica

Pileggi, Simone de Oliveira

Validação clínica do diagnóstico de enfermagem desobstrução ineficaz de vias aéreas de crianças e adolescentes submetidos à correção cirúrgica de cardiopatia congênita. Simone de Oliveira Pileggi - Ribeirão Preto, 2007.

Dissertação de Mestrado - Escola de Enfermagem de Ribeirão Preto, Universidade de São Paulo, 2007.

Orientadora: Maria Célia Barcellos Dalri

1- Diagnóstico de Enfermagem 2- Cardiopatia Congênita $\quad$ 3- Validação Clínica

4- Criança e Adolescentes 


\section{FOLHA DE APROVAÇÃO}

Simone de Oliveira Pileggi

Validação clínica do diagnóstico de enfermagem desobstrução ineficaz de vias aéreas de crianças e adolescentes submetidos à correção cirúrgica de cardiopatia congênita

Dissertação apresentada ao Programa de PósGraduação em Enfermagem Fundamental da Escola de Enfermagem de Ribeirão Preto da Universidade de São Paulo para obtenção do título de Mestre em Enfermagem Linha de pesquisa: Fundamentação teórica, metodológica e tecnológica do processo de cuidar em enfermagem.

Aprovado em:

\section{Banca Examinadora}

Prof. Dr.

Instituição: Assinatura:

Prof. Dr.

Instituição: Assinatura:

Prof. Dr.

Instituição:

Assinatura:

Prof. Dr.

Instituição: Assinatura: 
Dedico este trabalho:

Aos meus pais JOÃo E LÚCIA HELENA pela oportunidade de vida, por me aceitar como filha e pela dedicação de me educação. Pelo companheirismo, cuidado, carinho e paciência durante todo o período de elaboração desse trabalho.

\section{IDADE DE SER FELIZ...}

Existe somente uma idade para a gente ser feliz, somente uma época na vida de cada pessoa em que é possível sonhar e fazer planos e ter energia bastante para utilizá-los a despeito de todas as dificuldades e obstáculos.

Uma só idade para a gente se encantar com a vida e viver apaixonadamente e desfrutar tudo com toda intensidade sem medo nem culpa de sentir prazer.

... Fase dourada em que a gente pode criar e recriar a vida à nossa própria imagem e semelhança e vestir-se com todas as cores e experimentar todos os sabores e entregar-se a todos os amores sem preconceito nem pudor.

Tempo de entusiasmo e coragem em que todo desafio é um convite à luta que a gente enfrenta com toda disposição de tentar algo de novo, e quantas vezes foi preciso.

Essa idade tão fugaz na vida da gente chama-se PRESENTE e tem a duração do instante que passa"... 
AGRADECIMENTO ESPECIAL

A minha orientadora e sempre amiga, Prof $^{\mathrm{A}} \mathrm{Dr}^{\mathrm{a}}$ Maria Celia Barcellos Dalri, pelos grandes ensinamentos em Enfermagem, por acreditar na minha capacidade de ser Mestre em Enfermagem, e pelo apoio e estímulo mesmo nos momentos dificeis, pois "Bons professores são mestre temporários, professores fascinantes sāo mestres inesquecíveis, e ser um mestre inesquecível é formar seres humanos que farão diferença no mundo".

Augusto Cury 


\section{AGRADECIMENTOS}

A Deus pela oportunidade de crescimento intelectual e espiritual

Aos meus irmãos e esposas Flávio e Gecilmara, Rodrigo e Fábia, Mateus e Camila pelo carinho, amizade, companheirismo e compreensão pelos momentos de ausência.

Aos grandes amores da minha vida, meus sobrinhos João vitor, Murilo, Gabriela e Pedro, pelos momentos de descontração, proporcionados por vocês e pela capacidade de compreensão de minha ausência.

Ao Manoel, meu namorado, com amor, admiração e gratidão por sua compreensão, carinho, presença e incansável apoio ao longo do período de elaboração deste trabalho.

A Sra. Maria Zilah, minha sogra, pelo apoio e carinho dispensado durante a elaboração deste trabalho e pelo "cantinho" usado por mim em sua casa para estudar.

Aos meus demais familiares que estão sempre manifestando, de alguma forma, seu imenso amor.

À Profa. Dra. Adriana Moraes Leite, pelas sugestões na realização deste trabalho.

À Profa. Dra. Alexandra de Souza Melo, pela assessoria e sugestões para melhoria desse trabalho.

A Enfa. Léa, minha chefe e amiga, pelo apoio, amizade, compreensão, confiança, convivência e pelos ensinamentos em Enfermagem.

As Enfas. Cristina, Tatiana, Claudinéia, Mariléia, Maria Cândida e Rita Barbieri minhas ternas amigas, pelo companheirismo no dia a dia de trabalho, e pelo apoio nas horas mais difíceis.

Aos Enfos. Peritos, por terem aceitado participar desta pesquisa.

À Profa Dra. Silvia M. Canini pelo apoio nas horas mais difíceis.

A toda equipe multiprofissional do Centro de Terapia Intensiva Pediátrico Unidade Campus pela compreensão e esforço para realização deste trabalho. 
A Sra. Lúcia Helena de Oliveira Pileggi, minha mãe, pela correção ortográfica

A todas as crianças e responsáveis que fizeram parte deste estudo, por acreditar que algo poderia ser feito em benefício delas e de outras crianças.

Às secretárias do Departamento do EGE e da Seção de Pós-Graduação, em especial a Sra. Edilaine C. Amadio Domingues.

Ao Prof. Dr. Vanderley José Haas, pela orientação estatística.

Ao Prof. Dr. Francisco Martinez, chefe do Departamento de Pediatria e Puericultura e Profa. Dra. Ana Paula Carlotti, docente responsável pelo CTIP pela autorização da realização deste trabalho. 


\section{RESUMO}

PILEGGI, S.O. Validação clínica do diagnóstico de enfermagem Desobstrução ineficaz de vias aéreas de crianças e adolescentes submetidos à correção cirúrgica de cardiopatia congênita. 2007. 224f. Dissertação (Mestrado) - Escola de Enfermagem de Ribeirão Preto da Universidade de São Paulo, 2007.

Este estudo teve como objetivo realizar a validação clínica do diagnóstico de enfermagem da North American Nursing Diagnoses Association (NANDA, 2006) "Desobstrução ineficaz de vias aéreas" de crianças e adolescentes submetidos à correção cirúrgica de cardiopatia congênita, em um hospital de ensino público de nível terciário da cidade de Ribeirão Preto-SP. O projeto teve aprovação do Comitê de Ética e Pesquisa da referida instituição, foram incluídos os profissionais que aquiesceram em participar do estudo e os sujeitos cujos responsáveis autorizaram. Adotou-se o modelo de validação clínica proposto por Hoskins (1989) que inclui as seguintes etapas: análise de conceito, validação por especialistas e validação clínica. Após ampla revisão da literatura foram descritos os conceitos relacionados a cada uma das características definidoras, em seguida o diagnóstico foi analisado por 40 enfermeiros considerados peritos, segundo a pontuação de Fehring (1994). A adequação do título e da definição do diagnóstico em estudo foi considerada adequada por $70 \%$ dos peritos. Em relação às 13 características definidoras propostas pela NANDA (2006), 04 receberam, dos peritos, escores considerados "maiores", 07 " menores" e 02 obtiveram escores abaixo de 0,50, ou seja, avaliadas como não indicativas para o diagnóstico desobstrução ineficaz das vias aéreas. Procedeu-se a validação clínica por duas enfermeiras peritas, que analisaram a presença do diagnóstico e as respectivas características definidoras em 50 crianças e adolescentes. Em relação a presença do diagnóstico na clientela estudada houve a concordância de $97,7 \%$ dos enfermeiros peritos. A única característica definidora 
que obteve o coeficiente de confiabilidade segundo os critérios de Fehring foi "tosse ausente"; pesar de apenas esta característica definidora estar presente, foi suficiente para confirmar a presença deste diagnóstico na população estudada. Por se tratar de uma população específica e em condições de pós-operatório imediato, ou seja, $60 \%$ dos sujeitos estavam sob efeitos de anestésicos no momento da validação clínica, torna-se necessário o desenvolvimento de estudos futuros que possam validar o diagnóstico "Desobstrução ineficaz de vias aéreas" em crianças e adolescentes em outras situações clínicas. Porém, a identificação deste diagnóstico em crianças e adolescentes submetidos à correção cirúrgica de cardiopatia congênita poderá contribuir para a elaboração de um plano de assistência de enfermagem de qualidade, uma vez que se não atendido prontamente pode levar os indivíduos a sérias complicações.

Palavras-chave: diagnóstico de enfermagem, validação clínica, crianças, adolescentes, cardiopatia congênita. 


\begin{abstract}
PILEGGI, S.O. Clinical validation of nursing diagnosis of "Ineffective airway clearance" on children and teenagers who underwent surgical correction for congenital heart disease. 2007. 224f. Master Dissertation - University of São Paulo at Ribeirão Preto College of Nursing, 2007.
\end{abstract}

This study aimed to accomplish the clinical validation of the nursing diagnoses of the North American Nursing Diagnoses Association (NANDA, 2006) "Ineffective airway clearance" of children and teenagers who underwent surgical correction of congenital heart diseases at a public teaching hospital, working with complex diagnosis and treatments, in the city of Ribeirão Preto. The project has been approved by the Ethics and Research Committee of the referred institution. It has been included the professionals that wanted to participate in the study and subjects whose responsible have authorized. It has been adopted the clinical validation model proposed by Hoskins (1989) which includes the following stages: concept analysis, validation by specialist and clinical validation. After an ample literature review it has been described the concepts related to each one of the defining characteristics, afterwards the diagnoses was analyzed by 40 nurses who are considered to be experts, according to the Fehring scoring (1994). The adaptation of the title and the definition of the diagnoses under study were considered adequate by $70 \%$ of the experts. In relation to the 13 defining characteristics proposed by NANDA (2006), four received scores that were considered "higher" by experts, seven were considered "lower" and two scores were below 0,50 that is, they were assessed as not indicative for diagnosis of ineffective airway clearance. The clinical validation was carried out by two expert nurses, who analyzed the presence of the diagnoses and the respective defining characteristics in 50 children and teenagers. In relation to the presence of the diagnosis on the studied patients, there was the agreement of $97,7 \%$ of the 
expert nurses. The only defining characteristic which achieved the coefficient of reliability according to the Fehring criteria was "absence of cough". Although it was the only defining characteristic present, it was sufficient to confirm the presence of this diagnosis on the studied population. Because of the characteristics of being a specific population, under condition of immediate post operative, that is $60 \%$ of the subjects were under anesthetic effect at the moment of clinical validation, it is necessary the development of future studies that can validate the diagnosis "Ineffective airway clearance" in children and teenagers in other clinical situations. However the identification of this diagnosis in children and teenagers who underwent surgical correction for congenital heart disease will be able to contribute to the elaboration of a quality assistance program in nursing, once that if the individual is not promptly assisted there can be serious complications to the patients.

Keywords: nursing diagnosis, clinical validation, children, teenagers, congenital heart disease. 


\section{RESUMEN}

PILEGGI, S.O. Validación clínica del diagnóstico de enfermería. Desobstrucción ineficaz de vías aéreas en niños y adolescentes sometidos a la corrección quirúrgica de cardiopatía congénita.2007. 224f. Disertación (Maestría) - Escuela de Enfermería de Ribeirão Preto de la Universidad de São Paulo, 2007.

Este estudio tuvo como objetivo realizar la validación clínica del diagnóstico de enfermería de la North American Nursing Diagnoses Association (NANDA, 2006) "Desobstrucción ineficaz de vías aéreas" en niños y adolescentes sometidos a la corrección quirúrgica de cardiopatía congénita, en un hospital de enseñanza pública de nivel terciario de la ciudad de Ribeirão Preto-SP. El proyecto tuvo la aprobación del Comité de Ética y Pesquisa de la referida institución, fueron incluidos los profesionales que concordaron en participar del estudio y los sujetos cuyos responsables autorizaron. Se adoptó el modelo de validación clínica propuesto por Hoskins (1989) que incluye las siguientes etapas: análisis de concepto, validación por especialistas y validación clínica. Después de una amplia revisión de la literatura fueron descriptos los conceptos relacionados a cada una de las características definidoras, en seguida el diagnóstico fue evaluado por 40 enfermeros considerados peritos, según la puntuación de Fehring (1994). La adecuación del título y de la definición del diagnóstico en estudio fue considerada adecuada por el $70 \%$ de los peritos. Con relación a las 13 características definidoras propuestas por la NANDA (2006), 04 recibieron, de los peritos, puntaje considerados "mayores", 07 "menores" y 02 obtuvieron puntaje debajo de 0,50 , o sea, evaluados como no indicativas para el diagnóstico desobstrucción ineficaz de vías aéreas. Se procedió la validación clínica por dos enfermeras peritas, que analizaron la presencia del diagnóstico y las respectivas características definidoras en 50 niños y adolescentes. 
Con relación a la presencia del diagnóstico en la clientela estudiada hubo concordancia de $97,7 \%$ de los enfermeros peritos. La única característica definidora que obtuvo el coeficiente de confiabilidad según los criterios de Fehring fue "tos ausente" a pesar de apenas esta característica definidora estar presente, fue suficiente para confirmar la presencia de este diagnóstico en la población estudiada. Por tratarse de una población específica y en condiciones de post operatorio inmediato, o sea el $60 \%$ de los sujetos estaban sobre efectos de anestésicos, en el momento de la validación clínica, se vuelve necesario el desarrollo de estudios futuros que puedan validar el diagnóstico "Desobstrucción ineficaz de vías aéreas" en niños y adolescentes en otras situaciones clínicas. Sin embargo, la identificación de este diagnóstico en niños y adolescentes sometidos a la corrección quirúrgica de cardiopatía congénita podrá contribuir para la elaboración de un plan de asistencia de enfermería de calidad, ya que si no fuesen atendidos rápidamente puede llevar a los individuos a serias complicaciones.

Palabras claves: diagnóstico de enfermería, validación clínica, niños, adolescentes, cardiopatía congénita. 


\section{LISTA DE TABELAS}

\section{Tabela 1}

Distribuição dos enfermeiros peritos de acordo com sua localidade de trabalho no território nacional. Ribeirão Preto, 2006

\section{Tabela 2}

Distribuição dos enfermeiros peritos de acordo com a faixa etária profissional ( $\mathrm{N}=40)$. Ribeirão Preto, 2006.

Tabela 3

Distribuição de trabalhos ou atividades científicas dos enfermeiros peritos abordando o tema Diagnóstico de Enfermagem $(n=40)$. Ribeirão Preto, 2006 142

\section{Tabela 4}

Distribuição de trabalhos ou atividades científicas dos enfermeiros peritos abordando o tema Desobstrução Ineficaz de Vias Aéreas $(n=23)$. Ribeirão Preto, 2006 142

\section{Tabela 5}

Distribuição dos 40 enfermeiros peritos, segundo a pontuação obtida, conforme a proposta de Ferhing (1994). Ribeirão Preto, 2006 144

\section{Tabela 6}

Distribuição das respostas dos 40 enfermeiros peritos, segundo a adequação da definição e do título do Diagnóstico de Enfermagem "DIVA" apresentada pela NANDA (2006), Ribeirão Preto, 2006 145

\section{Tabela 7}

Distribuição das respostas dos 40 peritos segundo o padrão funcional ao qual o Diagnóstico de Enfermagem "DIVA" deveria pertencer. Ribeirão Preto, 2006 


\section{Tabela 8}

Distribuição das características definidoras do Diagnóstico de Enfermagem "Desobstrução Ineficaz de Vias Aéreas", de acordo com os escores obtidos na Validação por Especialista. Ribeirão Preto, 2006. 150

Tabela 9

Distribuição das 13 características definidoras do diagnóstico de enfermagem "Desobstrução ineficaz de vias aéreas", segundo os escores obtidos na validação por Especialistas $(\mathrm{N}=40)$. Ribeirão Preto, 2006 152

Tabela 10

Distribuição das 13 características definidoras do diagnóstico de enfermagem "Desobstrução Ineficaz de Vias Aéreas", segundo suas medianas e distâncias interquartílicas obtidas pelos enfermeiros peritos $(\mathrm{N}=40)$. Ribeirão Preto, 2006 153

Tabela 11

Distribuição das 13 características definidoras do diagnóstico de enfermagem "Desobstrução ineficaz de vias aéreas", segundo suas medianas e distâncias interquartílicas obtidas pelos dois grupos de enfermeiros peritos. Ribeirão Preto, 2006 154

Tabela 12

Distribuição das características definidoras do diagnóstico de enfermagem "Desobstrução Ineficaz de vias Aéreas", conforme o índice de concordância entre as enfermeiras diagnosticadoras. Ribeirão Preto, 2007. 163

Tabela 13

Distribuição das características definidoras do diagnóstico de enfermagem "Desobstrução Ineficaz de Vias Aéreas", segundo o coeficiente de confiabilidade ponderado entre as enfermeiras diagnosticadoras. Ribeirão Preto, 2007 166 


\section{Tabela 14}

Distribuição da freqüência das características definidoras do diagnóstico de enfermagem "Desobstrução Ineficaz de Vias aéreas" em crianças e adolescentes portadores de cardiopatia congênita $(N=50)$. Ribeirão Preto, 2007 169

\section{Tabela 15}

Distribuição das características definidoras do diagnóstico de enfermagem "Desobstrução Ineficaz de Vias Aéreas", segundo o escore da validação por especialistas e o coeficiente de confiabilidade ponderado entre as enfermeiras diagnosticadoras. Ribeirão Preto, 2007. 


\section{LISTA DE GRÁFICOS}

\section{Gráfico 1}

Distribuição da amostra estudada segundo a faixa etária $(N=50)$. Ribeirão Preto, 2007.................................................................................... 155

\section{Gráfico 2}

Distribuição da amostra estudada segundo o tipo de cirurgia realizada $(\mathrm{N}=$ 60). Ribeirão Preto, 2007. 156 


\section{LISTA DE QUADROS}

\section{Quadro 1}

Referências bibliográficas encontradas 126

\section{Quadro 2}

Características definidoras do Diagnóstico de Enfermagem "Desobstrução Ineficaz de Vias Aéreas": "incapacidade de eliminar secreções ou obstrução do trato respiratório para manter uma via aérea desobstruída" (NANDA, 2006, p. 84) e suas definições

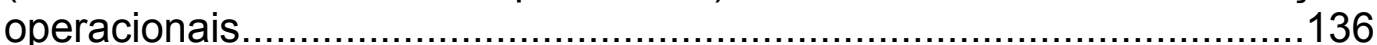

\section{Quadro 3}

Distribuição das características definidoras do diagnóstico de enfermagem "Desobstrução Ineficaz de Vias Aéreas" assinaladas para cada sujeito da amostra, segundo as respostas das enfermeiras peritas diagnosticadoras. 


\section{SUMÁRIO}

\section{Lista de Tabelas \\ Lista de Gráficos \\ Lista de Quadros \\ Lista de Abreviaturas}

1. Introdução

2. Objetivos 36

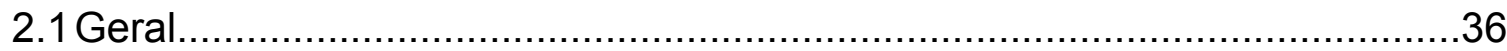

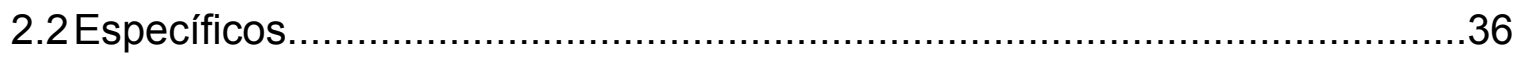

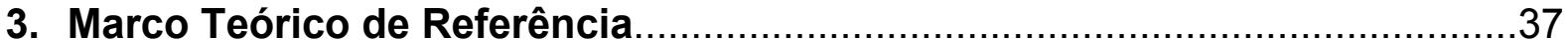

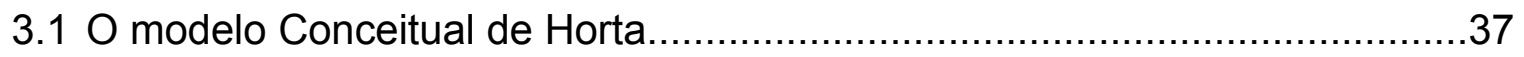

3.2 O Processo de Enfermagem........................................................... 39

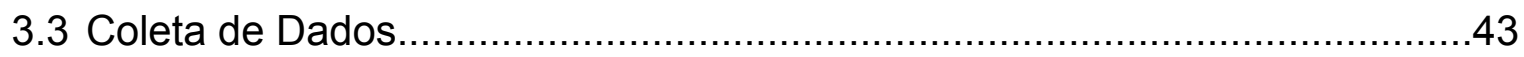

3.4 As Necessidades Humanas Básicas da Criança no Período Pós

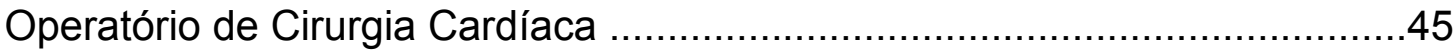

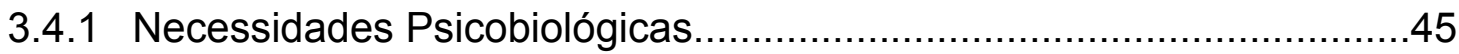

3.4.2 Necessidade de Oxigenação/ Respiração............................................46

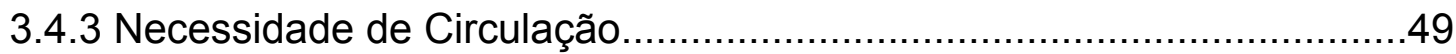

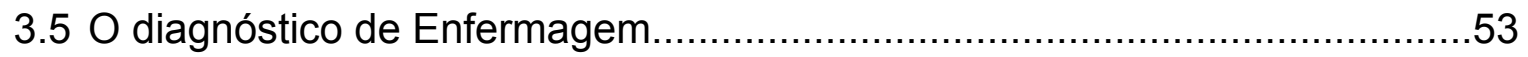

3.6 Classificação dos Diagnósticos de Enfermagem..........................................56

3.7 O diagnóstico de enfermagem "desobstrução ineficaz de vias aéreas"..........60

3.7.1 O fator relacionado "presença de via aérea artificial"..........................63

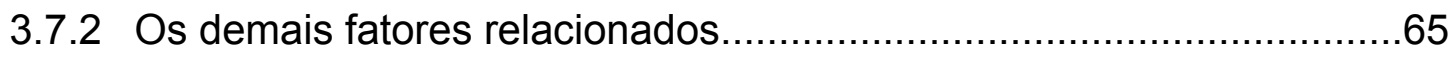

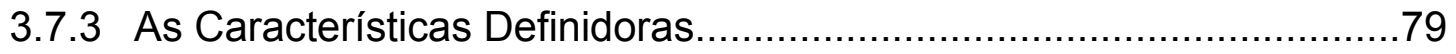


4. Material e Método

4.1 Primeira Etapa - Análise de Conceito..................................................101

4.2 Segunda Etapa - Validação por Especialistas..................................102

4.2.1 População e Amostra...............................................................103

4.2.2 Instrumento de Coleta de Dados da Segunda Etapa.......................105

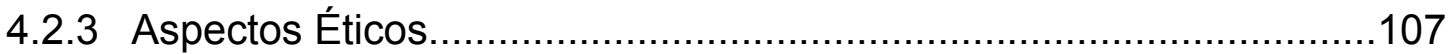

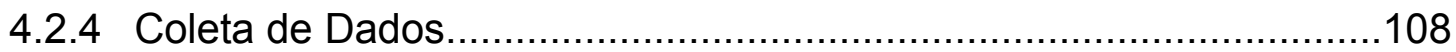

4.2.5 Análise dos Dados da Segunda Etapa........................................108

4.3 Terceira Etapa - Validação Clínica................................................111

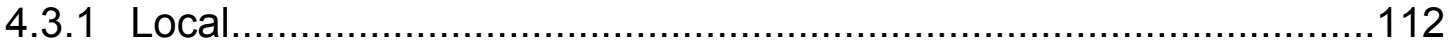

4.3.2 População e Amostra...............................................................113

4.3.3 Instrumento de Coleta de Dados da Segunda Etapa........................114

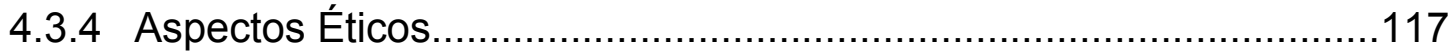

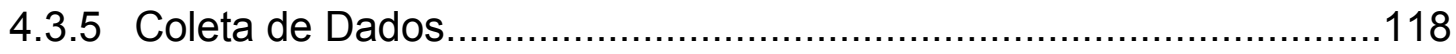

4.3.6 Análise dos Dados da Terceira Etapa........................................119

5. Resultados e Discussão

5.1 Primeira Etapa: Análise de Conceito....................................................122

5.2 Segunda Etapa: Validação por Especialista........................................137

5.2.1 Caracterização das pontuações obtidas pelos enfermeiros peritos segundo a metodologia de Fehring (1994)

5.2.2 Validação da definição do Diagnóstico de Enfermagem "Desobstrução ineficaz de vias aéreas" .145

5.2.3 Validação por especialista do diagnóstico de enfermagem "Desobstrução ineficaz de vias aéreas". 
5.3.1 Caracterização da amostra.

5.3.2 Índice de concordância das características definidoras do diagnóstico de enfermagem "Desobstrução Ineficaz de Vias Aéreas" observadas pelas enfermeiras diagnosticadoras em crianças e adolescentes submetidos à correção cirúrgica de cardiopatia congênita. 162

5.3.3 Coeficiente de confiabilidade ponderado entre os observadores clínicos das características definidoras do diagnóstico de enfermagem "Desobstrução Ineficaz de Vias Aéreas". 166

5.3.4 Incidência das características definidoras do diagnóstico de enfermagem "Desobstrução Ineficaz de Vias Aéreas" observadas pelas enfermeiras diagnosticadoras em crianças e adolescentes submetidos à correção cirúrgica de cardiopatia congênita 168

5.3.5 Análise comparativa entre a Validação por Especialistas e a Verificação da incidência das evidências clínicas

6. Conclusões

7. Considerações Finais. 185

8. Referências Bibliográficas. 188

APÊNDICES 200

ANEXOS 


\section{LISTA DE ABREVIATURAS E SIGLAS}

Art. - Artigo

AAP - Ampliação Artéria Pulmonar

AVSVE - Abertura da Via de Saída do Ventrículo Esquerdo

AT - Atresia da Tricúspide

CAVT - Canal Átrio Ventricular Total

CAVP - Canal Átrio Ventricular Parcial

CEC - Circulação Extra Corpórea

CEP - Comitê ética em Pesquisa

CINAHAL - Cumulative Index to Nursing Allied Health Literature

CIA - Comunicação Interatrial

CIV - Comunicação interventricular

COFEn - Conselho Federal de Enfermagem

COREn - Conselho Regional de Enfermagem

CoAo - Coarctação de Aorta

CTIP - Centro de Terapia Intensiva Pediátrico

DATASUS - Departamento de Informação e Informática do SUS

DEDALUS - Banco de dados bibliográficos da USP

DCV - Diagnoses Content Validation (Validação de Conceito Diagnóstico)

DIVA - Desobstrução Ineficaz de Vias Aéreas

HCFMRP - Hospital das Clínicas da Faculdade de Medicina de Ribeirão Preto

IAo - Interrupção do Arco Aórtico

LILACS - Literatura Latino-Americano e do Caribe em Ciências da Saúde

NANDA - North American Nurses Diagnoses Association

NIC - Nursing Intervention Classification

OVAS - Obstrução Vias Aéreas Superiores

PCA - Persistência do Canal Arterial

PG - Pós Graduação

POI - Pós-Operatório Imediato

PUBMED - National Library of Medicine and the National Institutes of Health

T4F - Tetralogia de Fallot

TV - Troca Valvar

USP - Universidade de São Paulo 


\section{1- INTRODUÇÃO}

As cardiopatias congênitas caracterizadas como anomalias resultantes de defeitos anatômicos no coração ou na rede circulatória (JANSEN et al., 2000), têm se apresentado como um importante problema de saúde pública nos países desenvolvidos e nos países em desenvolvimento.

A incidência dessa doença varia entre $0,8 \%$ nos países desenvolvidos e 1,2\% nos países mais pobres. No Brasil, estima-se o surgimento de 28.846 novos casos dela, por ano, e, é uma das principais causas de morte no primeiro ano de vida (PINTO JUNIOR et al., 2004).

No Rio Grande do Sul, caracteriza-se a terceira causa de morte no período neonatal e a terceira causa específica de mortalidade infantil (BACALTCHUK; ANTUNES; ZIELINSKY, 2001).

A prevalência desta mal formação cardíaca está entre oito e dez crianças por 1000 nascidos vivos, sendo atingidos infantes de todas as camadas sócioeconômicas (PINTO JUNIOR et al., 2004).

Estudos epidemiológicos revelam uma pequena expressividade da prevalência do referido mal, entre crianças nascidas vivas, porém não podemos ignorá-las, pois envolvem situações anatomofuncionais, que vão desde problemas hemodinâmicos simples, presentes ao nascimento e que geram uma função cardíaca anormal, até condições extremamente complexas incompatíveis com a vida (SILVA, V.M.; LOPES, M.V.O.; ARAUJO, T.L 2004a).

As cardiopatias congênitas começaram a ser investigadas e identificadas a partir do século XVII, com relatos esporádicos procurando correlacionar os sintomas clínicos com achados das autopsias (JANSEN et al., 2000). 
Hoffman; Christianson (1978) e Viñals; Giuliano (2002a), referem que mesmo com os avanços da ciência na área clínica, os defeitos físicos gerados por essas cardiopatias congênitas continuam a ser a primeira causa de morte em crianças com essa mal formação.

As malformações relacionadas à essa doença cardíaca resultam de causas multifatoriais, que atingem desde fatores genéticos até fatores ambientais.

A etiologia dos defeitos cardíacos, na maioria das vezes, é desconhecida, no entanto, vários fatores estão associados, tais como fatores pré-natais: rubéola, desnutrição, diabetes e idade materna acima dos 40 anos; e fatores genéticos onde existe um risco maior dessas doenças em crianças que têm familiares com algum problema cardíaco e alteração cromossômica.

Jansen et al. (2000) referem que as mesmas são anomalias resultantes de defeitos anatômicos no coração ou na rede circulatória, que comprometem sua função.

Os defeitos cardíacos congênitos são divididos em dois grupos que refletem as alterações fisiológicas, sendo eles: os acianogênicos e os cianogênicos. No grupo acianogênico, a lesão não tem capacidade de produzir cianose, pois não existe obstrução de sangue venoso na circulação sistêmica. No grupo cianogênico, a lesão pode produzir cianose, pois o sangue não oxigenado entra na circulação sistêmica (JANSEN et al, 2000).

Segundo Allan (2001) e Viñals; Giuliano (2002b), a incidência de algumas cardiopatias congênitas é maior que a apresentada em estudos de investigação perinatal, pois há falha diagnóstica, tanto no período pré-natal como no nascimento.

Nos lactentes com a doença, cerca de $99 \%$ apresentam os sintomas característicos de defeitos cardíacos ainda no primeiro ano de vida. Em 40\% dos 
portadores desta anomalia, o diagnóstico é estabelecido em até uma semana de vida e $50 \%$ em até um mês de idade (BERNSTEIN, 2002).

Suspeita-se da presença de tal anomalia, no período neonatal, em presença de quatro sinais clínicos principais: sopro cardíaco, cianose; taquipnéia e arritmias cardíacas (AMARAL et al., 2002).

Este mesmo autor refere que a avaliação diagnóstica de crianças com suspeita do problema consiste em uma abordagem sistematizada, que inclui os seguintes passos: exame físico acompanhado da avaliação da oximetria de pulso, onde será possível verificar a taxa de oxigênio no sangue, determinando assim presença ou não de cianose; a radiografia do tórax, que fornecerá informações como o tamanho do coração e os padrões de fluxo sanguíneo pulmonar; o eletrocardiograma, que possibilita analisar se há hipertrofia ventricular e a ausculta cardíaca para determinação das bulhas cardíacas e da presença de sopro. O ecocardiograma e o cateterismo, ou ambos, serão realizados para fins de confirmação diagnóstica.

A caracterização diagnóstica precoce e o tratamento cirúrgico paliativo ou corretivo mostram um aumento na sobrevida de tais crianças (SILVA; LOPES; ARAUJO; 2004a).

A correção cirúrgica é agressiva para a criança, porém é o tratamento mais indicado no momento, mesmo que o problema cardíaco tenha repercussão anátomo funcional discreta. Quanto mais precocemente forem efetuadas as correções cirúrgicas, menores serão os efeitos hemodinâmicos, ocasionados pelas alterações presentes após o nascimento, agravadas também pelas transformações do sistema cardiovascular durante o crescimento e desenvolvimento (SILVA; LOPES; ARAUJO, 2004a). 
O primeiro relato de um procedimento cirúrgico em criança com esse tipo de doença ocorreu no ano de 1939 (JANSEN et al., 2000).

Para a sobrevivência destas crianças, foram desenvolvidas técnicas cirúrgicas, que evoluíram de forma a corrigir desde a cardiopatia mais simples até a mais complexa, chegando até ao transplante cardíaco (EILOFT et al., 1996).

Pinto Junior et al. (2000) referem que em $20 \%$ dos casos, a cura ocorre de forma espontânea, sendo relacionada a defeitos menos complexos e de repercussão hemodinâmica mais leve.

O tratamento cirúrgico dos problemas cardíacos congênitos deve basear-se no princípio básico de procurar oferecer à criança, adequada qualidade de vida, com redução ou abolição dos sintomas, bem como dar uma perspectiva de sobrevida a longo prazo (JATENE, 2002).

Sabe-se que $50 \%$ dos portadores de cardiopatias congênitas devem ser operados no primeiro ano de vida (PINTO JUNIOR et al., 2004).

Jansen et al. (2000) referem que o momento mais adequado para a realização da cirurgia depende do tipo e da natureza da cardiopatia, da presença e da severidade dos sintomas e possibilidade de determinar as alterações secundárias reversíveis. Atualmente, a tendência é a intervenção cirúrgica o mais precoce possível, por oferecer melhores resultados imediatos e tardios.

Pinto Junior et al. (2004), em seu estudo, referem que segundo os dados do Datasus 2002, a necessidade média de cirurgia cardiovascular, em crianças portadoras de cardiopatia congênita, no Brasil fica na ordem de 23.077 procedimentos / ano, fazendo parte desta estimativa os novos nascimentos com cardiopatia congênita e casos de reintervenções. 
Para Garcia et al. (2002), as crianças submetidas à correção paliativa apresentaram maior sobrevida que as submetidas às cirurgias corretivas ou intervencionistas. Os autores destacam que não basta somente a intervenção cirúrgica, é importante acompanhar os pacientes operados para avaliar a qualidade de vida.

O avanço tecnológico, a evolução de novos equipamentos e técnicas e o desenvolvimento científico, vêm crescendo rapidamente e exigindo da Enfermagem, aprimoramento nos seus conhecimentos técnico-científicos, visto que o tratamento e o acompanhamento da doença estão diretamente relacionados à qualificação da assistência de Enfermagem ministrada (JANSEN et al., 2000).

Uma adequada assistência ao paciente portador da doença faz-se necessária nos períodos pré, trans e pós-operatório.

Ênfase especial será dada neste trabalho aos cuidados de Enfermagem que compõem a terceira fase do tratamento cirúrgico, o pós-operatório imediato, momento em que esta equipe desempenha importante papel de proporcionar ao paciente o retorno do equilíbrio do sistema orgânico e uma condição de sobrevivência com qualidade.

O pós-operatório imediato é um período que necessita de uma observação rigorosa e cuidadosa, devido às cirurgias exigirem circulação extra corpórea (CEC), acarretando grande risco de complicação. Isso nos levou a trabalhar com a fase de pós-operatório imediato. Neste período, há necessidade de uma avaliação acurada e precisa com monitoramento das alterações apresentadas e as intervenções devem ser implementadas de maneira rápida e eficiente, com o objetivo de restabelecer as funções fisiológicas vitais do paciente, de forma a mantê-lo estável. 
Segundo Noma et al. (2004), o pós-operatório é o período durante o qual se observa e assiste à recuperação dos pacientes em pós-anestésico e pós "stress" cirúrgico. O objetivo principal nesta fase é a manutenção do equilíbrio dos sistemas orgânicos, alívio da dor e do desconforto e prevenção de complicações.

Vale ressaltar que o período pós-operatório imediato corresponde às primeiras 24 horas após o término da cirurgia, na unidade de recuperação pós cirurgia cardíaca (CASTELLANOS; JOUCLAS, 1990).

O pós-operatório de cirurgia cardíaca seja ela paliativa ou corretiva, envolve um número expressivo de procedimentos realizados à beira do leito, que são: monitorização dos sinais vitais, dados hemodinâmicos, análises laboratoriais, ajustes ventilatórios, suporte nutricional, infusão e controle de drogas, e, às vezes procedimentos mais específicos como diálise peritoneal. Esse ritual envolve uma equipe multidisciplinar de profissionais treinados (FERREIRO; ROMANO; BOSISIO, 2002).

Os cuidados pós-operatórios dos lactentes ou crianças que foram submetidas à cirurgia cardíaca apresentam algumas características próprias e constituem uma parte importante da admissão em uma Unidade de Terapia Intensiva Pediátrica (SCHNITZLER et al., 1997).

Os cuidados de Enfermagem neste momento devem seguir um processo sistemático de pensamento, essencial à profissão e à qualidade da assistência ao paciente (SILVA; LOPES; ARAUJO, 2004a).

As vantagens verificadas com a sistematização da assistência de Enfermagem, é que ela proporciona direcionamento das ações, assistência individualizada e estimula os enfermeiros no aperfeiçoamento de seus conhecimentos (SILVA; LOPES; ARAUJO, 2004a). 
Não podemos deixar de mencionar, que atualmente a organização do trabalho de Enfermagem ainda está baseada na realização de tarefas e rotinas préestabelecidas, o que restringe a criatividade, habilidade, competência, destreza e a autonomia profissional.

Porém, esta condição vem sendo trabalhada gradativamente e a assistência de Enfermagem está passando por um período de mudanças, desde a decisão do CONSELHO REGIONAL DE ENFERMAGEM DO ESTADO DE SÃO PAULO de fundamentar a assistência prestada com base no Processo de Enfermagem, na tentativa de conscientizar toda a classe profissional quanto à importância de uma revisão e redefinição da sua prática (GALDEANO, 2002).

O CONSELHO REGIONAL DE ENFERMAGEM DO ESTADO DE SÃO PAULO - COREN - SP (2000), no uso de suas atribuições estabeleceu pela Lei do Exercício Profissional no. 7.498/86 a regulamentação do exercício da prática de Enfermagem e resolve que "é de competência do enfermeiro a consulta de enfermagem e a prescrição da assistência de enfermagem”. A decisão COREN- SP / DIR/ 008/99, no estado de São Paulo, foi homologada pelo Conselho Federal de Enfermagem em 04 de janeiro de 2000 - Decisão COFEN no. 001/2000, "normatiza a implementação da assistência de enfermagem - Sistematização da Assistência de Enfermagem (SAE) nas instituições de saúde no âmbito do Estado de São Paulo" e refere que é atividade privativa do Enfermeiro no seu $1^{\circ}$. Parágrafo (COREN 2000).

Essa assistência no pós-operatório imediato de cirurgia cardíaca é de alta complexidade clínica e o COREN refere que é de responsabilidade legal do enfermeiro, a tomada de decisões em relação ao paciente, de acordo com a lei No. 7.498, de 25 de junho de 1986, artigo II, inciso I, item "m" que traz como privativa do 
enfermeiro os cuidados de enfermagem de maior complexidade técnica e que exijam conhecimentos de base científica e capacidade de tomar decisões imediatas" (COREn, 2000 p.38).

O local de escolha para este estudo foi o Centro de Terapia Intensiva Pediátrico (CTIP), Unidade Campus do Hospital das Clínicas da Faculdade de Medicina da Universidade de São Paulo (HCFMRP-USP) que atende pacientes de alta complexidade, e, por seguir as decisões do COREN no desenvolvimento da sistematização da assistência de enfermagem. Esta unidade está vinculada ao HCFMRP-USP, uma instituição governamental de nível terciário que sempre atendeu pacientes com diagnóstico de cardiopatia congênita, porém nos últimos cinco anos apresentou um aumento significativo na demanda destes pacientes.

Esse aumento na demanda gerou a necessidade de se estruturar o serviço de atendimento às crianças e adolescentes portadores de tal problema, e, em 1998, foi inaugurado o Centro de Terapia Intensiva Pediátrico - Unidade Campus (CTIP), onde é realizado o pós-operatório imediato de crianças submetidas à correção cirúrgica.

Com uma população tão específica, a equipe de Enfermagem desta Unidade sentiu necessidade de aperfeiçoamento dos cuidados ministrados e foi em busca de novos conhecimentos e uma prática de enfermagem baseada em um modelo científico, que garantisse ao paciente uma assistência com qualidade.

Culminando com a exigência do órgão fiscalizador da profissão foi desenvolvido no CTIP, o Processo de Enfermagem baseado no modelo conceitual de Horta (1979). Optou-se por seguir as cinco fases propostas por Rossi (1992) sendo: coleta de dados, diagnósticos de enfermagem, prescrição, implementação e avaliação. A coleta de dados foi estruturada no modelo citado acima, ficando 
organizado em necessidades psicobiológicas, psicossociais e psicoespirituais, e, para a etapa do diagnóstico de enfermagem foi estruturada com base na taxonomia da North American Nursing Diagnoses Association (NANDA).

Tal prática foi implementada na unidade há cinco anos sendo registrada nos prontuários dos pacientes, o que vem facilitar o desenvolvimento deste estudo.

Concordamos com Silva, Lopes e Araújo (2004a) quando referem que o Processo de Enfermagem tem sido o método ideal para o levantamento dos problemas de crianças e adolescentes com cardiopatias congênitas, estabelecimento de metas e de um plano de cuidados para a solução dos problemas levantados, implementação e avaliação da eficácia do plano.

Para esta mesma autora, os cuidados de Enfermagem devem ser estabelecidos e executados tão logo se suspeite do diagnóstico de cardiopatia congênita. Para o desenvolvimento do plano de cuidados é indispensável um cuidadoso levantamento das necessidades, voltado, principalmente, para a avaliação da função cardíaca das respostas individuais frente ao problema de saúde e detecção de sinais e sintomas característicos de complicações.

Silva, Lopes e Araújo (2004b) realizaram um estudo que identificou dezoito diagnósticos de Enfermagem e seis problemas colaborativos na população de crianças portadoras da doença em estudo. Dos diagnósticos encontrados, os de maior prevalência foram: intolerância à atividade, desobstrução ineficaz das vias aéreas, crescimento e desenvolvimento retardados, nutrição desequilibrada: menos do que as necessidades corporais, padrão respiratório ineficaz, hipertermia e processos familiares interrompidos. $E$ os problemas colaborativos de maior incidência foram: complicação potencial, débito cardíaco diminuído, efeitos adversos da terapia medicamentosa e pneumonias. 
Neste mesmo estudo, além da determinação das freqüências dos diagnósticos de enfermagem e dos problemas colaborativos, foram verificadas as associações estatísticas entre os diagnósticos encontrados com prevalência superior a $50 \%$. Os diagnósticos de desobstrução ineficaz das vias aéreas e padrão respiratório ineficaz foram um dos que evidenciaram uma forte associação.

Consideramos que existem diversos aspectos para explorarmos cientificamente, relativos às diferentes fases do processo de Enfermagem, principalmente os sistemas de classificação dos diagnósticos já existentes. É necessário conhecer seus conceitos e propostas, testá-los, validá-los e analisá-los quanto a sua aplicabilidade nas diferentes realidades, contribuindo para um importante desafio aos enfermeiros na atualidade.

Verificamos que são raras as publicações sobre validação clínica dos diagnósticos de Enfermagem prioritários e a assistência de Enfermagem para crianças portadoras de cardiopatia congênita.

Há necessidade de manter pesquisas e estudos que permitam acompanhar modificações sociais e culturais locais, sempre considerando as peculiaridades das manifestações de tais problemas em populações específicas (MELO, 2004).

Determinar um diagnóstico de Enfermagem requer análise, síntese e percepção ao interpretar e fazer com que os sinais clínicos complexos tenham sentido. Esse processo de pensamento crítico possibilita ao enfermeiro tomar decisões em relação aos resultados esperados do paciente e às intervenções necessárias na obtenção desses resultados (DALRI, 2005).

Não podemos deixar de comentar que o diagnóstico de Enfermagem estabelece uma linguagem comum na identificação das respostas humanas, facilita a comunicação entre os enfermeiros e direciona o cuidado. Eles também 
determinam as condições clínicas do paciente permitindo ao enfermeiro agir de forma independente e autônoma na elaboração do planejamento e execução das intervenções (SILVA; LOPES; ARAUJO, 2004a; ALFARO-LEFEVRE, 2000).

Os diagnósticos de enfermagem propostos pela NANDA são conhecidos e bem aplicados, porém os mesmos não são definitivos, uma vez que pesquisas em populações específicas podem permitir seu aprimoramento e tornar sua estrutura conceitual mais aprimorada (MELO, 2004).

Para isso, existe a validação dos diagnósticos de enfermagem que, segundo Woodtli (1995) pode ser investigada por vários métodos de pesquisa, preferencialmente, por métodos que melhor estabelecem clinicamente a presença da resposta e das características definidoras associadas a uma determinada população.

Sendo assim, esse estudo tem por finalidade contribuir pelo aperfeiçoamento do diagnóstico de enfermagem "Desobstrução ineficaz de vias aéreas" no atendimento a crianças no período pós-operatório imediato de cirurgia cardíaca para correção de cardiopatia congênita, utilizando a abordagem da validação.

A escolha deste diagnóstico de enfermagem deu-se por tratar-se de uma resposta humana freqüentemente citada na literatura de Enfermagem nas situações de comprometimento das vias aéreas em crianças que se submetem à cirurgia cardíaca (KIM; LARSON, 1987; CARLSON-CATALANO et al., 1998; JARVIS, 2002; PILLITTERI, 1999; WONG, 1999).

A delimitação de alguns fatores relacionados também contribuiu para a nossa escolha, visto que conforme mostra a literatura, a maioria dos pacientes que se encontram no período pós-operatório imediato de cirurgia cardíaca apresentam-se, no mínimo, com "risco" de desenvolver sinais e sintomas de desobstrução ineficaz 
das vias aéreas. Temos que considerar que os fatores relacionados a esse diagnóstico, conferem com o estado crítico e complexidade clínica deste paciente.

Esperamos que os aspectos do conhecimento aqui levantados, em relação ao diagnóstico de Enfermagem selecionado para o estudo, possam ampliar as possibilidades de uma melhor fundamentação na determinação do diagnóstico de Desobstrução ineficaz de vias aéreas, no planejamento da assistência de enfermagem e que sejam utilizados pelos enfermeiros que atuam na prática clínica, trazendo benefícios que alcancem os níveis mais concretos de nossa atuação. 


\section{2 - OBJETIVOS}

\section{1 - Geral}

Validar clinicamente o diagnóstico de Enfermagem da NANDA (2006) "Desobstrução ineficaz de vias aéreas" em crianças e adolescentes submetidos à correção cirúrgica de cardiopatia congênita.

\section{2 - Específicos:}

- Analisar o diagnóstico de Enfermagem "Desobstrução ineficaz de vias aéreas", elaborando conceitos/conteúdos das características definidoras com base na literatura;

- Realizar a validação por especialistas do diagnóstico de Enfermagem "Desobstrução ineficaz de vias aéreas";

- Validação Clínica das características definidoras do diagnóstico estudado, no pós-operatório imediato de cirurgia cardíaca para correção de cardiopatia congênita. 


\section{3 - MARCO TEÓRICO DE REFERÊNCIA}

\section{1 - O modelo Conceitual de Horta}

Neste estudo, optamos por trabalhar com o Modelo Conceitual de Wanda Aguiar Horta, por considerá-lo um modelo que permite a avaliação do paciente como um todo indivisível, com seus componentes bio - psico - sócio - espirituais.

Horta (1979) classifica o ser humano, como um ser com capacidade de reflexão e imaginação, com unicidade, autenticidade, integrante de um universo dinâmico e agente de mudanças em seu ambiente, sujeito a estados de equilíbrio e desequilíbrio, ocasionados por mudanças na dinâmica do universo.

Esta mesma autora refere que os desequilíbrios são situações que o indivíduo, família ou a comunidade apresentam, em decorrência da alteração de suas necessidades básicas, e que podem ser aparentes, conscientes, verbalizados ou não. Estes desequilíbrios promovem no indivíduo, necessidades caracterizadas por estados de tensão que requerem solução. As necessidades não atendidas ou atendidas inadequadamente trazem desconforto, podendo causar a doença.

O pressuposto de Horta (1979), estabelece o desenvolvimento e inter relacionamento dos conceitos de Enfermagem e de assistir em Enfermagem, e descreve alguns pontos chaves: as funções do enfermeiro podem ser divididas em três áreas específicas, que se define no assistir o ser humano, no atendimento de suas necessidades básicas e no ensino do auto-cuidado, na área de colaboração que refere a atividades de manutenção, promoção e recuperação da saúde e a área social que são as atividades de ensino, pesquisa, administração, responsabilidade legal e de participação em associações de classe. 
As necessidades humanas básicas de Horta (1979) se apóiam e englobam as leis gerais que regem os fenômenos universais, sendo elas a Lei do equilíbrio, adaptação e holismo, e na motivação humana e utiliza a classificação de João Mohana que estabelece três níveis de necessidades: psicobiológicas, psicossociais e psicoespirituais.

Segundo Galdeano (2002) Horta expressa um conjunto teórico, que possui coerência, consistência, originalidade e possibilidade de retratar a realidade. Observou que todos os componentes básicos de uma teoria estão presentes: pressupostos básicos, conceitos e proposições.

Na literatura, há divergência quanto à caracterização da proposta de Horta, que é, ora denominada de Modelo Conceitual, ora de teoria (SOUZA, GUTIERREZ, CASTRO 1985; DALRI, 1993; LEOPARDI, 1999).

Horta (1979) propôs um modelo conceitual, baseado em seus pressupostos e conceitos, e, na teoria das necessidades humanas básicas de Maslow (1970), e também classifica as necessidades básicas a partir da denominação de Mohana (1964).

As necessidades humanas são comuns a todo ser humano. A variação de um indivíduo para o outro está na forma como as necessidades aparecem e na maneira como são satisfeitas (HORTA, 1979).

Maslow (1970) organizou as necessidades humanas básicas em cinco níveis: 1) necessidade fisiológica, 2) de segurança, 3) de amor, 4) de estima e 5) de autorealização.

E a denominação de Mohana (1964) classifica as necessidades básicas em três grupos: necessidades psicobiológicas, psicossociais e psicoespirituais. 
Segundo a teoria da necessidade humana básica, proposta por Maslow (1970), certas necessidades são mais básicas do que outras, devendo algumas serem supridas antes de se procurar satisfazer outras (POTTER; PERRY, 2005).

Horta (1979), partindo do seu pressuposto, define a enfermagem como a "ciência e a arte de assistir o ser humano no atendimento de suas necessidades básicas, de torná-lo independente desta assistência, quando possível, pelo ensino do auto-cuidado; de recuperar, manter e promover a saúde em colaboração com outros profissionais". Ela ainda diz que para a enfermagem atuar eficientemente é necessário desenvolver sua própria metodologia de trabalho, fundamentada no método científico. Esse método científico é denominado Processo de Enfermagem.

Segundo esta mesma autora, Processo de Enfermagem "é a dinâmica das ações sistematizadas e interrelacionadas, visando à assistência ao ser humano".

Neste estudo, utilizaremos a classificação das necessidades humanas básicas adotada por Horta (1979) como estrutura do levantamento dos dados objetivos e subjetivos que são significativos para a nossa clientela.

\section{2 - O Processo de Enfermagem}

Horta (1979) diz que Processo de Enfermagem "é a dinâmica das ações sistematizadas e interrelacionadas, visando à assistência ao ser humano". Refere também que é caracterizado pelo interrelacionamento e dinamismo de suas fases e passos.

Segundo Galdeano (2002), os enfermeiros estão preocupados com o tipo de assistência prestada, e estão tentando estabelecer novos métodos de trabalho, embasados em valores éticos e organizados de forma a possibilitar a continuidade da assistência. 
Horta (1979) refere que é a partir da sistematização da assistência de Enfermagem, que a profissão chega à sua maioridade, porém a autonomia profissional só será adquirida no momento em que toda a classe passar a utilizar essa metodologia científica em suas ações.

O termo "Processo de Enfermagem" começou a ser divulgado no Brasil a partir da década de 70, nos trabalhos de Wanda Aguiar Horta e até o momento é reconhecido como um método de sistematização da assistência de Enfermagem, pois dá aos cuidados de enfermagem, um caráter científico (JESUS, 1995; GALDEANO, 2002).

Para Jesus (1992) é um método sistemático de conduzir a prática da profissão, a partir da aplicação de um método científico, baseado na avaliação do estado de saúde do paciente, fazendo um levantamento de seus problemas reais e potenciais sob competência do enfermeiro.

O processo de enfermagem segundo Kenney (1990) é uma atividade deliberada, lógica e racional, e a prática da mesma é exercida sistematicamente.

Pimenta et al. (1993) referem que o processo de enfermagem é uma possibilidade de resposta a sérios questionamentos quanto à qualidade do cuidado e desenvolvimento científico da profissão.

É uma metodologia que busca a identificação das necessidades específicas do paciente, proporciona a elaboração de um plano de cuidados individualizado e facilita a comunicação dos profissionais envolvidos nos cuidados (GALDEANO, 2002).

Rossi (1992), em seu estudo, entende que é um conjunto de etapas como: coleta de dados, diagnósticos de enfermagem, planejamento, implementação e avaliação. Estas etapas focalizam a individualização da assistência, fundamentada 
nas teorias e modelos conceituais de Enfermagem. Também representa uma forma de registrar, documentar o plano de cuidados, constituindo-se um instrumento ético legal dos profissionais.

O processo de enfermagem é um instrumento no planejamento e execução dos cuidados (JESUS, 1992). Uma maneira de planejar e organizar as ações de Enfermagem prestadas ao paciente, embasada em conceitos científicos.

É um método sistemático e organizado também para administrar cuidados individualizados enfocando as respostas humanas, de um indivíduo ou grupo, a problemas de saúde atuais ou potenciais (ALFARO LEFEVRE, 2000).

Concordamos com Dalri (2000) quando define a idéia de que o profissional de Enfermagem que desenvolve a assistência fundamentada pelo processo de Enfermagem, através de um referencial teórico, será capaz de aprimorar suas habilidades teórico - práticas, associar e interrelacionar conhecimentos multidisciplinares, e, manter relações de trabalho melhor definidas e concretas.

O planejamento da assistência de enfermagem deve ser baseado no raciocínio crítico e em um modelo conceitual, visando a promover a recuperação do indivíduo. A prática de enfermagem na avaliação clínica, condução e organização de sua equipe de trabalho às estratégias administrativas, assistenciais, educativas e de pesquisa, tem um melhor resultado quando embasada no processo de Enfermagem (DALRI, 2005).

É importante dizermos que o processo de Enfermagem aproxima o enfermeiro e sua equipe de trabalho, do paciente. Estimula o enfermeiro na busca de conhecimentos técnicos - científicos, aperfeiçoamento de sua prática, na tentativa de garantir ao paciente uma assistência com qualidade. 
O enfermeiro deverá compreender as etapas do processo de Enfermagem, tendo consciência de que o desenvolvimento da capacidade de compreensão e adaptação à realidade e ao grupo de indivíduo que assiste, permitirá a ele ser capaz de atender a uma filosofia de trabalho e a objetivos estabelecidos.

O processo de enfermagem é um método pelo qual essa estrutura é aplicada à prática de enfermagem. É uma abordagem deliberativa de solução de problemas, que exige habilidades cognitivas, técnicas e interpessoais e está diretamente relacionada à satisfação das necessidades do paciente e da família (IYER; TAPTICH; BERNOCCHI - LOSEY, 1993).

Para estas mesmas autoras, o processo de enfermagem apresenta seis propriedades: intencional, sistemático, interativo, flexível e fundamentado em teorias. O processo é intencional, pois há uma meta; sistemático por utilizar uma abordagem organizada para alcançar seu propósito; dinâmico porque está diariamente em mudanças; interativo por basear-se em relações mútuas entre enfermeiro e paciente, família e outros; flexível por demonstrar adaptação à atividade de enfermagem em qualquer área de especialidade, e, por fim, o processo de enfermagem é fundamentado em teorias, por ser elaborado por uma ampla base de conhecimentos, onde se incluem as ciências físicas, biológicas e as humanas.

Horta (1979) descreve que é composto por seis fases ou passos. A primeira fase é a coleta de dados, que após serem avaliados e analisados, proporciona o raciocínio clínico que será estabelecido e concretizado com a segunda fase do processo, o diagnóstico de Enfermagem. O terceiro passo é o plano assistencial seguido do plano de cuidados ou prescrição das intervenções de enfermagem e o quinto passo, a avaliação onde será realizado o relato diário das mudanças que ocorreram, e, por fim a sexta fase, ou seja, o prognóstico de enfermagem, que é a 
estimativa da capacidade do indivíduo em atender suas próprias necessidades básicas alteradas, após a implementação do plano de cuidados.

A sistematização da assistência de enfermagem que acataremos foi descrita por muitos autores como Rossi (1992), Alfaro - LeFevre (2002), Christensen e Kenney (1990), Doenges e Moorhouse (1991) e Potter e Perry (2005) os quais contemplam o processo em cinco fases: coleta de dados, diagnóstico de enfermagem, planejamento, implementação e avaliação.

Considerando os objetivos deste estudo, a seguir faremos algumas considerações relacionadas às duas primeiras fases do processo de enfermagem: a coleta de dados e o diagnóstico de enfermagem.

\section{3 - Coleta de Dados}

Segundo Horta (1979) a coleta de dados ou histórico de enfermagem é um roteiro sistematizado para o levantamento de sinais e sintomas do paciente, tornando possível a identificação de seus problemas. Considera também um momento de interação entre o enfermeiro e o paciente, permitindo a construção de um cuidado profissional e individualizado.

Esta fase é que conduz ao diagnóstico de enfermagem e determina prioridades e intervenções posteriores.

A coleta de dados tem por finalidade identificar os problemas reais e potenciais do paciente de maneira a subsidiar o plano de cuidados, atender aos problemas identificados e prevenir complicações (GALDEANO, 2002)

Para Carpenito (2002) assessment (coleta de dados) é a coleta sistemática e deliberada de sinais e sintomas para a determinação do estado de saúde atual e 
passado do paciente e seu estado funcional, para avaliação do seu padrão de resolução de problemas do presente e passado.

Os enfermeiros coletam dados para determinar a necessidade dos cuidados de enfermagem e para auxiliar os outros profissionais na tomada de decisão de suas atividades (CARPENITO, 2002). É importante que haja uma interdiciplinalidade para que se troque informações sobre os dados coletados, proporcionando para o paciente a qualidade da assistência.

A coleta de dados é um processo sistematizado, em que existe a verificação e comunicação dos dados sobre o paciente. Tendo como meta proporcionar uma base de dados sobre as necessidades, problemas de saúde, experiências relacionadas, práticas de saúde, metas, valores, relacionamento familiares e estilo de vida do paciente (POTTER; PERRY, 2005; SMELTZER; BARE, 2005).

É uma das etapas que mais exige tempo e trabalho, reunindo dados (informações) indispensáveis à comprovação de hipóteses. É uma fase que sugere a confecção de instrumentos adequados de registros e leitura dos dados e o desenvolvimento de técnicas para obtenção dos mesmos (CHIZZOTTI, 2000).

Através de normas, padrões e teorias, as ciências sociais, comportamental, médica e de enfermagem têm fornecido indicadores concretos de saúde. Esses indicadores fornecem a base para que o enfermeiro colete dados e faça um julgamento clínico (CHRISTENSEN; KENNEY, 1990).

Segundo Pimenta et al. (1992) a natureza e a quantidade de dados a serem coletados dependerá dos objetivos do serviço, do paciente e do modelo teórico adotado. Refere que o enfermeiro inicia a coleta de dados no primeiro contato com o paciente, sendo o primeiro atendimento e durante o exame físico. A coleta de dados é a base na qual se fundamenta o cuidado de enfermagem. 
Para que se possa fazer uma avaliação cuidadosa e criteriosa do paciente, o enfermeiro deve: a) comunicar-se efetivamente utilizando a comunicação terapêutica e a empatia, na tentativa de estimular o paciente ou a família a compartilhar os seus pontos de vista e os seus sentimentos; b) observação sistemática, com a finalidade de direcionar a avaliação e identificar os dados que devem ser levantados, conhecer a interação humana e os sinais e sintomas e saber interpretar os dados coletados com exatidão (CARPENITO, 2002)

Como já foi dito anteriormente, a coleta de dados depende do modelo conceitual adotado. Neste estudo, escolhemos o modelo conceitual de Horta (1979), na tentativa de uma visão ampla do cuidado para o qual são necessários dados sobre o paciente como um todo nos aspectos psicobiológicos, psicossociais e psicoespirituais.

Utilizaremos o instrumento de coleta de dados da Unidade de Terapia Intensiva Pediátrica, do Hospital onde será realizado este estudo, pois ele foi elaborado no modelo conceitual de Horta (1979) e na teoria das necessidades humanas básicas. (APÊNDICE G)

A seguir apresentaremos a descrição das necessidades humanas organizadas no instrumento de coleta de dados, na assistência às crianças em pósoperatório imediato de correção cirúrgica de cardiopatia congênita.

\section{4 - As necessidades Humanas Básicas da Criança no período pós-operatório Imediato de Cirurgia Cardíaca}

\subsection{1 - Necessidades Psicobiológicas}


Mediante o tipo de abordagem que será realizada neste estudo, as necessidades fisiológicas serão a de maior prioridade.

As necessidades fisiológicas são as que os indivíduos procuram satisfazer em primeiro lugar, pois elas são essenciais para a sobrevivência.

As alterações cardíacas apresentadas pelas crianças portadoras de cardiopatia congênita, podem comprometer todos os órgãos do corpo, afetando portanto, diretamente, as necessidades fisiológicas. A diminuição da função cardíaca, geralmente resulta na alteração da perfusão de vários órgãos, comprometendo a oxigenação e a nutrição de seus tecidos (MONAHAN et al., 1994).

É importante neste momento, investigarmos os problemas decorrentes dos desequilíbrios das necessidades básicas do paciente, relacionados à especificidade da clientela e período específico da assistência de enfermagem.

\subsection{2 - Necessidade de Oxigenação / Respiração}

A necessidade de oxigenação ocupa o primeiro lugar na escala hierárquica das necessidades humanas básicas, pois é fundamental ao organismo. Sem oxigênio, as células do organismo podem sofrer lesões irreversíveis (ATKINSON; MURRAY, 1989).

O oxigênio é oferecido às células por um conjunto de atividades coordenadas pelo mecanismo de ventilação dos pulmões, difusão dos gases entre o sangue e os alvéolos pulmonares e o transporte dos gases pelas células do sangue. Qualquer falha ou alteração em uma dessas atividades resultará em problemas respiratórios (GUYTON, 1993). 
Segundo Faria (2000), o paciente com problema cardíaco apresenta alterações respiratórias associadas ou secundárias à insuficiência cardíaca, que interfere na situação de saúde, convalescença cirúrgica e na qualidade de vida.

O objetivo da investigação da necessidade de oxigenação / respiração no período pós-operatório imediato é identificar o mais precocemente possível, problemas respiratórios que podem acarretar ou agravar complicações nesta fase.

Mesmo com todo avanço das técnicas de cirurgias cardíacas e anestésicas, as complicações pulmonares continuam sendo uma das maiores causas de morbidade e mortalidade no período pós-operatório, principalmente, em pacientes com problemas respiratórios prévio (BLACK; MATASSARIN - JACOB, 1996; DIAS, 1992; DOYLE, 1999).

Segundo Finigan e Warm (1972), a maioria das toracotomias pode resultar em alterações pulmonares, pois há instabilidade da parede torácica e acúmulo de ar ou líquido nos espaços pleurais.

Outro fator importante e agravante é a circulação extra corpórea, que proporciona significantes alterações na fisiologia normal do organismo, podendo causar distúrbios pulmonares.

De acordo com Piva, Carvalho e Garcia (1997), Souza e Elias (1999) os problemas respiratórios pós-circulação extra corpórea são causados por vários fatores, entre eles, a ativação dos neutrófilos e sua degranulação, e, a injúria das células endoteliais, cujo resultado é a insuficiência respiratória de maior ou menor intensidade.

A maioria das crianças e adolescentes submetidas à intervenção cirúrgica para correção de cardiopatia congênita, desde a mais simples à mais complexa, são 
submetidas à colocação de uma via aérea artificial, sendo, a mais comumente usada, a via orotraqueal.

A via aérea artificial é inserida nos pacientes para manter as vias aéreas pérveas e favorecer a ventilação (POTTER; PERRY, 2005).

Após o término da cirurgia, estas crianças são transportadas do bloco cirúrgico para o CTIP com tubo endotraqueal, onde permanecem por algumas horas assistidas por ventilação mecânica; até a estabilização (PIVA; CARVALHO; GARCIA, 1997).

Os pacientes que se encontram com as vias aéreas artificiais, necessitam de uma assistência de enfermagem com conhecimento e habilidades específicas como fisiologia pulmonar e manejo desta via. Caberá ao enfermeiro, decisões importantes relativas aos cuidados de enfermagem dos pacientes com vias aéreas artificiais (NAPOLEÃO, 2005).

É importante lembrar que a presença de uma via aérea artificial traqueal leva o paciente a não dispor de diversos mecanismos importantes na respiração / ventilação como: umidificação, aquecimento e filtro do ar inspirado, e a remoção de secreção, presentes nos cílios da mucosa traqueal (KIM; LARSON, 1987; SHEKLETON; NIELD, 1987; POTTER; PERRY, 2005).

O reflexo de tosse, com uma via aérea artificial, pode ser menos efetivo também, pois a tosse efetiva requer uma respiração mais profunda, que expanda as vias aéreas, fecha a glote e contraia os músculos da expiração, com aumento na pressão intra-torácica e súbita abertura da glote. A via aérea artificial por sua vez, aumenta a resistência das vias aéreas, devido ao menor diâmetro do tubo, bem como da sua capacidade de distensão diminuída e força expulsiva insuficiente (SHEKLETON; NIELD, 1987). 
Outros fatores podem estar relacionados a alterações no sistema respiratório, que de acordo com Senra; Lasbech e Oliveira (1998), pode ser resultado da anestesia, que deprime a freqüência e a profundidade da respiração; da circulação extra corpórea, que pode promover insuficiência pulmonar; da esternotomia e presença de drenos, que levam à alteração dinâmica torácica e da dor que leva o paciente a evitar uma inspiração mais profunda, restringindo a expansibilidade pulmonar.

Frente a estas situações torna-se necessária a verificação da saturação de oxigênio no sangue, pois uma baixa saturação de oxigênio pode sugerir problemas significativos de troca gasosa, o que necessita de intervenção imediata (GOLDMAN; BRAUNWAULD, 2000).

Portanto, a necessidade de oxigenação deve ser investigada por meio da identificação de sinais e sintomas, do estado geral do paciente, do exame físico, dos parâmetros utilizados na ventilação mecânica e da avaliação dos exames laboratoriais (GALDEANO, 2002).

Desta forma, o enfermeiro deve basear-se no entendimento dos mecanismos de defesa, normalmente presentes nas vias aéreas, bem como dos fatores ambientais e fisiopatológicos que contribuem para as falhas desses mecanismos, e nas evidências clínicas das alterações apresentadas pela clientela em questão.

\subsection{3 - Necessidade de Circulação}

A circulação sanguínea tem por função atender às necessidades dos tecidos, remover produtos de excreção, transportar substâncias e manter um ambiente 
adequado à sobrevida e função das células (GUYTON, 1993; GEORGE-GAY; PARKER, 2003).

O coração com sua função eficiente, como uma bomba, vasos sanguíneos pérveos e um volume de sangue circulante adequado, são essenciais para uma adequada circulação. A perfusão adequada resulta em oxigenação e nutrição dos tecidos orgânicos (GALDEANO, 2002).

Para melhor compreendermos o sistema circulatório, Porto (2001) propõe colocarmos o coração num extremo, cuja função é bombear o sangue para todo o organismo, e no outro extremo a micro circulação, onde ocorrem as trocas metabólicas, razão da existência deste sistema. Entre os dois extremos, estende-se uma intrínseca rede de vasos, artérias e veias, que serve de leito para o sangue. Porém, para que haja eficiência deste mecanismo é necessário existir um complexo sistema de integração.

George-Gay e Parker (2003) referem que a distribuição do sangue pelo organismo é diferente para cada órgão ou sistema. Os valores variam de acordo com diferentes situações fisiológicas, como por exemplo, em condições patológicas. A função básica, através da circulação, promove uma atividade complexa intensa e regulada por diversos fatores intrínsecos e extrínsecos, permitindo adaptação de funções que venham a ser necessárias para manter o equilíbrio do organismo, seja na condição de saúde ou de doença.

A observação da necessidade de circulação no período pós-operatório imediato é realizada por meio da avaliação da freqüência e ritmo cardíaco, dos pulsos periféricos, da pressão arterial, da perfusão tecidual, da presença de edema, avaliação do turgor e da coloração da pele. O objetivo é identificar, o mais rápido 
possível, alterações e complicações que possam levar o paciente ao comprometimento de outros sistemas.

Os pacientes portadores de cardiopatia congênita apresentam, freqüentemente, complicações que deterioram seu estado, comprometendo sua vida e, às vezes, ocasionam danos irreversíveis. Entre as complicações mais freqüentes, as mais observadas nesta patologia são: insuficiência cardíaca, a hipoxemia e a hipertensão pulmonar (FLORES; GALLARDO et al., 1997).

As alterações circulatórias encontradas nos pacientes com defeitos cardíacos congênitos são decorrentes da própria insuficiência do coração como uma bomba e dos mecanismos compensatórios, cuja intenção é manter um débito cardíaco adequado para satisfazer às necessidades teciduais (MILES; ZIPES, 1994).

O débito cardíaco é a quantidade de sangue ejetado pelos ventrículos durante um determinado tempo. O débito cardíaco depende do volume sistólico, que por sua vez é dependente da pré-carga, pós-carga e da contratilidade, e da freqüência cardíaca que determinam a regularidade da contração miocárdica e o tempo de enchimento diastólico. A alteração de algum destes fatores, alterará o débito cardíaco, comprometendo os mecanismos compensatórios, contribuindo para a deterioração do miocárdio e da continuidade da insuficiência cardíaca (GUYTON, 1993).

As manifestações clínicas da insuficiência cardíaca são: cansaço para alimentar-se, irritabilidade, sudorese, dificuldade para ganhar peso mesmo com adequado aporte calórico, dificuldade respiratória, às vezes, acompanhada de cianose e taquipnéia (FLORES; GALLARDO 1997).

Outra complicação são as crises de hipertensão arterial pulmonar caracterizadas por súbita elevação da pressão arterial pulmonar, que geralmente 
são acompanhadas de broncoespasmo, redução do débito cardíaco e queda da saturação arterial de oxigênio. Podem estar relacionadas à agitação durante procedimentos ou aspiração da cânula endotraqueal (FERREIRO; ROMANO; BOSISIO, 2002).

A hipertensão arterial pulmonar pode ser causada por múltiplos fatores. Nas cardiopatias congênitas pode ser gerada devido ao hiperfluxo pulmonar, a hipóxia, o não fechamento do canal arterial pós-nascimento e a hipertensão secundária devido a um aumento da pressão venosa pulmonar (FLORES; GALLARDO 1997).

Outro sinal, que deve ser avaliado nos pacientes portadores de problemas cardíacos congênitos é a coloração da pele, pois a sua coloração azulada ou cianose significa diminuição do fluxo sanguíneo para a periferia, devido à vasoconstricção periférica (POTTER;PERRY, 2005).

Portanto, mais uma vez, reforça-se a importância do conhecimento em fisiologia para que se detectem todos esses sinais e sintomas decorrentes das alterações cardiocirculatórias. Tal fato é essencial para que haja comprometimento do enfermeiro em uma assistência de enfermagem de qualidade para uma clientela com elavado grau de complexidade.

A partir desta base de dados o enfermeiro realiza julgamento clínico relacionado às condições de saúde do paciente ou das suas respostas a problemas de saúde e processos vitais das condições reais ou de risco. Assim, o propósito desta avaliação é de fazer o julgamento para o diagnóstico de enfermagem "desobstrução ineficaz de vias aéreas". 


\section{5 - O Diagnóstico de Enfermagem}

Uma das definições que Horta (1979) refere em sua obra, é a da autora Faye Abdellah que diz "Diagnóstico de Enfermagem é a determinação da natureza e extensão dos problemas de enfermagem apresentados pelos pacientes ou família, que recebem cuidados de enfermagem".

Corresponde à segunda fase do processo, em que os dados coletados são julgados e analisados para o levantamento dos problemas de enfermagem, que por sua vez levam o enfermeiro a identificar as necessidades básicas afetadas e o grau de dependência do paciente em relação à enfermagem (HORTA, 1979).

Segundo Gordon (1994), este processo passou a ser chamado de diagnóstico de Enfermagem há cerca de três décadas atrás. Porém, foi durante o século XX, que o julgamento clínico da enfermagem foi se desenvolvendo e tornou-se um componente visível na prática e um conceito essencial na educação da enfermagem.

A evolução histórica do diagnóstico de Enfermagem é marcada por mudanças na forma de pensar e agir do enfermeiro. No momento, o diagnóstico de enfermagem é conhecido como um guia para o planejamento e implementação dos cuidados de enfermagem (JESUS, 1995).

A segunda fase do processo determina a condição clínica do paciente e o enfermeiro atua de forma independente no planejamento e execução das intervenções no paciente (SILVA, 2005).

O diagnóstico de Enfermagem é definido pela NANDA (2006) como "um julgamento clínico das respostas do indivíduo, da família ou da comunidade aos processos vitais ou aos problemas de saúde reais ou potenciais, os quais fornecem 
uma base para a seleção das intervenções de enfermagem, para atingir os resultados, pelos quais o enfermeiro é responsável".

Foi a partir da necessidade de identificar, organizar e classificar tais fenômenos ou diagnósticos de enfermagem que a NANDA resolveu desenvolver sua taxonomia para descrever os problemas de saúde levantados e tratados pelos enfermeiros (SILVA, 2005). A taxonomia da NANDA consiste em uma organização sistemática de fenômenos de enfermagem relacionados em grupos ou categorias e baseada nas características que tais fenômenos têm em comum NANDA (2006).

Esta taxonomia foi adotada pela Associação de Enfermeiras NorteAmericanas como o sistema oficial de diagnósticos para os Estados Unidos em 1988 (IYER; TAPTICH; BERNOCCHI - LOSEY, 1993).

O diagnóstico de enfermagem proporciona um mecanismo útil para o alicerce do conhecimento de enfermagem, tentando definir o papel e domínio do enfermeiro (CARPENITO, 2002).

Esta mesma autora coloca que a enfermagem necessita aplicar, na prática, um sistema de classificação ou de uma taxonomia, para descrever e desenvolver um modelo científico confiável para o preenchimento dos critérios da nossa profissão.

Segundo Iyer; Taptich; Bernocchi - Losey, (1993) os enfermeiros fazem julgamentos relativos a vários dados coletados, visando a ajudar o paciente a alcançar ou manter o estado de saúde desejado. Este julgamento resulta na identificação dos diagnósticos de enfermagem.

O diagnóstico envolve um raciocínio complexo dos sinais e sintomas apresentados pelo paciente, familiares e outros profissionais da saúde. Esse raciocínio combinado com as informações relevantes depositadas na memória do 
enfermeiro, deve ser usado para elaborar possíveis explicações para os dados (DALRI, 2005).

O diagnóstico de enfermagem é uma afirmativa que descreve um tipo específico de problema ou de uma resposta que o enfermeiro identifica (CARPENITO, 2002).

Concordamos com Jesus (2000), quando relata que o diagnóstico de enfermagem fornece critérios mensuráveis para avaliação dos cuidados ministrados, direciona a assistência, facilita a pesquisa e o ensino, estimula o paciente a participar de seu tratamento e do plano de cuidado e contribui para o crescimento de um corpo de conhecimento próprio para a enfermagem.

Porém, esta mesma autora também aponta algumas dificuldades na utilização do diagnóstico de Enfermagem sendo elas: falta de uniformidade nas definições brasileiras e definição de alguns termos, falta de habilidade no estabelecimento do diagnóstico e resistência em implementar o processo de enfermagem por parte dos enfermeiros.

Warrem (1983), em seu estudo, identificou sete benefícios relacionados ao uso dos diagnósticos de enfermagem segundo a taxonomia da NANDA: proporciona a padronização da comunicação entre os enfermeiros, facilita a documentação do cuidado de enfermagem e sua conseqüente padronização, fundamenta a assistência de enfermagem, promove o desenvolvimento e elaboração de instrumentos para coleta de dados computadorizados, permite identificar as intervenções de enfermagem adequadas para alcançar os resultados esperados, proporciona a unificação de definições na prática e leva ao desenvolvimento de teorias de enfermagem. 


\section{6 - Classificação dos Diagnósticos de Enfermagem}

O diagnóstico de enfermagem é "uma forma de expressar as necessidades de cuidados que identificamos naqueles de quem cuidamos" (BRAGA, 2003).

A responsabilidade do cuidar em enfermagem exige que as decisões sobre as intervenções propostas sejam fundamentadas na avaliação do estado de saúde do indivíduo. Essa avaliação requer que se adote o diagnóstico de enfermagem como referência (BRAGA, 2003).

Segundo Farias et al. (1990) a primeira menção do termo diagnóstico de enfermagem, ocorreu em 1953, por Vera Fry, ao identificar cinco áreas de necessidades do paciente, considerando-as como domínio da enfermagem, como foco para os diagnósticos de enfermagem e como meio de elaborar o cuidado individualizado.

Em meados de 1970, houve uma maior aceitação dos diagnósticos de enfermagem. Também foi nesta década, que se iniciou a busca da informatização dos serviços de assistência à saúde. Em 1973, na primeira Conferência do Grupo Norte-Americano para Classificação dos Diagnósticos de Enfermagem, foram apresentados e validados 34 diagnósticos, distribuídos em ordem alfabética (NANDA, 1999).

A NANDA contribuiu de forma significativa para o desenvolvimento e refinamento dos diagnósticos de enfermagem e desenvolveu um sistema conceitual para classificar os mesmos em uma taxonomia.

Em 1977, várias teoristas de Enfermagem se reuniram para desenvolver uma estrutura conceitual do sistema de classificação dos diagnósticos de enfermagem. Foram realizados anos de estudos, até o surgimento da lista alfabética dos 
diagnósticos em padrões amplos que os agrupavam individualmente. O trabalho final propunha nove Padrões do Homem Unitário, proposta por Roy (MICHEL, 2003; NANDA, 1999).

No ano de 1982, foram apresentados oficialmente os diagnósticos de enfermagem agrupados em nove Padrões do Homem Unitário, na $5^{\mathrm{a}}$. Conferência (FARIAS et al.,1990).

$\mathrm{Na} 7^{\mathrm{a}}$. Conferência, em 1986, ocorreu a substituição do termo Padrões do Homem Unitário por Padrões de Respostas Humanas e foi aprovada a Taxonomia I da NANDA (1999).

Os nove Padrões de Respostas Humanas eram: trocar, comunicar, relacionar, valorizar, escolher, mover, perceber, conhecer e sentir (NANDA, 1999).

A taxonomia I organizou os diagnósticos em diferentes níveis teóricos, dos abstratos e gerais para os concretos e específicos (MELO, 2004).

Logo, surgiu a proposta de inclusão desta taxonomia na Classificação Internacional das Doenças, havendo a necessidade de uma nova revisão, com inclusão de novos diagnósticos de enfermagem. A taxonomia I revisada teve sua publicação em 1989.

O principal trabalho da NANDA é proporcionar e direcionar a padronização da linguagem dos diagnósticos. Padronizar a linguagem é estabelecer um acordo sobre regras para utilização de determinados termos (BRAGA, 2003).

A taxonomia I foi muito criticada, pois apresentava sérias dificuldades para classificar novos diagnósticos que eram aceitos. Diante desta dificuldade, a NANDA passou a reconhecer que necessitava de uma nova estrutura para a taxonomia dos diagnósticos de enfermagem. Decidiram, então, verificar se surgiriam 
conjuntos naturais de diagnósticos utilizando o método "Q-Sort naturalístico" e a primeira etapa concluiu-se em 1994, na Conferência da NANDA (BRAGA, 2003).

Quatro anos mais tarde, o comitê de taxonomia e o Conselho de Diretores da NANDA, diante de quatro novas estruturas conceituais, escolheram os Padrões Funcionais de saúde de Gordon de 1998 (NANDA, 2002).

Esta estrutura proposta foi estudada por dois anos e sofreu algumas alterações no modelo original de Gordon até que se transformou na quinta proposta de estrutura conceitual. Na $14^{a}$ Conferência, no ano de 2000 , foi apresentada a Taxonomia II, composta por 13 domínios, 46 classes e 155 diagnósticos de enfermagem (NANDA, 2002).

A Taxonomia II publicada em 2006 tem 13 domínios, 46 classes, 167 diagnósticos e 7 eixos.

Cada domínio é composto por classes e cada classe é composta por conceitos diagnósticos.

Os domínios propostos pela taxonomia II compreendem: promoção da saúde, nutrição, eliminação, atividade / repouso, percepção / cognição, autopercepção, relacionamentos de papel, sexualidade, enfrentamento / tolerância ao estresse, princípios de vida, segurança / proteção, conforto e crescimento / desenvolvimento (NANDA, 2006).

A taxonomia II foi organizada para ser multiaxial, isto é, ela é mais flexível, permitindo realizar facilmente acréscimos e modificações (NANDA, 2006).

Com esta nova taxonomia os enfermeiros clínicos poderão beneficiar-se de conhecimento, quando necessitarem recuperar informações rapidamente, além do que, a idéia geral desta estrutura ajuda o enfermeiro compreender os diagnósticos que serão utilizados em sua prática clínica (NANDA, 2006). 
Segundo Braga (2003), a taxonomia II apresenta termos e significados que nos são mais familiares, que fazem parte de uma enfermagem tradicional e contemporânea, o que poderá ser mais efetivo para a comunicação com outros profissionais, com o próprio paciente e com instâncias de planejamento dos serviços de saúde.

Os eixos são representados no diagnóstico de enfermagem por seus valores, às vezes implícitos ou explícitos, sendo eles:

Eixo 1 - o conceito diagnóstico

Eixo 2 - Tempo (de agudo a crônico, curta duração, longa duração)

Eixo 3 - unidade de cuidado (indivíduo, família, comunidade, grupo alvo)

Eixo 4 - Idade (de feto a idoso)

Eixo 5 - Potencialidade (real, risco, oportunidade ou potencial para crescimento / aumento)

Eixo 6 - Descritor (limita ou especifica o significado do conceito diagnóstico)

Eixo 7 - Topologia (partes / regiões do corpo)

Segundo mostra NANDA (2006) a estrutura de códigos é formada por cinco dígitos, isto é, um código é representado por cinco dígitos. Essa estrutura favorece a evolução do sistema de classificação como um resultado do desenvolvimento do conhecimento sem que seja preciso mudar o código dos diagnósticos.

É importante dizermos que cada diagnóstico da enfermagem, ao ser incluído na classificação da NANDA passa por um processo de validação. E esta é uma das recomendações dadas pela NANDA, investigar os diagnósticos já incluídos na sua taxonomia em diferentes situações clínicas.

Validar entre outras significações, é legitimar, o que implica em reconhecer como autêntico, verdadeiro (MICHAELIS, 2005). 
Portanto, validar um diagnóstico de enfermagem significa torná-lo verdadeiro para aquela situação clínica e para todos os profissionais de enfermagem. Os diagnósticos devem representar a realidade clínica, para isso, devem ser sempre revisados e nunca serão finalizados (MELO, 2004).

As abordagens metodológicas de validação de diagnósticos, consistem na revisão da literatura fornecendo suporte teórico que sustente o diagnóstico de enfermagem estudado, a respeito do grau com que cada característica definidora é indicativa e na verificação da existência de um dado diagnóstico no ambiente clínico (WHITLEY, 1999).

No Brasil, já foram realizados vários estudos de validação de diagnósticos de enfermagem, (BACHION; ARAÚJO; SANTANA, 2002; CARVALHO; ROSSI; JESUS, 1998; CORRÊA, 1997; OLIVA, 2000; OLIVEIRA, 2001; SANTANA; SAWADA, 2002; MELO, 2004), porém há necessidade de mais trabalhos nesta área para que possamos descrever os fenômenos com que a enfermagem trabalha. Estes fenômenos, segundo Gordon e Sweeney (1979) dizem respeito à identificação e tratamento das respostas dos indivíduos aos problemas de saúde ou aos processos de vida (MELO, 2004).

Portanto, em busca de visibilidade social de nossa prática, a enfermagem deve fazer da utilização dos diagnósticos de enfermagem um caminho para novas conquistas, continuando a validá-los, pois eles não são definitivos (MELO, 2004).

\section{7 - O diagnóstico de enfermagem "Desobstrução ineficaz de vias aéreas"}


Segundo Carpenito (2002) o diagnóstico de enfermagem é tanto uma estrutura como um processo. Esta estrutura e seus componentes, dependem de seu tipo: real, de risco, de bem estar ou síndrome.

Diagnósticos de enfermagem reais descrevem respostas humanas às condições de saúde ou aos processos vitais presentes no indivíduo, família ou comunidade (NANDA, 2006). Representam diagnósticos clinicamente validados por manifestações identificáveis. Esses diagnósticos possuem quatro componentes: título, definição, características definidoras e fatores relacionados (CARPENITO, 2002).

Diagnósticos de enfermagem de risco descrevem respostas humanas a condições de saúde / processos vitais que podem desenvolver-se em um indivíduo, família ou comunidade vulneráveis (NANDA, 2002). Possuem como componentes: o título, a definição e os fatores de risco (CARPENITO, 2002).

Diagnósticos de enfermagem de bem-estar descrevem respostas humanas de um indivíduo, família ou comunidade que possuem um potencial para elevar-se a um nível superior de bem-estar e de saúde, comparado ao atual (CARPENITO, 2002; NANDA, 2000). Esse tipo de diagnóstico possui como único componente o título.

Diagnósticos de enfermagem de síndrome compreendem um conjunto de diagnósticos de enfermagem reais ou potenciais, cuja presença é prevista devido a algum evento ou situação (CARPENITO, 2002).

O diagnóstico de enfermagem em estudo é um diagnóstico real. Ele descreve as respostas humanas a condições de saúde / processos vitais das crianças submetidas à correção de cardiopatia congênita e está sustentado por características definidoras (NANDA, 2006). Dessa forma, quando formulado, 
compõe-se de um título, definição de fatores relacionados e características definidoras.

As características definidoras são sugestões / inferências observáveis que se agrupam como manifestação de um diagnóstico de enfermagem real ou de bem estar (NANDA, 2006).

Os fatores relacionados aparecem para mostrar algum tipo de relacionamento padronizado com o diagnóstico de enfermagem (NANDA, 2006). Nos diagnósticos reais, os fatores relacionados são fatores de natureza etiológicos ou outros fatores contribuintes que influenciaram a mudança no estado de saúde. Estes fatores podem ser agrupados em quatro categorias: fisiopatológicos (biológicos ou psicológicos); os relacionados ao tratamento; os situacionais (ambientais, pessoais) e os maturacionais (Carpenito, 2002).

A escolha do diagnóstico de enfermagem "Desobstrução ineficaz de vias aéreas", baseia-se no entendimento dos mecanismos de defesa normalmente presentes nas vias aéreas, bem como nos fatores fisiopatológicos que contribuem para as falhas desses mecanismos e nas evidências clínicas de alterações nesses aspectos apresentados pelos pacientes.

Acreditamos que após confirmarmos a presença de algumas características definidoras do diagnóstico em estudo, os enfermeiros poderão decidir sobre as intervenções de enfermagem adequadas para o cliente.

O diagnóstico de enfermagem "Desobstrução ineficaz de vias aéreas" encontra-se na taxonomia II da NANDA (2006) como conceito diagnóstico desobstrução de vias aéreas. Localiza-se no domínio 11 - segurança / proteção, tendo a seguinte definição: "estar livre de perigo, lesão física ou dano do sistema imunológico, preservação contra perdas e proteção da segurança e seguridade"; na 
classe 2, que corresponde à lesão física que refere se há dano ou ferimento corporal (NANDA, 2006. p. 268).

Este diagnóstico tem a seguinte definição: "incapacidade de eliminar secreções ou obstruções do trato respiratório para manter uma via aérea desobstruída" (NANDA, 2006. p. 84).

Suas características definidoras são: dispnéia, murmúrios vesiculares diminuídos, ortopnéia, ruídos adventícios respiratórios (estertores, crepitação, roncos, sibilos), tosse ineficaz ou ausente, expectoração, cianose, vocalização dificultada, olhos arregalados, mudanças na freqüência e no ritmo respiratórios e agitação (NANDA, 2006. p. 84).

Os fatores relacionados ao diagnóstico em estudo são: "Ambientais (fumo, inalação de fumaça e fumo passivo); Vias aéreas obstruídas (espasmo de via aérea, secreções retidas, muco excessivo, presença de via aérea artificial, corpo estranho na via aérea, secreções nos brônquios, exsudato nos alvéolos); Fisiológicos (disfunção neuromuscular, hiperplasia das paredes brônquicas, doença pulmonar obstrutiva crônica, infecção, asma e alergia respiratória)" (NANDA, 2006. p. 84).

Dos fatores relacionados do diagnóstico de enfermagem escolhido, um chamou-nos a atenção por estar sempre presente no paciente em POI de cirurgia cardíaca para correção de cardiopatia congênita que é a "presença de via aérea artificial". Sua presença pressupõe uma complexidade no cuidado de enfermagem.

\subsection{1 - O fator relacionado "presença de via aérea artificial"}

Este fator encontra-se no grupo "via aérea obstruída" do diagnóstico de enfermagem "Desobstrução ineficaz de vias aéreas". Segundo Napoleão (2005) é 
um fator que pode se apresentar sozinho ou acompanhado de outros fatores relacionados.

O objetivo da colocação de uma via aérea artificial nos pacientes é para manter as vias aéreas pérveas e favorecer, dessa forma, a ventilação. Sua indicação consiste na prevenção de riscos de aspiração de conteúdo gástrico, necessidade de ventilação mecânica e nos casos em que a patência das vias aéreas é ameaçada ou abolida por obstrução, trauma ou retenção de secreções (SHEKLETON; NIELD, 1987; POTTER; PERRY, 2005).

Existem dois tipos de vias aéreas artificiais mais freqüentemente usadas: a orofaríngea a as traqueais. A via aérea orofaríngea é indicada para pacientes inconscientes que estão respirando espontaneamente, e serve para impedir que a língua se desloque para trás, contra a região da faringe, e obstrua a via aérea. É um dispositivo plástico, semicircular, que é posicionado sobre e ao longo da língua, até a orofaringe, mantendo a língua em posição normal. Também permite a realização de aspiração das secreções acumuladas na orofaringe e boca por parte da enfermagem. Na aparência externa, possui um rebordo circular em uma das extremidades, semelhante ao de uma "chupeta", que é mantido na parte externa da boca, próximo aos lábios. Sua extensão tubular fica posicionada na cavidade oral, é arqueada acompanhando o ângulo do palato, até chegar à orofaringe (SMELTZER; BARE, 2005; POTTER; PERRY, 2005). Esta via aérea artificial não é a indicada para pacientes em POI de cirurgia cardíaca, pois a maioria destes pacientes encontramse anestesiados com drogas que bloqueiam a função respiratória.

As vias aéreas artificiais, indicadas para pacientes em POI de cirurgia cardíaca são as vias aéreas traqueais que incluem os tubos orotraqueal, nasotraqueal e as cânulas de traqueostomia (POTTER; PERRY, 2005). 
Com a presença de vias aéreas artificiais, principalmente as traqueais, os pacientes não possuem mais os mecanismos de umidificação, aquecimento e "filtro" do ar inspirado e o de remoção através dos cílios presentes na mucosa traqueal (SHEKLETON; NIELD, 1987; POTTER; PERRY, 2005).

O reflexo de tosse pode ser menos efetivo também, com a presença de uma via aérea artificial. Uma tosse eficiente requer uma respiração profunda que expanda as vias aéreas, feche a glote e contraia os músculos da expiração com um subseqüente aumento na pressão intratorácica e súbita abertura da glote. Devido ao diâmetro do tubo que é menor, a resistência das vias aéreas aumenta e a capacidade de distensão diminui, e como resultado, a habilidade para gerar fluxo de ar necessário para uma força expulsiva também é diminuída (SHEKLETON; NIELD, 1987).

Diante do exposto, fica evidente que a criança e o adolescente que necessitam de uma via aérea artificial precisa de cuidados de controle e manutenção de suas funções respiratórias e orgânicas, bem como de uma assistência de enfermagem embasada no atendimento de sua fisiologia e na compreensão das várias etapas de seu crescimento e desenvolvimento.

\subsection{2 - Os demais fatores relacionados}

Para melhor entendermos o diagnóstico de "Desobstrução ineficaz de vias aéreas", é importante fazermos a descrição dos seus fatores relacionados:

a) Ambientais: fumo; inalação de fumaça e fumo passivo. 
Segundo Kim; Larson (1987) e Haddad; Fontám (2005), o sistema respiratório está freqüentemente exposto ao ambiente alterado, ou seja, poluído com irritantes, patógenos e alérgenos.

Os fatores relacionados ambientais são importantes agressores dos mecanismos de defesa e de troca gasosa, normalmente presentes nas vias aéreas, sendo entendidos, como possíveis causas da resposta humana "Desobstrução ineficaz de vias aéreas" (NAPOLEÃO, 2005).

- Fumo e fumo passivo

O fumo é considerado uma das fontes de contaminação ambiental mais importante, pois a fumaça é um poluente que ameaça significativamente a saúde das crianças (RUVINSKI, BALANZAL, 1998; WONG, 1999; ORENSTEIN, 2005).

As funções fagocitárias dos macrófagos alveolares e o mecanismo mucociliar podem se tornar comprometidos com a inalação de fumaça de cigarro, que é descrita também como agente tóxico para as células epiteliais (HADDAD; FONTÁN, 2005; ORENSTEIN, 2005).

Crianças que são expostas à fumaça de cigarro, no ambiente, apresentam um número aumentado de doenças respiratórias, levando a um desempenho reduzido nos testes de função pulmonar (WONG, 1999; ORENSTEIN, 2005).

Wong (1999) refere que o fumo passivo, geralmente ocasionado pelas mães com hábitos de fumar, está associado à taxa de doenças respiratórias como bronquites, asma e otite média, ao crescimento fetal diminuído, ao aumento do número de nascimentos prematuros e natimortos e à grande incidência de síndrome da morte súbita infantil. Esta autora ainda refere que o fumante passivo durante a infância, pode ser na fase adulta, o mais importante precursor da doença pulmonar crônica. Afirma que é necessário incluir essa informação em todas as avaliações de 
crianças saudáveis, especialmente, para aquelas com doenças respiratórias e alérgicas.

- Inalação de fumaça

Segundo Wong (1999) suspeita-se de lesão por inalação de fumaça quando há história de chamas em um espaço fechado, com queimaduras ou não. Pêlos nasais chamuscados ou queimaduras de mucosas nasais, labiais, orais ou de faringe, fuligem ao redor do nariz ou no escarro constituem sinais que levam à suspeita de possível lesão pulmonar por inalantes. Tosse ou voz rouca, estridor inspiratório e expiratório e sinais de angústia também são evidências adicionais.

Devemos considerar, dentro do ambiente doméstico, a presença de fogões à lenha, que podem expor os indivíduos à fumaça, uma vez que seu uso mostra também relação com diversas doenças pulmonares, especialmente na população infantil. Sibilância e pneumonia episódica foram descritas em crianças expostas à combustão de madeira dentro de casa, pois resulta na exposição a material particulado e hidrocarbonetos policíclicos. O tratamento prévio da madeira com substâncias tóxicas, também é outro fator associado à queima da madeira, o que pode ocasionar outros problemas sistêmicos (RUVINSKI; BALANZAL, 1998; WONG, 1999; ORENSTEIN, 2005).

b) Via aérea obstruída: espasmo de via aérea; secreções retidas; muco excessivo; presença de via aérea artificial; corpo estranho na via aérea; secreções nos brônquios; exsudato nos alvéolos. 
Este grupo de fatores relacionados mostra possíveis causas de obstrução das vias aéreas, que levam à resposta humana de desobstrução ineficaz. Esses fatores relacionados podem estar associados a processos patológicos das vias aéreas que proporcionam, aumento da secreção de muco e formação de exsudato inflamatório, à entrada de corpo estranho nas vias aéreas e à presença de vias aéreas artificiais, sendo que esta última já foi descrita anteriormente (NAPOLEÃO, 2005).

- Espasmo de via aérea

O laringoespasmo e o broncoespasmo são mecanismos de defesas adicionais do corpo humano, uma vez que, juntamente com a interrupção temporária da respiração, a respiração superficial reflexa e a tosse limitam a profundidade e a quantidade de penetração de material estranho nas vias aéreas, ocasionando uma breve proteção (KIM; LARSON, 1987; HADDAD; FONTÁM, 2005).

Quando ocorre espasmo das vias aéreas, há um aumento da resistência ao ar quando passa, dificultando a sua entrada e saída, gerando também maior dificuldade para eliminação das secreções produzidas nas vias aéreas (NAPOLEÃO, 2005).

- Corpo estranho na via aérea

Normalmente, a maioria dos corpos estranhos aspirados para o trato respiratório é expelida pela tosse reflexa e não requer assistência médica. Porém, nos casos em que um objeto muito grande para ser eliminado pelo mecanismo mucociliar foi aspirado e não expelido com a tosse, inevitavelmente, aparecerão sintomas de angústia respiratória. Se um corpo estranho for grande o suficiente para ocluir completamente a via aérea superior, trata-se de risco de vida imediato. $\mathrm{O}$ 
objeto de menor porte que se aloja em um dos brônquios principais ou lobares, causam sintomas crônicos, e, geralmente, são menos graves (ORENSTEIN, 2005).

Esta mesma autora refere que as complicações e os sinais e sintomas ocasionados por corpos estranhos dependem de sua natureza, local de alojamento e grau de obstrução.

Se a obstrução for profunda, observa-se afonia. Um corpo estranho laríngeo causa tosse com características da tosse encontrada no crupe e rouca. Sinais e sintomas como hemoptise, dispnéia, sibilância e cianose também podem ocorrer (ORENSTEIN, 2005).

Corpos estranhos traqueais também podem ocasionar tosse, rouquidão, dispnéia e cianose (ORENSTEIN, 2005).

Corpos estranhos brônquicos, os sintomas iniciais são parecidos aos corpos estranhos na laringe ou traquéia como tosse, sibilância, escarro com estrias de sangue e gosto metálico (se o objeto for de metal). Um corpo estranho não obstrutivo e não irritante, geralmente, produz poucos sintomas, mesmo após um período de tempo prolongado. Porém, se um corpo estranho ocasiona obstrução, produz rapidamente sinais e sintomas e alterações anatomopatológicos. Se a obstrução for de grau leve, isto é, há passagem de ar em ambas as direções com uma pequena interferência, pode haver sibilância. Caso a obstrução permita somente a entrada de ar, sem a saída, a hiperinsuflação obstrutiva se desenvolve. No caso de obstrução completa, a atelectasia obstrutiva é produzida à medida que o ar dos pulmões é absorvido. No caso de uma dessas alterações persistir, a doença broncopulmonar crônica pode aparecer (ORENSTEIN, 2005).

Essa mesma autora relata que no caso de crianças, pode aparecer um episódio esquecido de engasgo enquanto a criança comia ou brincava com objetos 
pequenos. O exame físico pode mostrar desvio da traquéia, murmúrio vesicular diminuído no lado da obstrução, porém esse sinal não é óbvio se houver sibilância difusa. Se os sintomas iniciais forem esquecidos, há um intervalo assintomático que pode durar horas, dias e/ou semanas.

A aspiração de líquidos ou alimentos constitui perigo para a criança que tem dificuldade em deglutir ou que é incapaz de deglutir em virtude de paralisia, fraqueza e debilidade (ORENSTEIN, 2005).

É importante lembrarmos que a vítima não consegue falar, respirar ou tossir e na maioria das vezes demonstra o sinal universal de angústia que é agarrar o pescoço entre o polegar e os dedos (SMELTZER; BARE, 2005).

- Secreções retidas, muco excessivo, secreções nos brônquios e exsudato nos alvéolos

O termo secreção é definido por Ferreira (1998) como "produto específico elaborado por glândula"; muco, como sendo "secreção viscosa das membranas mucosas"; e exsudato, como "o processo pelo qual alguns dos constituintes do sangue passam lentamente através das paredes dos pequenos vasos congestionados para os espaços ou tecidos vizinhos, durante a inflamação".

As vias respiratórias, desde o nariz até os bronquíolos terminais, são mantidas úmidas através de uma camada de muco que reveste toda a superfície. As secreções do trato respiratório são derivadas das células mucosas (glicoproteínas) e serosas das glândulas submucosas que se esvaziam na superfície epitelial - na mucosa há ductos que transportam as secreções, eliminando-as para a luz; das células califormes e células da Clara que são células secretoras especiais no epitélio superficial dos brônquios e bronquíolos, respectivamente (WEINBERGER, 1989; 
GUYTON, 1993; HADDAD; FONTÁN, 2005); do transudato proveniente do espaço vascular e do líquido alveolar, que contribui com a maior parte dos fosfolipídeos encontrados no muco traqueobrônquico. Cabe ressaltar que esse muco contém cerca de 95\% de água (KIM; LARSON, 1987; HADDAD; FONTÁN, 2005).

O muco além de manter as superfícies úmidas, também tem por função capturar pequenas partículas do ar inspirado, impedindo-as de atingir os alvéolos. Logo em seguida, o próprio muco é removido em direção à faringe, para ser secretado, em parte pelas células califormes no revestimento epitelial e, em parte, por pequenas glândulas submucosas (GUYTON, 1993).

A remoção de partículas depositadas nas vias aéreas condutoras se dá dentro de horas pelo mecanismo mucociliar e a remoção de partículas que atingem os alvéolos pode levar vários dias a meses. As partículas nos alvéolos também podem ser fagocitadas por macrófagos alveolares e removidas dos pulmões, pelo sistema mucociliar ou podem ser transportadas para o interstício para remoção através dos linfócitos até os nodos regionais ou o sangue. Algumas partículas penetram no interstício sem fagocitose. A remoção mucociliar pode ser auxiliada pela tosse, que coloca para fora o excesso de muco, para cima nas vias aéreas (HADDAD; FONTÁN, 2005).

Alguns processos patológicos que ajudam no aumento das secreções e interferem nos mecanismos de defesa das vias aéreas (sistema mucociliar, imunológico, tosse, outros), produzem alterações a nível do sistema respiratório que, de acordo com a fisiopatologia, podem ocasionar retenção das secreções, muco excessivo, secreção nos brônquios e exsudato nos alvéolos (NAPOLEÃO, 2005).

As patologias mais comuns nas quais os fenômenos acima citados podem ocorrer são: a pneumonia que é um processo inflamatório do pulmão em que os 
alvéolos ficam cheios de líquidos e células sanguíneas (exsudato inflamatório), podendo não ocorrer uma ventilação efetiva (GUYTON, 1993; WEINBERGER, 1989); a bronquite, processo inflamatório dos brônquios que ocorre em associação a várias outras doenças dos tratos respiratórios superior e inferior, com envolvimento freqüente da traquéia, em que há, após alguns dias de início da doença, aumento da secreção de muco e escarro purulento (GUYTON, 1993; WEINBERGER, 1989; ORENSTEIN, 2005), na bronquite crônica, há diminuição do calibre da via aérea como conseqüência das secreções, aumento do mecanismo mucosecretor e inflamação; a bronquiolite é uma doença comum do trato inferior de lactentes em que há obstrução bronquiolar devida ao edema, bem como acúmulo de muco e restos celulares nos bronquíolos também compõem esse grupo de patologias em que há aumento nas secreções do trato respiratório (ORENSTEIN, 2005).

Nas crianças com estreitamento das vias aéreas por muco excessivo associado ou não ao espasmo, causam aprisionamento do ar, isto é, o ar inspirado entra nos alvéolos mais facilmente do que sai, ocasionando a distensão das vias aéreas distais e dos alvéolos, prejudicando a troca de gases (MATHERS; FRANKEL, 2005).

c) Fisiológicos: disfunção neuromuscular, hiperplasia das paredes brônquicas, doença pulmonar obstrutiva crônica, infecção, asma e vias aéreas alérgicas

Os vários estados patológicos apresentados nesse grupo, também podem ocasionar a resposta humana "desobstrução ineficaz das vias aéreas". Napoleão (2005) observou que esses fatores, freqüentemente, ocasionam aqueles contidos no 
grupo via aérea obstruída e possuem relação com os fatores ambientais apresentados, especialmente o fumo e fumo passivo.

- Disfunção neuromuscular

Hoffman (1987) em seu estudo refere que no corpo existem vários sistemas interdependentes, sendo a relação entre o sistema respiratório e o neuro muscular um excelente exemplo dessa interdependência. Como exemplo, ele cita que a troca gasosa não pode ocorrer sem a assistência do diafragma e dos demais músculos respiratórios.

Doenças neuromusculares agudas e crônicas causam problemas respiratórios. A fraqueza neuromuscular lentamente progressiva e crônica tem maior chance de causar anormalidades respiratórias de início insidioso, que acabam por tornar-se incapacitantes e amiúde limitadoras da vida. Com a progressão da fraqueza, os pacientes não conseguem gerar pressão intratorácica suficiente para uma tosse eficaz, ou não conseguem manter a glote suficientemente fechada para permitir um aumento adequado da pressão no pulmão. A progressiva redução na capacidade vital também compromete a eficácia da tosse, embora os volumes correntes possam continuar normais. Isso ocasiona múltiplos episódios pequenos de aspiração à medida que os músculos laríngeos tornam-se mais fracos, portanto com a perda de suspiros adequados e a capacidade diafragmática reduzida para evitar o comprometimento do volume torácico pelos órgãos abdominais, ocorre atelectasia microscópica difusa, acompanhada de uma anormalidade da ventilação - perfusão e hipoxemia (ORENSTEIN, 2005).

Cabe ressaltar que segundo este mesmo autor, todo mecanismo acima descrito sobrevém infecção recidivante ou crônica que restringe ainda mais a 
capacidade vital. A viscosidade das secreções infectadas compromete a remoção mucociliar já debilitada. A perda progressiva do tecido pulmonar pela fibrose associada à infecção e a hipoxemia pode acarretar com o passar do tempo, hipertensão arterial pulmonar e pode levar o paciente à insuficiência cardíaca direita.

Quando as funções respiratórias e neuromusculares estão com as funções normais, a maioria das pessoas pode efetivamente limpar suas vias aéreas das secreções. A perda relativa ou total da função neuromuscular diminui essa habilidade (HOFFMAN, 1987).

- Hiperplasia das paredes brônquicas

Processos patológicos, ocasionados por algumas doenças, promovem o aumento na espessura das paredes brônquicas. Podemos citar como exemplo a bronquite crônica, na qual gera de maneira recorrente a diminuição do calibre da via aérea como conseqüência das secreções, aumento das glândulas mucossecretoras e inflamação. E como resultado, a quantidade de muco dentro da via aérea está também aumentada. As paredes brônquicas também mostram evidências de processo inflamatório, com infiltração celular e graus variáveis de fibrose. As secreções presentes nestes pacientes são espessas e mais viscosas que o normal (WEINBERGER, 1989).

- Doença pulmonar obstrutiva crônica

Os dois distúrbios mais freqüentes que fazem parte dessa categoria são a bronquite crônica e o enfisema pulmonar. A doença pulmonar obstrutiva crônica geralmente se refere a desordens que perturbam o fluxo aéreo, em que o processo mais proeminente esteja dentro das vias aéreas ou dentro do parênquima pulmonar. 
Na bronquite crônica há presença de tosse crônica com produção de escarro e vários fatores estão implicados em sua etiologia, como o fumo, poluição do ar, infecção e hereditariedade. Geralmente, os pacientes apresentam alterações nas glândulas submucosas, aumento no tamanho e número de células caliciformes secretoras de muco dentro das vias aéreas (WEINBERGER, 1989; SMELTZER; BARE, 2005).

Esses mesmos autores citam que no enfisema pulmonar, há uma dilatação e destruição dos espaços aéreos distais ao bronquíolo terminal. Os fatores etiológicos principais identificados nesta afecção foram o fumo de cigarros e uma predisposição hereditária (WEINBERGER, 1989; SMELTZER; BARE, 2005).

- Infecção

Pacientes com infecção das vias aéreas, geralmente possuem dificuldade de limpeza das secreções produzidas. Este grupo de enfermidade varia de uma irritação trivial da rinite e tosse produtiva até uma séria inabilidade para expectorar as secreções traqueobrônquicas, levando a problemas na troca gasosa (HANLEY; TYLER, 1987).

A resposta humana para "Desobstrução ineficaz de vias aéreas" ocorre, freqüentemente, nos pacientes com infecção por bactérias e com defesas comprometidas. Apesar dos avanços na identificação dos agentes causadores, mecanismos de infecção, fatores do hospedeiro, grupos de risco, antibióticoterapia e imunizações, o problema continua atingindo adversamente os pacientes, seus familiares e a sociedade (NAPOLEÃO, 2005).

Os vírus respiratórios podem danificar os cílios e alterar seu código genético, diminuindo sua mobilidade e a efetividade da limpeza, levando a um aumento de 
bactérias, que superam a capacidade fagocitária dos macrófagos alveolares, favorecendo a invasão (RUVINSKI, BALANZAL, 1998).

Segundo Haddad; Fontán (2005) a lesão do epitélio respiratório pode ser reversível em algumas infecções como a rinite, sinusite, bronquite, bronqueolite, infecção respiratória aguda associada aos altos níveis de poluição do ar e na descamação epitelial ocasionada pela asma ou com alguns irritantes, no broncoespasmo, edema, congestão e às vezes na ulceração superficial leve. Contudo, a ulceração acentuada, bronquiectasia, bronquiolectasia, metaplasia de células escamosas e fibrose representam lesões sérias e comprometimento permanente dos mecanismos de remoção normais. Outros fatores que podem afetar os pulmões incluem a hiperventilação, hipóxia alveolar, tromboembolia pulmonar, edema pulmonar, reações de hipersensibilidade e certas drogas como os salicilatos.

As infecções pulmonares causam suas seqüelas clínicas, seja pela alteração do funcionamento normal do parênquima pulmonar, ou seja, pela indução dessa resposta generalizada aos microorganismos invasores. A conseqüência fisiopatológica principal da infecção e da inflamação envolvendo as aéreas distais das vias aéreas é o decréscimo da ventilação nas aéreas afetadas. Se a perfusão se mantém relativamente, como geralmente ocorre, resulta em desequilíbrio, com relação ventilação-perfusão baixa, nas aéreas afetadas. Quando os alvéolos estão totalmente preenchidos com exsudato inflamatório, pode ocorrer nenhuma ventilação nessas regiões, resultando numa extrema desigualdade na ventilaçãoperfusão (WEINBERGER, 1989).

Com relação à defesa contra agentes microbianos, a fagocitose e a remoção mucociliar podem não ser proteção suficiente contra agentes bacterianos e virais. Existem fatores adicionais que são a destruição celular dos microorganismos e as 
repostas imunes que ajudam no processo de fagocitose-destruição. Os macrófagos alveolares e intersticiais, derivados de monócitos, são componentes essenciais do sistema de defesa pulmonar. A destruição e a fagocitose das partículas vivas por esses macrófagos podem ser ajudadas pelas opsoninas ou por pequenos linfócitos. O interferon, a lisozima e a lactoferrina também podem desempenhar um papel de defesa nas secreções respiratórias (KIM; LARSON, 1987; RUVINSKI; BALANZAL, 1998; HADDAD; FONTÁN, 2005).

Pacientes com vias aéreas artificiais, infecções respiratórias baixas e com limitação ventilatória crônica, produzem um distúrbio entre a produção e limpeza do muco. A limpeza mucociliar, nesses pacientes, pode ser aumentada pela tosse e quando a tosse é inefetiva em desobstruir as vias aéreas, intervenções de enfermagem adicionais podem ser propícias para manter as vias aéreas pérveas (KIM; LARSON, 1987).

- Asma

A asma é uma das causas mais importantes de doença crônica na infância e é caracterizada por episódios de estreitamento reversível das vias aéreas, associados à contração da musculatura lisa (WEINBERGER, 1989; WONG, 1999; SLY, 2005).

Segundo WONG (1999) não existe uma definição precisa para a asma; ela pode ser considerada uma doença pulmonar obstrutiva difusa com hiper-reatividade das vias aéreas a diversos estímulos e/ou um alto grau de reversibilidade do processo obstrutivo, que ocorre naturalmente ou em conseqüência de um tratamento. 
Além da broncoconstrição, a inflamação é um fator fisiopatológico importante. As manifestações da obstrução das vias aéreas na asma decorrem de broncoconstrição, hipersecreção de muco, edema da mucosa, infiltração celular e descamação de células epiteliais e inflamatórias (WONG, 1999; SLY, 2005).

Varia de paciente para paciente a gama particular de estímulos que desencadeiam as crises asmáticas, mas o efeito final, a broncoconstrição é qualitativamente semelhante (WEINBERGER, 1989; WONG, 1999; SLY, 2005).

Estudos em crianças com asma sugerem que a alergia influencia a persistência e a gravidade da doença (WEINBERGER, 1989; WONG, 2002). Porém, nem todos os asmáticos se enquadram na categoria de alérgicos; muitos sofrem exacerbações quando expostos a antígenos. Nestes casos, a asma é chamada de "idiossincrática" e é freqüentemente exacerbada por infecções das vias aéreas superiores. Pacientes alérgicos, tem freqüentemente uma história familiar importante de asma ou de outras alergias, sugerindo que a genética possa ser um fator presente no desenvolvimento da asma (WEINBERGER, 1989).

Sly (2005) refere que a obstrução é mais intensa durante a expiração, porque as vias aéreas, normalmente, intratorácicas tornam-se menores durante a expiração. A obstrução não se distribui uniformemente pelos pulmões. Pode ocorrer atelectasia segmentar, agravando a desigualdade da ventilação e da perfusão. A elevação das pressões transpulmonares, necessária à expiração através de vias aéreas obstruídas, pode causar maior estreitamento ou fechamento precoce completo de algumas vias aéreas durante a expiração, aumentando, assim, o risco de pneumotórax. 
- Vias aéreas alérgicas

A rinite alérgica sazonal, polinose sazonal e febre do feno descrevem um complexo de sintomas que sucede a sensibilização a polens de árvores, gramas e ervas levados pelo vento (SLY, 2005).

Os esporos de fungos e antígenos de animais ou ácaros da poeira, os polens inalados depositam-se na mucosa nasal. Os antígenos hidrossolúveis difundem-se para dentro do epitélio e, em indivíduos atópicos geneticamente predispostos, desencadeiam a produção de antígenos locais, como $\lg \mathrm{E}$. A liberação estimulada dos antígenos mediadores dos mastócitos, síntese de novos mediadores dos mastócitos e subseqüentemente recrutamento dos neutrófilos, eosinófilos, basófilos e linfócitos, são responsáveis pelas reações das fases precoce e tardia aos alérgenos inalantes. Essas reações produzem muco, edema, inflamação, prurido e vasodilatação. A inflamação tardia pode contribuir para a hiper-responsividade a alérgenos específicos, uma reação de preparação e estímulos específicos, como substâncias irritantes e odores fortes (SLY, 2005).

Apresentados os fatores relacionados, como próximo passo discursaremos sobre as características definidoras do diagnóstico de enfermagem em estudo.

\subsection{3 - As Características Definidoras}

As características definidoras para o diagnóstico de enfermagem “Desobstrução ineficaz de vias aéreas” já citadas anteriormente são: dispnéia, murmúrios vesiculares diminuídos, ortopnéia, ruídos adventícios respiratórios (estertores, crepitações, roncos e sibilos), tosse ineficaz ou ausente, expectoração, 
cianose, vocalização dificultada, olhos arregalados, mudanças na freqüência e ritmo respiratório e agitação (NANDA, 2006).

Faremos a seguir uma descrição de aspectos relativos a cada uma dessas características definidoras.

a) Dispnéia e Ortopnéia

A dispnéia definida por Tarantino (2001) e Turino (2001) como a dificuldade para respirar. Já a ortopnéia, segundo Tarantino (2001) e Potter; Perry (2005) é a dificuldade respiratória que melhora quando o paciente eleva o tórax, colocando-o na posição vertical, mantendo-se sentado no leito.

Segundo Turino (2001), o sintoma da dispnéia consiste no aumento do trabalho mecânico da respiração, freqüentemente produzido pelo aumento na resistência das vias aéreas, como ocorre nas doenças obstrutivas ou na diminuição da distensibilidade dos pulmões como nas reações fibróticas.

Será um sintoma subjetivo, quando somente o doente a percebe e objetivo quando o sintoma da dispnéia for acompanhado de manifestações que são evidentes ao exame físico (TARANTINO, 2001).

Esse mesmo autor refere que o paciente pode ou não ter consciência deste sintoma.

Para relacionar a dispnéia a atividades físicas temos que classificá-la. Dispnéia aos pequenos esforços é a que surge após as atividades de rotina; dispnéia de repouso, a dificuldade respiratória mesmo durante o repouso; a dispnéia aos médios esforços, a que decorre dos exercícios habituais, antes realizados sem dificuldade; e dispnéia aos grandes esforços, aquela que aparece após esforços 
acima dos habituais, mas dentro das possibilidades de cada um (TARANTINO, 2001).

Cabe ressaltar alguns outros tipos de dificuldade respiratória que podem vir a aparecer nas crianças com problema cardíaco congênito, que são a platipnéia que consiste na sensação de falta de ar ao levantar-se e a trepopnéia que é a dispnéia que aparece em determinado decúbito lateral, como acontece nos pacientes com derrame pleural que se deitam sobre o lado não afetado (WEINBERG, 1989; TARANTINO, 2001).

Tarantino (2001) refere que as causas da dispnéia podem ser divididas em atmosférica, obstrutiva, pleurais, toracomusculares, diafragmática, teciduais ou ligadas ao sistema nervoso central.

As causas atmosféricas ocorrem quando a composição da atmosfera é pobre em oxigênio ou quando sua pressão parcial estiver diminuída, aparece então a dispnéia. O organismo reage com taquipnéia, no início, mas se a situação perdurar, aparece a sensação de falta de ar (TARANTINO, 2001).

Causas obstrutivas são quando as vias respiratórias, da faringe aos brônquios, sofrem redução no calibre. Tais obstruções podem ser intraluminais, parietais ou mistas. As obstruções laríngeas parietais são ocasionadas por algumas doenças como a difteria, laringe estridulosa, entre outras. As obstruções da traquéia geralmente por compressão extrínseca, decorrem do bócio, neoplasias malignas, aneurisma da aorta e adenomegalias mediastinais. As obstruções brônquicas são classificadas em intraluminais, parietais ou mistas, sendo causadas por neoplasias do mediastino, adenomegalias, entre outras. $E$ por último, as obstruções bronquiolares são sempre mistas e surgem na asma e nas bronqueolites (TARANTINO, 2001). 
As causas parenquimatosas segundo Tarantino (2001) são todas as afecções que podem reduzir a área de hematose de modo intenso, tais como condensações e rarefações parenquimatosas, causando a dispnéia.

As causas toracopulmonares são alterações capazes de modificar a dinâmica toracopulmonar, diminuindo sua elasticidade e movimentação ou provocando assimetria entre os hemitórax, levando à dispnéia. Como exemplo dessas alterações estão as fraturas dos arcos costais, cifoescoliose e alterações musculares (TARANTINO, 2001).

Tarantino (2001) refere que as causas diafragmáticas são todas as afecções que interferem com os movimentos do diafragma. É o músculo respiratório mais importante, pois contribui com mais de $50 \%$ na ventilação pulmonar. As principais causas são paralisia, hérnias e elevações uni ou bilaterais.

A pleura parietal é dotada de inervação sensitiva e sua irrigação provoca dor que aumenta com a inspiração. Para evitar a dor, o doente procura limitar ao máximo seus movimentos, bem como deitar sobre o lado que o incomoda. Esses dois mecanismos juntos explicam a dispnéia. Os grandes derrames reduzem a expansão pulmonar e também causam dispnéia. Essas são as causas pleurais citadas por Tarantino (2001).

As causas de origem tecidual são devido ao aumento do consumo celular de oxigênio que é uma resposta fisiológica normal ao aumento de atividade metabólica. Basta intensificar a atividade muscular (exercício físico, crise convulsiva, entre outras) para condicionar o aparecimento da dispnéia (TARANTINO, 2001).

Existem as causas de origem neurológica por alterações do ritmo respiratório, como em certos tipos de hipertensão craniana, e as psicogênicas, que se 
manifestam sob a forma de dispnéia suspirosa. Essas são as causas de dispnéia ligadas ao sistema nervoso.

b) Sons respiratórios diminuídos

A ausculta pulmonar é o exame realizado para a detecção dos sons respiratórios, através da utilização do estetoscópio e é considerada de grande importância para o exame dos pulmões, pois segundo Tarantino (2001) "é o método semiológico básico no exame físico dos pulmões".

A ausculta normal produz ruídos respiratórios broncovesiculares nas áreas periféricas dos pulmões de lactentes e crianças até 5 a 6 anos de idade. As paredes torácicas relativamente delgadas, com musculatura pouco desenvolvida, não amortecem o som, como fazem as paredes mais espessas do adulto, portanto os ruídos respiratórios são mais altos e estridentes (JARVIS, 2002).

Cabe ressaltarmos aqui um pouco dos sons respiratórios normais:

- Som traqueal e respiração brônquica

O som traqueal tem sua origem na passagem de ar através da fenda glótica e na traquéia e é audível na região de projeção da traquéia, no pescoço e na região esternal. No som traqueal, como nos outros sons pulmonares, são possíveis o reconhecimento de dois componentes, o inspiratório e o expiratório e suas características estetoacústicas são específicas para cada som. O som inspiratório é característico de um ruído soproso, mais ou menos rude, após o qual existe um curto intervalo silencioso que separa os dois componentes. O som expiratório é um pouco mais forte e mais prolongado (TARANTINO, 2001). 
A respiração brônquica assemelha-se ao som traqueal, diferenciando apenas por ter uma menor intensidade do componente expiratório. É audível na região de projeção dos brônquios de maior calibre, no tórax anterior, nas proximidades do esterno. Nas áreas de atelectasia ou nas regiões próximas de cavernas superficiais e nas áreas de condensação pulmonar, a respiração brônquica substitui o murmúrio vesicular (TARANTINO, 2001).

- Murmúrio vesicular

Os murmúrios vesiculares são ruídos respiratórios audíveis na maior parte do tórax, produzidos pela turbulência do ar circulante ao chocar-se contra as saliências das bifurcações brônquicas e na passagem pelas cavidades de tamanhos diferentes, como os bronquíolos para os alvéolos e vice - versa (TARANTINO, 2001).

O murmúrio vesicular é auscultado na maior parte do tórax, com exceção da região esternal superior, região inter-escapulo-vertebral direita e ao nível da $3^{a}$. e $4^{a}$. Vértebras dorsais. Nessas regiões, é mais audível a respiração broncovesicular. O murmúrio vesicular é mais forte na parte Antero-posterior do tórax, nas axilas e nas regiões infra-escapulares. Ele sofre variações em sua intensidade que dependem da amplitude dos movimentos respiratórios e da espessura da parede torácica, sendo mais fraco nas pessoas musculosas e obesas. (TARANTINO, 2001).

Este mesmo autor refere que o componente inspiratório é mais intenso e duradouro e possui uma tonalidade mais alta em relação ao componente expiratório que é mais fraco, de curta duração e de tonalidade mais baixa. Geralmente, não se percebe diferença do que ocorre na respiração traqueal, um intervalo de silêncio entre as duas fases da respiração. Comparando o murmúrio vesicular com a 
respiração brônquica, detectou-se que o murmúrio vesicular é mais suave e mais fraco.

Murmúrios vesiculares mais intensos são característicos quando o paciente respira amplamente e pela boca, após esforços, em crianças e em pessoas emagrecidas. Torna-se, também, mais intenso no hemitórax onde não existe comprometimento pulmonar, nos portadores de afecções pulmonares unilaterais (TARANTINO, 2001).

Inúmeras causas podem provocar diminuição do murmúrio vesicular, sendo elas: pneumotórax (presença de ar), hidrotórax (líquido) ou espessamento da pleura (tecido sólido) na cavidade pleural; dor torácica que reduza a expansibilidade do tórax, enfisema pulmonar, obstrução das vias aéreas superiores (espasmo, edema de glote, obstrução da traquéia), oclusão parcial ou total dos brônquios ou bronquíolos (TARANTINO, 2001).

Tarantino (2001) refere que a fase expiratória prolongada é uma importante alteração do murmúrio vesicular, sendo em condições normais, mais curta e suave que a fase inspiratória. Geralmente esse prolongamento da expiração surge nas doenças obstrutivas como o enfisema, asma brônquica e na bronquite espastiforme levando à dificuldade de saída do ar (TARANTINO, 2001).

Hoelkeman (2001) refere que na criança os ruídos respiratórios ficam geralmente diminuídos no lado torácico oposto ao que está posicionada a cabeça.

- Respiração broncovesicular

Este tipo de respiração é a junção das características da respiração brônquica com as do murmúrio vesicular. A duração e a intensidade da inspiração e da expiração têm igual magnitude, sendo um pouco mais forte que o murmúrio 
vesicular, mas com menos intensidade do que a respiração brônquica. Normalmente, a respiração broncovesicular tem a freqüência e amplitude moderada e é audível na região esternal superior, na interescápulo-vertebral direita e ao nível da terceira e quarta vértebra dorsais. Quando auscultada em outras regiões, pode significar a presença de condensação pulmonar, atelectasia por compressão ou presença de caverna (TARANTINO, 2001; JARVIS, 2002).

Nas crianças, devido ao tamanho do tórax, a respiração broncovesicular é auscultada nas regiões mais periféricas (TARANTINO, 2001).

c) Ruídos adventícios respiratórios (estertores, crepitações, roncos, sibilos)

Os ruídos adventícios respiratórios são divididos em dois grupos, dependendo da forma como se apresentam na ausculta pulmonar em relação à continuidade ou descontinuidade (NAPOLEÃO, 2005).

Os sons contínuos são representados pelos roncos, sibilos e estridor. Os sons descontínuos são representados pelos estertores, que se subdividem em finos, crepitantes e grossos ou bolhosos (TARANTINO, 2001).

Napoleão (2005) refere que embora o estridor não seja citado na NANDA, ele constitui um importante sinal nas obstruções parciais da laringe e traquéia.

- Ruídos respiratórios contínuos

\section{Roncos}

Os roncos são constituídos por sons graves, como nota monofônica isolada, de baixa freqüência. Sua origem vem das vibrações das paredes brônquicas e do conteúdo gasoso, quando ocorre estreitamento desses ductos, por edema da 
parede, espasmo ou ainda pela presença de secreção aderida a ela, como ocorre na asma brônquica, nas bronquites, nas obstruções localizadas e nas bronquiectasias. Geralmente é auscultado em todo ciclo respiratório, embora sejam mais proeminentes na expiração, mas podem aparecer na inspiração e desaparecerem um pouco com a tosse. São mutáveis, fugazes, surgindo e desaparecendo em curto período de tempo (TARANTINO, 2001; JARVIS, 2002).

Hoelkeman (2001) refere que, nas crianças, na maioria das vezes o muco e as mucosas do nariz e faringe edemaciadas ocasionam ruídos inspiratórios e expiratórios semelhantes a roncos, e que são transmitidos para todos os campos pulmonares.

\section{Sibilos}

São sons agudos, possuem tom musical e timbre elevado, podendo ser comparado ao miado de um gato, são formados por ondas de alta freqüência. (PERNETTA, 1990; TARANTINO, 2001; POTTER; PERRY, 2005; HADDAD; PALAZZO, 2005)

Segundo Jarvis (2002) são chiados musicais agudos polifônicos, normalmente presentes na expiração, mas podem ocorrer tanto na inspiração quanto na expiração.

Originam-se de vibrações das paredes bronquiolares e de seu conteúdo gasoso, presente na inspiração e na expiração, sendo mais predominante na expiração. Geralmente é acompanhado de dispnéia (TARANTINO, 2001).

Sua presença é devida à redução do calibre da árvore causado pelo espasmo (TARANTINO, 2001; POTTER; PERRY, 2005; HADDAD; PALAZZO, 2005). 
Geralmente são disseminados por todo o tórax, quando provocados por enfermidades que comprometem a árvore brônquica. Quando presentes em determinada região, podem ser devido a uma obstrução (TARANTINO, 2001; JARVIS, 2002).

Às vezes podem ser percebidos pelo paciente que se refere a esse ruído como "chiadeira" (NAPOLEÃO, 2005).

Na literatura, as causas brônquicas e pulmonares de sibilos relatadas são a bronquite aguda e crônica, a asma, a bronquiolite, as pneumonias, as tumorações benignas e malignas, entre outras (TARANTINO, 2001; JARVIS, 2002; ORENSTEIN, 2005).

Geralmente, nas crianças, os sibilos têm uma maior freqüência no lactente e no pré-escolar do que nas mais velhas, devido ao menor diâmetro das vias aéreas (HOELKEMAN, 2001).

\section{* Estridor}

Constituído por som produzido pela semi-obstrução da laringe ou da traquéia, sendo as causas mais relatadas na literatura a laringite, a epiglotite, a difteria, a estenose da traquéia e os corpos estranhos (TARANTINO, 2001; JARVIS, 2002).

Ruído inspiratório agudo, monofônico, mais alto no pescoço que sobre a parede torácica (JARVIS, 2002).

Segundo Tarantino (2001) quando a respiração é calma e pouco profunda, sua intensidade é baixa, mas na respiração forçada, o aumento do fluxo de ar provoca significativa intensificação desse som. 
Quando a criança apresenta obstrução das vias aéreas, devido inflamação laríngea ou corpo estranho, além do estridor, ela pode apresentar movimento de inclinação do queixo para frente ou sialorréia intensa (DiCARLO; FRANKEL, 2005).

O movimento da cabeça com a inspiração e a extensão da cabeça mostram um alto grau de gravidade (HOELKEMAN, 2001).

- Ruídos respiratórios descontínuos

\section{* Estertores}

Presentes e audíveis na inspiração ou expiração, geralmente se superpondo aos sons respiratórios normais, podendo ser finos ou grossos (TARANTINO, 2001).

Os estertores finos ou crepitantes são agudos e têm duração curta, durante a inspiração. O som produzido pode ser comparado ao atrito de um punhado de cabelo junto ao ouvido ou ao som percebido ao se fechar ou abrir um fecho do tipo velcro. Raramente se modificam com a presença de tosse. São audíveis principalmente nas zonas pulmonares influenciadas pela força da gravidade. Os estertores grossos ou bolhosos têm uma freqüência menor e uma maior duração que os finos. Sofrem alteração com a tosse e podem ser ouvidos em todas as regiões da caixa torácica. São ouvidos no início da inspiração e durante toda a expiração (TARANTINO, 2001; JARVIS, 2002).

Nos lactentes normais, ao final de uma inspiração profunda, podem ser auscultados estertores crepitantes finos. O autor ressalta que com o choro a criança pode propiciar respirações profundas e há melhora da ausculta pulmonar (PERNETTA, 1990; HOELKEMAN, 2001). 
d) Tosse ineficaz ou ausente

A tosse é um mecanismo de defesa das vias aéreas na reação aos irritantes ou na eliminação de secreções anormais. Ela pode se tornar nociva devido ao aumento da pressão na árvore brônquica que pode culminar na distensão dos septos alveolares (TARANTINO, 2001).

Este mesmo autor descreve a tosse como "o mais importante e mais freqüente sintoma respiratório".

Segundo Potter e Perry (2005) o mecanismo da tosse consiste em uma expulsão súbita e audível, de ar dos pulmões, por meio da respiração rápida e profunda, seguida de fechamento da glote, contração dos músculos expiratórios, principalmente o diafragma, terminando com uma expiração forçada, após abertura súbita da glote.

A última parte da tosse, a expiração forçada, constitui um mecanismo de grande importância para as vias aéreas (TARANTINO, 2001).

A tosse é resultado da transmissão de impulsos nervosos aos centros integradores da tosse no cérebro, com estimulação dos receptores da mucosa das vias respiratórias (TARANTINO, 2001; TURINO, 2001; BOAT; ORENSTEIN, 2005).

Segundo Tarantino (2001) os mecanismos para ocorrência da tosse se dão através das vias aferentes que partem das zonas tussígenas até o bulbo, mediadas pelo nervo vago. Estas vias aferentes dirigem-se do bulbo à glote e aos músculos expiratórios e são formadas pelo nervo laríngeo inferior, responsável pelo fechamento da glote, pelo nervo frênico e por aqueles que inervam os músculos expiratórios. 
Os estímulos podem ser de natureza inflamatória, mecânica e química. Edema, secreções e ulcerações geram estímulos de natureza inflamatória. Estímulos mecânicos são ocasionados pela poeira, corpo estranho, aumento ou diminuição da pressão pleural, que geralmente ocorrem na presença de derrame e nas atelectasias e os estímulos químicos, como inalação de gases irritantes, fumaça de cigarro e aspiração de suco gástrico e ainda térmico, como frio ou calor excessivos (TARANTINO, 2001; ORENSTEIN, 2005).

$\mathrm{Na}$ investigação clínica da tosse é necessário observar as seguintes características: freqüência, intensidade, tonalidade, ausência ou presença de expectoração, relações com o decúbito e o período do dia em que ela é mais intensa. Essas características podem ajudar a distinguir sua origem (TARANTINO, 2001; ORENSTEIN, 2005).

Tarantino (2001) também caracteriza a tosse como produtiva ou úmida e seca. A tosse produtiva ou úmida é acompanhada da produção de secreção escarro e nestes casos não é recomendado combatê-lo. A tosse seca, apenas causa irritação das vias respiratórias. Pode ter origem em áreas fora do pulmão, como no canal auditivo externo, na faringe, nos seios paranasais, no palato mole, na pleura e no mediastino.

Este mesmo autor refere que a presença de corpo estranho nas vias aéreas provoca tosse seca, quase contínua, e posteriormente se torna mais branda chegando a ser produtiva na ocorrência de inflamação com ou sem infecção. Refere ainda que a tosse seca, rebelde, que não cessa à medicação comum, deve ser investigada e tratada, pois pode ter várias origens, sendo uma delas a asma.

Em paciente com bronquite, a tosse é produtiva e naqueles que têm enfisema a tosse é mais seca. Geralmente o asmático quase não tosse, porém em alguns 
casos ela pode levar ao broncoespasmo, desencadeando uma crise dispnéica (TARANTINO, 2001).

Após a intubação traqueal com tubo ou cânula de traqueostomia, pode ocorrer tosse produtiva (TARANTINO, 2001).

A dor torácica ou abdominal, pode levar o paciente a evitar a tosse, ocasionando a "tosse reprimida". Geralmente isto acontece no início das pleuropneumopatias, no pneumotórax espontâneo, nas nevralgias intercostais, nos traumatismos tóraco-abdominais e nas fraturas de costela (TARANTINO, 2001).

\section{e) Expectoração}

Segundo Tarantino (2001) e Potter; Perry (2005) a expectoração é uma conseqüência da tosse. Suas características semiológicas compreendem o volume, a cor,o odor, a transparência e a consistência.

É importante ressaltarmos que as crianças geralmente têm o costume de deglutir a expectoração.

Cabe recordarmos que as células caliciformes e as glândulas mucíparas da mucosa produzem, $100 \mathrm{ml}$ de muco nas 24horas, aproximadamente, que são eliminados pela movimentação ciliar, através do seguinte processo: uma leve camada de muco deposita-se nas extremidades livres dos cílios que, através de movimento contínuo, o conduz à faringe, onde é deglutido reflexamente. As características da secreção ou escarro dependem de sua composição: o escarro mucóide contém muita água, proteínas, mucoproteínas, eletrólitos e contém baixa celularidade; o seroso contém água, eletrólitos, proteínas do leite e é pobre em 
células; o purulento é rico em piócitos e tem alta celularidade; o hemoptórico tem todos os elementos acima descritos e presença de sangue (TARANTINO, 2001).

Um escarro mucoso, de coloração clara, está mais associado a uma reação alérgica ou à bronquite asmática. Um escarro turvo ou purulento, sugere infecção, mas também pode ser aumento da celularidade (eosinofilia), geralmente presente nos processos asmáticos. O escarro purulento também pode estar presente na bronquiectasia. Escarros fétidos sugerem infecção anaeróbica dos pulmões (ORESTEIN, 2005).

No início da bronquite, a expectoração é mucóide e no enfisema ela é quase constante nos pacientes de constituição física "obesa" e quase ausente no paciente com constituição física "magra". No paciente com bronquite crônica, quando o escarro muda de aspecto, de mucóide para mucopurulento ou purulento, é sinal de infecção. Na maioria das vezes, essa mudança denuncia a presença de germes como pneumococo e o hemófilo. Esses pacientes quando já apresentam bronquiectasia, principalmente na fase aguda, costumam eliminar grande quantidade de secreção acumulada no período da noite, pela manhã na sua "toalete" brônquica (TARANTINO, 2001).

A expectoração contribui para diferenciar as lesões alveolares (pneumonias bacterianas) das intersticiais (pneumonias viróticas), por isso sua presença torna-se importante. Cabe dizermos que na pneumonia bacteriana não existe expectoração ou ela é muito discreta. Após algumas horas ou dias é que aparece uma secreção abundante, geralmente de cor amarelo esverdeado, espessa e densa, podendo nesta fase aparecer a presença de sangue. Na presença de germes anaeróbios, o hálito fica fétido e o escarro pútrido (TARANTINO, 2001). 
f) Cianose

Porto (2001) refere que a cianose é a cor azulada da pele e manifesta-se quando a hemoglobina reduzida alcança no sangue valores superiores a $5 \mathrm{~g} / 100 \mathrm{ml}$. Ela deve ser observada, geralmente ao redor dos lábios, na ponta do nariz, nos lobos das orelhas e nas extremidades das mãos e dos pés (leito ungueal e polpas digitais). Em caso de cianose intensa, todo o tegumento cutâneo estará na coloração azulada ou mesmo arroxeada.

Quanto à localização, pode ser generalizada ou localizada. A cianose universal ou generalizada é vista na pele toda e pode ser devido a vários mecanismos. A cianose localizada está presente em apenas algumas áreas do corpo (PORTO, 2001),

Esse mesmo autor refere que a intensidade da cianose pode ser leve, moderada ou intensa, sendo que a experiência do examinador é importante nesta classificação.

Quanto ao tipo de cianose, a partir de sua localização, Porto (2001) refere:

- Cianose do tipo central - ocorre insaturação arterial excessiva, permanecendo normal o consumo de oxigênio nos capilares, por baixa concentração de oxigênio no ar inspirado; hipoventilação pulmonar na qual o ar atmosférico não chega em quantidade suficiente para que se faça a hematose, por obstrução da superfície respiratória pulmonar ou por diminuição da expansibilidade toracopulmonar e shunt venoarterial, observado nas cardiopatias congênitas; 
- Cianose periférica - surge em conseqüência da perda excessiva de oxigênio ao nível da rede capilar, por estase venosa ou por diminuição funcional ou orgânica do calibre dos vasos da microcirculação;

- Cianose tipo misto - associam-se mecanismos responsáveis por cianose do tipo central com o tipo periférico (ex. na congestão pulmonar);

- Cianose por alteração da hemoglobina - alterações bioquímicas que ocorrem na hemoglobina impedindo a fixação do oxigênio pelo pigmento, geralmente presente na metahemoglobina por ação medicamentosa.

Porto (2001) ainda refere que é importante termos conhecimento de que a cianose localizada é sempre do tipo periférico, a cianose universal ou generalizada pode ser periférica por alteração da hemoglobina, pulmonar ou cardíaca e a oxigenoterapia é eficaz na cianose central e não influi na periférica, apenas melhora a cianose do tipo misto. Estas são informações que permitem a diferenciação dos tipos de cianose.

g) Vocalização dificultada

As alterações da voz, também conhecidas como disfonias, incluem desde a rouquidão até a afonia, observáveis nos casos de laringites crônicas, presentes nos casos de neoplasias, nas paralisias das cordas vocais, entre outras (HUNGRIA, 2001).

Mudanças no timbre da voz ou rouquidão são alterações na dinâmica das cordas vocais. Se aguda, de curta duração, não têm maior significado, ocorrendo com freqüência nas laringites viróticas comuns. As lesões das cordas vocais podem 
ser laríngeas ou extralaríngeas. As laríngeas incluem as: tuberculose, blastomicose, pólipos neoplásicos ou não e tumores benignos e malignos. As lesões localizadas fora da laringe são: os tumores localizados no mediastino médio inferior, incluindo os tumores malignos, as adenomegalias, o aneurisma do arco aórtico e a estenose mitral (TARANTINO, 2001).

Este mesmo autor refere ainda que a difteria, mononucleose infecciosa e neurite diabética podem também causar disfonia.

h) Mudanças na freqüência e ritmo respiratórios

- Ritmo respiratório

A inspiração e a expiração, normalmente, possuem quase o mesmo tempo de duração sucedendo-se os dois movimentos com a mesma amplitude, intercalados por leve pausa. Quando um destes mecanismos se altera, aparecem os ritmos respiratórios anormais: respiração suspirosa, respiração de Kussmaul, respiração de Biot e respiração de Cheyne Stokes (TARANTINO, 2001).

$\mathrm{Na}$ respiração suspirosa, o paciente executa uma série de movimentos inspiratórios de amplitude crescente seguido de expiração breve e rápida. Algumas vezes os movimentos respiratórios normais são interrompidos por "suspiros" isolados ou agrupados, sugerindo uma tensão emocional e ansiedades (TARANTINO, 2001).

A respiração de Kussmaul é composta por quatro fases: 1) inspirações ruidosas, gradativamente mais amplas, alternadas com inspirações rápidas de pequena amplitude; 2) apnéia na inspiração; 3) expirações ruidosas gradativamente mais profundas alternadas com inspirações rápidas e de pequena amplitude e 4) 
apnéia na expiração. Sua causa principal é a acidose, principalmente a diabética (TARANTINO, 2001).

$\mathrm{Na}$ respiração de Biot, o ritmo respiratório apresenta-se com duas fases sendo observada apnéia seguida de movimentos inspiratórios e expiratórios anárquicos quanto ao ritmo e à amplitude. Na maioria das vezes este tipo de respiração indica grave comprometimento cerebral e as causas mais freqüentes desse tipo de ritmo são as mesmas encontradas na respiração de Cheyne-Stokes (JARVIS, 2002; TARANTINO, 2001).

Na respiração de Cheyne-Stokes, o ritmo respiratório se caracteriza por uma fase de apnéia seguida de incursões inspiratórias cada vez mais profundas até atingir um máximo, para depois vir decrescendo até uma nova pausa (TARANTINO, 2001).

Segundo Potter; Perry (2005) a respiração de Cheyne-Stokes é um padrão respiratório que se caracteriza pela alternância de períodos de apnéia com respiração rápida e profunda. O ciclo começa com movimentos respiratórios lentos e superficiais que aumentam gradativamente até alcançarem uma profundidade e freqüência anormais, conseqüentemente, a respiração diminui progressivamente, voltando a se tornar lenta e superficial.

$\mathrm{Na}$ literatura são apontados como causas deste tipo de respiração na insuficiência cardíaca, na hipertensão intracraniana, nos acidentes vasculares cerebrais, nos traumatismos crânio encefálico, na insuficiência renal, na meningite e nas doses excessivas de drogas (TARANTINO, 2001; JARVIS, 2002; POTTER; PERRY, 2005).

Esse tipo de ritmo ocorre devido a variações da pressão de 02 e $\mathrm{CO} 2$ no sangue. O excesso de $\mathrm{CO} 2$ durante o período de apnéia faz com que os centros 
respiratórios bulbares enviem estímulos mais intensos que ocasionam um aumento da amplitude dos movimentos respiratórios, provocando maior eliminação de CO2 e diminuindo sua concentração no sangue. Conseqüentemente, não havendo estímulos exacerbados nos centros respiratórios, a amplitude dos movimentos respiratórios diminui. Nesse ritmo respiratório, a percepção "auditiva" é maior que a "visual", portanto a respiração de Cheyne Stokes é melhor ouvida que vista (TARANTINO, 2001).

- Freqüência respiratória

É um sinal vital de importante significado clínico, principalmente para pacientes com problemas respiratórios. É um modo prático e acessível que complementa a avaliação funcional dos pulmões (NAPOLEÃO, 2005).

Para que os resultados reflitam com uma maior exatidão o quadro respiratório, é necessário que o paciente esteja em repouso, preferencialmente dormindo. Os valores da freqüência respiratória variam de acordo com a idade (HOEKELMAN, 2001; HADDAD; PALAZZO, 2005; POTTER; PERRY, 2005).

Nos lactentes e crianças, a freqüência respiratória é extremamente sensível a estímulos externos, sofrendo maiores variações frente aos estados patológicos, exercícios e emoções quando comparada a dos adultos, desta forma, é importante não se satisfazer com uma única medida deste sinal vital em crianças (HOEKELMAN, 2001; HADDAD; PALAZZO, 2005).

Tomamos por referência, os valores apresentados por Mathers e Frankel (2002), por se tratar de uma literatura atual e específica para a área de pediatria, que são: 
Prematuros $\quad 40$ a 70 movimentos por minuto;

$0-3$ meses $\quad 35$ a 55 movimentos por minuto;

$3-6$ meses $\quad 30$ a 45 movimentos por minuto;

$6-12$ meses $\quad 25$ a 40 movimentos por minuto;

$1-3$ anos $\quad 20$ a 30 movimentos por minuto;

$3-6$ anos $\quad 20$ a 25 movimentos por minuto;

$6-12$ anos $\quad 14$ a 22 movimentos por minuto;

acima de 12 anos 12 a 18 movimentos por minuto;

\section{i) Agitação}

Nos casos em que há insuficiência respiratória e hipóxia, desencadeadas por afecções que causam alteração no estado respiratório, a agitação é considerada como um importante sinal. Esses distúrbios aumentam o trabalho da respiração, aumentando, conseqüentemente, as demandas de energia dos músculos respiratórios. Se as demandas excedem a capacidade dos músculos respiratórios, a insuficiência respiratória é desencadeada, e a agitação é um sinal descrito nesses casos (SMELTZER; BARE, 2005).

A hipóxia, a hipoperfusão cerebral, os desequilíbrios eletrólitos, hipo ou hiperglicemia são alguns dos distúrbios relatados na literatura como causadores de agitação (DOHERTY, 2005).

Segundo Napoleão (2005) é possível verificarmos, em vários estados patológicos relativos ao sistema respiratório nos quais há uma diminuição crescente ou acentuada dos níveis de oxigenação, a presença de agitação nos pacientes. 
Wong (1999) refere como exemplo a presença de agitação em crianças acometidas pelo vírus sincicial respiratório, quando a infecção alcança níveis de alta gravidade.

Pacientes com obstrução parcial das vias aéreas apresentam agitação, juntamente com outros sinais e sintomas, tais como estridor inspiratório, dispnéia, uso da musculatura acessória, confusão, podendo a vítima também agarrar o queixo entre o polegar e o indicador, além de apresentar tosse fraca e ineficaz (SMELTZER; BARE, 2005).

j) Olhos arregalados

Esse sinal não foi encontrado na literatura pesquisada, mas ele pode ser observado nos estados de angústia respiratória, juntamente com o sinal universal de angústia, como descrito por alguns autores como Potter e Perry (2005) e Smeltzer e Bare (2005), nas situações em que o paciente apresenta uma aparência apreensiva e alguns sinais e sintomas já descritos anteriormente, demonstrando uma possível obstrução das vias aéreas. 


\section{4 - MATERIAL E MÉTODO}

Trata-se de um estudo não experimental do tipo descritivo, que se caracteriza pela presença de uma variável independente não manipulável. Será descritiva por observar, descrever e explorar aspectos de uma situação (POLIT; HUNGLER, 1995).

Devido à natureza do estudo, para fins didáticos, a proposta metodológica de validação adotada foi a de Hoskins (1989), abordada em três etapas: primeira etapa análise de conceito, segunda validação por especialista e terceira validação clínica.

O desenvolvimento das etapas metodológicas deste estudo foi constituído com base na pesquisa realizada por Melo (2004).

\section{1 - Primeira Etapa: Análise de Conceito}

A primeira etapa do estudo - análise de conceito, correspondeu à estrutura teórica do processo de pesquisa, que constou do desenvolvimento de um modelo para explicar porque se esperava que certas características estivessem presentes, quando ocorrer um determinado fenômeno (HOSKINS, 1989).

Nesta etapa, realizamos um levantamento bibliográfico sobre o diagnóstico de Enfermagem "Desobstrução ineficaz de vias aéreas", a partir da definição e das características definidoras da NANDA (2006). Este levantamento foi realizado nas bases de dados: Literatura Latino Americana e do Caribe em Ciências da Saúde (LILACS), Biblioteca Nacional de Medicina e Instituto Nacional de Saúde (PUBMED), Cinahal Information Systems (CINAHAL) e da Base de Dados Bibliográficos da USP (DEDALUS), com as seguintes palavras chaves: enfermagem, diagnóstico de enfermagem, criança, desobstrução ineficaz de vias aéreas, cardiopatia congênita, 
Ineffective airway clearence, nursing, nursing diagnoses, child, heart diseases, congenital heart diseases e validation studies.

Além dessas fontes de dados, foi realizado um levantamento manual nos NANDA Conference Proceedings e nos Anais dos Simpósios Nacionais de Diagnóstico de Enfermagem.

A partir deste levantamento bibliográfico, foram estabelecidas as definições operacionais de cada característica definidora.

\section{2 - Segunda Etapa: Validação por Especialista}

Para Fehring (1987), este modelo de validação denomina-se validação de conteúdo diagnóstico (DCV) e para Hoskins (1989) é validação por especialistas.

A segunda etapa deste estudo - validação por especialistas, segundo Hoskins (1989), é um tipo de validação que visa ao estabelecimento de quais características definidoras encontradas na primeira etapa irão representar o conceito, e, quais deverão ser excluídas.

Para determinação das características que permanecem e quais devem ser excluídas, utilizamos os passos metodológicos estabelecidos por Fehring (1987) que constituem em: uma seleção de peritos, identificação pelos peritos de quais características definidoras representam a definição do diagnóstico estudado, cálculo dos escores para cada característica definidora e cálculo do escore total do diagnóstico estudado.

Posteriormente, cada um destes passos foram detalhadamente descritos. 
Para esta etapa estabelecemos, a seguir, a população e amostra, o instrumento de coleta de dados e os aspectos éticos da pesquisa e como procedemos à análise dos dados.

\subsection{1 - População e Amostra}

Nesta etapa, foram incluídos enfermeiros peritos ou especialistas no diagnóstico de Enfermagem em estudo e os que obtiveram pontuação mínima de cinco pontos. Os parâmetros de critérios para escolha destes enfermeiros foram os adotados por Fehring (1994):

- Ter titulação de Mestre em Enfermagem (4 pontos);

- Ter titulação de Mestre em Enfermagem com dissertação direcionada para o conteúdo relevante do diagnóstico de interesse (1 ponto);

- Tese de Doutorado sobre diagnóstico de Enfermagem (2 pontos);

- Prática clínica de pelo menos um ano de duração, na área do diagnóstico de interesse (1 ponto);

- Certificado de prática clínica (especialização) relevante ao diagnóstico de interesse (2 pontos);

- Publicação de pesquisa versando sobre diagnóstico de enfermagem e com conteúdo relevante para a área em foco (2 pontos);

- Publicação de artigo sobre diagnóstico de Enfermagem em periódico de referência (2 pontos).

Portanto, para ser considerado enfermeiro perito deve ter, no mínimo, grau de mestre em Enfermagem com uma área definida de experiência clínica, porém o autor ressalta que o mestrado deve ser necessário, mas não é o suficiente (FEHRING, 1994). 
Esse autor recomenda que o perito tenha conhecimento especializado sobre o diagnóstico em questão, demonstrando por meio de pesquisa, artigos científicos, prática clínica e especialização sobre o diagnóstico em estudo.

Partindo destas considerações foi constituída uma listagem dos possíveis peritos que possuem no mínimo titulação acadêmica de mestrado e que trabalham com os diagnósticos de enfermagem da NANDA na assistência, no ensino ou na pesquisa. Em contato prévio mantido com uma docente pesquisadora na temática da Escola de Enfermagem de Ribeirão Preto da Universidade de São Paulo, foi disponibilizada uma listagem de enfermeiros peritos em diagnóstico de Enfermagem, nacionalmente, que foram contatados após aprovação deste projeto, junto ao Comitê Ético em Pesquisa (CEP), para continuidade desta etapa do estudo.

Quanto ao tamanho da amostra, Hoskins (1989) não faz menção sobre um número determinado de enfermeiros peritos para validar um diagnóstico de enfermagem. Porém, Fehring (1986) recomenda a necessidade de ter 25 ou 50 enfermeiros especialistas na temática.

Procurando atender aos critérios pré-estabelecidos, a população deste estudo foi constituída por enfermeiros que possuem, no mínimo, grau de mestre, que trabalham ou trabalharam com a temática de "Processo de Enfermagem e Diagnóstico de Enfermagem" na pesquisa, ou no ensino, ou na assistência, e, abordem o tema "Desobstrução ineficaz de vias aéreas", no ensino, ou na assistência ou na pesquisa.

Considerando a temática e tendo em mãos uma lista de peritos cedida por uma docente da EERP, a seleção dos enfermeiros peritos ocorreu por "amostragem tipo bola de neve", referida por Polit e Hungler (1995), que consiste na seleção de sujeitos, por meio de indicação ou recomendação de sujeitos anteriores. 
Neste estudo, enfermeiros que atuam na área de Processo de Enfermagem, em especial com Diagnóstico de Enfermagem e Desobstrução ineficaz de vias aéreas foram abordados pela pesquisadora e, por sua vez, indicaram outros profissionais com o mesmo perfil que o seu.

A nossa amostra foi composta por 40 enfermeiros peritos que avaliaram e opinaram quanto à adequação da definição do diagnóstico em estudo, o título, e quanto também à pertinência das características definidoras em relação ao diagnóstico de enfermagem "Desobstrução ineficaz de vias aéreas”.

\subsection{2 - Instrumento de Coleta de Dados da Segunda Etapa}

Atendendo ao modelo proposto por Hoskins (1989), as características definidoras do diagnóstico de Enfermagem "Desobstrução ineficaz de vias aéreas" passaram por um processo de redefinição prévia à avaliação, para torná-las, operacionalmente, compatíveis com a análise pretendida.

Foi elaborado por Melo (2004) um instrumento de coleta de dados para contemplar a validação por especialistas com vistas ao diagnóstico de Enfermagem de disfunção sexual e padrões de sexualidade ineficazes. Com base na construção dessa autora realizamos uma adaptação para o nosso estudo, atendendo ao diagnóstico de enfermagem de Desobstrução ineficaz de vias aéreas, composto de 3 partes conforme apresentado no apêndice A.

Este instrumento de coleta de dados contém um questionário semi estruturado da seguinte forma: 
Parte A) Dados de identificação e questões referentes à experiência profissional no ensino, na pesquisa e na assistência de enfermagem. Esses foram os itens que selecionaram o profissional como perito ou não;

Parte B) composta por definições do diagnóstico de enfermagem "Desobstrução ineficaz de vias aéreas" segundo a NANDA (2006) e dos treze Padrões Funcionais de Saúde e questões referentes à adequação do título desse diagnóstico com sua definição e a pertinência do diagnóstico no domínio e classe estabelecidos para a taxonomia II da NANDA; e pela Lista das características definidoras com suas respectivas definições operacionais, segundo NANDA (2006) e por meio de busca à literatura pertinente.

Esta lista foi elaborada em uma escala do tipo Likert, composta de cinco pontos. Nela os peritos atribuíram um valor conforme sua pertinência, sendo que os valores atribuídos pelos peritos, indicaram a representatividade de cada característica definidora. Esta é a primeira etapa do modelo de Validação de Conteúdo Diagnóstico (DCV) referido por Fehring (1986) e acatada por Hoskins (1989).

Nesta escala do tipo Likert, pontuou-se a característica definidora da seguinte forma: nota 1, quando o perito responder que aquela característica definidora não é indicativa do diagnóstico de enfermagem; nota 2, quando é muito pouco indicativa; nota 3 , de algum modo indicativa; nota 4 , muito indicativa e nota 5 , quando é muitíssimo indicativa.

Algumas características definidoras fictícias foram acrescentadas nesta lista, com o objetivo de verificar possível tendência dos peritos para responder o instrumento. Hoskins (1989) não menciona nada a respeito de usar características 
fictícias, porém, Fehring (1986) sugere este tipo de procedimento para estudo de validação.

No final desta lista de características definidoras, para o diagnóstico de Enfermagem em estudo, deixamos um espaço para sugestões de outras características que se fizeram pertinentes, apontadas pelos peritos. Nas instruções gerais do instrumento, orientamos que frente à presença de novas sugestões, deverá conter não só o nome da característica, como também, a definição operacional.

\subsection{3 - Aspectos Éticos}

Esta pesquisa foi aprovada pelo Comitê de Ética em Pesquisa do HCFMRPUSP, número do processo 3229 / 2006 (ANEXO B)

Foi elaborado um "Termo de Consentimento Livre e Esclarecido" com informações sobre os objetivos do estudo, da determinação do que consiste a participação do sujeito, do direito de sair da pesquisa sem nenhum dano ou ônus, da garantia de total sigilo e do direito do pesquisador quanto à divulgação dos dados em trabalhos e eventos científicos; contém assinatura do pesquisador e do sujeito, autorizando sua participação na pesquisa. Essas determinações atendem às recomendações da Resolução 196/96 do Conselho Nacional de Saúde prevista para pesquisa envolvendo seres humanos (APÊNDICE B). 


\subsection{4 - Coleta de dados}

A coleta de dados da segunda etapa deste estudo foi feita com contatos diretos por meio de um telefonema ou envio de e-mail para os enfermeiros considerados peritos. Houve a identificação da pesquisadora, explicação do que consiste a pesquisa, solicitação para enviar o instrumento via correio ou e-mail e solicitação de indicação de outros enfermeiros com perfil para ser enfermeiro perito. Com a indicação de outros enfermeiros, solicitamos ao enfermeiro a colaboração e autorização para enviarmos por correio ou via e-mail, os instrumentos de coleta dos indicados, para o seu endereço, bem como a solicitação para que fizessem a distribuição deste, ou indicassem os endereços para contato pela pesquisadora. Todos os instrumentos enviados tinham envelopes selados para posterior resposta.

\subsection{5 - Análise dos Dados da Segunda Etapa}

A análise da adequação das definições do diagnóstico de Enfermagem em estudo foi quantitativa. Nos casos de afirmação pelos enfermeiros peritos de que a definição e/ou título não estivessem adequados, solicitamos uma nova descrição. Acreditamos que as definições ou títulos sugeridos pelos enfermeiros peritos mereciam uma análise de sua pertinência na literatura.

Para análise dos dados referentes ao grau com que cada característica definidora era indicativa do diagnóstico, foi utilizada a escala proposta por Fehring (1987) que realiza a média ponderal dos escores obtidos.

As médias ponderadas foram obtidas pela somatória dos pesos marcados para cada resposta e divididos pelo número total de respostas (FEHRING, 1986). 
Para cada característica definidora, foi calculada a freqüência de resposta assinalada em cada item da escala de Likert; o passo seguinte foi constituído da multiplicação desta freqüência com seus respectivos pesos: 1 (não característico) = 0,$2 ; 2$ (muito pouco característico) $=0,25 ; 3$ (de algum modo característico) $=0,50 ; 4$ (muito característico $)=0,75$ e 5 (muitíssimo característico) $=1,0$; a somatória dos produtos destas multiplicações foi dividida pelo número de sujeitos, obtendo-se a média ponderada para cada uma das características.

A partir destas médias, procedemos às fases seguintes do modelo de Fehring (1987), classificando as características definidoras, de acordo com o seu escore.

$\mathrm{Na}$ literatura, há controvérsias quanto aos escores a serem atribuídos pelo modelo de Fehring. Ele, em seu artigo em 1986, determina que as características definidoras com escore menor ou igual a 0,50 devem ser descartadas e as com escore maior que 0,75 devem ser consideradas características críticas. Fehring (1987) publica modificações em seu modelo, sendo que a principal delas inclui mudanças nos critérios para determinar as características definidoras como "maiores" e "menores". Ele refere neste artigo que as características definidoras com escore menor que 0,50 deveriam ser descartadas, porém, o autor ressalta que esse passo é provisório, ou seja, para descartar uma ou mais características definidoras é preciso que façam um estudo mais amplo de enfermeiros peritos de diferentes localidades do país ou que sejam submetidas a pequenos estudos até que se confirmem os resultados. Fehring (1987), neste mesmo artigo, classificou as características definidoras com escore maior ou igual a 0,80 como "maiores"e as menores que 0,80 e maior que 0,50 como "menores" e, ainda, ressalta que estas características necessitariam ser submetidas a estudos menores ou generalizados. 
O autor não refere o que deve ser feito com as características definidoras com escore maior que 0,05 e menor que 0,50 .

Em alguns estudos que utilizaram a metodologia de Fehring, as autoras trabalharam com a exclusão das características definidoras com escore menor que 0,50; características que obtiveram nota maior ou igual a 0,80 como "maiores" e as com escore entre 0,50 e 0,80 como "menores" (CARVALHO; ROSSI, 1998; CORRÊA, 1997; IDVAL et al., 2001;JESUS, 1998; KELLY, 1990; LEVIN, 1990; MELO, 2004; OLIVA, 1989; OLIVA, 2000; OLIVEIRA, 2001; SANTANA; SAWADA, 2002).

Bachion, Araújo e Santana (2002) em seu estudo adotaram a metodologia de exclusão das características definidoras menores que 0,05.

Diante das controvérsias existentes, neste estudo, optamos por excluir as características definidoras com peso menor que 0,50 , ressaltando que estas necessitam passar por uma nova avaliação para serem testadas em outros estudos, para realmente confirmarmos esses resultados.

Segundo o modelo proposto por Fehring, classificaram-se as características definidoras com escore entre 0,50 e 0,80 como "menores" e as com escore maior ou igual a 0,80 como "maiores". Denominamos as características definidoras "maiores" como as de maior freqüência e as "menores" como as de menor freqüência.

Fehring (1987) refere que a característica definidora que recebe um escore maior ou igual a 0,80 , significa que os enfermeiros peritos concordam que esta característica é muito indicativa do diagnóstico estudado.

Este mesmo autor também relata que para uma característica definidora ser denominada de "maior ou menor" exige-se a confirmação por meio de estudos repetitivos ou de um estudo generalizado que envolva todo o país. Até que tal fato 
não ocorra, as características serão chamadas de "possíveis indicadores maiores ou menores".

Ocorreu divergência entre os peritos, considerando suas áreas de atuação, apesar de se enquadrarem nos critérios descritos anteriormente. Verificamos por meio da estatística descritiva, conhecida também como análise exploratória de dados, a coincidência entre os escores dados a cada característica definidora pelo grupo de enfermeiros peritos que trabalham, predominantemente, com a Desobstrução ineficaz de vias aéreas e os que utilizam os Diagnósticos de Enfermagem da NANDA.

Para análise desta etapa, utilizamos as medianas e quartis (primeiro e terceiro) dos escores de cada característica definidora atribuídos pelos grupos de enfermeiros peritos.

Nas duas últimas fases do modelo, determinamos o escore total, denominado por Fehring (1987) como validação de conteúdo diagnóstico total, sendo a somatória dos escores individuais dividida pelo número total das características definidoras do diagnóstico em estudo, sendo que aquelas que obtiveram escores menores ou iguais a 0,50 não foram incluídas no escore total.

\section{3 - Terceira Etapa: Validação Clínica}

A terceira e última etapa - validação clínica, consiste na confirmação da lista das características definidoras que apareceram na primeira etapa (Análise de conteúdo) e que foram validadas pelos enfermeiros especialistas (Validação por Especialistas) no ambiente clínico (HOSKINS, 1989). 
Nesta etapa, Hoskins (1989) adota os mesmos critérios referidos por Fehring (1987), para classificar as características definidoras como "maiores" e "menores" e quais devem ser descartadas.

\subsection{1 - Local}

Este estudo foi desenvolvido no Centro de Terapia Intensiva Pediátrico (CTIP) do Hospital das Clínicas da Faculdade de Medicina de Ribeirão Preto da Universidade de São Paulo (HCFMRP-USP). Esta unidade foi inaugurada em 1998, para atendimento de crianças em estado de risco de vida, e, atualmente, conta com 8 leitos. Recebe clientes de 28 dias a 18 anos de idade, sendo que, com grande freqüência, recebem crianças a partir de zero ano de idade que foram ou serão submetidas a algum procedimento de cardiologia. Dos 8 leitos existentes, 4 deles são destinados, semanalmente, a atendimento à criança submetida à correção cirúrgica de cardiopatia congênita. O tempo médio de internação dos pacientes com cardiopatia congênita varia, dependendo da cardiopatia. No ano de 2005, o tempo de permanência no CTIP foi de horas a 43 dias.

O referido Hospital é uma entidade autárquica com personalidade jurídica e patrimônios próprios, vinculada à Secretaria de Saúde do Estado de São Paulo para fins de ensino, pesquisa e assistência. A área de atuação do hospital concentra-se, basicamente, no município de Ribeirão Preto, entretanto, diante das suas características de "Hospital Regional” e integrado ao Sistema Único de Saúde, em nível terciário, são atendidos pacientes das várias cidades da região. Dos 35 Hospitais da região de Ribeirão Preto, distribuídos em 21 cidades, o HCFMRP-USP absorve, aproximadamente, 20\% da demanda das internações (UNIVERSIDADE DE SÃO PAULO, 2006). 
O HCFMRP-USP atende clientes portadores de cardiopatia congênita, porém esta demanda tem aumentado significativamente nos últimos anos. Esse aumento na demanda ocasionou para o hospital o título de Centro Regional de Cardiopatias Congênitas.

\subsection{2 - População e Amostra}

Fizeram parte deste estudo sujeitos que internaram no CTIP após serem submetidos à correção cirúrgica para cardiopatia congênita e, que realizaram o pósoperatório imediato na Unidade de Terapia Intensiva Pediátrica do HCFMRP-USP.

A abordagem metodológica de Hoskins (1989) não estabelece um número determinado de sujeitos para a amostra, porém, Fehring (1987) sugere uma amostra de 50 pacientes.

Portanto, a amostra constou de 50 crianças e/ou adolescentes durante o período pós-operatório imediato e que foram selecionadas com base nos seguintes critérios de inclusão:

- Pertencer à faixa etária de criança segundo a determinação do Estatuto da Criança e do Adolescente

Art. $2^{\circ}$ Considera-se criança, para os efeitos desta Lei, a pessoa até doze anos de idade incompletos, e, adolescente, aquela entre doze e dezoito anos de idade.

- Ser portador de cardiopatia congênita desde o nascimento;

- Ficar internado no Centro de Terapia Intensiva Pediátrico, no pósoperatório de cirurgia cardíaca; 
- Estar internado no período de janeiro a abril de 2007. Esse tempo foi o suficiente para adquirir 50 pacientes, pois, atualmente, o setor do CTIP recebe quatro pacientes em pós-operatório de cirurgia cardíaca por semana;

- O cliente deveria estar fazendo uso de tubo endotraqueal.

Foram excluídos do nosso estudo:

- Sujeitos que vieram a falecer no período trans-operatório e pós-operatório imediato;

- Sujeitos que não foram portadores de cardiopatia congênita desde o nascimento;

\subsection{3 - Instrumento de Coleta de Dados da Terceira Etapa}

Para se verificar a incidência de características definidoras numa população, Fehring (1987) e Hoskins (1989) referem que caso a natureza do diagnóstico se relacione com desempenho fisiológico, a técnica da observação clínica é a mais indicada.

A avaliação física, segundo Wong (1999) é um processo contínuo, que se inicia durante a entrevista, principalmente por meio da utilização da técnica de interação, observação (inspeção, palpação, percussão e ausculta), estendendo-se durante todo o relacionamento profissional para continuidade do cuidado.

A avaliação clínica para os achados dos sinais e sintomas que sustentam a afirmação do DE de desobstrução ineficaz de vias aéreas leva a obter informações 
de dados significativos e focalizados, voltando-se principalmente com foco do problema de saúde do paciente.

Utilizamos o instrumento de coleta de dados do Centro de Terapia Intensiva Pediátrica do Hospital onde foi realizado este estudo, elaborado no modelo conceitual de Horta (1979) à luz das necessidades humanas básicas (APÊNDICE G). O instrumento serviu de guia para identificar as características definidoras do diagnóstico de Enfermagem em estudo.

Segundo Dalri (1993), a estrutura do instrumento de coleta de dados deve retratar o referencial teórico adotado, a dinâmica do serviço e o padrão de organização da assistência à especialidade da clientela assistida.

O instrumento de coleta de dados do CTIP do HCFMRP - USP foi elaborado para atender a criança e o adolescente gravemente enfermo, incluindo a clientela portadora de cardiopatia congênita. Esse instrumento de avaliação compreende as seguintes etapas: identificação (nome, registro, data de internação, diagnóstico e cirurgia realizada), pastas de avaliação das necessidades psicobiológicas: oxigenação / respiração, circulação, termorregulação, integridade tecidual, motilidade, percepção sensorial, alimentação / hidratação, eliminação e sono e repouso; pasta de necessidades psicossociais (comunicação interação) (APÊNDICE G).

Este instrumento foi submetido a uma validação aparente e de conteúdo por quatro enfermeiros, sendo duas enfermeiras que atuam na área da assistência e duas docentes da Escola de Enfermagem de Ribeirão Preto - (USP) que possuíam título de mestrado ou doutorado, todas trabalharam com o processo de Enfermagem no ensino, na pesquisa e na assistência, sendo que também atuam com área assistencial e com experiência em elaboração de instrumento de coleta de dados. 
A validação consiste em avaliar se o instrumento mede o que está sendo proposto medir. Para a validação do instrumento de coleta de dados elaboramos um questionário, que foi entregue a cada enfermeiro perito convidado para realizar esta etapa (APÊNDICE F).

O questionário de avaliação compreendeu cinco questões norteadoras, relacionadas à avaliação dos enfermeiros quanto à forma de apresentação e conteúdo do instrumento, e sugestões quanto ao acréscimo e à retirada ou modificações dos itens.

A elaboração do instrumento para o levantamento de dados no período pósoperatório imediato foi sob a forma de planilhas de necessidades, configurado da seguinte forma: total de 6 planilhas (necessidade de oxigenação, circulação, termorregulação, integridade tecidual, motilidade, percepção sensorial, hidratação e nutrição, eliminação, sono e repouso e comunicação e interação); na vertical estabelecemos os horários (24 horas do dia) e na horizontal colocamos os elementos necessários para avaliação do paciente. Entre os elementos e as horas foi deixado um espaço para a colocação dos dados, na forma de siglas. Ao final de cada planilha, no rodapé da folha constam os sinais e sintomas com suas respectivas siglas (APÊNDICE G).

Todos os enfermeiros peritos convidados para realizarem a avaliação expressaram que o instrumento favorece a formulação dos diagnósticos de enfermagem e que os dados são suficientes para identificar alterações nas necessidades básicas. Referiram que o instrumento é organizado, seqüencial permitindo fácil entendimento e os descritores são de fácil compreensão. Porém, algumas alterações foram sugeridas como: aumentar alguns espaços, acrescentar 
sinais e sintomas na legenda (no rodapé), modificar algumas siglas para o valor numérico e especificar alguns sinais e sintomas.

As sugestões foram aceitas o que proporcionou maior clareza nos itens, facilitando a leitura e compreensão do instrumento.

Foi realizado um teste piloto, para complementar a validação do instrumento, nas crianças internadas no CTIP em POI de cirurgia cardíaca para correção de cardiopatia congênita.

\subsection{4 - Aspectos Éticos}

Esta etapa teve aprovação do Comitê de Ética em Pesquisa. Conforme recomendação do CEP do HCFMRP-USP, colocamos em anexo (ANEXO A) uma autorização do chefe do Departamento da Pediatria e Puericultura e da Docente responsável pelo Centro de Terapia Intensiva Pediátrico - Unidade Campus.

Foram elaborados três Termos de Consentimento Livre e Esclarecidos, instruídos conforme a Resolução 196/96 do Conselho Nacional de Saúde. Um termo refere à autorização dos pais ou responsáveis pela criança ou adolescente e outros dois foram para os enfermeiros peritos que aceitaram participar do estudo, na etapa de validação do instrumento de coleta de dados e validação clínica do diagnóstico em estudo (APÊNDICE E, B,C e D). 


\subsection{5 - Coleta de Dados}

Segundo Hoskins (1989), para se detectar um diagnóstico de Enfermagem em um ambiente clínico, é necessária a presença de pelo menos 2 enfermeiros competentes diagnosticadores, para observarem o mesmo paciente. Portanto, nesta etapa, participaram além da pesquisadora, mais duas enfermeiras clínicas que se revezaram, conforme sua disponibilidade de horário, sendo que a pesquisadora esteve presente em todas as coletas de dados dos sujeitos da amostra, intercalando em dupla com estas outras enfermeiras.

Consideramos enfermeiros competentes e diagnosticadores, aqueles que atuam na área assistencial com criança e adolescente, que possua residência em Enfermagem Pediátrica e Neonatal ou mestrado e que desenvolveram artigos científicos na área de metodologia da assistência de Enfermagem.

Ressaltamos que os dois enfermeiros que participaram desta etapa acima citada, não fizeram parte do quadro de peritos da etapa metodológica de Validação por Especialistas (segunda etapa deste estudo).

Após o consentimento do responsável pelo paciente, em participar da pesquisa, os dados foram obtidos simultaneamente por dois peritos, através de um instrumento de coleta de dados para exame clínico. Conforme os sinais e sintomas foram aparecendo, referentes à desobstrução das vias aéreas, cada enfermeiro perito identificou a presença ou não do diagnóstico em estudo, com suas respectivas características definidoras já validadas na segunda etapa.

A literatura sugere que a coleta de dados deve ser feita de modo independente pelos enfermeiros assistenciais, observando a presença ou ausência 
de cada característica definidora que está sendo estudada, portanto, procederemos à coleta de dados simultaneamente.

Antes de proceder à mesma, os enfermeiros diagnosticadores receberam a definição do diagnóstico de Enfermagem em estudo e suas características definidoras também com suas definições operacionais, sendo mostrado em que consiste cada uma delas.

Para executar a coleta de dados, a pesquisadora realizou uma visita prévia à criança e/ou adolescente e responsável antes da cirurgia, para apresentação e explicação a respeito do estudo e objetivos da pesquisa, e a consulta quanto à permissão para a coleta de dados.

A coleta de dados ocorreu conforme a data da cirurgia e foi realizada no período de pós-operatório imediato de cirurgia cardíaca para correção de cardiopatia congênita. O período da coleta dependeu do término da cirurgia sendo realizado de manhã, tarde e/ou de noite. Este período totalizou-se em quatro meses, sendo de janeiro a abril de 2007.

Ressaltamos que durante o período de coleta de dados, toda identificação de necessidade de assistência foi prontamente prestada ou encaminhada aos setores competentes pela pesquisadora.

\subsection{6 - Análise dos Dados da Terceira Etapa}

Segundo recomenda Hoskins (1989), a análise e síntese dos dados foram realizadas pelos enfermeiros que participaram da coleta de modo independente.

Para o estabelecimento do diagnóstico, foi feita a análise dos dados com sua categorização atendendo ao instrumento da coleta dos mesmos, validado 
anteriormente referente à identificação de possíveis lacunas, em seguida procedeuse a fase de síntese com o agrupamento desses dados e a elaboração do diagnóstico de Enfermagem "Desobstrução ineficaz de vias aéreas" (GRIFFTHKENNEY E CHRISTENSEN 1986).

Com o diagnóstico firmado, procedemos ao cálculo da seguinte estatística, segundo Hoskins (1989): porcentagem de concordância sobre a presença ou ausência das características definidoras e a freqüência de ocorrência das características na população estudada, e o coeficiente de confiabilidade ponderado entre os observadores, segundo Fehring (1987).

A porcentagem ou índice de concordância de cada característica definidora foi calculado pela divisão entre o número de concordância de cada característica entre os dois enfermeiros diagnosticadores e o número de concordância somado ao número de discordância. Procedemos, em seguida, ao cálculo do índice de concordância total para o diagnóstico de Enfermagem em estudo, realizado pela somatória dos índices de cada característica, dividindo-se pelo número total de características definidoras do diagnóstico.

A freqüência de ocorrência das características definidoras foi computada pelas características coincidentes entre os dois enfermeiros diagnosticadores.

O coeficiente de confiabilidade ponderado entre os observadores foi calculado através da fórmula proposta por Fehring (1987), para cada característica definidora:

$$
R=\frac{A}{A+D} \times \frac{\frac{F 1}{N} \underline{F 2}}{2}
$$


O "R" é o coeficiente de confiabilidade ponderado entre observadores; "A" significa o número de concordâncias; "D" o número de discordâncias; F1 é a freqüência de características definidoras observadas pelo observador 1; F2 corresponde à freqüência das características que foram observadas pelo observador 2 e "N" é o número de sujeitos observados.

Esta fórmula permite identificar a freqüência de cada característica definidora, assegurando que uma característica que é pouco observada seja considerada altamente avaliada. É importante ressaltar a importância de se utilizar mais de um observador na avaliação clínica do paciente (FEHRING, 1987).

Outro dado que justifica esta etapa de observação é a possibilidade da característica definidora receber altos escores na validação por especialistas, porém, pode ter um índice baixo de incidência, no ambiente clínico, especialmente uma clientela específica como a estudada (MELO, 2004).

Portanto, é uma fórmula que retrata a incidência clínica da característica definidora corrigida pela concordância.

Realizado o cálculo deste coeficiente, Fehring (1987) classifica as características definidoras com os mesmos escores adotados na validação por especialista: características "maiores", "menores" e as que deverão ser descartadas e melhor estudadas.

O último passo desta fase consiste em obter o escore total calculado por meio da somatória dos coeficientes de cada característica definidora dividido pelo número de características, considerando-se a exclusão de algumas características com escore menor que 0,50 (FEHRING, 1987). 


\section{RESULTADOS E DISCUSSÃO}

\subsection{Primeira etapa: Análise de Conceito}

Nesta primeira fase da pesquisa realizamos um levantamento bibliográfico nas bases de dados "LILACS" (Literatura Latino-Americano e do Caribe em Ciências da Saúde), "PUBMED" (National Library of Medicine and the National Institutes of Health, "CINAHAL" (Cumulative Index to Nursing Allied Health Literature) e "DEDALUS" (Banco de dados bibliográfico da USP) sobre o tema em estudo.

Para a seleção das publicações encontradas nessas bases de dados, adotamos como critério de inclusão, os artigos que envolvessem o tema Diagnóstico de Enfermagem na assistência. Percebendo a abrangência de estudos nessas bases de dados, passamos a fazer uma seleção mais criteriosa dessas publicações sobre Diagnóstico de Enfermagem na pesquisa e na assistência, dando ênfase a artigos referentes ao tema: Desobstrução ineficaz de vias aéreas, Criança e/ou Adolescente e Cardiopatia Congênita.

Os descritores aqui mencionados estão de acordo com os descritores em Ciência da Saúde da Bireme, respeitando os termos em inglês, espanhol e português.

Identificamos na base de dados "LILACS" 345 publicações, com a palavra chave "Diagnóstico de Enfermagem". Dos que tinham resumo, 49 artigos foram selecionados. Por se tratar de artigos dos mais diversos temas sobre o assunto em estudo, realizamos um refinamento do assunto, cruzando as seguintes palavras chaves: "Diagnóstico de Enfermagem and Criança", e, assim, 15 publicações foram selecionadas. Destes 15 artigos, cinco estudos foram pertinentes para o nosso trabalho. Nesta mesma base de dados inserimos a palavra chave "Cardiopatias 
Congênitas" e surgiram 993 artigos. Refinamos novamente a busca cruzando as palavras "Cardiopatias Congênitas and Enfermagem" e 12 publicações foram selecionadas. Seguindo os critérios de inclusão referidos anteriormente, somente cinco artigos foram pertinentes à pesquisa. Inserindo as palavras chaves "Cardiopatias Congênitas and Diagnóstico de Enfermagem”, dois artigos já identificados com outras palavras foram selecionados pela base de dados, conforme apresentado no quadro 1.

$\mathrm{Na}$ base de dados "PUBMED" utilizamos primeiramente a palavra chave "Nursing Diagnosis" e 3.356 artigos foram identificados. Devido ao número excessivo de publicações, refinamos nossa busca cruzando as palavras "nursing diagnósis and Child" e o banco reconheceu 286 artigos. Refinamos nossa busca, colocando limites como: publicações nos últimos 20 anos (1987 a 2007), pesquisas em seres humanos, artigos em inglês e espanhol e idade de criança de 0 a 18 anos e assim, foram reconhecidos 195 artigos; destes 142 tinham resumo. Para o nosso estudo foram pertinentes somente sete artigos. Com as palavras chaves "child and heart diseases" surgiram 22.916 publicações, refinamos a busca acrescentando a palavra "nursing" e 217 artigos foram selecionados, sendo 163 com resumo e 54 sem resumo. Procedemos às leituras dos 163 resumos e somente cinco foram pertinentes a nossa pesquisa. Cruzando as palavras chaves "nursing diagnoses and child and heart diseases", dois artigos foram selecionados, somente um apresentava resumo, porém o artigo não era pertinente a nossa pesquisa, e, em "nursing diagnoses and heart diseases" e "nursing diagnoses and congenital heart diseases", nenhum artigo foi identificado.

No "CINAHAL" utilizamos as seguintes palavras chaves: "nursing diagnosis", "congenital heart diseases" e "child" e o número de publicações selecionadas foram 
2.758, 1.307 e 86.330, respectivamente. Diante de um conjunto de artigos, refinamos nossa busca cruzando as seguintes palavras: "nursing diagnosis and congenital heart diseases and child" e dois artigos foram identificados, mas nenhum foi selecionado para o nosso estudo. Com as palavras "nursing diagnosis and child", 42 publicações surgiram, colocamos alguns limites como últimos 20 anos e artigos em inglês e o número de artigos foram 10. Procedemos à leitura dos resumos e um artigo foi pertinente ao nosso estudo. Nesta mesma base de dados procuramos identificar pesquisas com a palavra chave "ineffective airway clearence - NANDA" e 71 artigos foram encontrados, refinamos nossa busca acrescentando a palavra "child" e cinco artigos surgiram e somente dois foram pertinentes. Com as palavras "nursing diagnosis" and "Validation studies" 76 artigos foram apresentados, cruzamos com a palavra "child" e um artigo foi selecionado, não pertinente ao nosso estudo.

Para a busca de publicações na base de dados "DEDALUS" procedemos da seguinte forma: com a palavra chave "diagnóstico de enfermagem" com limite de teses da USP, 106 pesquisas de mestrado e doutorado foram apresentadas, destas, 12 foram pertinentes ao nosso estudo; inserindo a palavra "enfermagem" 694 publicações apareceram, refinamos nossa busca acrescentando a palavra "criança" e nove trabalhos de mestrado foram mostrados, nenhum pertinente ao nosso estudo; com as palavras chaves "cardiopatia congênita and enfermagem" nenhum estudo de mestrado ou doutorado foi selecionado e inserindo somente "cardiopatia congênita" 15 trabalhos (mestrado e doutorado) apareceram, porém nenhum selecionado, por se tratar de estudos não correlacionados à temática de nosso trabalho. 
$\mathrm{Na}$ base de dados "DEDALUS" também pesquisamos sobre fisiopatologia das crianças portadoras de cardiopatias congênitas, sobre vias aéreas superiores e criança criticamente enferma e selecionamos 17 capítulos de livros, sendo referência para nosso estudo.

Realizamos também um levantamento nos Manuais da NANDA Conference Proceedings, localizando oito artigos pertinentes ao tema, quatro foram pertinentes a nossa pesquisa.

Após este levantamento, procedemos à leitura dos artigos na íntegra com o objetivo de avaliarmos o conteúdo, quanto a sua relevância ou não ao estudo.

Em seguida, verificamos a disponibilidade dos artigos, dissertações de Mestrado e tese de Doutorado, na Biblioteca Central do Campus da USP de Ribeirão Preto e nas Bibliotecas Virtuais sem ônus, possibilidade de empréstimos de acervos pessoais de docentes, para leitura. As leituras foram realizadas de maneira reflexiva, levando em conta o diagnóstico em estudo com sua definição apresentada pela NANDA (2006) e a população específica estudada.

Decidimos excluir os artigos que envolviam Diagnóstico de Enfermagem (DE) no ensino fora do contexto do nosso trabalho. Concentramos a busca em nossa área de atuação: assistência de enfermagem a crianças e adolescentes portadores de cardiopatia congênita.

O quadro a seguir mostra quais referências bibliográficas foram pertinentes ao estudo. 


\begin{tabular}{|c|c|c|c|c|c|c|c|c|c|c|}
\hline \multirow{3}{*}{\begin{tabular}{|l|} 
Bases de dados \\
Palavras chaves
\end{tabular}} & \multicolumn{10}{|c|}{ Public ações } \\
\hline & \multicolumn{2}{|l|}{ LILACS } & \multicolumn{2}{|l|}{ PUBMED } & \multicolumn{2}{|l|}{ CINAHAL } & \multicolumn{2}{|c|}{ DEDALUS } & \multicolumn{2}{|c|}{ PROCEEDINGS } \\
\hline & $\mathrm{AE}$ & AS & $\mathrm{AE}$ & AS & $\mathrm{AE}$ & AS & $\mathrm{AE}$ & AS & $\mathbf{A E}$ & AS \\
\hline Enfermagem & -- & -- & -- & -- & -- & -- & 694 & -- & -- & -- \\
\hline $\begin{array}{ll}\text { Diagnóstico } & \text { de } \\
\text { enfermagem (DE) } & \end{array}$ & 345 & 49 & -- & -- & -- & -- & 106 & 12 & 8 & 4 \\
\hline DE $\times$ criança & 15 & 5 & -- & -- & -- & -- & 9 & -- & -- & -- \\
\hline Cardiopatia congênita & 993 & -- & -- & -- & -- & -- & 15 & -- & -- & -- \\
\hline $\begin{array}{l}\text { Cardiopatia congênita } x \\
\text { enfermagem }\end{array}$ & 12 & 5 & -- & -- & -- & -- & -- & -- & -- & -- \\
\hline $\begin{array}{l}\text { Cardiopatia congênita } x \\
\text { DE }\end{array}$ & 2 & -- & - & -- & -- & -- & -- & -- & -- & -- \\
\hline Nursing diagnosis(ND) & -- & -- & 3.356 & -- & 2.758 & -- & -- & -- & -- & -- \\
\hline Child & -- & -- & -- & -- & 86.330 & -- & 2000 & 3 & -- & -- \\
\hline ND $\times$ child & -- & -- & 142 & 7 & 10 & 1 & -- & -- & -- & -- \\
\hline Child $\mathrm{x}$ heart diseases & -- & -- & 22.916 & -- & -- & -- & -- & -- & -- & -- \\
\hline $\begin{array}{l}\text { Child } x \text { heart diseases } x \\
\text { nursing }\end{array}$ & -- & -- & 163 & 5 & -- & -- & -- & -- & -- & -- \\
\hline $\begin{array}{l}\text { ND } x \text { child } \times \text { Heart } \\
\text { diseases }\end{array}$ & -- & -- & 2 & -- & - & -- & -- & -- & -- & -- \\
\hline ND $\times$ heart diseases & -- & -- & -- & -- & -- & -- & -- & -- & -- & -- \\
\hline $\begin{array}{l}\text { Congenital Heart } \\
\text { diseases }\end{array}$ & -- & -- & -- & -- & 1.307 & -- & -- & -- & -- & -- \\
\hline $\begin{array}{l}\text { ND } \times \text { Congenital Heart } \\
\text { diseases }\end{array}$ & -- & -- & -- & -- & -- & -- & -- & -- & -- & -- \\
\hline $\begin{array}{l}\text { ND } \times \text { child } \times \text { Congenital } \\
\text { Heart diseases }\end{array}$ & -- & -- & -- & -- & 2 & -- & -- & -- & -- & -- \\
\hline $\begin{array}{l}\text { Ineffective airway } \\
\text { clearence - NANDA }\end{array}$ & -- & -- & -- & 4 & 71 & -- & -- & -- & -- & -- \\
\hline $\begin{array}{l}\text { Ineffective airway } \\
\text { clearence - NANDA x } \\
\text { child }\end{array}$ & -- & -- & -- & -- & 5 & 1 & -- & -- & -- & -- \\
\hline $\begin{array}{l}\text { Nursing diagnosis } \mathrm{X} \\
\text { validation studies }\end{array}$ & -- & -- & -- & -- & 76 & 2 & -- & -- & -- & -- \\
\hline TOTAL & 1.367 & 59 & 26.579 & 16 & 90.549 & 4 & 2824 & 15 & 8 & 4 \\
\hline
\end{tabular}

$\mathrm{AE}=$ artigos encontrados, $\mathrm{AS}=$ artigos selecionados,

Quadro 1: referências bibliográficas encontradas

Dos artigos pertinentes ao nosso estudo 98 foram identificados nas bases de dados, conforme mostra o quadro 1 e tivemos acesso aos acervos particulares de 
docentes que trabalham com a temática em estudo e foi possível obter 11 referências bibliográficas entre artigos, dissertações e teses.

Os artigos encontrados com temas sobre Diagnóstico de Enfermagem na assistência a pacientes em período de pós-operatório de cirurgia nos mostraram a importância destas pesquisas para se descobrir as reais necessidades do paciente assistido. Detectamos na literatura que há necessidade de uma enfermagem especializada para assistir o paciente, levando-se em conta a especificidade dos cuidados prestados.

A etapa de identificação do Diagnóstico de Enfermagem tem merecido destaque por se tratar de uma fase dinâmica, sistemática, organizada e complexa do processo de enfermagem, significando não apenas uma simples listagem de problemas, mas uma fase que envolve avaliação crítica e tomada de decisão (GALDEANO et al., 2003)

Esses mesmos autores mostraram em seu estudo a complexidade de cuidados requeridos por pacientes que se encontram no período perioperatório de cirurgia cardíaca, cujas condições de saúde podem variar de minuto a minuto, necessitando de intervenção de enfermagem alicerçada em um método que privilegia a tomada de decisão.

Braga (2003) em seu estudo sobre a taxonomia II da NANDA, refere que a nova classificação contribuiu para atualizar os conhecimentos e facilitar a enfermagem brasileira a acompanhar a evolução do assunto. As pesquisas que exploram a estrutura da taxonomia contribuirão para definirmos melhor o cuidar, com vista a melhorar a qualidade da assistência de enfermagem: o que seria essencial para o cuidado de enfermagem à criança submetida à correção cirúrgica de cardiopatia congênita. 
A taxonomia II é multiaxial e possui termos cujos significados nos são mais familiares, pois fazem parte da enfermagem tradicional e contemporânea, facilitando a comunicação com outros profissionais e com o paciente (BRAGA, 2003).

Identificamos nas publicações analisadas que são poucos os estudos que abordam a análise de Diagnóstico de Enfermagem em crianças e adolescentes portadores de cardiopatia congênita, principalmente no período pós-operatório imediato. Encontramos cinco artigos que envolvessem o tema em estudo.

O estudo de Jasen et al. (2000) teve por objetivo mostrar a importância da intervenção de enfermagem nos períodos pré, trans e pós-operatório e a integração das equipes de cada setor, no cuidado ao paciente por meio de um roteiro sistematizado da assistência de enfermagem. As autoras concluíram que a integração das unidades e um roteiro sistematizado orienta melhor a equipe na prevenção e diagnóstico antecipados das possíveis complicações, favorecendo a recuperação precoce da criança, e, conseqüentemente, diminuindo o tempo de permanência no ambiente hospitalar.

Almeida (1994) ressalta em seu estudo a importância do Diagnóstico de Enfermagem "troca de gases prejudicada" em crianças portadoras de cardiopatia congênita cianogênica; e teve como proposta estabelecer intervenções de enfermagem perante as crianças com esse diagnóstico, visando a melhorar o tratamento e acompanhamento.

Guerriero et al. (2002) identificaram os Diagnósticos de Enfermagem apresentados por crianças no primeiro dia de pós-operatório de cirurgia cardíaca. Elas observaram 16 Diagnósticos de Enfermagem, sendo seis considerados reais e que apareceram em $100 \%$ da amostra, sendo eles: dor (torácica e lombar); integridade da pele prejudicada; déficit para auto-cuidado: higiene e alimentação; 
distúrbio do padrão do sono; rompimento do vínculo familiar e mobilidade física prejudicada. Dos dez diagnósticos de risco, oito apareceram em 100\%: risco para alteração da temperatura; risco para déficit de volume de líquido; risco para diminuição do débito cardíaco; alto risco para infecção; risco para inapetência; risco para alteração no metabolismo da glicose, risco para alteração do padrão respiratório e risco para limpeza ineficaz de vias aéreas. Os dois últimos diagnósticos de risco foram: risco para prejuízo na integridade da pele e risco para constipação que apareceram em 88,2\% e 83\%, respectivamente.

Silva et al. (2004) realizaram um estudo, detectando os Diagnósticos de Enfermagem e problemas colaborativos na população de crianças portadoras de cardiopatia congênita, com a finalidade de conhecer melhor os pacientes e orientar as condutas da enfermagem no cuidado das crianças. Os diagnósticos de maior prevalência segundo esses autores foram: intolerância à atividade (86,4\%), Desobstrução ineficaz de vias aéreas $(72,7 \%)$, crescimento e desenvolvimento retardado $(68,2 \%)$, desequilíbrio nutricional: menos que as necessidades corporais $(68,2 \%)$, padrão respiratório ineficaz $(68,2 \%)$, hipertermia $(50 \%)$ e vínculo familiar interrompido (50\%). Os problemas colaborativos mais freqüentes foram as complicações potenciais como: diminuição da função cardíaca (77,3\%), efeitos adversos à terapia medicamentosa $(68,2 \%)$ e pneumonia $(50 \%)$. Com esses dados os autores concluíram que é importante realizar pesquisas de identificação de Diagnósticos de Enfermagem e problemas colaborativos, para se determinar as reais necessidades de assistência dos pacientes.

Silva et al. (2006) descreveram a evolução dos Diagnósticos de Enfermagem em crianças portadoras de cardiopatia congênita acompanhadas durante quinze dias de internação e encontraram, nesta clientela, 21 diagnósticos de Enfermagem. 
Desses diagnósticos, 6 mostraram-se com maior oscilação em suas trajetórias de ocorrência no tempo, sendo eles: padrão respiratório ineficaz, intolerância à atividade, Desobstrução ineficaz de vias aéreas, hipertermia, padrão do sono perturbado e risco para intolerância à atividade. Os autores argumentam que o conhecimento da evolução temporal das respostas das crianças ajudou nas intervenções de enfermagem elaboradas por meios de decisões diagnósticas, facilitando na escolha das ações mais adequadas, melhorando, assim, o seu prognóstico. Perceberam também que as ações de enfermagem devem se direcionar para as respostas humanas relacionadas às alterações hemodinâmicas que precocemente surgirem, conduzindo à necessidade de maior atenção por parte da equipe de enfermagem.

Cabe ressaltar no trabalho de Silva et al. (2006) que o diagnóstico de Desobstrução ineficaz de vias aéreas apareceu nas seis avaliações realizadas pela autora e teve um crescimento significativo do número de crianças que apresentavam o diagnóstico em estudo, da data de internação até 48 horas após a mesma. Das 45 crianças avaliadas, somente 14 apresentaram o diagnóstico de Desobstrução ineficaz de vias aéreas na primeira avaliação, e, na sexta avaliação da mostra, 32 sujeitos apresentaram o diagnóstico acima referido.

Dos trabalhos de mestrado e doutorado encontrados nas bases de dados, 15 foram importantes para a nossa pesquisa, porém duas teses foram relevantes e norteadoas: "Validação dos diagnósticos de Enfermagem disfunção sexual e padrões de sexualidade ineficaz", de Melo (2004), por se tratar de validação clínica e "Estudo da aplicabilidade de intervenções da NIC no atendimento a crianças com o Diagnóstico de Enfermagem Desobstrução ineficaz de vias aéreas relacionada à presença de via aérea artificial em um centro de terapia intensiva pediátrico", de 
Napoleão (2005), por trabalhar com o diagnóstico de "Desobstrução ineficaz de vias aéreas" e pela população ser infantil.

Napoleão (2005) refere que de todos os fatores relacionados, propostos pela NANDA no diagnóstico em estudo, a "presença de via aérea artificial", pressupõe uma maior complexidade na assistência de enfermagem, e, conseqüentemente, uma atuação consistente e efetiva do enfermeiro.

$\mathrm{Na}$ literatura internacional, encontramos quatro publicações cujo tema envolvia o Diagnóstico de Enfermagem "Desobstrução ineficaz de vias aéreas" e validação clínica.

A pesquisa de Hoffman (1987) descreve a presença do diagnóstico em estudo nos pacientes com disfunção neuromuscular. O autor concluiu que a população estudada tem um maior risco para apresentar Desobstrução ineficaz de vias aéreas e também refere que é essencial uma intervenção de enfermagem mais precoce para que os pacientes não venham a desenvolver tal problema.

Hanley (1987) desenvolveu um estudo relatando a presença do diagnóstico de "Desobstrução ineficaz de vias aéreas" nos pacientes com infecção aguda do trato respiratório. A conclusão da pesquisa foi que são vários os fatores que levam o paciente a apresentar o diagnóstico, porém o maior fator é o próprio microorganismo.

Shekleton (1987) pesquisou o tema em estudo nos pacientes com vias aéreas artificiais. O autor refere que a assistência e intervenções de enfermagem são a chave para manter as vias aéreas pérveas. Os cuidados de enfermagem como aspiração traqueobrônquica, drenagem postural e umidificação do ar inspirado são as intervenções mais indicadas para manter as vias aéreas patentes. Sugere ainda a realização de novas pesquisas, futuras, para a validação dos sinais e sintomas e 
conhecimento específico das causas da Desobstrução ineficaz de vias aéreas, para mostrar a eficácia das várias intervenções de enfermagem nos pacientes que apresentam este diagnóstico.

Carlson - Catalano et al. (1998) validaram clinicamente três diagnósticos de enfermagem: padrão respiratório ineficaz, Desobstrução ineficaz de vias aéreas e troca de gases prejudicada e concluiram que o método de validação clínica permitiu discriminar os possíveis sinais e sintomas e possibilitou visualizar que algumas características definidoras apresentadas não são necessariamente sinais e sintomas dos diagnósticos estudados.

Ao compararmos a literatura internacional com as da América Latina, percebemos que os estudos de validação clínica estão mais avançados, nos países considerados de primeiro mundo enquanto que no Brasil estão começando a desenvolver este tipo de pesquisa.

E, por fim, com a revisão da literatura podemos observar que há uma escassez de pesquisa sobre Diagnóstico de Enfermagem e novas características definidoras na população de crianças e adolescentes portadores de cardiopatia congênita, visto que os artigos encontrados mostraram a presença do diagnóstico de Desobstrução ineficaz de vias aéreas nesta população, e, portanto, vem corroborar com a necessidade de novas investigações.

Como próximo passo, apresentaremos o Diagnóstico de Enfermagem "Desobstrução ineficaz de vias aéreas" com sua respectiva definição e suas características definidoras com as definições operacionais. 


\begin{tabular}{|c|c|}
\hline $\begin{array}{l}\text { Característica } \\
\text { Definidora }\end{array}$ & Definição Operacional \\
\hline Dispnéia & É a dificuldade para respirar (TARANTINO, 2001). \\
\hline $\begin{array}{l}\text { Murmúrios } \\
\text { Vesiculares } \\
\text { diminuídos }\end{array}$ & $\begin{array}{l}\text { Murmúrio vesicular é o ruído respiratório produzido pela turbulência } \\
\text { do ar circulante ao chocar-se com as saliências das bifurcações } \\
\text { brônquicas, ao passar por cavidades de tamanhos diferentes, tais } \\
\text { como os bronquíolos para os alvéolos, e vice versa (TARANTINO, } \\
2001 \text { ). } \\
\text { Murmúrios vesiculares diminuídos é a redução dos sons } \\
\text { respiratórios. }\end{array}$ \\
\hline Ortopnéia & $\begin{array}{l}\text { É a dispnéia que impede o paciente de ficar deitado e o obriga a } \\
\text { assentar-se ou a ficar de pé para obter algum alívio (TARANTINO, } \\
2001 \text { ). } \\
\text { É a dificuldade respiratória que melhora quando o paciente eleva o } \\
\text { tórax, colocando-o na posição vertical, mantendo-se sentado no leito } \\
\text { (TARANTINO, 2001; POTTER; PERRY, 2005). }\end{array}$ \\
\hline $\begin{array}{l}\text { Ruídos Adventícios } \\
\text { (Estertores, } \\
\text { Creptações, } \\
\text { Roncos, Sibilos) }\end{array}$ & $\begin{array}{l}\text { Estertores: sons anormais descontínuos. São ruídos audíveis na } \\
\text { inspiração ou na expiração, superpondo-se aos sons respiratórios } \\
\text { normais (TARANTINO, 2001). } \\
\text { Crepitação ou estertores crepitantes: são ruídos audíveis no final da } \\
\text { inspiração e têm freqüência alta, isto é, são agudos e de curta } \\
\text { duração. Não se modificam com a tosse. Podem ser comparados ao } \\
\text { ruído produzido pelo atrito de um punhado de cabelos junto ao } \\
\text { ouvido ou a som percebido ao se fechar ou abrir um fecho tipo velcro } \\
\text { (TARANTINO, 2001). Roncos: sons graves, de baixa freqüência. } \\
\text { Originam-se nas vibrações das paredes brônquicas e do conteúdo } \\
\text { gasoso quando há estreitamento destes ductos. Aparecem na } \\
\text { inspiração como na expiração, mas predominantemente na } \\
\text { expiração. São fugazes, mutáveis, surgindo e desaparecendo em } \\
\text { curto período de tempo (Tarantino, 2001). Sibilos: sons agudos. } \\
\text { Também se originam nas vibrações das paredes brônquicas e do } \\
\text { conteúdo gasoso e aparecem na inspiração como na expiração. Em } \\
\text { geral são múltiplos e disseminados por todo o tórax (TARANTINO, } \\
\text { 2001). }\end{array}$ \\
\hline
\end{tabular}




\begin{tabular}{|c|c|}
\hline $\begin{array}{l}\text { Característica } \\
\text { Definidora }\end{array}$ & Definição Operacional \\
\hline Tosse Ineficaz & $\begin{array}{l}\text { Tosse: é um mecanismo de defesa das vias respiratórias, as quais } \\
\text { reagem aos irritantes ou procuram eliminar secreções anormais, } \\
\text { sempre com o objetivo de se manter as VAS pérveas. A tosse } \\
\text { consiste numa inspiração rápida e profunda, seguida de fechamento } \\
\text { da glote, contração dos músculos expiratórios, principalmente o } \\
\text { diafragma, terminando com uma expiração forçada, após a abertura } \\
\text { súbita da glote. A última parte da tosse, a expiração forçada, constitui } \\
\text { um mecanismo expulsivo de grande importância para as vias aéreas } \\
\text { (TARANTINO, 2001). } \\
\text { Ineficaz: que não produz efeito; que não dá resultado; impróprio, } \\
\text { inconveniente (Dicionário MICHAELIS, 2005). }\end{array}$ \\
\hline Tosse Ausente & $\begin{array}{l}\text { A tosse é um mecanismo de defesa das vias respiratórias, as quais } \\
\text { reagem aos irritantes ou procuram eliminar secreções anormais, } \\
\text { sempre com o objetivo de se manter as VAS pérveas. A tosse } \\
\text { consiste numa inspiração rápida e profunda, seguida de fechamento } \\
\text { da glote, contração dos músculos expiratórios, principalmente o } \\
\text { diafragma, terminando com uma expiração forçada, após a abertura } \\
\text { súbita da glote. A última parte da tosse, a expiração forçada, constitui } \\
\text { um mecanismo expulsivo de grande importância para as vias aéreas } \\
\text { (TARANTINO, 2001). } \\
\text { Ausente: que não está presente (Dicionário MICHAELIS,2005). }\end{array}$ \\
\hline Expectoração & $\begin{array}{l}\text { É o ato de expectorar } \\
\text { Expectorar é expelir, lançar do peito, escarrar (Dicionário } \\
\text { MICHAELIS, 2005). } \\
\text { Costuma ser a conseqüência da tosse (TARANTINO, 2001). }\end{array}$ \\
\hline Cianose & $\begin{array}{l}\text { É a coloração azulada da pele. } \\
\text { Para ser considerada cianose o paciente tem que estar com pelo } \\
\text { menos } 5 \% \text { da hemoglobina reduzida (TARANTINO, 2001). Porto } \\
\text { (2001) refere que a cianose é a cor azulada da pele e manifesta-se } \\
\text { quando a hemoglobina reduzida alcança no sangue valores } \\
\text { superiores a } 5 \mathrm{~g} / 100 \mathrm{ml} \text {. Ela deve ser observada, geralmente ao redor } \\
\text { dos lábios, na ponta do nariz, nos lobos das orelhas e nas } \\
\text { extremidades das mãos e dos pés (leito ungueal e polpas }\end{array}$ \\
\hline
\end{tabular}




\begin{tabular}{|c|c|}
\hline $\begin{array}{l}\text { Característica } \\
\text { Definidora }\end{array}$ & Definição Operacional \\
\hline $\begin{array}{l}\text { Cianose } \\
\text { (cont.) }\end{array}$ & $\begin{array}{l}\text { digitais). Cianose intensa, todo o tegumento cutâneo estará na } \\
\text { coloração azulada ou mesmo arroxeada. }\end{array}$ \\
\hline $\begin{array}{l}\text { Vocalização } \\
\text { Dificultada }\end{array}$ & $\begin{array}{l}\text { É a alteração da voz, como disfonias, rouquidão e a afonia, que são } \\
\text { observáveis nos casos de laringites crônicas, presentes nos casos de } \\
\text { neoplasias, nas paralisias das cordas vocais, entre outras } \\
\text { (HUNGRIA, 2001). } \\
\text { Mudanças no timbre da voz ou rouquidão são alterações na dinâmica } \\
\text { das cordas vocais (TARANTINO, 2001). }\end{array}$ \\
\hline Olhos Arregalados & $\begin{array}{l}\text { Olhos: órgão da visão, formado pelos globos oculares e seus anexos } \\
\text { (Dicionário MICHAELIS,2005).. } \\
\text { Arregalado: muito aberto, esbugalhado. Adjetivo do verbo arregalar } \\
\text { que significa abrir muito por espanto ou satisfação } \\
\text { (MICHAELIS,2005). } \\
\text { Ele pode ser observado nos estados de angústia respiratória, } \\
\text { juntamente com o sinal universal de angústia, como descrito por } \\
\text { alguns autores como Potter e Perry (2005) e Smeltzer e Bare (2005), } \\
\text { nas situações em que o paciente apresenta uma aparência } \\
\text { apreensiva e alguns sinais e sintomas já descritos anteriormente, } \\
\text { demonstrando uma possível obstrução das vias aéreas. }\end{array}$ \\
\hline $\begin{array}{l}\text { Mudanças } \\
\text { Ritmo } \\
\text { Respiratório }\end{array}$ & $\begin{array}{l}\text { É a alteração para mais ou menos na amplitude da respiração. } \\
\text { Normalmente a inspiração dura quase o mesmo tempo que a } \\
\text { expiração, sucedendo-se os dois movimentos com a mesma } \\
\text { amplitude, intercalados por leve pausa. Quando uma dessas } \\
\text { características se modifica, surgem os ritmos respiratórios anormais } \\
\text { (TARANTINO, 2001). }\end{array}$ \\
\hline $\begin{array}{l}\text { Mudanças } \\
\text { Freqüência } \\
\text { Respiratória }\end{array}$ & $\begin{array}{l}\text { É a alteração para mais ou para menos do número de ciclos } \\
\text { respiratórios. } \\
\text { Os valores da freqüência respiratória variam de acordo com a idade. } \\
\text { (POTTER; PERRY, 2005; HOEKELMAN, 2001; HADDAD; } \\
\text { PALAZZO, 2005). }\end{array}$ \\
\hline
\end{tabular}




\begin{tabular}{|l|l|}
\hline \hline $\begin{array}{l}\text { Característica } \\
\text { Definidora }\end{array}$ & \multicolumn{1}{|c|}{ Definição Operacional } \\
\hline \hline & $\begin{array}{l}\text { Agitação é perturbação, alvoroço, desasossego (Dicionário } \\
\text { MICHAELIS, 2005). } \\
\text { Agitação }\end{array}$ \\
& $\begin{array}{l}\text { desencadeadas por afecções que causam alteração no estado } \\
\text { respiratório, a agitação é considerada como um importante sinal }\end{array}$ \\
\hline \hline
\end{tabular}

Quadro 2 - Características definidoras do Diagnóstico de Enfermagem "Desobstrução ineficaz de vias aéreas": incapacidade de eliminar secreções ou obstrução do trato respiratório para manter uma via aérea desobstruída (NANDA, 2006, p. 84) e suas definições operacionais.

Por se tratar de um Diagnóstico de Enfermagem que tem um desempenho fisiológico, as suas características definidoras são manifestações mais objetivas, isto é, possível de serem visualizadas e suas definições facilmente encontradas na literatura.

As definições operacionais das características definidoras do Diagnóstico de Enfermagem "Desobstrução ineficaz de vias aéreas" foram construídas a partir da literatura, sustentadas nos conceitos e particularidades dos sinais e sintomas. As manifestações clínicas relacionadas no quadro I, foram listadas a partir da NANDA (2006), Carpenito (2004) e, a revisão da literatura foi sustentada na primeira fase deste estudo por meio de livros de fisiologia, fisiopatologia e fundamentos de enfermagem.

Após as definições e descrições das características definidoras, demos início à Validação por Especialista, sendo a segunda etapa do nosso estudo. 


\subsection{Segunda Etapa: Validação por Especialista}

\subsubsection{Caracterização das pontuações obtidas pelos enfermeiros peritos segundo a metodologia de Fehring (1994)}

Nesta fase, enviamos 52 instrumentos de coleta de dados aos enfermeiros peritos. Destes, 10 instrumentos não retornaram para análise. Dois peritos tiveram que ser excluídos, por não atingirem os critérios inclusão propostos por Fehring (1994). Um perito não totalizou os cinco pontos necessários, apesar de ter Mestrado e o outro por não ter Mestrado. Sendo assim, a amostra de enfermeiros peritos foi composta por 40 enfermeiros. Desta amostra, 23 referiram ter experiência com Diagnóstico de Enfermagem e Desobstrução ineficaz de vias aéreas $(57,5 \%)$, considerando que a experiência com o diagnóstico em estudo se deu na assistência, pesquisa e ensino, e, 17 afirmaram ter experiência com Diagnóstico de Enfermagem $(42,5 \%)$.

Os peritos exercem suas atividades profissionais no território brasileiro distribuídos em 07 estados, sendo no total 15 cidades diferentes.

Tivemos a participação de enfermeiros das cidades de São Paulo, Ribeirão Preto, Itajubá, Bauru, Santos, Campinas, Araras, Jaboticabal, São Bernardo do Campo, Fortaleza, João Pessoa, Londrina, Belo Horizonte, Rio Grande do Sul e Niterói, conforme mostra a tabela a seguir. 
Tabela 1 - Distribuição dos enfermeiros peritos de acordo com sua localidade de trabalho no território nacional. Ribeirão Preto, 2006.

\begin{tabular}{|c|c|c|c|c|c|c|}
\hline \multirow[b]{2}{*}{ Localidade } & \multicolumn{2}{|c|}{ Aérea de } & \multicolumn{4}{|l|}{ Atuação } \\
\hline & $\begin{array}{l}\text { Diagnóstico de } \\
\text { Enfermagem e } \\
\text { DIVA }^{1}(\mathrm{~N}=23)\end{array}$ & & $\begin{array}{l}\text { Diagnóstico de } \\
\text { Enfermagem }^{2} \\
\qquad(\mathrm{~N}=17)\end{array}$ & & TOTAL & \\
\hline & Freqüência & $\%$ & Freqüência & $\%$ & Freqüência & $\%$ \\
\hline São Paulo & 17 & 74 & 13 & 76,4 & 30 & 75 \\
\hline Paraná & 1 & 4,3 & - & - & 1 & 2,5 \\
\hline Minas Gerais & 1 & 4,3 & 1 & 5,9 & 2 & 5 \\
\hline Ceará & 3 & 13 & - & - & 3 & 7,5 \\
\hline Rio Grande Sul & - & - & 1 & 5,9 & 1 & 2,5 \\
\hline Rio de Janeiro & 1 & 4,3 & 1 & 5,9 & 2 & 5 \\
\hline Paraíba & - & - & 1 & 5,9 & 1 & 2,5 \\
\hline TOTAL & 23 & 99,9 & 17 & 100 & 40 & 100 \\
\hline
\end{tabular}

1 Enfermeiros peritos que relataram trabalhar com Diagnóstico de Enfermagem e Desobstrução ineficaz de vias aéreas

${ }^{2}$ Enfermeiros peritos que relataram trabalhar com Diagnóstico de Enfermagem

O maior número de instrumentos distribuídos foi no Estado de São Paulo, no total de 30 , conforme mostra a tabela 1. Pode-se observar também, nesta tabela, que os enfermeiros peritos que trabalham com Diagnóstico de Enfermagem da NANDA e Desobstrução ineficaz de vias aéreas estão presentes em 05 dos 07 estados brasileiros que participaram do estudo.

Poucos são os enfermeiros que se interessam por esta temática, porém a presença de profissionais em diferentes estados mostra que a temática vem merecendo atenção da profissão de Enfermagem (MELO, 2004)

A tabela a seguir mostra o tempo de experiência profissional dos peritos. 
Tabela 2 - Distribuição dos enfermeiros peritos de acordo com a faixa etária profissional ( $\mathrm{N}=40)$. Ribeirão Preto, 2006.

\begin{tabular}{ccc}
\hline \hline Faixa Etária Profissinal & Freqüência & $\%$ \\
\hline$\leq 5$ Anos & 2 & 5 \\
6 I-----| 10 anos & 4 & 10 \\
11 I-----| 15 anos & 6 & 15 \\
16 I-----| 20 anos & 7 & 17,5 \\
21 I-----| 25 anos & 12 & 30 \\
26 I------| 30 anos & 6 & 15 \\
$\geq 31$ anos & 3 & 7,5 \\
& & \\
TOTAL & $\mathbf{4 0}$ & $\mathbf{1 0 0}$ \\
\hline \hline
\end{tabular}

A maioria dos peritos tem experiência profissional entre 16 e 25 anos (47,5\%). Ferhing (1994) não adota como critério de inclusão o tempo de experiência profissional, porém Oliveira (2001) em seu estudo de validação para o Diagnóstico de Enfermagem de "Dor", concluiu que para serem peritos é importante possuir alguns anos de formação. Sendo assim, nossos resultados, mostrados na tabela acima, reforçam o perfil da amostra como peritos.

Com relação aos peritos trabalharem com o Diagnóstico de Enfermagem da NANDA: $97,5 \%$ referiram que os utilizam na sua prática profissional, seja no ensino, pesquisa e/ou assistência. Uma perita relata não trabalhar com os Diagnósticos de Enfermagem da NANDA, mas, por ter o título de Mestre e Doutor e por ter implantado o SAE em um Hospital, enquadrou-se nos critérios de inclusão e perfez a pontuação necessária.

Dos 40 enfermeiros peritos, $90 \%$ estão concentrados no campo do ensino em relação aos diagnósticos da NANDA, $82,5 \%$ na pesquisa e somente $10 \%$ na assistência. Melo (2004), em seu estudo, mostrou que a mesma porcentagem de peritos concentrava-se na área do ensino e $76,6 \%$ no campo da pesquisa. Nosso 
trabalho mostra que houve um aumento considerável no estudo do Diagnóstico de Enfermagem da NANDA no campo da pesquisa. Quatro (10\%) sujeitos afirmaram que utilizam os diagnósticos de Enfermagem somente no campo do ensino, e, dois (5\%) referem usar somente na área da pesquisa.

A relevância da aplicação do Diagnóstico de Enfermagem na prática clínica precisa ter visibilidade para os resultados de estudo, não apenas para estruturas de modelos teóricos, mas também para melhorar as intervenções com impacto na assistência prestada.

A assistência implica em dificuldades e obstáculos que provavelmente estão relacionados ao desenvolvimento de estratégias para a implantação do Processo de Enfermagem no ambiente do cuidado de saúde, com vista aos diferentes graus de complexidade da assistência. A adoção da taxonomia para os fenômenos dos diagnósticos de enfermagem proposta pela NANDA, a transformação do modelo de gerenciamento da assistência em serviços de enfermagem vigente e capacitação dos enfermeiros para o desenvolvimento do pensamento crítico são propostas para criar possibilidades de absorção dos enfermeiros no campo da assistência com experiência clínica para o julgamento dos diagnósticos de enfermagem.

Dos 23 sujeitos que trabalham com Diagnóstico de Enfermagem e DIVA, $52,17 \%$ atuam no ensino, pesquisa e assistência, $30,43 \%$ no ensino e pesquisa e $17,4 \%$ trabalham somente no ensino ou na pesquisa. Melo (2004) em seu estudo mostra que a maioria dos peritos que utilizam os diagnósticos de Enfermagem da NANDA dedicavam-se a mais de um campo de atuação entre ensino, pesquisa e assistência, o que vem a corroborar com o nosso estudo. 
Dos peritos que atuam no campo do ensino em Diagnóstico de Enfermagem, concomitante ou não com pesquisa e assistência, $90 \%$ têm mais de um ano de experiência nesta área.

Independente da área de atuação, seja ela ensino, pesquisa ou assistência, 97,5\% dos enfermeiros peritos referiram ter mais que um ano de experiência trabalhando com os Diagnósticos de Enfermagem da NANDA. Uma perita $(2,5 \%)$ referiu não trabalhar com a temática do nosso estudo, porém é aquela que em um de seus projetos ajudou a implantar o SAE em um hospital.

Segundo Ferhing (1994), um dos critérios de inclusão para ser enfermeiro perito, é ter pelo menos 01 ano de prática clínica na área do Diagnóstico de Enfermagem. Em nosso estudo, destacamos que $97,5 \%$ da nossa amostra possuem mais de um ano de experiência com relação ao diagnóstico.

Com relação à titulação acadêmica dos peritos,100\% tinham título de mestre, $30 \%$ da amostra possuíam somente grau de mestre e $70 \%$ grau de doutor. Dos $30 \%$ de mestres somente 01 perito $(8,3 \%)$ trabalhou com tema de Diagnóstico de Enfermagem e Desobstrução ineficaz de vias aéreas e 32,5\% desenvolveram pesquisa com tema sobre Diagnóstico de Enfermagem. Dos 70\% de doutores, 35,7\% desenvolveram pesquisa com Diagnóstico de Enfermagem da NANDA.

Todos os sujeitos da amostra tinham outras atividades científicas e trabalhos, além do Mestrado e do Doutorado, conforme mostra a tabela abaixo. 
Tabela 3 - Distribuição de trabalhos ou atividades científicas dos enfermeiros peritos abordando o tema Diagnóstico de Enfermagem $(n=40)$. Ribeirão Preto, 2006.

\begin{tabular}{lcc}
\hline \multicolumn{1}{c}{ Trabalhos e Atividade Científicas } & Freqüência & $\%$ \\
\hline Publicação de artigos em periódicos / revistas & 28 & 70 \\
Apresentação de trabalhos em eventos científicos & 30 & 75 \\
Publicaçãos de trabalhos de pesquisa & 22 & 55 \\
Outros & 29 & 72,5 \\
\hline \hline
\end{tabular}

Podemos observar que a maioria dos sujeitos têm mais de uma atividade científica que envolve o tema Diagnóstico de Enfermagem, o que vem a confirmar que este assunto está sendo bastante divulgado e estudado em nosso meio. Melo (2004) refere em seu estudo que o Processo de Enfermagem vem se destacando nos três campos de atuação da Enfermagem.

Houve um destaque significativo no estudo, além dos artigos científicos e pesquisa, onde $72,5 \%$ referiram "outras" atividades envolvendo utilização dos Diagnósticos de Enfermagem da NANDA, sendo elas: orientação de alunos da graduação e pós-graduação, disciplinas na grade curricular da graduação e pósgraduação, participação em grupos de pesquisa e implementação da Sistematização da Assistência de Enfermagem em hospitais.

Tabela 4 - Distribuição de trabalhos ou atividades científicas dos enfermeiros peritos abordando o tema Desobstrução ineficaz de vias aéreas $(n=23)$. Ribeirão Preto, 2006.

\begin{tabular}{lcc}
\hline \hline \multicolumn{1}{c}{ Trabalhos e Atividade Científicas } & Freqüência & $\%$ \\
\hline Publicação de artigos em periódicos / revistas & 5 & 21,7 \\
Apresentação de trabalhos em eventos científicos & 5 & 21,5 \\
Publicação de trabalhos de pesquisa & 4 & 17,4 \\
Outros & 20 & 87 \\
\hline \hline
\end{tabular}


A tabela 4 mostra dados referentes à publicação de pesquisa e observamos um baixo número de artigos com relação à temática da Desobstrução ineficaz de vias aéreas: somente 04 enfermeiros $(17,4 \%)$. Por ser uma área de pesquisa especializada, justifica-se ter muito mais pesquisas publicadas sobre Diagnóstico de Enfermagem do que aquelas que envolvem a temática, no nosso caso da desobstrução ineficaz de vias aéreas.

Com relação ao item "outros", os sujeitos da pesquisa referiram que abordam o tema na área do ensino e da assistência de Enfermagem, na orientação de alunos com trabalhos de conclusão de curso e em dissertações de teses de Mestrado e Doutorado e na realização de conferências e cursos.

A nossa amostra foi composta em sua maioria por docentes, com experiência profissional entre 16 e 25 anos e que trabalham nas três áreas da Enfermagem, com destaque no campo do ensino e pesquisa relacionado à temática do estudo.

A seguir, para análise melhor dos dados, classificamos os enfermeiros peritos em 2 grupos: os que atuam somente com tema de Desobstrução ineficaz de vias aéreas (grupo 1) e os que trabalham somente com o tema de Diagnóstico de Enfermagem (grupo 2).

Segundo Ferhing (1994), para ser considerado enfermeiro perito, há necessidade de todo um critério de avaliação e pontuação. A pontuação obtida pelos peritos, em nosso estudo, variou de 5 a 14 pontos, tendo uma média igual 5,7 e desvio padrão de 2,5 conforme apresentado na tabela 5 . 
Tabela 5 - Distribuição dos 40 enfermeiros peritos, segundo a pontuação obtida, conforme a proposta de Ferhing (1994). Ribeirão Preto, 2006.

\begin{tabular}{|c|c|c|c|c|c|c|}
\hline & Aérea & de & Atuação & & & \\
\hline Pontuação & $\begin{array}{l}\text { Diagnóstico de } \\
\text { Enfermagem e } \\
\text { DIVA }^{1}(\mathrm{~N}=23)\end{array}$ & & $\begin{array}{l}\text { Diagnóstico de } \\
\text { Enfermagem }^{2} \\
(\mathrm{~N}=17)\end{array}$ & & TOTAL & \\
\hline & Freqüência & $\%$ & Freqüência & $\%$ & Freqüência & $\%$ \\
\hline 5 & -- & -- & 3 & 17,6 & 3 & 7,5 \\
\hline 6 & -- & -- & -- & -- & -- & -- \\
\hline 7 & 1 & 4,3 & 2 & 11,7 & 3 & 7,5 \\
\hline 8 & 2 & 8,7 & 1 & 5,9 & 3 & 7,5 \\
\hline 9 & 4 & 17,4 & 3 & 17,6 & 7 & 17,5 \\
\hline 10 & -- & -- & -- & -- & -- & -- \\
\hline 11 & 7 & 30,4 & 6 & 35,3 & 13 & 32,5 \\
\hline 12 & -- & -- & -- & -- & -- & -- \\
\hline 13 & 5 & 21,7 & 2 & 11,7 & 7 & 17,5 \\
\hline 14 & 4 & 17,4 & -- & -- & 4 & 10 \\
\hline TOTAL & 23 & 99,9 & 17 & 99,8 & 40 & 100 \\
\hline
\end{tabular}

1 Enfermeiros peritos que relataram trabalhar com Diagnóstico de Enfermagem e Desobstrução ineficaz de vias aéreas

${ }^{2}$ Enfermeiros peritos que relataram trabalhar com Diagnóstico de Enfermagem

O grupo 1 obteve de 7 a 14 pontos e o grupo 2 de 5 a 13 pontos. O grupo 1 obteve a média de 3,2, a mediana de 4,0 e o desvio padrão de 2,4. O segundo grupo, o dos peritos com experiência em DE, encontramos a média e a mediana, respectivamente, 2,4 e 2,0 e o desvio padrão de 1,9.

A metodologia de Ferhing (1994) valoriza o profissional segundo sua experiência científica e prática clínica no Diagnóstico de Enfermagem a ser estudado, por isso há uma diferença de pontuação entre os grupos. Na nossa amostra, caracterizações do sujeito têm $57,5 \%$ dos peritos com algum tipo de trabalho ou atividade científica sobre o tema Desobstrução ineficaz de vias aéreas, além do Mestrado e Doutorado. Porém, o importante desta metodologia é que ela 
não descarta o sujeito que tem experiência em trabalhar com os Diagnósticos de Enfermagem da NANDA de uma maneira geral.

\subsubsection{Validação da definição do Diagnóstico de Enfermagem "Desobstrução ineficaz de vias aéreas"}

Ao perguntar aos sujeitos da pesquisa, quanto à adequação da definição do Diagnóstico de Enfermagem, DIVA, apresentada pela NANDA (2006, p.84) "incapacidade de eliminar secreções ou obstrução do trato respiratório para manter uma via aérea desobstruída" - ao título do diagnóstico, $70 \%$ da amostra referiu serem adequados.

Na tabela 6, podemos observar que a maioria, $73,2 \%$ do grupo 1 e $64,7 \%$ do grupo 2, julgou adequada a definição de "DIVA" apresentada pela NANDA (2006).

Tabela 6 - Distribuição das respostas dos 40 enfermeiros peritos, segundo a adequação da definição e do título do Diagnóstico de Enfermagem "DIVA" apresentada pela NANDA (2006), Ribeirão Preto, 2006.

\begin{tabular}{|c|c|c|c|c|c|c|}
\hline \multirow[b]{2}{*}{$\begin{array}{c}\text { Nível de } \\
\text { Adequação }\end{array}$} & Aérea & de & Atuação & & & \\
\hline & $\begin{array}{l}\text { Diagnóstico de } \\
\text { Enfermagem e } \\
\text { DIVA }^{1}(\mathrm{~N}=23)\end{array}$ & & $\begin{array}{l}\text { Diagnóstico de } \\
\text { Enfermagem }^{2} \\
(\mathrm{~N}=17)\end{array}$ & & TOTAL & \\
\hline & Freqüência & $\%$ & Freqüência & $\%$ & Freqüência & $\%$ \\
\hline Adequado & 17 & 73,9 & 11 & 64,7 & 28 & 70 \\
\hline Pouco Adequado & 6 & 26 & 5 & 29,4 & 11 & 27,5 \\
\hline Nada Adequado & -- & -- & -- & -- & -- & -- \\
\hline Não Respondeu & -- & -- & 1 & 5,9 & 1 & 2,5 \\
\hline TOTAL & 23 & 99,9 & 17 & 100 & 40 & 100 \\
\hline
\end{tabular}

${ }^{1}$ Enfermeiros peritos que relataram trabalhar com Diagnóstico de Enfermagem e Desobstrução ineficaz de vias aéreas

${ }^{2}$ Enfermeiros peritos que relataram trabalhar com Diagnóstico de Enfermagem 
No caso de discordância total ou parcial da definição ou do título, foi deixado um espaço para comentários, com o objetivo de os peritos deixarem sugestões. Nove peritos sugeriram troca do título do diagnóstico; 02 responderam pouco adequado, porém não deram sugestão alguma.

Os peritos que sugeriram a troca do título referiram que os termos incapacidade ou limpeza descrevem com melhor propriedade a definição dada pela NANDA (2006). Relataram também que são termos mais cotidianos para os enfermeiros. Os títulos sugeridos foram: "Incapacidade de eliminar secreção", "limpeza ineficaz de vias aéreas" e "eliminação ineficaz de vias aéreas". Um perito referiu que "vias aéreas obstruídas" poderia facilitar o entendimento do enunciado do diagnóstico.

Procuramos na literatura as definições de algumas palavras que foram sugeridas pelos peritos na alteração do título, como: eliminação: ato ou efeito de eliminar; na fisiologia é chamada de excreção; incapacidade: falta de capacidade física ou moral; limpeza: ação ou efeito de limpar; ineficaz: que não é eficaz, que não dá resultado (MICHAELIS, 2005). Temos que ressaltar que realmente são palavras do cotidiano dos enfermeiros, porém os fatores relacionados deste diagnóstico de enfermagem, assim como as características definidoras estabelecem claramente um conjunto de informações precisas e delineadas para o significado do título ora estabelecido pela NANDA (2006).

A palavra Desobstrução vem do verbo desobstruir que significa desatravancar, desimpedir, removendo ou tirando o que obstrui ou estorva (MICHAELIS, 2005). Esta definição denota já uma denominação do problema e ao mesmo tempo uma ação para resolução do mesmo. 
O diagnóstico de Desobstrução ineficaz de vias aéreas, na classificação da NANDA (2006) está localizado no domínio 11 (segurança e proteção) - "estar livre de perigo, lesão física ou dano do sistema imunológico, preservação contra perdas e proteção da segurança e seguridade" e na classe 2 (lesão física) - "dano ou ferimento corporal' (NANDA, 2006, p.268 e 269). Analisando as respostas dos peritos quanto à pertinência do padrão funcional do diagnóstico em estudo, $77,5 \%$ referiram que o padrão funcional mais adequado seria o de eliminação, conforme mostra a tabela abaixo. 
Tabela 7 - Distribuição das respostas dos 40 peritos segundo o padrão funcional ao qual o Diagnóstico de Enfermagem "DIVA" deveria pertencer. Ribeirão Preto, 2006.

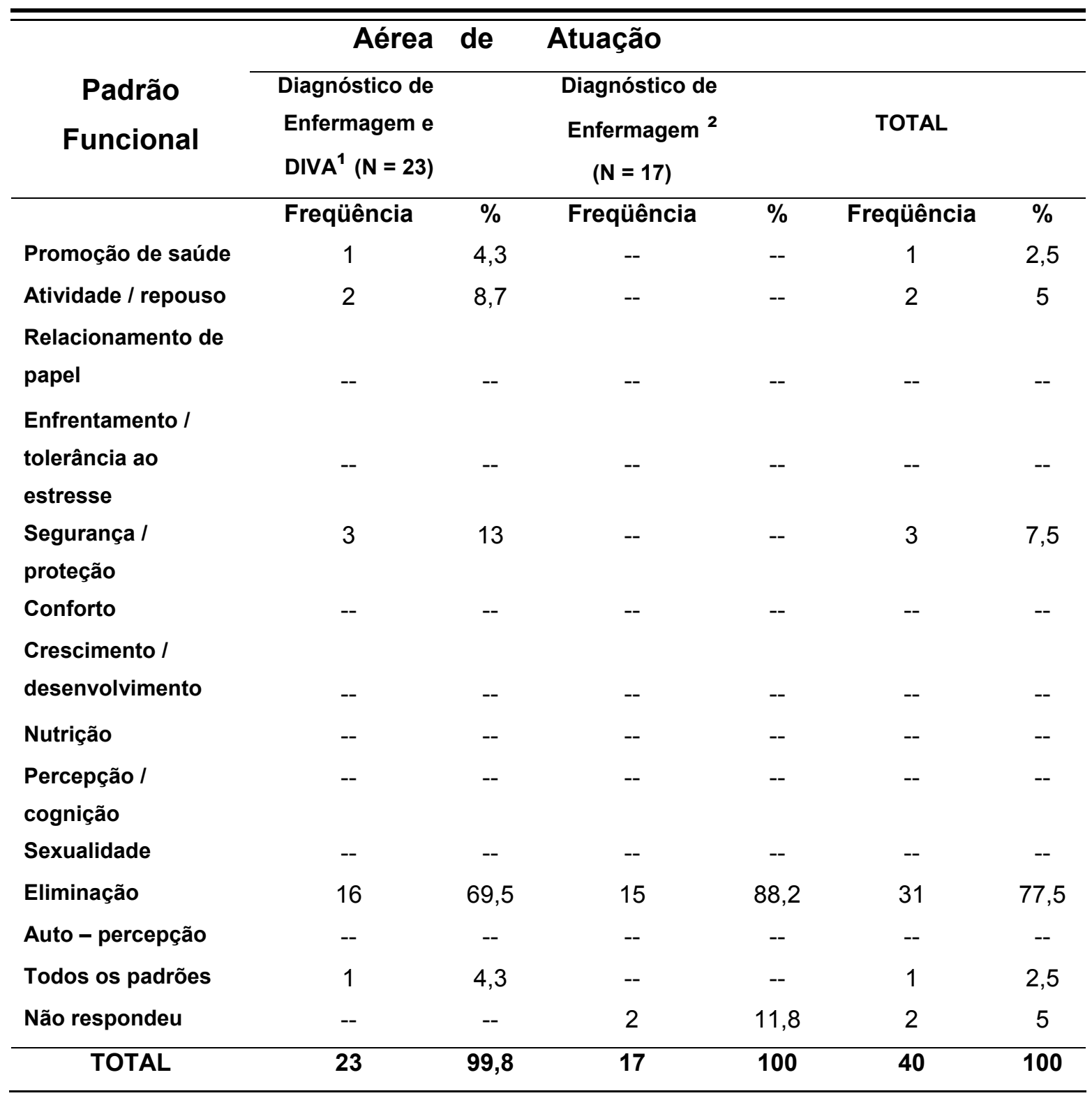

${ }^{1}$ Enfermeiros peritos que relataram trabalhar com Diagnóstico de Enfermagem e Desobstrução ineficaz de vias aéreas

${ }^{2}$ Enfermeiros peritos que relataram trabalhar com Diagnóstico de Enfermagem.

Ao analisarmos o domínio 3 (eliminação), padrão funcional mais referido pelos enfermeiros peritos, tem como definição: "secreção e excreção dos produtos residuais do metabolismo do organismo", sendo que os enfermeiros provavelmente acreditam estar na classe 4 - função respiratória "processo de troca de gases e remoção dos produtos finais do metabolismo". 
No diagnóstico de enfermagem "desobstrução ineficaz de vias aéreas" o produto final é a desobstrução, isto é, manter uma via aérea pérvea, garantindo a segurança e proteção do paciente.

Tomando por base o conjunto dessas definições do domínio 3 classe 4, os componentes do Diagnóstico de Enfermagem "Desobstrução ineficaz de vias aéreas" em especial as características definidoras e fatores relacionados não descrevem elementos necessários para representar o substantivo e o adjetivo que denota o referido diagnóstico. Diante do exposto, parece que fica claro, neste momento, que o domínio e a classe mais adequada para representar os achados está no que foi proposto pela taxonomia II da NANDA.

Ressaltamos aqui, que estudos futuros com outras especificidades, outras clientelas e outras causas serão necessários para, realmente, propormos mudança do domínio do diagnóstico em estudo, para a NANDA.

\subsubsection{Validação das Características Definidoras do Diagnóstico de Enfermagem "Desobstrução ineficaz de vias aéreas"}

Nesta etapa, houve o julgamento dos 40 peritos quanto à pertinência ao Diagnóstico de Enfermagem, a partir da lista de características definidoras geradas, na etapa de Análise de Conceito.

A tabela a seguir mostra os escores, de cada característica definidora, obtidos pelos peritos. 
Tabela 8 - Distribuição das características definidoras do Diagnóstico de Enfermagem "Desobstrução ineficaz de vias aéreas", de acordo com os escores obtidos na Validação por Especialista. Ribeirão Preto, 2006.

\begin{tabular}{lc}
\hline \multicolumn{1}{c}{ CARACTERÍSTICAS DEFINIDORAS } & ESCORE \\
\hline Tosse ineficaz & 0,86 \\
Ruídos adventícios respiratórios (estertores, crepitação, roncos, sibilos) & 0,85 \\
Mudanças na freqüência respiratória & 0,81 \\
Mudanças no ritmo respiratório & 0,81 \\
Dispnéia & 0,76 \\
Murmúrios vesiculares diminuídos & 0,72 \\
Agitação & 0,65 \\
Ortopnéia & 0,62 \\
Cianose & 0,61 \\
Tosse ausente & 0,58 \\
Expectoração & 0,57 \\
Vocalização dificultada & 0,47 \\
Olhos arregalados & 0,48 \\
\hline \hline
\end{tabular}

Podemos observar, na tabela, que duas características definidoras receberam escore abaixo de 0,50 ; sete receberam escores maiores que 0,50 e menores que 0,80 , sendo consideradas características de menor freqüência, e, quatro obtiveram escores maior que 0,80 , consideradas as de maior freqüência. Com relação às 03 características definidoras fictícias acrescentadas na escala de Likert, para o diagnóstico em estudo, receberam escores entre 0,20 a 0,30 e por serem fictícias, não foram consideradas na análise.

Observando os escores, constatamos que as 02 características definidoras que receberam escores menores que 0,50 , sendo elas vocalização dificultada e olhos arregalados, são manifestações clínicas que realmente podem sugerir desobstrução ineficaz de vias aéreas, porém no caso da criança com cânula traqueal, fica difícil de avaliar a característica de vocalização dificultada, pois é uma alteração da voz, também conhecida como disfonia e que, segundo Hungria (2001), 
inclue desde a rouquidão até a afonia. A presença da cânula traqueal impede que a avaliação seja efetiva e quanto aos olhos arregalados sua avaliação está comprometida, devido à situação clínica, pois a criança encontrava-se sob efeitos das drogas anestésicas que impediam a sua reação a qualquer estímulo.

A característica definidora, olhos arregalados é um sinal bastante visível na avaliação da Desobstrução, pois pode ser observada nos estados de angústia respiratória, juntamente com o sinal universal de angústia, como descrito por autores como Potter e Perry (2005) e Smeltzer e Bare (2005), nas situações em que o paciente apresenta uma aparência apreensiva e alguns sinais e sintomas já descritos anteriormente, demonstrando uma possível obstrução das vias aéreas.

Ressaltamos que as duas características definidoras descritas anteriormente, foram analisadas em nosso estudo, apesar de terem recebido baixos escores pelas enfermeiras peritas.

Na tabela 9 podemos visualizar os escores de cada característica definidora, atribuídos pelos enfermeiros peritos para o diagnóstico em estudo. Observamos que as características definidoras: dispnéia, ruídos adventícios respiratórios, tosse ineficaz, tosse ausente, mudanças na freqüência respiratória e mudanças no ritmo respiratório, foram classificadas pelos peritos como "muitíssimo característica" para este diagnóstico.

As características definidoras consideradas "de algum modo característica" foram: ortopnéia, cianose, vocalização dificultada, olhos arregalados e agitação.

Três características definidoras receberam o escore que as caracterizava como "muito característica", sendo elas: murmúrios vesiculares diminuídos, expectoração e mudança no ritmo respiratório. 
Tabela 9 - Distribuição das 13 características definidoras do diagnóstico de enfermagem "Desobstrução ineficaz de vias aéreas", segundo os escores obtidos na validação por Especialistas (N= 40). Ribeirão Preto, 2006.

\begin{tabular}{|c|c|c|c|c|c|c|c|c|c|c|}
\hline \multirow[b]{2}{*}{ CARACTERÍSTICAS DEFINIDORS } & \multicolumn{2}{|l|}{0,20} & \multicolumn{2}{|c|}{0,25} & \multicolumn{2}{|l|}{0,50} & \multicolumn{2}{|l|}{0,75} & \multicolumn{2}{|c|}{1,00} \\
\hline & $\mathrm{F}$ & $\%$ & $\mathrm{~F}$ & $\%$ & $\mathrm{~F}$ & $\%$ & $\mathrm{~F}$ & $\%$ & $\mathrm{~F}$ & $\%$ \\
\hline Dispnéia & 2 & 5 & 1 & 2,5 & 6 & 15 & 15 & 37,5 & 16 & 40 \\
\hline Murmúrios vesiculares diminuídos & 1 & 2,5 & 2 & 5 & 7 & 17,5 & 21 & 52.5 & 9 & 22,5 \\
\hline Ortopnéia & 4 & 10 & 3 & 7,5 & 12 & 30 & 14 & 35 & 7 & 17,5 \\
\hline Ruídos adventícios respiratórios & 2 & 5 & 0 & -- & 3 & 7,5 & 13 & 32,5 & 22 & 55 \\
\hline Tosse ineficaz & 2 & 5 & 0 & -- & 2 & 5 & 11 & 27,5 & 25 & 62,5 \\
\hline Tosse ausente & 9 & 22,5 & 5 & 12,5 & 9 & 22,5 & 4 & 10 & 13 & 32,5 \\
\hline Expectoração & 7 & 17,5 & 5 & 12,5 & 10 & 25 & 11 & 27,5 & 7 & 17,5 \\
\hline Cianose & 2 & 5 & 3 & 7,5 & 19 & 47,5 & 8 & 20 & 8 & 20 \\
\hline Vocalização dificultada & 8 & 20 & 7 & 17,5 & 15 & 37,5 & 7 & 17,5 & 3 & 7,5 \\
\hline Olhos arregalados & 6 & 15 & 8 & 20 & 16 & 40 & 7 & 17,5 & 3 & 7,5 \\
\hline $\begin{array}{l}\text { Mudanças na freqüência } \\
\text { respiratória }\end{array}$ & 0 & -- & 1 & 2,5 & 6 & 15 & 14 & 35 & 19 & 47,5 \\
\hline Mudanças no ritmo respiratório & 0 & -- & 1 & 2,5 & 5 & 12,5 & 17 & 42,5 & 17 & 42,5 \\
\hline Agitação & 3 & 7,5 & 1 & 2,5 & 15 & 37,5 & 12 & 30 & 9 & 22.5 \\
\hline
\end{tabular}

$\mathrm{Na}$ tabela a seguir, mostramos cada característica definidora analisada por meio dos cálculos das medianas e das distâncias interquartílicas (diferença entre o terceiro e o primeiro quartis), segundo avaliação do grupo de enfermeiros peritos. 
Tabela 10 - Distribuição das 13 características definidoras do diagnóstico de enfermagem "Desobstrução ineficaz de vias aéreas", segundo suas medianas e distâncias interquartílicas obtidas pelos enfermeiros peritos ( $N=$ 40). Ribeirão Preto, 2006.

\begin{tabular}{lcccc}
\hline \hline $\begin{array}{l}\text { CARACTERíSTICAS } \\
\text { DEFINIDORAS }\end{array}$ & $\begin{array}{c}\mathbf{1}^{\mathbf{0}} \\
\text { Quartil }\end{array}$ & $\begin{array}{c}\mathbf{3}^{\mathbf{0}} \\
\text { Mediana }\end{array}$ & $\begin{array}{c}\text { Distância } \\
\text { Quartil }\end{array}$ & \begin{tabular}{c} 
Interquartílica \\
\hline Dispnéia
\end{tabular} \\
Murmúrios vesiculares diminuídos & 0,75 & 0,75 & 1,00 & 0,25 \\
Ortopnéia & 0,50 & 0,75 & 0,75 & 0,25 \\
Ruídos adventícios respiratórios & 0,75 & 1,00 & 1,00 & 0,25 \\
Tosse ineficaz & 0,75 & 1,00 & 1,00 & 0,25 \\
Tosse ausente & 0,25 & 0,50 & 1,00 & 0,75 \\
Expectoração & 0,25 & 0,50 & 0,75 & 0,50 \\
Cianose & 0,50 & 0,50 & 0,75 & 0,25 \\
Vocalização dificultada & 0,25 & 0,50 & 0,69 & 0,44 \\
Olhos arregalados & 0,25 & 0,50 & 0,69 & 0,44 \\
Mudanças na freqüência respiratória & 0,75 & 0,75 & 1,00 & 0,25 \\
Mudanças no ritmo respiratório & 0,75 & 0,75 & 1,00 & 0,25 \\
Agitação & 0,50 & 0,75 & 0,75 & 0,25 \\
\hline \hline
\end{tabular}

Na tabela 10 observamos que os valores da mediana estão próximo ao do primeiro quartil, o que significa que os peritos deram grande importância para a maioria das características definidoras.

Pelos valores da mediana, apresentada na tabela 10, podemos referir que as características definidoras do diagnóstico de enfermagem "Desobstrução ineficaz de vias aéreas" foram classificadas pelos enfermeiros peritos de "algum modo característico" a "muitíssimo característico", o que significa que são características relevantes para o diagnóstico em estudo.

$\mathrm{Na}$ próxima tabela, poderemos observar os escores segundo a mínima, máxima, mediana e distâncias interquartilícas atribuídos às características definidoras, comparando os dois grupos de peritos os que trabalham com DE e 
desobstrução ineficaz de vias aéreas e o grupo que trabalha com diagnóstico de enfermagem.

Tabela 11 - Distribuição das 13 características definidoras do diagnóstico de enfermagem "Desobstrução ineficaz de vias aéreas", segundo suas medianas e distâncias interquartílicas obtidas pelos dois grupos de enfermeiros peritos. Ribeirão Preto, 2006.

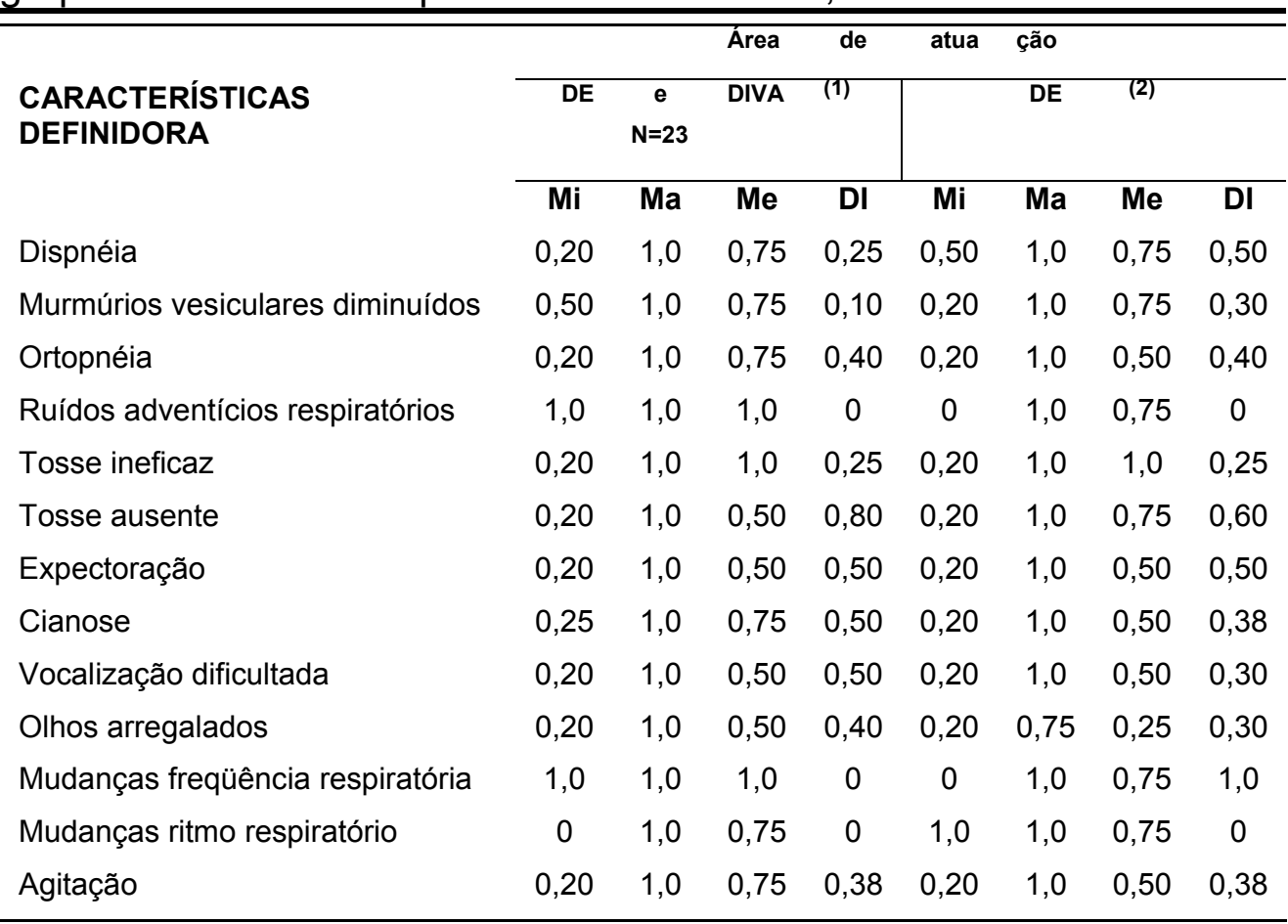

Enfermeiros peritos que relataram trabalhar com Diagnóstico de Enfermagem e Desobstrução ineficaz de vias aéreas

${ }^{2}$ Enfermeiros peritos que relataram trabalhar com Diagnóstico de Enfermagem.

Na tabela 11, podemos afirmar por meio dos valores das medianas dos dois grupos de enfermeiros peritos, que $46,1 \%$ das características definidoras coincidiram para ambos os grupos: "dispnéia", "murmúrios vesiculares diminuídos", "tosse ineficaz", "expectoração", "vocalização dificultada" e "mudança no ritmo respiratório".

Podemos afirmar que os escores atribuídos às características definidoras do diagnóstico de enfermagem "desobstrução ineficaz de vias aéreas" entre o grupo de enfermeiros peritos que trabalham com o tema e o grupo que trabalha com diagnóstico de enfermagem, de modo geral, foram semelhantes para seis características definidoras. 
Analisando os valores das medianas das características que se diferiram, podemos referir que a "ortopnéia", "ruídos adventícios respiratórios", "cianose", "olhos arregalados", "mudança na freqüência respiratória" e "agitação" receberam escore maior pelo grupo 1 e a característica "tosse ausente" pelo grupo 2.

\subsection{Terceira etapa: Validação Clínica}

\subsubsection{Caracterização da amostra}

Na população estudada, observamos que houve um predomínio da faixa dos 0 - 3 meses de idade (36\%), conforme mostra o gráfico 1 . Em relação ao sexo informamos que 26 (52\%) pacientes eram do sexo Masculino e 24 (48\%) eram do sexo feminino.

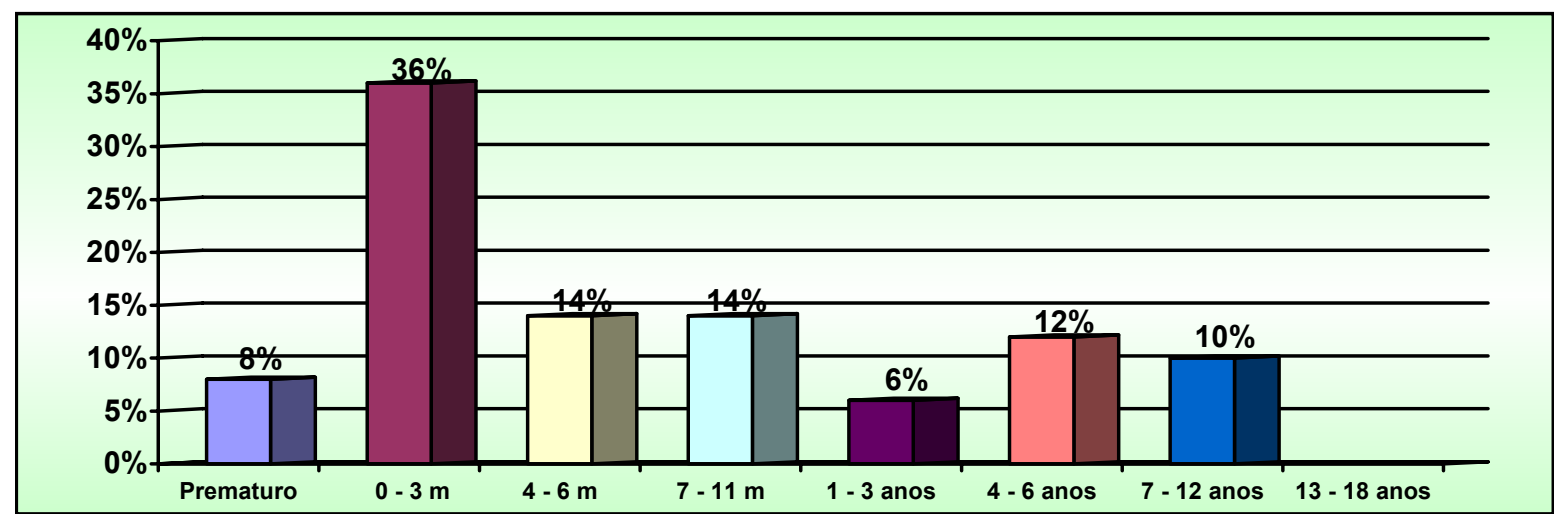

Gráfico 1 - Distribuição da amostra estudada segundo a faixa etária $(N=50)$. Ribeirão Preto, 2007.

O gráfico 1 também nos mostra que, no primeiro ano de vida que as crianças apresentaram os sinais e sintomas da cardiopatia congênita, e, neste período, também foram submetidas à correção cirúrgica, seja ela paliativa ou corretiva. Este fato vem a corroborar com Bernstein (2002) que refere que nos lactentes com a doença, cerca de 99\% apresentam os sintomas característicos de defeitos cardíacos 
ainda no primeiro ano de vida. Em 40\% dos portadores desta anomalia, o diagnóstico é estabelecido em até uma semana de vida e $50 \%$ em até um mês de idade.

No gráfico 2, mostramos as freqüências e os tipos de cirurgias cardíacas realizadas na população em estudo.

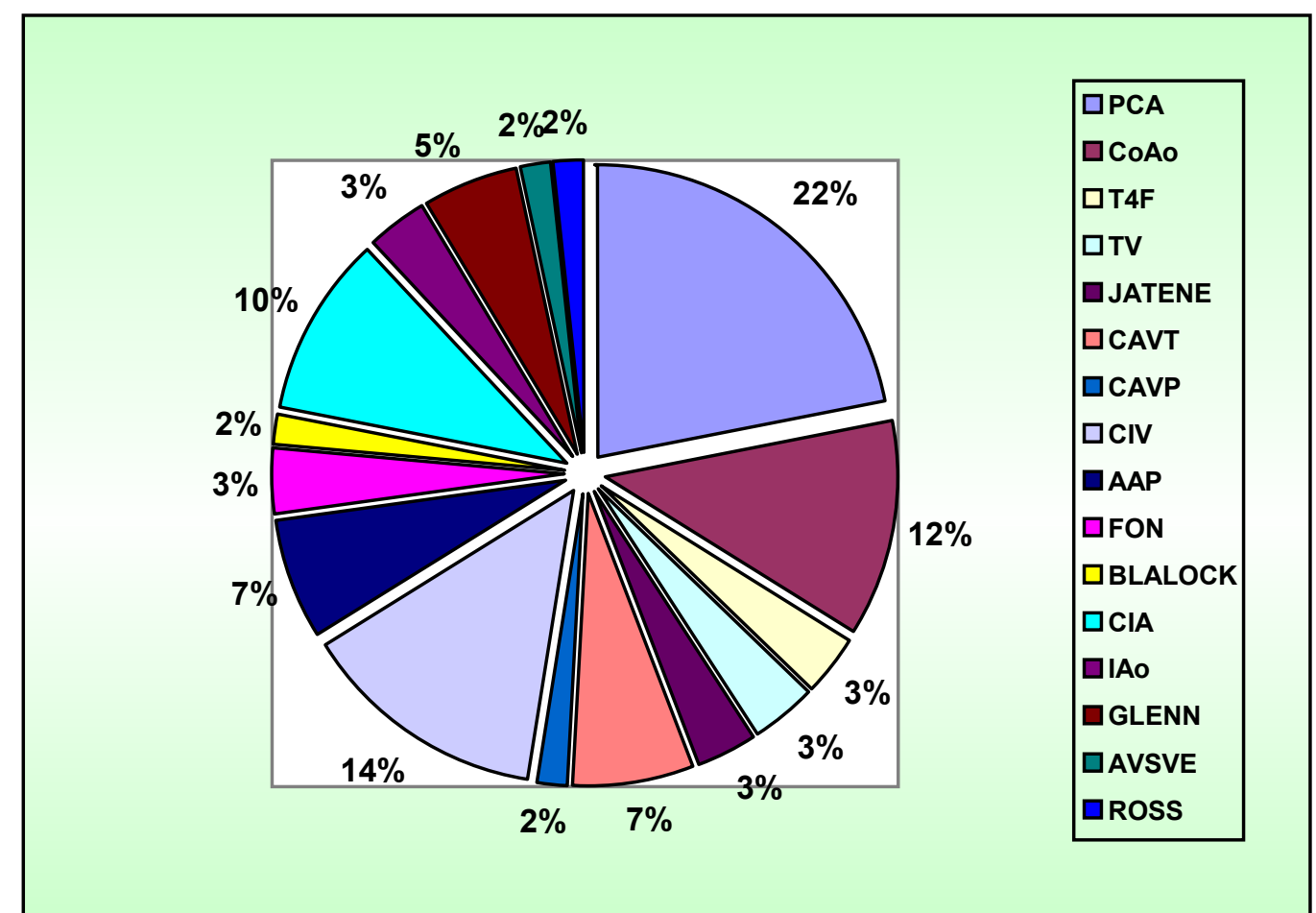

Cirurgia para correção de: $\mathrm{PCA}=$ Persistência do canal arterial; CoAo = Coarctação da aorta; T4F = Tetralogia de Fallot; TV = Troca Valvar; JATENE = Cirurgia de Jatene; DSAVT = Defeito do septo átrio ventricular total; CAVP = Defeito do septo átrio ventricular parcial; CIV = Comunicação interventricular; AAP = Abertura da atresia da pulmonar; FON = cirurgia de Fontam; BLALOCK = Shunt de Blalock- Taussig; CIA = Comunicação interatrial; IAÔ = cirurgia para correção de interrupção do arco aórtico; GLENN = Cirurgia de Glenn: AVSVE = Cirurgia para ampliação da via de saída do ventrículo esquerdo; ROSS = Cirurgia de Ross.

Gráfico 2 - Distribuição da amostra estudada segundo o tipo de cirurgia realizada $(\mathrm{N}=60)$. Ribeirão Preto, 2007.

O tratamento cirúrgico das malformações congênitas do coração, sejam cianogênicas ou acianogênicas, deve basear-se no princípio de procurar sempre que possível, devolver ou oferecer à criança portadora da cardiopatia, adequada qualidade de vida, com redução ou ausência de sintomas, bem como perspectiva de sobrevida a longo prazo (JATENE, 2002). 
As cirurgias apresentadas no gráfico 2, variam desde a mais simples até a mais complexa.

A cirurgia de maior freqüência foi a correção da persistência do canal arterial (22\%). O canal arterial é de fundamental importância na vida uterina e normalmente se fecha após o nascimento. O período de fechamento pode variar de algumas horas até algumas semanas. Na presença da persistência do canal arterial, deve-se programar seu fechamento, baseado na avaliação cardíaca de possíveis complicações pós-fechamento. Várias técnicas podem ser empregadas, porém a técnica convencional de fechamento do PCA ainda prevalece devido à baixa morbidade. O tempo de permanência hospitalar é curto (2 a 4 dias) e a maioria das crianças deixam a sala cirúrgica extubada e com respiração espontânea (JATENE, 2002). Em nosso serviço, a extubação da criança ocorre no Centro de Terapia Intensiva Pediátrico, conforme protocolo de assistência médica determinado pelo Departamento de Pediatria e Anestesia.

A correção cirúrgica para coarctação da aorta teve incidência de $12 \%$, sendo a terceira cirurgia de maior freqüência. Esta cardiopatia é uma discreta estenose na aorta proximal. É um defeito na camada média da aorta, que origina uma dobra posterior proeminente a qual, em alguns casos, estende-se por toda a circunferência do vaso. Esta cardiopatia congênita ocorre em 6 a $8 \%$ dos pacientes e é mais comum no sexo masculino. O reparo cirúrgico continua sendo o tratamento convencional para a maioria das crianças com este problema. Há uma variedade de técnica cirúrgica, sendo elas: ressecção e anastomose terminoterminal; aortoplastia com remendo usando prótese; aortoplastia com flap da subclávia e bypass entre a aorta torácica ascendente e descendente (EMMANOUILIDES et al., 2000). 
Segundo este mesmo autor, a maior complicação desta cirurgia está no clampeamento da aorta. Esta é clampada acima e abaixo do local da coarctação. Os efeitos desfavoráveis serão mínimos se o tempo de clampeamento total for limitado: de 30 a 35 minutos.

A mal formação cardíaca, tetralogia de Fallot, caracteriza-se por desvio do septo infundibular, com deslocamento para a direita e cavalgamento da aorta no septo interventricular, comunicação interventricular, estenose da via de saída do ventrículo direito e hipertrofia ventricular direita. A sua etiologia é quase completamente desconhecida, constitui aproximadamente $10 \%$ das más formações cardíacas e há uma certa predominância do sexo masculino. Quanto ao momento de intervenção cirúrgica, nos casos em que há cianose estável, dá-se preferência pela correção total a partir do sexto mês de vida (JATENE, 2002; EMMANOUILIDES et al., 2000).

A cirurgia de troca valvar é realizada nos casos em que há estenose das valvas cardíacas, seja ela aórtica ou pulmonar. Sob o ponto de vista clínico, a evolução está diretamente relacionada ao grau de comprometimento valvar. Nos casos de estenose crítica, geralmente as manifestações são precoces e surgem no período neonatal. A cirurgia é realizada com o auxílio de circulação extra-corpórea (JATENE, 2002).

Crianças com diagnóstico de transposição dos grandes vasos, devem ser abordadas cirurgicamente, no período neonatal, por meio da operação de Jatene. Preferencialmente as crianças devem ser operadas nas duas primeiras semanas de vida, período em que o ventrículo esquerdo apresenta capacidade de suportar o fluxo sistêmico após a correção da anastomose. A incidência é de 20 a 30 / 100.000 nascidos vivos, tem forte predominância no sexo masculino e corresponde entre 5 a 
$7 \%$ das más formações cardíacas congênitas. As principais complicações pósoperatórias precoces são a disfunção ventricular, a estenose pulmonar, insuficiência aórtica e arritmias (JATENE, 2002; EMMANOUILIDES et al., 2000).

Antes do advento da correção cirúrgica em 1960, aproximadamente $90 \%$ das crianças com transposição morriam antes de um ano de idade. No momento, com os cuidados intensivos neonatais modernos, um diagnóstico rápido e reparo anatômico neonatal, 85 a $90 \%$ dos pacientes sobrevivem ao primeiro ano de vida (EMMANOUILIDES et al., 2000).

Segundo Emmanouilides et al. (2000), os defeitos dos septos atrioventriculares correspondem a 4 e $5 \%$ das cardiopatias congênitas. A distribuição do sexo é aproximadamente igual ou pode mostrar uma predominância leve do sexo feminino. O defeito pode ser total ou parcial. O objetivo do reparo cirúrgico é o fechamento da comunicação interatrial e a restauração e preservação da competência da válvula atrioventricular esquerda. No pós-operatório a criança ou adolescente pode apresentar bloqueio atrioventricular total ou parcial e outras bradiarritmias.

A comunicação interventricular (CIV) isolada é a anomalia congênita mais comum do coração, correspondendo a cerca de $20 \%$ de todas as cardiopatias congênitas. Os sintomas estão diretamente relacionados ao tamanho do defeito, ou abertura, e à magnitude do "shunt" esquerda - direita. A intervenção cirúrgica depende do tamanho do defeito e da repercussão hemodinâmica na criança e/ou adolescente (Jatene, 2002). As seqüelas pós-operatórias dos pacientes submetidos ao reparo de uma CIV não complicada na infância ou crianças jovens têm um excelente resultado, sem sinais clínicos e sobrevida a longo prazo aparentemente 
normal. As complicações tardias mais comuns são: bloqueio cardíaco e arritmias ventriculares (EMMANOUILIDES et al., 2000).

Cabe ressaltar que a cirurgia para correção de CIV, em nosso estudo, foi a segunda mais realizada (14\%), o que vem a corroborar com os artigos encontrados.

Jatene (2002), em seu artigo, refere que dentre todas as cardiopatias, a comunicação interatrial (CIA) costuma ser a de evolução mais benigna, permitindo que se programe eletivamente seu tratamento cirúrgico. A complicação mais comum é o flutter atrial, que são arritmias dos átrios.

A atresia da pulmonar é uma cardiopatia cuja válvula pulmonar encontra-se hermeticamente fechada ou imperfurada. O fluxo de sangue pulmonar normalmente é propiciado pelo canal arterial patente (Emmanouilides et al, 2000). Dependendo do caso, a cirurgia é abertura da válvula atrésica ou a realização da cirurgia de Rastelli ou o Blalock Taussing.

As cirurgias de Fontam e Glenn são duas etapas realizadas na correção da cardiopatia congênita de atresia tricúspide (AT), definida como a agenesia completa da válvula tricúspide sem comunicação direta entre o átrio direito e o ventrículo direito. A correção deste defeito cardíaco é realizada em até 3 tempos, duas cirurgias paliativas e uma correção definitiva, sendo a primeira o shunt de Blalock Taussig modificado, realizada em crianças com menos de um mês de idade. Depois de seis meses de idade, pode ser feito novo Blalock ou uma anastomose bidirecional de Glenn, ligando a veia cava superior direita à artéria pulmonar direita. E a terceira etapa é o procedimento de Fontan, quando a criança se encontra com mais de dois anos, e o átrio direito é unido diretamente à artéria pulmonar. O prognóstico de vida das crianças com este tipo de patologia, após 3,5 anos é de $89 \%$. As arritmias são 
complicações comuns a longo prazo subseqüentes ao procedimento de Fontan (EMMANOUILIDES et al., 2000).

A interrupção do arco aórtico é definida como uma separação completa da aorta ascendente e descendente. A abordagem cirúrgica para o tratamento depende do grau de obstrução subaórtica, que deverá ser tratada com um bypass. O método preferido é unir a artéria pulmonar principal proximal com a aorta ascendente, usando um aumento com homoenxerto para completar a reconstrução aórtica. O arco aórtico pode ser reconstruído através de dissecção liberal ao redor dos componentes dos dois arcos com anastomoses diretas das duas extremidades (EMMANOUILIDES et al., 2000).

A ampliação da via de saída do ventrículo esquerdo é a cirurgia realizada para correção da cardiopatia congênita que causa obstrução à ejeção do sangue do ventrículo esquerdo, sendo ela a estenose aórtica valvular. Sua incidência ocorre em 3 a $6 \%$ dos pacientes com mal formação cardíaca congênita e é mais freqüente no sexo masculino. Quando criança, a cirurgia realizada é a valvuloplastia, que pode ocorrer através do cateterismo, com uso de um balão ou com cirurgia a céu aberto. Mais tarde, quando adulto, é realizada a cirurgia de Ross, que consiste na retirada da válvula pulmonar, que é reimplantada na aorta e no lugar dela é colocada uma prótese sintética (EMMANOUILIDES et al, 2000).

As cirurgias cardíacas com circulação extra-corpórea (CEC) promovem várias alterações no organismo sendo sua principal complicação os problemas de hemostasia, por desencadear ativação da coagulação. Para sanar o problema da coagulação é utilizada a heparina, durante a cirurgia. Por este motivo, o paciente pode desenvolver um sangramento intenso no pós-operatório. 
Segundo Silveira et al. (1998) a utilização de CEC pode se associar a hemorragias graves no pós-operatório de cirurgia cardíaca. Este mesmo autor também refere que a incidência varia de 5 a 25\% e além das causas já citadas, o paciente pode apresentar rebote da heparina, excesso de protamina e defeitos qualitativos na formação do polímero de fibrina.

Dos sujeitos deste estudo, $32(64 \%)$ dos pacientes foram submetidos durante a cirurgia à circulação extra-corpórea.

\subsection{2 Índice de concordância das características definidoras do diagnóstico de enfermagem "Desobstrução ineficaz de vias aéreas" observadas pelas enfermeiras diagnosticadoras em crianças e adolescentes submetidos à correção cirúrgica de cardiopatia congênita}

Nesta etapa, tivemos por intuito apresentar as variações entre os dados das enfermeiras diagnosticadoras, com a identificação clínica das características definidoras na população estudada.

No Diagnóstico de Enfermagem de "desobstrução ineficaz de vias aéreas", dentre as 13 características definidoras observadas nos pacientes portadores de cardiopatia congênita, 10 características estavam presentes na observação das duas enfermeiras diagnosticadoras e 06 características apresentaram discordância entre as peritas.

A tabela 12, mostra que as características definidoras "murmúrios vesiculares diminuídos, ruídos adventícios respiratórios e mudança no ritmo respiratório" apresentaram o menor índice de concordância entre as enfermeiras diagnosticadoras. Acreditamos que tal fato pode ser explicado pelo desenvolvimento de habilidades do conjunto de atributos para os achados desta avaliação clínica. 
Tabela 12 - Distribuição das características definidoras do diagnóstico de enfermagem "Desobstrução ineficaz de vias aéreas", conforme o índice de concordância entre as enfermeiras diagnosticadoras. Ribeirão Preto, 2007.

\begin{tabular}{lc}
\hline \hline CARACTERÍSTICAS DEFINIDORAS & Índice de Concordância \\
Ortopnéia & 1,0 \\
Expectoração & 1,0 \\
Cianose & 1,0 \\
Mudanças na freqüência respiratória & 1,0 \\
Agitação & 1,0 \\
Vocalização dificultada & 1,0 \\
Olhos arregalados & 1,0 \\
Dispnéia & 0,98 \\
Tosse ineficaz & 0,98 \\
Tosse ausente & 0,98 \\
Murmúrios vesiculares diminuídos & 0,92 \\
Ruídos adventícios respiratórios & 0,92 \\
Mudanças no ritmo respiratório & 0,92 \\
\hline \hline
\end{tabular}

No quadro 3, os índices de concordância revelam que as enfermeiras peritas discordaram entre si em 17 possibilidades (2,6\%). Com estes dados, podemos concluir que no diagnóstico em estudo, a concordância total entre as enfermeiras diagnosticadoras foi de $97,7 \%$.

Ao se observarem os dados relacionados ao diagnóstico de "desobstrução ineficaz de vias aéreas", notamos que das 13 características definidoras observadas, seis apresentaram discordância de aparição entre as enfermeiras diagnosticadoras, quatro estavam presentes na avaliação das duas enfermeiras e 03 não estavam presentes na observação das enfermeiras peritas.

Neste mesmo quadro, observamos que o número de características definidoras detectadas pelos enfermeiros peritos variou de zero a quatro características para cada paciente. Considerando a média de 2,1 características, a moda 4 e o desvio padrão de 1,07, que significa referirmos que a grande maioria dos sujeitos 
apresentou características definidoras que sustentaram o diagnóstico de enfermagem "Desobstrução ineficaz de vias aéreas".

Podemos afirmar que no diagnóstico estudado, os índices de concordância apresentados foram considerados satisfatórios. 


\begin{tabular}{|c|c|c|c|c|c|c|c|c|c|c|c|c|c|c|}
\hline Suj. & 1 & 2 & 3 & 4 & 5 & 6 & 7 & 8 & 9 & 10 & 11 & 12 & 13 & $\begin{array}{c}\text { Total de CD } \\
\text { presentes } \\
\text { para os dois } \\
\text { observadores }\end{array}$ \\
\hline & $\mathrm{O}^{1} \mathrm{O}^{2}$ & $\mathrm{O}^{1} \mathrm{O}^{2}$ & $\mathrm{O}^{1} \mathrm{O}^{2}$ & $\mathrm{O}^{1} \mathrm{O}^{2}$ & $\mathrm{O}^{1} \mathrm{O}^{2}$ & $\mathrm{O}^{1} \mathrm{O}^{2}$ & $\mathrm{O}^{1} \mathrm{O}^{2}$ & $\mathrm{O}^{1} \mathrm{O}^{2}$ & $\mathrm{O}^{1} \mathrm{O}^{2}$ & $\mathrm{O}^{1} \mathrm{O}^{2}$ & $\mathrm{O}^{1} \mathrm{O}^{2}$ & $\mathrm{O}^{1} \mathrm{O}^{2}$ & $\mathrm{O}^{1} \mathrm{O}^{2}$ & \\
\hline S1 & & $X X$ & & $\mathrm{XX}$ & & $\mathrm{XX}$ & & & & & & & & 3 \\
\hline S2 & $X$ & $X \times$ & & $\mathrm{XX}$ & $\times X$ & & & & $x$ & & & & & 3 \\
\hline S3 & & & & & $X$ & $\mathrm{X}$ & & & & & & & & 0 \\
\hline $\mathrm{S} 4$ & & $\mathrm{XX}$ & & & $\mathrm{XX}$ & & & & $\bar{x}$ & & & & & 2 \\
\hline S5 & & $X$ & & & & $\mathrm{XX}$ & & & & & & & & 1 \\
\hline S6 & & $\mathrm{XX}$ & & & & $\mathrm{XX}$ & & & & & & & & 2 \\
\hline S7 & & $\mathrm{XX}$ & & $\mathrm{XX}$ & & $X X$ & & & & & & & & 3 \\
\hline S8 & & & & & $\bar{X}$ & & & & $x$ & & & & & 0 \\
\hline S9 & & $\mathrm{XX}$ & & & & $\mathrm{XX}$ & & $X X$ & & & & & & 3 \\
\hline $\mathrm{S} 10$ & & $\bar{X}$ & & & & $\mathrm{XX}$ & & & & & & & & 1 \\
\hline S11 & & & & $\times X$ & & $\mathrm{XX}$ & & & $\mathrm{XX}$ & & & & & 3 \\
\hline S12 & & $\mathrm{XX}$ & & $x$ & & $\mathrm{XX}$ & & & & & & & & 2 \\
\hline $\mathrm{S} 13$ & & & & & $\mathrm{XX}$ & & & & $x$ & & & & & 1 \\
\hline $\mathrm{S} 14$ & & & & & $\mathrm{XX}$ & & & & & & & & & 1 \\
\hline S15 & $\mathrm{X} \quad \mathrm{X}$ & $\mathrm{XX}$ & & & $\mathrm{XX}$ & & & & $\mathrm{XX}$ & & & & & 4 \\
\hline S16 & & & & & & $\mathrm{XX}$ & & & & & & & & 1 \\
\hline S17 & & & & & & $\mathrm{XX}$ & & & & & & & & 1 \\
\hline S18 & & & & & & $\mathrm{XX}$ & & & & & & & & 1 \\
\hline S19 & & $x$ & & & & $\mathrm{XX}$ & & & & & & & & 1 \\
\hline S20 & & $\times x$ & & $X$ & & $\mathrm{XX}$ & & & & & & & & 2 \\
\hline S21 & & & & & & $\mathrm{XX}$ & & & & & & & & 1 \\
\hline S22 & & & & & $\times X$ & & & & & & & & & 1 \\
\hline $\mathrm{S} 23$ & & $\mathrm{XX}$ & & $\mathrm{XX}$ & & $\mathrm{XX}$ & & & & & & & & 3 \\
\hline S24 & & $\mathrm{XX}$ & & $\mathrm{XX}$ & & & & & $\mathrm{XX}$ & & $X X$ & & & 4 \\
\hline S25 & & & & & $\mathrm{XX}$ & & & & $X$ & $\mathrm{XX}$ & & & & 2 \\
\hline S26 & & $\times x$ & & $\mathrm{XX}$ & & $\mathrm{XX}$ & & & $\mathrm{XX}$ & & & & & 4 \\
\hline S27 & & & & $X X$ & & & & & & & $X X$ & $X X$ & & 2 \\
\hline S28 & & $\times x$ & & & & $\mathrm{XX}$ & & & $\mathrm{XX}$ & & & & & 3 \\
\hline S29 & & & & $\mathrm{XX}$ & & $\mathrm{XX}$ & & $X X$ & & & & & & 3 \\
\hline S30 & & & & & $\mathrm{XX}$ & & & & & & & & & 1 \\
\hline S31 & & $\mathrm{XX}$ & & $X$ & & $\mathrm{XX}$ & & & & & & & & 2 \\
\hline S32 & & & & & $\mathrm{XX}$ & & & & $\mathrm{XX}$ & & & & & 2 \\
\hline S33 & & & & $\times x$ & $\mathrm{XX}$ & & & & $\mathrm{XX}$ & & & & & 3 \\
\hline S34 & & $X$ & & & & $x x$ & & & & & & & & 1 \\
\hline S35 & & $\mathrm{XX}$ & & $\mathrm{XX}$ & & $\mathrm{XX}$ & & & & & & & & 3 \\
\hline S36 & & $\mathrm{XX}$ & & & & $\mathrm{XX}$ & & & & & & & & 2 \\
\hline S37 & & & & & & $\mathrm{XX}$ & & & & & & & & 1 \\
\hline S38 & & & & & & $\mathrm{XX}$ & & & & & & & & 1 \\
\hline S39 & & & & $\mathrm{XX}$ & & $\mathrm{XX}$ & & & $\mathrm{XX}$ & & & & & 3 \\
\hline $\mathrm{S} 40$ & & $\mathrm{XX}$ & & $X$ & & $\mathrm{XX}$ & & & $\mathrm{XX}$ & & & & & 3 \\
\hline S41 & & $\mathrm{XX}$ & & $\mathrm{XX}$ & & $\mathrm{XX}$ & & & & & & & & 3 \\
\hline S42 & & & & $\mathrm{XX}$ & & $\mathrm{XX}$ & & $X X$ & $\mathrm{XX}$ & & & & & 4 \\
\hline S43 & & & & $\mathrm{XX}$ & $\mathrm{XX}$ & & & & & & & & & 2 \\
\hline S44 & & & & $\mathrm{XX}$ & & $\mathrm{XX}$ & & & & & & & & 2 \\
\hline S45 & & & & & & $\mathrm{XX}$ & & & & & & & & 1 \\
\hline S46 & & & & & & $\mathrm{XX}$ & & $\mathrm{XX}$ & & & & & & 2 \\
\hline S47 & & & & & $\mathrm{XX}$ & & & & & & & & & 1 \\
\hline S48 & & $\mathrm{XX}$ & & $\mathrm{XX}$ & & $\mathrm{XX}$ & & & & & & & & 3 \\
\hline S49 & & & & $\mathrm{XX}$ & & $\mathrm{XX}$ & & $\mathrm{XX}$ & & & & & & 3 \\
\hline S50 & & & & & & $\mathbf{X X}$ & & & $\mathbf{X X}$ & & & & & 2 \\
\hline
\end{tabular}

$\mathrm{O}^{1}=$ Pesquisadora; $\mathrm{O}^{2}=$ enfermeiras observadoras clínicas

1 = Dispnéia; 2 = Murmúrios vesiculares diminuídos; 3 = Ortopnéia; 4 = Ruídos adventícios respiratórios; 5 = Tosse Ineficaz; 6 = Tosse ausente; 7 = Expectoração; 8 = Cianose; 9 = Mudança na freqüência; 10 = Mudança no ritmo respiratório; $11=$ Agitação; 12 = Vocalização dificultada e $13=$ olhos arregalados.

Quadro 3 - Distribuição das características definidoras do diagnóstico de enfermagem "Desobstrução ineficaz de vias aéreas" assinaladas para cada sujeito da amostra, segundo as respostas das enfermeiras peritas diagnosticadoras. 


\subsubsection{Coeficiente de confiabilidade ponderado entre os observadores clínicos das características definidoras do diagnóstico de enfermagem "Desobstrução ineficaz de vias aéreas"}

$\mathrm{Na}$ tabela a seguir, descreveremos o coeficiente de confiabilidade com a intenção de apresentarmos a incidência de cada característica definidora corrigida pela concordância entre as enfermeiras diagnosticadoras.

Tabela 13 - Distribuição das características definidoras do diagnóstico de enfermagem "Desobstrução ineficaz de vias aéreas", segundo o coeficiente de confiabilidade ponderado entre as enfermeiras diagnosticadoras. Ribeirão Preto, 2007.

\begin{tabular}{lc}
\hline \hline CARACTERÍSTICAS DEFINIDORAS & Coeficiente de Confiabilidade \\
Tosse ausente & 0,67 \\
Murmúrios vesiculares diminuídos & 0,38 \\
Ruídos adventícios respiratórios & 0,37 \\
Mudanças no ritmo respiratório & 0,25 \\
Tosse ineficaz & 0.24 \\
Cianose & 0,10 \\
Agitação & 0,04 \\
Dispnéia & 0,03 \\
Mudanças na freqüência respiratória & 0,02 \\
Vocalização dificultada & 0,02 \\
Olhos arregalados & 0,00 \\
Ortopnéia & 0,00 \\
Expectoração & 0,00 \\
\hline \hline
\end{tabular}

Podemos observar na tabela 13, que 09 características definidoras não alcançaram o escore 0,50: "murmúrio vesicular diminuído"; "ruídos adventícios respiratórios"; "tosse ineficaz"; "mudança no ritmo respiratório"; "agitação"; "dispnéia"; mudança na freqüência respiratória"; "vocalização dificultada" e "cianose", 
e três características definidoras "olhos arregalados", "ortopnéia" e "expectoração" não apareceram em nenhuma das 50 avaliações realizadas.

A característica definidora que recebeu coeficiente maior que 0,50 e menor que 0,80 , classificamos como característica de menor freqüência "tosse ausente", porém foi a característica de maior freqüência na observação das enfermeiras diagnosticadoras.

Estabelecidos os coeficientes de confiabilidade, calculamos o escore total do diagnóstico estudado que foi de 0,67. Lembramos que as características definidoras que obtiveram coeficientes menores que 0,50, não foram incluídas nesse cálculo, atendendo aos critérios de Fehring (1987).

Segundo Fehring (1987), um escore total menor que 0,60 significa que o diagnóstico deve ser novamente apurado e/ou rejeitado ou removido da lista de diagnóstico da NANDA. Este não é o nosso caso, pois apesar do escore estar baixo conseguimos mostrar a existência do diagnóstico em estudo em uma população tão específica de crianças e adolescentes submetidos à correção cirúrgica de cardiopatia congênita, no pós-operatório imediato.

Com enfoque no fator relacionado estudado e constatado que a característica definidora de maior impacto foi "tosse ausente", afirmamos, com base nas informações, que o planejamento da assistência de enfermagem para essa clientela tem sua especificidade para os resultados presentes no cuidado a ser administrado.

Apontamos algumas considerações importantes nos resultados encontrados: 1 - a população escolhida foi muito específica e exige um preparo da enfermeira na avaliação clínica (a coleta de dados); 2 - a amostra atendeu ao tamanho que Fehring (1987) sugere, porém o diagnóstico escolhido tem um elenco grande de características definidoras e 3 - na população específica e na coleta de dados no 
primeiro pós-operatório, temos que considerar que $60 \%$ da nossa amostra encontrava-se anestesiada, isto é, sem expressão de algumas características definidoras.

A presença de uma característica definidora foi considerada condição suficiente para determinar o Diagnóstico de Enfermagem, devido ao mérito do objeto em estudo.

Portanto, avaliamos que os dados obtidos refletem a natureza do objeto.

\subsubsection{Incidência das características definidoras do diagnóstico de enfermagem} “Desobstrução ineficaz de vias aéreas” observadas pelas enfermeiras diagnosticadoras em crianças e adolescentes submetidos à correção cirúrgica de cardiopatia congênita

Nesta etapa, apresentaremos como resultados os dados coincidentes pelas enfermeiras diagnosticadoras.

No Diagnóstico de Enfermagem “Desobstrução ineficaz de vias aéreas”, das 13 características definidoras avaliadas, a mais freqüente foi "tosse ausente", conforme mostra a tabela 14: 
Tabela 14 - Distribuição da freqüência das características definidoras do diagnóstico de enfermagem "Desobstrução ineficaz de vias aéreas" em crianças e adolescentes portadores de cardiopatia congênita ( $N=50)$. Ribeirão Preto, 2007.

\begin{tabular}{lcc}
\hline \hline CARACTERÍSTICAS DEFINIDORAS & Freqüência & $\%$ \\
Tosse ausente & 34 & 68 \\
Murmúrios vesiculares diminuídos & 19 & 38 \\
Ruídos adventícios respiratórios & 18 & 36 \\
Tosse ineficaz & 12 & 24 \\
Mudanças na freqüência respiratória & 11 & 22 \\
Cianose & 5 & 10 \\
Agitação & 2 & 4 \\
Dispnéia & 1 & 2 \\
Mudanças no ritmo respiratório & 1 & 2 \\
Vocalização dificultada & 1 & 2 \\
Olhos arregalados & 0 & -- \\
Ortopnéia & 0 & -- \\
Expectoração & 0 & -- \\
\hline \hline
\end{tabular}

No instrumento de coleta de dados estavam presentes todas as perguntas específicas necessárias para detecção dos possíveis sinais e sintomas.

Para detectar a característica definidora que teve maior incidência de observação "tosse ausente" realizamos manobras de estímulo à tosse que foram: manipular discretamente a cânula oro traqueal e apertar a fúrcula até atingir a traquéia. Em um dos casos não houve necessidade de fazer a estimulação, pois no momento do exame foi necessária aspiração endotraqueal do paciente e através deste procedimento foi possível detectar a presença ou não da tosse. Cabe ressaltar que a estimulação da tosse foi realizada concomitantemente pelas duas enfermeiras diagnosticadoras, após realizarem todo o exame físico. Tal conduta foi tomada porque percebemos que o estímulo em alguns pacientes alterava todos os sinais e sintomas, quando cada perita o realizava, porém conforme já referido anteriormente 
cada uma registrou separadamente da outra, sem comum acordo para tal característica definidora.

Sendo assim, a característica "tosse ausente" foi observada em $68 \%$ dos pacientes. Dos sujeitos que apresentaram tal sinal, 17 (34\%) estavam sob efeito de anestésicos; 10 (20\%) estavam recebendo sedativos (midazolan e fentanila) e neuro bloqueador muscular (brometo de vecurônio); cinco (10\%) faziam uso somente de sedativos e dois (4\%) não faziam uso de nenhum tipo de sedativo ou neuro bloqueador muscular.

Os 17 sujeitos sob efeito da anestesia prolongada no POI atenderam à normatização de procedimentos médicos realizados pela equipe da anestesia. 0 efeito da anestesia prolongada no cuidado a essas crianças / adolescentes em CTIP merece atenção por parte da equipe de enfermagem. O controle das respostas destes anestésicos prolongados impõe medidas de avaliações contínuas da função ventilatória e circulatória na assistência e na manutenção da via aérea pérvea e controle hemodinâmico.

Os 10 pacientes que recebiam midazolan, fentanila e brometo de vecurônio foram sujeitos que após a recepção no CTIP, permaneceram instáveis hemodinamicamente, impossibilitando o despertar e posterior extubação da cânula traqueal. Nestes pacientes, a avaliação física variou da segunda hora de POI até a décima sétima hora, pois dependíamos da estabilização do paciente. Cabe ressaltar que $100 \%$ destes pacientes apresentaram a característica "tosse ausente", devido ao uso do brometo de vecurônio, um neuro-bloqueador muscular. Este medicamento é administrado quando o esforço físico (ex.: respiração, agitação, etc...) propicia ao paciente repercussão hemodinâmica importante. Ele tem por finalidade paralisar 
todos os músculos do corpo, o que também impede a criança e o adolescente de reagir aos estímulos da tosse.

Cinco pacientes faziam uso somente de midazolan e fentanila, após a monitorização no CTIP. O uso de sedativos no pós-operatório imediato de uma cirurgia cardíaca indica que o paciente não está preparado hemodinamicamente para despertar e assumir a sua fisiologia espontaneamente, porém alguns fatores, durante este período de estabilização, precisam ser amenizados como: dor, estresse, presença da cânula orotraqueal, procedimentos (aspiração endotraqueal) que precisam ser realizados, entre outros.

O grau de sedação varia de paciente para paciente, e representa mudanças sutis no estado de consciência (EMMANOUILIDES et al., 2000). Cada serviço deve ter um protocolo de sedação, de acordo com a clientela atendida. Porém, o Committee on Drugs of the Academy of Pediatrics define sedação da seguinte forma:

- Sedação consciente: "um estado medicamente controlado de consciência deprimida que permite manter os reflexos protetores; retêm a capacidade do paciente em manter uma via aérea patente independente e continuamente e permite a resposta apropriada pelo paciente a um estímulo físico ou comando verbal";

- Sedação profunda: "um estado medicamente controlado de consciência deprimida ou de inconsciência, do qual o paciente não é facilmente despertado. Pode ser acompanhado por uma perda parcial ou completa de reflexos protetores, e inclui a incapacidade para manter uma patente via aérea independentemente e responder ao estímulo físico ou comando verbal" (EMMANOUILIDES et al., 2000 p. 139).

Com essas definições podemos referir que os cinco pacientes que faziam uso de sedativos estavam com sedação profunda, pois não apresentaram reflexo protetor, a tosse.

Em dois pacientes, as enfermeiras peritas, nessa fase do estudo, julgaram nos sujeitos que não fizeram uso de nenhum tipo de sedativo no POI, mas 
perceberam a abertura da boca enquanto um possível reflexo de tosse, mas não efetivaram o ato.

Quatro características definidoras merecem atenção no nosso estudo que são: "murmúrios vesiculares diminuídos" (38\%), "ruídos adventícios respiratórios" (36\%), "tosse ineficaz" (24\%), "mudança na freqüência respiratória" (22\%) e "cianose" (10\%).

As duas primeiras características são sinais que necessitam de observação criteriosa e sistemática da enfermeira. Esse critério de avaliação por meio da ausculta pulmonar pressupõe atributos de competência e domínio da enfermeira, alicerçada no conhecimento e nas habilidades técnicas. O exame realizado para a detecção dos sons respiratórios é a ausculta pulmonar, por meio da utilização do estetoscópio. Segundo Tarantino (2001) "é o método semiológico básico no exame físico dos pulmões".

A presença de murmúrios vesiculares diminuídos são alterações encontradas nas vias aéreas inferiores e nos alvéolos que interferem na troca gasosa. A condição de colapso de parte dos alvéolos de um ou dos dois pulmões pode ocorrer em decorrência da obstrução de vias aéreas (por exsudato espesso, com ar alveolar sendo gradualmente absorvido pelos capilares pulmonares enquanto as paredes alveolares ficam justapostas), compressão pulmonar e ausência de surfactante (JARVIS, 2002).

A presença de ruídos adventícios respiratórios são auscultados sobreposto aos ruídos respiratórios, tem como causa a colisão do ar em movimento com secreções nas vias traqueobrônquicas ou o estouro de abertura das vias aéreas anteriormente vazias (JARVIS, 2002). 
$\mathrm{Na}$ nossa amostra, 12 pacientes (24\%) apresentaram a característica "tosse ineficaz". Destes, três sujeitos estavam sob efeito dos sedativos midazolan e fentanila e 9 não recebiam. Dos que estavam recuperando-se desses efeitos das drogas ao realizarmos o estímulo da tosse, eles reagiam tossindo ineficazmente e ao mesmo tempo denotavam expressão facial de dor, e em algumas situações, gesto protetor tentando levar as mãos de encontro ao peito. Neste momento, as duas enfermeiras observadoras, interpretaram que a tosse ineficaz poderia ter sido devido à dor ou à presença da cânula oro traqueal.

A característica definidora "mudança na freqüência respiratória" esteve presente em 11 pacientes (22\%). Quatro apresentaram esta característica, por estar se recuperando dos efeitos dos anestésicos, isto é, ela estava acordando e retomando a respiração espontânea. E sete pacientes, cuja respiração estava completamente assistida pelo ventilador, apresentavam os parâmetros do respirador alterado.

Segundo Tarantino (2001) na presença de dor torácica, o paciente pode evitar a tosse, ocasionando tosse reprimida ou ineficaz.

Em cinco pacientes (10\%) que apresentaram a característica "cianose", as enfermeiras diagnosticadoras procuraram identificar a relação / causa da cor azulada da pele. Consideramos, em nosso estudo, somente a cianose causada por problemas respiratórios. Foi avaliado o exame de gasometria arterial e as crianças que apresentaram anormalidades dos gases arteriais, acompanhada de baixa saturação de oxigênio sangüíneo, consideramos tal característica.

Entretanto, todo resultado de saturação precisa ser avaliado no contexto do nível de hemoglobina, equilíbrio ácido-base e estado ventilatório (JARVIS, 2002). 
A saturação de oxigênio no sangue, dos cinco pacientes que apresentaram o nível de saturação resultante da gasometria arterial, variou de 68 a $88 \%$, o que significa que a troca gasosa não estava sendo efetiva. Dois destes pacientes, tinham sido submetidos à cirurgia Glenn, que ocasiona a mistura de sangue arterial e venoso e apresentaram uma saturação de oxigênio muito abaixo da esperada, sendo $68 \%$ e $80 \%$ respectivamente. Num paciente a saturação estava baixa, devido à congestão pulmonar e no outro era devido à presença de secreção (estertores).

Porto (2001) refere que a intensidade da cianose pode ser leve, moderada ou intensa, sendo que somente a experiência dará ao examinador capacidade para essa classificação.

A cianose cuja causa é cardíaca é porque há mistura de sangue arterial e venoso, no coração. A presença da cianose significa que há presença de hemoglobina não saturada, isto é, sem oxigênio correndo nas artérias e veias (PORTO, 2001).

Outras características definidoras que foram identificadas pelas enfermeiras diagnosticadoras, com freqüência menor foram: agitação, dispnéia, mudança no ritmo respiratório e vocalização dificultada.

Neste estudo, em duas crianças (4\%) que apresentaram "agitação", uma delas, além da manifestação referida, também apresentou murmúrio vesicular diminuído, ruídos adventícios e mudança na freqüência respiratória e a outra apresentou ruídos adventícios (roncos) e vocalização dificultada. Diante de tais fatos julgamos que os sujeitos estavam agitados por hipóxia. A presença da cânula orotraqueal é fator de desconforto para o paciente.

A agitação é descrita como um sinal importante nos casos em que há insuficiência respiratória e hipóxia. Esses distúrbios aumentam o trabalho da 
respiração e conseqüentemente, elevam as demandas de energia dos músculos respiratórios, com isso sobrevém a insuficiência respiratória, sendo que a agitação é um sinal descrito nesses casos (SMELTZER; BARE, 2005).

Napoleão (2005) refere que em vários estados patológicos relativos ao sistema respiratório que ocorre diminuição crescente ou acentuada dos níveis de oxigênio, há presença de agitação nos pacientes.

Somente um paciente apresentou "dispnéia", na avaliação do POI de correção cirúrgica de persistência do canal arterial. Esta criança de 4 meses de idade ficou intubada, isto é, com uma cânula orotraqueal no primeiro POI, por ser uma criança broncodisplásica. No exame das enfermeiras diagnosticadoras, apresentava-se com uso da musculatura acessória, taquidispnéia $(56 \mathrm{mpm})$ e o murmúrio vesicular diminuído à esquerda. Este paciente também foi o único da amostra que teve o ritmo respiratório alterado.

Quanto à característica "mudança no ritmo respiratório" ter tido uma baixa incidência (2\%), temos que levar em consideração que da amostra, $58 \%$ dos sujeitos estavam sob efeito da anestesia, e a respiração foi realizada com suporte ventilatório. Os ajustes dos parâmetros do ventilador eram realizados de acordo com a idade e estado hemodinâmico da criança e/ou adolescente.

O paciente que apresentou "vocalização dificultada", tentou verbalizar algum sentimento no momento da avaliação e os examinadores procuraram interpretar suas manifestações indicando a presença do tubo traqueal como possível desconforto naquele momento.

As características definidoras "ortopnéia", "expectoração" e "olhos arregalados" não foram observadas em nenhum sujeito. As enfermeiras 
diagnosticadoras concordaram com a ausência dessas manifestações na avaliação clínica.

A expectoração foi uma característica bem comentada pelas enfermeiras diagnosticadoras, durante a coleta de dados. Ao analisarmos a definição de expectoração: "o ato de expectorar", expectorar: "expelir / escarrar" (Michaelis, 2005), algumas dúvidas e questionamentos surgiram como: 1 - que tipo de expectoração a NANDA se refere ineficaz ou eficaz; 2 - se a criança tem uma boa expectoração ela consegue desobstruir as vias aéreas e, portanto, não apresenta o diagnóstico de DIVA e 3 - ela só vai apresentar o diagnóstico em estudo se a expectoração for ineficaz.

Tarantino (2001) e Potter; Perry (2005) referem que a expectoração é uma conseqüência da tosse.

Diante das dúvidas resolvemos procurar a definição do Diagnóstico de Enfermagem de "desobstrução ineficaz de vias aéreas", na NANDA (2006) na versão em inglês, para podermos entender melhor a característica "expectoração". Na versão em inglês a NANDA refere "sputum secretion" que traduzido significa: secreção salivar (sputum = saliva, cuspe e escarro e secretion = secreção).

Se realizarmos uma análise crítica desta tradução veremos que a palavra expectoração não é a tradução adequada de "sputum secretion", pois o paciente que expectora não tem vias aéreas obstruídas, enquanto que a secreção salivar em excesso, pode levar o paciente à desobstrução ineficaz de vias aéreas. 


\subsubsection{Análise comparativa entre a Validação por Especialistas e a Verificação da incidência das evidências clínicas}

Ao compararmos os escores das características definidoras do Diagnóstico de Enfermagem, em estudo, nas etapas de validação por especialista e de verificação da incidência das evidências clínicas, podemos observar que as características "olhos arregalados" e "vocalização dificultada", que receberam um escore de 0,48 e 0,47 respectivamente, pelos enfermeiros peritos, obtiveram na evidência clínica nos pacientes submetidos à correção cirúrgica de cardiopatia congênita um escore de 0,00 e 0,02 . Isto significa que os enfermeiros peritos acreditam que são características muito pouco encontradas nos pacientes com Desobstrução ineficaz de vias aéreas, o que veio a se confirmar no contexto clínico, pois obtiveram uma incidência muito baixa, conforme mostra a tabela abaixo. 
Tabela 15 - Distribuição das características definidoras do diagnóstico de enfermagem "Desobstrução ineficaz de vias aéreas", segundo o escore da validação por especialistas e o coeficiente de confiabilidade ponderado entre as enfermeiras diagnosticadoras. Ribeirão Preto, 2007.

\begin{tabular}{lcc}
\hline \hline CARACTERÍSTICAS DEFINIDORAS & Validação por especialista & $\begin{array}{c}\text { Coeficiente de } \\
\text { Confiabilidade }\end{array}$ \\
Tosse ineficaz & 0,86 & 0,22 \\
Ruídos adventícios respiratórios & 0,85 & 0,37 \\
Mudanças na freqüência respiratória & 0,81 & 0,02 \\
Mudanças no ritmo respiratório & 0,81 & 0,25 \\
Dispnéia & 0,76 & 0,03 \\
Murmúrios vesiculares diminuídos & 0,72 & 0,38 \\
Agitação & 0,65 & 0,04 \\
Ortopnéia & 0,62 & 0,00 \\
Cianose & 0,61 & 0,10 \\
Tosse ausente & 0,58 & 0,67 \\
Expectoração & 0,57 & 0,00 \\
Olhos arregalados & 0,48 & 0,00 \\
Vocalização dificultada & 0,47 & 0,02 \\
\hline \hline
\end{tabular}

Cabe relembrarmos que na característica definidora "olhos arregalados", "expectoração" e "ortopnéia" a concordância foi de 100\%, na evidência clínica de que os pacientes não apresentavam estes sinais e sintomas, ou seja, não foram observados nessa clientela.

As características definidoras "dispnéia", "murmúrio vesicular diminuído", "agitação", "ortopnéia", "cianose", "tosse ausente" e "expectoração" na avaliação dos enfermeiros peritos foram consideradas como característica de menor freqüência. A NANDA (2006) refere que este tipo de característica "proporciona evidência de sustentação ao diagnóstico, mas pode não estar presente". Na nossa amostra, as características acima relacionadas apareceram com a seguinte incidência $2 \%, 38 \%$, $4 \%, 0 \%, 10 \%, 67 \%$ e $0 \%$, respectivamente. 
Das características consideradas de menor freqüência pelos peritos, em cinco realmente foram confirmadas, na evidência clínica, sua baixa incidência. Porém duas características "tosse ausente" e "murmúrio vesicular diminuído" obtiveram as maiores freqüências na população de crianças e adolescentes submetidos à correção cirúrgica de cardiopatia congênita.

$\mathrm{Na}$ avaliação clínica da população estudada, a característica "tosse ineficaz" apareceu em $24 \%$ dos sujeitos; "ruídos adventícios respiratórios" em 36\%; "mudança na freqüência respiratória" em $22 \%$ da amostra e "mudança no ritmo respiratório" em $2 \%$ dos pacientes. Essas características receberam escores que as classificavam como características de maior freqüência pelos enfermeiros peritos, isto é, são características que podem aparecer quando o diagnóstico estiver presente.

Como se pode observar, os sinais e sintomas que os enfermeiros peritos acreditam estarem presentes nos pacientes que apresentam o Diagnóstico de Enfermagem "desobstrução ineficaz de vias aéreas" obtiveram, na validação clínica, baixos índices, segundo a proposta de Fehring (1994). Porém diante de uma população tão especifica, a freqüência não foi tão baixa, a ponto de não considerarmos o diagnóstico. É importante levarmos em consideração a natureza e complexidade do diagnóstico estudado, da clientela e da situação da avaliação inicial no POI.

A única característica que na evidência clínica teve uma incidência maior do que o esperado pelos enfermeiros peritos foi "tosse ausente", ressaltando que tal fato ocorreu devido à população em estudo estar no período pós-operatório imediato de cirurgia cardíaca.

Por fim, considerando os escores totais de 0,71 adquiridos na Validação por Especialistas e de 0,67 na incidência das evidências clínicas para o diagnóstico 
"desobstrução ineficaz de vias aéreas", concluímos que o diagnóstico avaliado alcançou os escores propostos por Fehring (1986), acima de 0,60, nas duas etapas de validação. 


\section{CONCLUSÕES}

Diante dos objetivos propostos e as etapas do método apresentado, temos a considerar:

- Foi realizada uma análise de conceito/conteúdo das características definidoras do diagnóstico de enfermagem em estudo para a validação por especialista compreendendo o levantamento da literatura;

- As características definidoras do diagnóstico de enfermagem "desobstrução ineficaz de vias aéreas" foram revistas e atualizadas a partir de um levantamento da literatura e passaram a abranger conceitos/conteúdos refletindo a importância do conhecimento para a enfermagem e a intersecção dos sinais e sintomas para a investigação focalizada deste diagnóstico;

- Com a realização da revisão da literatura sobre o Diagnóstico de Enfermagem "Desobstrução ineficaz de vias aéreas", identificamos nas publicações analisadas que são poucos os estudos que abordam a análise de Diagnósticos de Enfermagem em crianças e adolescentes submetidos à correção cirúrgica de cardiopatia congênita, principalmente no período pós-operatório imediato;

- Na literatura Latino-Americana encontramos cinco artigos que envolvessem a temática em estudo e na literatura norte-americana quatro pesquisas que foram pertinentes ao nosso estudo;

- Observamos na literatura Internacional que as pesquisas sobre validação de Diagnóstico de Enfermagem, vêm sendo desenvolvidas desde a década passada enquanto que no Brasil este tipo de pesquisa foi iniciada recentemente;

- Os enfermeiros peritos que alcançaram a pontuação, segundo os critérios de Fehring (1987), se diferenciaram em dois grupos, um que usa os diagnósticos de 
enfermagem da NANDA e os que além de utilizarem os diagnósticos em geral, trabalham com "desobstrução ineficaz de vias aéreas";

- Na validação por especialista, os enfermeiros peritos (70\%) determinaram que a definição do Diagnóstico de Enfermagem "desobstrução ineficaz de vias aéreas" é adequada ao rótulo do diagnóstico e $27,5 \%$ referiram ser pouco adequado. $\mathrm{Na}$ avaliação do título nove enfermeiros sugeriram a troca do nome. Referiram que os termos incapacidade ou limpeza descrevem melhor a definição dada pela NANDA (2006). Disseram também que são termos mais cotidianos para os enfermeiros;

- Nas respostas dos peritos quanto à pertinência do padrão funcional do diagnóstico em estudo, $77.5 \%$ referiram que o padrão funcional mais adequado seria o de eliminação, porém tomando-se por base o conjunto dessas definições do domínio 3 classe 4, os componentes do Diagnóstico de Enfermagem “desobstrução ineficaz de vias aéreas” em especial, as características definidoras e fatores relacionados não descrevem elementos necessários para representar o substantivo e o adjetivo que denota o referido diagnóstico. Em outros casos parece que fica declarado, neste momento, que o domínio e a classe mais adequada para representar os achados está no que foi proposto pela taxonomia II da NANDA.;

- Na análise da Escala de Likert podemos observar que duas características definidoras receberam escore abaixo de 0,50: "vocalização dificultada" e "olhos arregalados"; sete receberam escores maiores que 0,50 e menores que 0,80, sendo consideradas características de menor freqüência: "dispnéia", "murmúrios vesiculares diminuídos", "agitação", "ortopnéia", "cianose”, "tosse ausente" e "expectoração", e, quatro obtiveram escores maior que 0,80 , consideradas as de 
maior freqüência: "tosse ineficaz", "ruídos adventícios respiratórios", "mudanças na freqüência respiratória" e "mudanças no ritmo respiratório";

- As características definidoras: dispnéia, ruídos adventícios respiratórios, tosse ineficaz, tosse ausente, mudanças na freqüência respiratória e mudanças no ritmo respiratório, foram classificadas pelos peritos como "muitíssimo característica" para este diagnóstico.

- Todos os enfermeiros peritos convidados para realizarem a avaliação do instrumento de coleta de dados, expressaram que, ele favorece a formulação dos diagnósticos de enfermagem e que os dados são suficientes para identificar alterações nas necessidades básicas. Referiram que o instrumento é organizado, seqüencial, permitindo fácil entendimento, e, os descritores são de fácil compreensão.

- A validação clínica foi realizada por duas enfermeiras diagnosticadoras que obtiveram um índice de concordância entre si de 97,7\%;

- Na validação clínica, as características definidoras do diagnóstico em estudo foram verificadas na prática em 50 sujeitos (crianças e adolescentes) submetidos à correção cirúrgica de cardiopatia congênita, que fizeram o pós-operatório imediato no Centro de Terapia Intensiva Pediátrico com presença de canulação endotraqueal; as características definidoras mais freqüentes para o diagnóstico em estudo, foram: tosse ausente, murmúrios vesiculares diminuídos, ruídos adventícios, mudança na freqüência respiratória e tosse ineficaz;

- Apontamos algumas considerações importantes nos resultados encontrados: 1 a população escolhida foi muito específica e exige um preparo da enfermeira na avaliação clínica (a coleta de dados); 2 - a amostra atendeu ao tamanho que Fehring (1987) sugere, porém o diagnóstico escolhido tem um elenco grande de 
características definidoras e 3 - na população específica e na coleta de dados no primeiro pós-operatório, temos que considerar que $60 \%$ da nossa amostra encontrava-se anestesiada, isto é, sem expressão de algumas características definidoras.

- Na análise comparativa entre a Validação por Especialista e a Validação Clínica fica comprovado que as características definidoras, que os peritos acreditam estarem presente nos pacientes que apresentam desobstrução ineficaz de vias aéreas, foram encontradas entre $2 \%$ a $68 \%$ da amostra de crianças e adolescentes submetidos à correção cirúrgica de cardiopatia congênita;

- Segundo a metodologia de Fehring (1987), os escores totais obtidos na validação por especialistas foram de 0,71 e de 0,67 na validação clínica;

- Levando em consideração as recomendações propostas por Fehring (1986) de que o nível adequado do escore total deve ser superior a 0,60, podemos afirmar que o Diagnóstico de Enfermagem "desobstrução ineficaz de vias aéreas" foi validado em crianças e adolescentes submetidos à correção cirúrgica de cardiopatia congênita. 


\section{7 - CONSIDERAÇÕES FINAIS}

Além de atingirmos os objetivos do presente estudo, este nos proporcionou uma reflexão objetiva e precisa da assistência de enfermagem a crianças e adolescentes submetidos à correção cirúrgica de cardiopatia congênita.

O local escolhido para a realização desta pesquisa foi o Centro de Terapia Intensiva Pediátrico do HCFMRP-USP, no qual a equipe de enfermagem tem como modelo metodológico da assistência o "Processo de Enfermagem", com utilização da taxonomia da NANDA.

Por meio deste estudo foi possível observar que os enfermeiros do CTIP conseguem, utilizando o "Processo de Enfermagem", promover cuidados especializados e de forma organizados, fundamentados no conhecimento.

O fato de termos escolhido e trabalhado com o Diagnóstico de Enfermagem "desobstrução ineficaz de vias aéreas" e com o fator relacionado "presença de via aérea artificial" resultou na necessidade de analisarmos, não somente a presença ou não do Diagnóstico de Enfermagem, mas levou-nos também a uma reflexão dos cuidados e intervenções necessárias para a população em estudo.

É fundamental desenvolver pesquisas relacionadas à identificação de diagnósticos de enfermagem com o objetivo de direcioná-las à análise de problemas dos pacientes que demandam ações específicas da mesma. Dessa forma pode-se contribuir para o desenvolvimento científico da profissão (ROCHA, 2006).

Conhecer os problemas de saúde de um grupo de pessoas com características comuns poderá direcionar a assistência de enfermagem, fornecendo subsídios para a elaboração de planos de cuidados, Implementação das 
intervenções e avaliação de acordo com as necessidades do paciente (ROCHA, 2006).

A assistência de enfermagem no POI é de fundamental importância dentro do contexto do atendimento multidisciplinar ao paciente grave. $\mathrm{O}$ profissional, nesta unidade, deve ter amplo conhecimento das alterações fisiológicas induzidas pelo ato cirúrgico, estando apto a detectar precocemente alterações que possam comprometer a evolução do paciente, comunicando e discutindo o quadro clínico com a equipe multidisciplinar, para que ações imediatas possam ser tomadas.

Os pacientes que se encontram em POI de correção cirúrgica de cardiopatia congênita exigem uma assistência de enfermagem embasada no conhecimento e habilidades específicas, e cabe ao enfermeiro tomadas de decisões importantes, para um cuidado de alta complexidade.

Refletindo um pouco sobre a questão da validação, concluí que validar é ampliar conhecimentos, reconhecer conceitos / conteúdos das manifestações clínicas, é apropriar-se dos atributos necessários para tomada de decisão com vistas à obtenção de melhores resultados para a assistência.

A experiência deste trabalho me proporcionou visualizar a importância da validação clínica, pois possibilita ao enfermeiro ficar mais próximo da assistência, que confirme sinais e sintomas importantes que sustentem os cuidados prestados e ainda pode ele discutir esses achados com outras categorias profissionais, alicerçando sua assistência com qualidade.

Validar também é um exercício para o desenvolvimento de competência, autonomia e atitude do enfermeiro.

Porém o enfermeiro necessita acreditar mais em sua capacidade e autonomia e aceitar que a enfermagem é uma ciência e que está alicerçada em princípios 
teóricos científicos. Acreditar que somos capazes de prestar uma assistência com qualidade, tendo como base o conhecimento específico da profissão.

Por se tratar de uma população tão específica e em condições especiais, torna-se necessário o desenvolvimento de estudos futuros que possam validar o diagnóstico de "desobstrução ineficaz de vias aéreas" em crianças e adolescentes em outras situações clínicas.

Por fim, realizar este trabalho foi extremamente gratificante, por possibilitar uma visão mais ampla da importância da atuação da Equipe de Enfermagem nos cuidados intensivos às crianças e adolescentes em pós-operatório imediato de cirurgia cardíaca. 


\section{8 - REFERÊNCIAS BIBLIOGRÁFICAS}

ALFARO-LEFEVRE, R. Aplicação do Processo de enfermagem:um guia passo a passo. $4^{a}$ ed. Porto Alegre: Artes Médicas, 2000.

ALLAN, L. D. Isolated major congenital heart disease. Ultrasound Obstet. Gynecol., v. 17, p. 370, 2001.

ALMEIDA, F.A. "Troca de gases prejudicada": diagnóstico e intervençōes de enfermagem relacionados a crianças com cardiopatia congênita cianogênica. Rev. Soc. Cardiol. Estado de São Paulo, V. 4, no. 2 (supl. A), p. 1- 4, mar / abr., 1994.

AMARAL, F.; GRANZOTTI, J.; MANSO, P.H.; CONTI, L.S. de. Quando suspeitar de cardiopatia congênita no recém-nascido. Medicina, v. 35, n. 2, p. 192-197, 2002.

ATKINSON, L. D.; MURRAY, M. E. Fundamentos de enfermagem: introdução ao processo de enfermagem. Rio de Janeiro: Guanabara Koogan, 1989. 618p.

BACALTCHUK, T.; ANTUNES, P.; ZIELINSKY, P. Rastreamento pré-natal de anormalidades cardiacas: papel da ultra-sonografia obstétrica de rotina. RBGO, v. 23, n. 9, p. 553-558, 2001.

BACHION, M. M.; ARAUJO, L. A. O.; SANTANA, R. F. Validação de conteúdo do diagnóstico de enfermagem "mobilidade física prejudicada" em idosos: uma contribuição. Acta Paul. Enfermagem, v. 15, n. 4, p. 66-72, 2002.

BERNSTEIN, D. O sistema cardiovascular. In: BEHRMAN, R. E.; KLIEGMAN, R. M.; JENSON, H. B. Nelson: tratado de pediatria. 16. ed. Rio de Janeiro: Guanabara Koogan, 2002. p. 1318-1433.

BLACK, J. M.; MATASSARIN-JACOB, E. Enfermagem médico-cirúrgica: uma abordagem psicofiológica. $4^{\mathrm{a}}$.ed. Rio de Janeiro: Guanabara Koogan, 1996. v. 1, $1050 \mathrm{p}$.

BOAT, T. F.; ORENSTEIN, D. M. Sintomas respiratórios crônicos ou recorrentes. In: BEHRMAN, R. E.; KLIEGMAN, R. M.; JENSON, H. B. Nelson: tratado de pediatria. $17^{\mathrm{a}}$ ed. Rio de Janeiro: Guanabara Koogan, 2005. p. 1292-1296. 
BRAGA, C. G.; CRUZ, D. A. L. M. A taxonomia II proposta pela North American Nursing Diagnosis Association (NANDA). Rev. Latino-am. Enfermagem, Ribeiräo Preto, v. 11, n. 2, p. 240-244, abril 2003.

CARLSON-CATALANO, J.; LUNNEY, M.; PARADISO, C.; BRUNO, J.; LUISE, B. K.; MARTIN, T.; MASSONI, M.; PACHTER, S. Clinical validation oh ineffective breathing pattern, ineffective airway clearence, and impaired gas exchange. Image: J. Nurs. Schol., Indianapolis, v. 30, n. 3, p. 243-248, third quarter 1998.

CARPENITO, L. J. Diagnósticos de enfermagem: aplicação à pratica clínica. 8. ed. Porto Alegre: Artmed, 2002. 880 p.

CARVALHO, E. C.; ROSSI, L. A.; JESUS, C. A. C. Validação de diagnósticos de enfermagem. In: SIMPÓSIO NACIONAL SOBRE DIAGNÓSTICO DE ENFERMAGEM, 4., 1998, Curitiba. Anais... Curitiba: Associação Brasileira de Enfermagem, 1998. p. 1-15.

CASTELLANOS, B. E. P.; JOUCLAS, V. M. G. Assistência de enfermagem perioperatória: um modelo conceitual. Rev. Esc. Enfermagem USP, Ribeirão Preto, v. 24, n. 3, p. $359-370,1990$.

COREN - CONSELHO REGIONAL DE ENFERMAGEM DO ESTADO DE SÃO PAULO. Documentos básicos de enfermagem: principais leis e resoluções que regulamentam o exercício profissional de enfermeiros, técnicos e auxiliares de enfermagem. São Paulo, 2000.

CORREAA, C. G. Dor: validação clínica no pós-operatório de cirurgia cardiaca. 1997. 128f. Dissertação (Mestrado em Enfermagem) - Escola de Enfermagem de São Paulo, Universidade de São Paulo, São Paulo, 1997.

CHIZZOTTI, A. Pesquisa em ciências humanas e sociais. São Paulo: Cortez, 2000, 164p.

CHRISTENSEN, P.J.; KENNEY, Y.W. Nursing process: application of theories, frameworks, and models. 2.ed. St, louis: Mosby, 1990, 367p.

DALRI, M.C.B. Perfil diagnóstico de pacientes queimados segundo modelo conceitual de Horta e a Taxonomia I da NANDA. 1993. 203 f. Dissertação (Mestrado em Enfermagem Fundamental) - Escola de Enfermagem de Ribeirão Preto, Universidade de São Paulo, Ribeirão Preto, 1993. 
DALRI, M. C. B. Assistência de enfermagem a paciente portador de queimadura utilizando um software. 2000. $328 \mathrm{f}$. Tese de doutorado (Doutorado em Enfermagem Fundamental) - Escola de Enfermagem de Ribeirão Preto, Universidade de São Paulo, Ribeirão Preto, 2000.

DALRI, C. C. Diagnósticos de Enfermagem de Pacientes em período pósoperatório imediato de cirurgia de colicistectomia laparoscópica. 2005. 196f. Dissertação (mestrado em Enfermagem Fundamental) - Escola de Enfermagem de Ribeirão Preto, Universidade de São Paulo, Ribeirão Preto, 2005.

DIAS, F. S. et al. Ventilação mecânica prolongada após cirurgia cardiaca. Arq. Bras. Cardiol., São Paulo, v. 59, n. 4, p. 269-273, 1992.

DiCARLO, J. V.; FRANKEL, L. R. Sistemas de escore e fatores preditivos da mortalidade. In: BEHRMAN, R. E.; KLIEGMAN, R. M.; JENSON, H. B. Nelson: tratado de pediatria. $17^{\mathrm{a}}$. ed. Rio de Janeiro: Guanabara Koogan, 2005. p. 249.

DOENGES, M. E.; MOORHOUSE, M. F. Nursing diagnoses with interventions. In: DOENGES, M. E.; MOORHOUSE, M. F. Nurses's pocket guide: nursing diagnosis with interventions. $3^{\text {a }}$. ed. Philadelphia: F.A. Davis, 1991.

DOHERTY, M. H. Agitação e delírio. In: SCHELL, H. M.; PUNTILLO, K. A. Segredos em enfermagem na terapia intensiva. Porto Alegre: Artmed, 2005. p. 423-427.

DOYLE, R. L. Assessing and modifying the risk of postoperative pulmonary complications. Chest, Northbrook, v. 115, p. 77-82, 1999.

EILOFT, L.; FUIVIMEISTER, J.; DIAS, V.; VERA, L. Enfermagem em UTI pediátrica. Rio de Janeiro: MEDSI, 1996.

EMMANOUILIDES, G. C.; ALLEN, H. D.; RIEMENSCHNEIDER, T. A.; GUTGESELL, H. P. Moss e Adams' doenças do coração na criança e no adolescente (incluindo feto e adulto jovem). Rio de Janeiro: MEDSI, 2000.

FARIA, M. de F. G. Diagnósticos de enfermagem respiratórios em pacientes cardíacos cirúrgicos. 2000, 170 f. Dissertação (Mestrado em Enfermagem Fundamental) - Escola de Enfermagem de Ribeirão Preto, Universidade de São Paulo, Ribeirão Preto, 2000. 
FARIAS, J. N. et al. Diagnóstico de enfermagem: uma abordagem conceitual e prática. João Pessoa: Santa Marta, 1990. 160 p.

FEHRING, R. J. Validation diagnostic labels: standardized methodology. In: HURLEY, M. E. et al. (Ed.). Classification of nursing diagnoses: proceedings of the sixth conference of North American Nursing Diagnoses Association. St. Louis: C. V. Mosby, 1986. p. 183-190.

FEHRING, R. J. Methods to validate nursing diagnoses. Heart and Lung, St. Louis, v.16, n. 6 , p. 625-629, Nov. 1987.

FEHRING, R. J. The Fehring model. In: CARROL-JOHNSON, R. M.; PAQUETE, M. (Ed.). Classification of nursing diagnoses: proceedings of the Tenth Conference. Philadelphia: J. B. Lippincott, 1994. p. 55-62.

FERREIRA, A. B. H. Novo dicionário da língua portuguesa. $4^{\mathrm{a}}$. ed. Rio de Janeiro: Nova Fronteira, 1998.

FERREIRO, C. R.; ROMANO, E. R.; BOSISIO, I. B. J. Pós-operatório nas cardiopatias congênitas. Rev. Soc. Cardiol. Estado de São Paulo, v. 12, n. 5, p. 776 - 786, set./out. 2002.

FINIGAN, M.; WARM, J. Ventilary considerations in cardiac patients. Nurs. Clin. North Am., v. 7, n. 3, p. 541-548, Sep. 1972.

FLORES, C.; GALLARDO, N. Cuidados de enfermeria al niño cardiopata. Medicina Infantil, v. 4, n. 2, p.127-131, junio 1997.

GALDEANO, L. E. Diagnósticos de Enfermagem de pacientes no período perioperatótio de cirurgia cardíaca. 2002. 180 f. Dissertação (Mestrado em Enfermagem Fundamental) - Escola de Enfermagem de Ribeirão Preto, Universidade de São Paulo, Ribeirão Preto, 2002.

GALDEANO, L. E.; ROSSI, L. A.; NOBRE, L. F.; IGNÁCIO, D. S. Diagnóstico de enfermagem de pacientes no transoperatório de cirurgia cardíaca. Rev. Latino Am. Enfermagem, v. 11, n. 2, mar. /abril, 2003. 
GARCÍA, H.; JIMÉNEZ, A. R.; SILVA, R. V.; RODRÍGUEZ, L.; CANELO, M. V. Sobrevida al egreso hospitalario de recién nascidos com cardiopatias congênitas sometidos a cirugía cardiaca o cateterismo intervencionista. Rev. Invest. Clin., v. 54, n. 4, 2002.

GEORGE-GAY, B.; PARKER, K. Understanding the complete blood count with differential. J. PeriAnesth. Nurs., v. 18, n. 2, p. 96-117, 2003.

GOLDMAN, L.; BRAUNWALD, E. B. Exame clinico. In: GOLDMAN, L.; BRAUNWALD, E. B. Cardiologia na clínica geral. Rio de Janeiro: Guanabara Koogan, 2000. Cap. 3, p. 26-42.

GORDON, M. Nursing diagnosis: process and application. $3^{\text {a }}$ ed. Mosby, 1994.

GORDON, M.; SWEENEY, M. A. Methodologycal problems and issues in identifying and standardizing nursing diagnosis. Adv. Nurs. Sci., Hagerstown, v. 2, n. 1, p. 115, jan. 1979.

GRIFFITH - KENNEY, J. W.; CHRISTENSEN, P. Nursing process: application of theories, frameworks and models. 2. ed. St. Louis: Mosby, 1986. 429 p.

GUERRIERO, A.L.S.; ALMEIDA, F.A.; GUIMARĀES, H.C.Q.C.P.. Diagnósticos de enfermagem infantil no primeiro pós-operatório de cirurgia cardiaca. Acta Paul. Enf., São Paulo, v. 16, n. 1, p. $14-21,2003$.

GUYTON, A. C. Fisiologia humana e mecanismos das doenças. 5. ed. Rio de Janeiro: Guanabara Koogan, 1993.

HADDAD, G. G.; FONTÁN, J. P. Mecanismo de defesa e funções metabólicas dos pulmōes. In: BEHRMAN, R. E.; KLIEGMAN, R. M.; JENSON, H. B. Nelson: tratado de pediatria. 17.ed. Rio de Janeiro: Guanabara Koogan, 2005. p. 1234.

HADDAD, G. G.; PALAZZO, R. M. Abordagem diagnóstica das doenças do respiratórias: In: BEHRMAN, R. E.; KLIEGMAN, R. M.; JENSON, H. B. Nelson: tratado de pediatria. 17.ed. Rio de Janeiro: Guanabara Koogan, 2005. p. 1236-40.

HANLEY, M. V.; TYLER, M. L. Ineffective airway clearance related to airway infection. Nurs. Clin. North Am., lowa City, v. 22, n. 1, p. 135-150, March 1987. 
HOEKELMAN, R. A. Exame físico de lactentes e crianças. In: BICKLEY, L. S.; HOEKELMAN, R. A. Bates propedêutica médica. 7.ed. Rio de Janeiro: Guanabara Koogan, 2001. p. 579-673.

HOFFMAN, L. A. Ineffective airway clearence related to neuromuscular dysfunction. Nurs. Clin. North Am., lowa City, v. 22, n. 1, p. 151-166, March 1987.

HOFFMAN, J. I. E.; CHRISTIANSON, R. Congenital heart disease in a cohort of 19502 births with long-term follow-up. Am. J. Cardiol., v. 42, n. 4, p. 641-647, 1978.

HORTA, W. de A. Processo de enfermagem. São Paulo: EDUSP, 1979. 99 p.

HOSKINS, L. M. Clinical validation, methodologies for nursing diagnoses research. In: CAAROL JOHNSON, R. M. et al. (Ed.). Classification of nursing diagnoses: proceedings of the eighth conference of North American Nursing Diagnosis Association. Philadelphia: Lippincott, 1989. Cap. 19, p. 126-131.

UNIVERSIDADE DE SÄO PAULO. Relatório de atividades do Hospital das Clínicas da Faculdade de medicina de Ribeirão Preto . Ribeirão Preto, 2006. p. 150 .

HUNGRIA, H. Ouvidos, nariz, seios paranasais, faringe e laringe. In: PORTO, C. C. Semiologia médica. 4.ed. Rio de Janeiro: Guanabara Koogan. 2001. p. 271-318.

IDVAL, E. et al. Quality indicator in postoperative pain management: a validation study. Scand J Caring Sci, Sweden, v. 15, n. 1, p. 331-338, jan. 2001.

IYER, P. W.; TAPTICH, B. J.; BERNOCCHI-LOSEY, D. Processo e diagnóstico de enfermagem. Porto Alegre: Artes Médicas, 1993. 325 p.

JARVIS, C. Exame físico e avaliação de saúde. Rio de Janeiro: Guanabara Koogan, 2002.

JATENE, M. B. Tratamento cirúrgico das cardiopatias congênitas acianogênicas e cianogênicas. Rev. Soc. Cardiol. Estado de São Paulo, v. 12, n. 5, p. 763-775, set./out. 2002. 
JANSEN, D.; SILVA, K. V. P. T.; NOVELLO, R.; GUIMARÃES, T. C. F.; SILVA, V. G. Assistência de enfermagem à criança portadora de cardiopatia. Rev. SOCERJ, v. 13, n. 1, p. 22-29, 2000.

JESUS, C. A. C. Assistência de enfermagem a clientes hematológicos: uma visão sistêmica. 1992. 279 f. Dissertação (Mestrado em Enfermagem Fundamental) - Escola de Enfermagem de Ribeirão Preto, Universidade de São Paulo, Ribeirão Preto, 1992.

JESUS, C. A. C. Evolução histórica do diagnostico de enfermagem e sua aplicabilidade no planejamento da assistência. Rev. Saúde Distrito Federal, v. 6, n. 1/2, jan./jun. 1995.

JESUS, C. A. C. Raciocínio clínico de graduandos e enfermeiros na construção de diagnósticos de enfermagem. 2000. 232 f. Tese (Doutorado em Enfermagem Fundamental) - Escola de Enfermagem de Ribeirão Preto, Universidade de São Paulo, Ribeirão Preto, 2000.

KELLY, D.J. The identification and clinical validation of the defining characteritics of alteration in cardiac tissue perfusion. In: CARROL-JONHSON. R. M. (Ed.). Calssification of nursing diagnoses: proceeding of the ninth Conference. Philadelphia: J.B. Linppincott, 1990. p. 105-111.

KENNEY, J. W. Relevance of theoretical approaches in nursing pratice. In: CHRISTENSEN, P. J.; KENNEY, Y. W. (Ed.). Nursing process: Nursing process: application of theories, frameworks, and models. 2.ed. St. Louis: Mosby, 1990. Cap.1, p. 3-19.

KIN, M. J.; LARSON, J. L. I neffective airway clearance and ineffective breading patterns. Nurs. Clin. North Am., Philadelphia, v. 22, n. 1, p. 125-134, March 1987.

LEOPARDI, M. T. Teorias em enfermagem: instrumentos para a prática. Florianópolis: Papa-Livros, 1999. p. 226.

LEVIN, R. F. Diagnostic content validity of nursing diagnoses. IMAGE: Journal of Nursing Scholarship, Spring, v. 21, n. 1, p. 40-44, jan. 1990.

MASLOW, A. H. Motivation and personality. 2 $2^{\text {a }}$ ed. New York: Harper \& Row, 1970. 369 p. 
MATHERS, L. H.; FRANKEL, L. R. Estabilização da criança criticamente enferma: In: BEHRMAN, R. E.; KLIEGMAN, R. M.; JENSON, H. B. Nelson: tratado de pediatria. 17.ed. Rio de Janeiro: Guanabara Koogan, 2005. p. 249-272.

MELO, A. S. Validação dos diagnósticos de enfermagem disfunção sexual e padrões de sexualidade ineficaz. 2004. 197 f. Tese (Doutorado em Enfermagem Fundamental) - Escola de Enfermagem de Ribeirão Preto, Universidade de São Paulo, Ribeirão Preto, 2004.

MICHAELIS Moderno dicionário da lingua portuguesa. São Paulo: Melhoramentos, 2005. 951p.

MICHEL, J. L. M. Adaptação transcultural da taxonomia II de diagnósticos de enfermagem da NANDA (North American Nursing Diagnosis Association) ao contexto Brasileiro. 2003. 150 f. Tese (Doutorado) - Escola de Enfermagem da Universidade Federal de São Paulo, Universidade Federal de São Paulo, São Paulo, 2003.

MILES, W. M.; ZIPES, D. P. Doenças cardiovasculares. In: ANDREOLI, T. E. et al. CECIL: medicina interna básica. 3.ed. Rio de Janeiro: Guanabara Koogan, 1994. Cap. 1, p. 2-212.

MOHANA, J. O mundo e eu. 2.ed. Rio de Janeiro: Agir, 1964.

MONAHAN, F. D. et al. Nursing care of adults. Philadelphia: Saunders, 1994.

NORTH AMERICAN NURSING DIAGNOSIS ASSOCIATION - NANDA. Diagnóstico de enfermagem da NANDA: definições e classificação, 1990-2000. Porto Alegre: Artmed, 1999.

NORTH AMERICAN NURSING DIAGNOSIS ASSOCIATION - NANDA. Diagnóstico de enfermagem da NANDA: definiçōes e classificação, 2005-2006. Porto Alegre: Artmed, 2006.

NAPOLEÃO, A. A. Estudo da aplicabilidade de intervenções da NIC no atendimento a crianças com o diagnóstico de enfermagem "desobstrução ineficaz de vias aéreas relacionada à presença de via aérea artificial" em um centro de terapia intensiva pediátrico. 2005. $300 \mathrm{f}$. Tese (Doutorado em Enfermagem Fundamental) - Escola de Enfermagem de Ribeirão Preto, Universidade de São Paulo, Ribeirão Preto, 2005. 
NOMA, H. H.; MALTA, M.A.; NISHIDE, V. M. Assistindo ao paciente em pós operatório na UTI - aspectos gerais. 2004. Disponivel em:

http://www.hospvirt.org.br/enfermagem/port/posoputi.htm , 2006

OLIVA, A. P.. Diagnóstico de débito cardíaco diminuído: validação clínica no pósoperatório de cirurgia cardiaca. 2000.113. Dissertação (Mestrado em Enfermagem) - Escola de Enfermagem da Universidade de São Paulo, Universidade de São Paulo, São Paulo, 2000.

OLIVEIRA, N. M. S. Diagnóstico de enfermagem de ansiedade - validação da definição das caracteristicas definidoras. 2001. 94 f. Dissertação (Mestrado em Enfermagem) - Escola de Enfermagem da Universidade Federal de Minas Gerais, Universidade Federal de Minas Gerais, Belo Horizonte, 2001.

ORENSTEIN, D. M. Bronquite, poluição do ar e tabagismo. In: BEHRMAN, R. E.; KLIEGMAN, R. M.; JENSON, H. B. Nelson: tratado de pediatria. 17.ed. Rio de Janeiro: Guanabara Koogan, 2005. p. 1265-1267.

PERNETTA, C. Semiologia pediátrica. Rio de Janeiro: Guanabara Koogan. 1990.

PILLITTERI, A. Child health nursing: care of the child and family. Philadelphia: Lippincott, 1999.

PIMENTA, C. A. M. et al. Dor: ocorrência e evolução no pós-operatório de cirurgia cardiaca e abdominal. Rev. Paul. Enfermagem, v. 11, n. 1, p. 3-10, 1992.

PIMENTA, C. A. M. et al. O ensino da avaliação do paciente: delineamento do conteúdo pelo diagnóstico de enfermagem. Rev. Latino-Am. Enfermagem, v. 2, n. 1, p. 69-73, jul. 1993.

PINTO JÚNIOR, V. C. et al. Situação das cirurgias cardiacas congênitas no Brasil. Braz. J. Cardiovasc. Surg., São José do Rio Preto, v. 19, n. 2, p.3-6, abr./jun. 2004.

PIVA, J. P.; CARVALHO, P.; GARCIA, P. C. Terapia intensiva em pediatria. 4.ed. Rio de Janeiro: Medsi, 1997. 1002 p.

POLIT, D.; HUNGLER, B. P. Coleta de dados da pesquisa. In: Fundamentos da pesquisa em enfermagem. Porto Alegre: Artes Médicas Sul, 1995. p. 163-219. 
PORTO, C. C. Semiologia médica. 4.ed. Rio de Janeiro: Gaunabara Koogan, 2001. $1428 \mathrm{p}$.

POTTER, P. A.; PERRY, A. G. Grande tratado de enfermagem prática: conceitos básicos, teorias e prática hospitalar. 2.ed. São Paulo: Ed. Santos, 2005. 999 p.

ROCHA, L. A.; MAIA, T. F.; SILVA, L. F. Diagnóstico de enfermagem em pacientes submetidos à cirurgia cardiaca. Rev. Bras. Enferm., v. 59, n. 3, p. 321-326, maiojun., 2006.

ROSSI, L. A. O processo de enfermagem em uma unidade de queimados: análise e reformulação fundamentada na metodologia da problematização. 1992. 222 f. Dissertação (Mestrado em Enfermagem Fundamental) - Escola de Enfermagem de Ribeirão Preto, Universidade de São Paulo, Ribeirão Preto, 1992.

RUVINSKI, R.; BALANZAL, M. C. Pneumonias bacterianas e virais. In: BENGUIGUI, Y. et al. Infecções respiratórias em crianças. Washington: OPAS/OMS, 1998. p. 217-251.

SANTANA, M. E.; SAWADA, N. O. Paciente laringectomizado total: validação das características definidoras para o diagnóstico de enfermagem comunicação prejudicada. Rev. Bras. Enfermagem, Brasilia, v. 55, n. 6, p. 658-663, nov./dez. 2002.

SENRA, D. F.; IASBECH, J. A.; OLIVEIRA, S. A. Pós-operatório em cirurgia cardiaca de adultos. Rev. Soc. Cardiol. Estado de São Paulo, São Paulo, v. 8, n. 3, p. 446454, 1998.

SCHNITZLER, E. J et al. Cuidados pós-operatórios em cirurgia cardiaca. In: PIVA, J. P.; CARVALHO, P.; GARCIA, P. C. Terapia intensiva em pediatria. 4.ed. Rio de Janeiro: Medsi, 1997, p. 708-729.

SHEKLETON, M. E.; NIELD, M. Ineffective airway clearance related to artificial airway. Nurs. Clin. North Am., Philadelphia, v. 22, n. 1, p. 167-178, March 1987.

SLY, R. M. Doenças alérgicas. In: BEHRMAN, R. E.; KLIEGMAN, R. M. JENSON, H. B. Nelson: tratado de pediatria. 17.ed. Rio de Janeiro: Guanabara Koogan, 2005. p. 640-690. 
SHEKLETON, M. E.; NIELD, M. Ineffective airway clearance related to artificial airway. Nurs. Clin. North Am., v. 22, n. 1, p. 167-178, 1987.

SILVA, V. M. da; LOPES, M. V. O.; ARAUJO, T. L. Diagnósticos de enfermeria y problemas colaboradores em niños com cardiopatías congênitas. Rev. Mex. Enf. Cardiol.,, v. 12, n. 2, p. $50-55,2004$ a.

SILVA, V.M. da; LOPES, M. V. O.; ARAUJO, T. L. Asociación entre diagnósticos de enfermería em niños con cardiopatias congênitas. Enf. Cardiol., año 11, p. 33-37, 2004b.

SILVA, V. M. da. Caracterização de diagnósticos de enfermagem em crianças com cardiopatia congênita: estudo num hospital especializado em doenças cardiopulmonares. 2005. Dissertação (Mestrado em Enfermagem) - Escola de Enfermagem da Universidade Federal do Ceará, Universidade Federal do Ceará, Fortaleza, 2005.

SILVA, V. M. da; LOPES, M. V. O.; ARAUJO, T. L. Evolução dos diagnósticos de enfermagem de crianças com cardiopatias congênitas. Rev. Latino-Am. Enfermagem, v. 14, n. 4, jul. / ago, 2006.

SILVEIRA, F. M. R. C. et al. Alterações da hemostasia em crianças submetidas a cirurgia cardiaca com circulação extracorpórea. Arq Bras Cardiol, v. 70, n. 1, p. 2935, 1998.

SMELTEZER, S. C.; BARE, B. G. Brunner e Suddarth: tratado de enfermagem médico-cirurgica. 10ª ed., Rio de Janeiro: Guanabara Koogan, 2005.

SOUZA, M. F.; GUTIERREZ, M. G. R.; CASTRO, R. A. P. Análise da teoria das necessidades humanas básicas de Wanda de Aguiar Horta. In: SIMPÓSIO BRASILEIRO DE TEORIAS DE ENFERMAGEM, 1., 1985, Florianópolis. Anais... Florianópolis: Universidade Federal de Santa Catarina, 1985. p. 209.

SOUZA, M. F. Aplicabilidade das teorias de enfermagem. Rev. Esc. Enfermagem USP, v. 22, n. especial, p. 62-67, jun. 1988.

SOUZA, M. H. L.; ELIAS, D. O. Resposta inflamatória sistêmica à circulação extracorpórea. In: SOUZA, M. H. L.; ELIAS, D. O. Fundamentos da circulação extracorpórea. Cap. 21, p. 374-391, 1999. 
TARANTINO, A. B. Sistema respiratório. In: PORTO, C. C. Semiologia médica. 4.ed. Rio de Janeiro: Guanabara Koogan, 2001. p. 319-418.

TURINO, G. M. Abordăgem do paciente com doença respiratória. In: GOLDMAN, L.; BENNET, J. C. Cecil: tratado de medicina interna. 21.ed. Rio de Janeiro: Guanabara Koogan, 2001. p. 419-422. v. 1.

VIÑALS, F.; GIULIANO, A. Cardiopatias congénitas: incidencia antenatal. Rev. Chil. Obstet. Ginecol., v. 67, n. 3, p. 203-206, 2002a.

VIÑALS, F.; GIULIANO, A. Cardiopatias congénitas: incidencia postnatal (II). Rev. Chil. Obstet. Ginecol., v. 67, n. 3, p. 207-210, 2002b.

WARREM, J. Accountability and nursing diagnosis. J. Nurs. Adm., v. 13, n. 10, p. 34-37, 1983.

WEINBERGER, S. E. Fundamentos de pneumologia. Porto Alegre: Artes Médicas, 1989.

WONG, D. L.; WHALEY, L. F. Enfermagem pediátrica: elementos essenciais à intervenção efetiva. Rio de Janeiro: Guanabara Koogan, 1999.

WHITLEY, G. G. Processes and methodologies for research validation of nursing diagnoses. Nurs. Diagn., Philadelphia, v. 10, n. 1, p. 5-13, Jan. 1999.

WOODTLI, A. Stress incontinence: clinical identification and validation of definig characteristics. Nurs. Diagn., Philadelphia, v. 6, n. 3, p. 115-122, Jul. 1995. 


\section{APÊNDICE A - Instrumento de coleta de dados da validação por especialistas}

\section{PARTE A - CARACTERIZAÇÃO DOS SUJEITOS}

Com a finalidade de caracterizar a experiência dos respondentes na área de interesse, solicitamos sua colaboração respondendo os itens abaixo:

- Tempo de experiência profissional: anos.

- Você trabalha com os diagnósticos de enfermagem da NANDA?
( ) Sim
( ) Não
se Sim , especifique a área e o tempo de experiência:
( ) Ensino
( ) menos de 1 ano
( ) Pesquisa
( ) Mais de 1 ano
( ) Extensão

- Titulação acadêmica
( ) Graduação
( ) Especialista - Tema da Monografia;
( ) Mestrado - Tema da Dissertação:
( ) Doutorado - Tema da tese:

- Possui algum trabalho (s) ou atividade (s) científica que realizou abordando o tema diagnóstico de enfermagem?
( ) Dissertação de mestrado
( ) Tese de doutorado
( ) Publicação de artigos em periódicos / revistas
( ) Publicação de trabalho de pesquisa
( ) Apresentação de trabalhos em eventos científicos
( ) Outros. Especifique:

- Realiza trabalho(s) ou atividade(s) científica que aborda o tema Desobstrução ineficaz de vias aéreas?
( ) Dissertação de mestrado
( ) Tese de doutorado
( ) Publicação de artigos em periódicos / revistas
( ) Publicação de trabalho de pesquisa
( ) Apresentação de trabalhos em eventos científicos
( ) Outros. Especifique: 


\section{PARTE B - VALIDAÇÃO DO DIAGNÓSTICO DE ENFERMAGEM}

A literatura mostra a necessidade de uma revisão do diagnóstico em análise quanto à sua definição, padrão funcional de saúde em que está incluído e pertinência de suas características definidoras. Diante de tal situação, venho solicitar sua ajuda. Inicialmente, solicitamos uma leitura atenta para a definição do diagnóstico de enfermagem Desobstrução ineficaz de vias aéreas, para os domínios e classes. Retorne a definição sempre que julgar necessário. Prosseguindo, assinale com um X, uma das alternativas das questões apresentadas:

Diagnóstico de enfermagem Desobstrução ineficaz de vias aéreas: "incapacidade de eliminar secreções ou obstruções do trato respiratório pra manter uma via aérea desobstruída" (NANDA, 2005 - 2006, p.84).

Domínio 1 - Promoção da Saúde : "a consciência de bem-estar ou a normalidade de função e as estratégias utilizadas para manter sob controle ou aumentar esse bem-estar ou normalidades de função" (NANDA, 2005 - 2006, p.262).

Classe 1 - Consciência da Saúde: "reconhecimento da função normal e do bem-estar";

Classe 2 - Controle da Saúde: "identificar, controlar, realizar e integrar atividades para manter a saúde e o bem estar";

Domínio 2 - Nutrição: "as atividades de ingerir, assimilar e utilizar nutrientes para fins de manutenção dos tecidos, reparação de tecidos e produção de energia" (NANDA, 2005 - 2006, p.262 e 263).

Classe 1 - Ingestão: "introdução de alimentos ou nutrientes no organismo" Classe 2 - Digestão: "as atividades físicas e químicas que convertem gêneros alimentícios em substancias adequadas para a absorção e assimilação"

Classe 3 - Absorção: "o ato de absorver os nutirentes pelos tecidos do organismo"

Classe 4 - Metabolismo: "os processos químicos e físicos que ocorrem em organismos vivos e células para o desenvolvimento e a utilização de 
protoplasma e produção de resíduos e energia, com a liberação de energia para todos os processos vitais"

Classe 5 - Hidratação: "a ingestão e absorção de fluidos e eletrólitos"

Domínio 3 - Eliminação e Troca: "secreção e excreção dos produtos residuais do metabolismo do organismo" (NANDA, 2005 - 2006, p.263).

Classe 1 - Sistema Urinário: "o processo de secreção e excreção de urina";

Classe 2 - Sistema Gastrintestinal: "excreção e expulsão de excrementos pelo intestino";

Classe 3 - Sistema Tegumentar: "processo de secreção e excreção através da pele";

Classe 4 - Sistema Pulmonar: "remoção de produtos secundários de processos metabólicos, secreções e corpos estranhos do pulmão ou brônquios";

Domínio 4 - Atividade I Repouso: "a produção, conservação, gasto ou balanço de recursos energéticos" (NANDA, 2005 - 2006, p. 263 e 264).

Classe 1 - Sono / Repouso: "Sono, repouso, ócio ou inatividade";

Classe 2 - Atividade I Exercício: "mover partes do corpo (mobilidade), realizar trabalho ou desempenhar ações com freqüência (mas não sempre) contra resistência";

Classe 3 - Equilíbrio de energia: "um estado dinâmico de harmonia entre o influxo e o gasto de recursos";

Classes 4 - Resposta Cardiovasculares I Pulmonares: "mecanismo cardiopulmonar que apóiam a atividade / repouso";

Domínio 5 - Percepção / Cognição: "o sistema humano de processamento de informações, incluindo atenção, orientação, sensação, percepção, cognição e comunicação" (NANDA, 2005 - 2006, p.264 e 265).

Classe 1 - Atenção: "disposição mental para tomar conhecimento ou observar";

Classe 2 - Orientação: "consciência de tempo, lugar e pessoa";

Classe 3 - Sensação / Percepção: "receber informações pelos sentidos de tato, paladar, olfato, visão, audição e cinestesia, e a compreensão dos dados 
provenientes desses sentidos resultar em nomear, associar e/ou reconhecer padrões";

Classe 4 - Cognição: "uso da memória, aprendizagem, pensamento, resolução de problemas, abstração, julgamento, discernimento, capacidade intelectual, calculo e linguagem";

Classe 5 - Comunicação: "enviar e receber informações verbais e não verbais";

Domínio 6 - Autopercepção: "consciência quanto a si mesmo" (NANDA, 2005 2006, p.265 e 266).

Classe 1 - Autoconceitos: "a (s) percepção (ões) quanto ao seu total";

Classe 2 - Auto-estima: "avaliação de alguem quanto ao seu próprio valor, capacidade, importância e sucesso";

Classe 3 - Imagem Corporal: "uma imagem mental que alguém tem de seu próprio corpo".

Domínio 7 - Relacionamentos de Papel: "as conexões ou associações positivas e negativas entre pessoas ou grupos de pessoas e os meios pelos quais essas conexões são demonstradas" (NANDA, 2005 - 2006, p.266).

Classe 1 - Papéis do Cuidador: "padrões de comportamento socialmente esperados de pessoas que estão provendo cuidados e que não são profissionais da saúde";

Classe 2 - Relações Familiares: "associações de pessoas que são biologicamente relacionadas ou relacionadas por escolha";

Classe 3 - Desempenho de Papel: "qualidade de estar funcionando em padrões de comportamento socialmente esperados".

Domínio 8 - Sexualidade: "identidade sexual, função sexual e reprodução" (NANDA, 2005 - 2006, p.267).

Classe 1 - Identidade sexual: "o estado de ser uma pessoa específica em relação à sexualidade e/ou gênero";

Classe 2 - Função Sexual: "a capacidade ou habilidade para participar de atividades sexuais"; 
Classe 3 - Reprodução: "qualquer processo por meio do qual novos indivíduos (pessoas) são produzidos";

Domínio 9 - Enfrentamento / Tolerância ao estresse: "lutar contra os eventos / processos da vida" (NANDA, 2005 - 2006, p.267 e 268).

Classe 1 - Resposta Pós Trauma: "reações que ocorrem após trauma físico ou psicológico";

Classe 2 - Respostas de Enfrentamento: "o processo de controlar o estresse ambiental";

Classe 3 - Estresse Neuro comportamental: "respostas comportamentais que refletem a função cerebral e nervosa"

Domínio 10 - Princípios de vida: "princípios nos quais são baseados a conduta, o pensamento e o comportamento quanto a atos, costumes ou instituições, encarados como verdadeiros ou como dotados de valor intrínseco" (NANDA, 2005 - 2006, p.268).

Classe 1 - Valores: "a identificação e classificação dos modos de conduta ou estados finais preferidos";

Classe 2 - Crenças: "opiniões, expectativas ou julgamentos sobre atos, costumes ou instituições, encarados como verdadeiros ou como dotados de valor intrínseco";

Classe 3 - Congruência entre Valores I Crenças I Ações: "a correspondência ou equilíbrio encontrado entre valores, crenças e ações"

Domínio 11 - Segurança / Proteção: "estar livre de perigo, lesão física ou dano do sistema imunológico, preservação contra perdas e proteção da segurança e seguridade" (NANDA, 2005 - 2006, p.268 e 269).

Classe 1 - Infecção: "resposta do hospedeiro após invasão patogênica";

Classe 2 - Lesão Física: "dano ou ferimento corporal";

Classe 3 - Violência: "a aplicação de forca ou potencia excessiva de modo a causar lesão ou abuso";

Classe 4 - Riscos Ambientais: "fontes de perigo nos arredores";

Classe 5 - Processos Defensivos: "os processos por meio dos quais a pessoa protege a si mesma contra fatores externos"; 
Classe 6 - Termorregulação: "o processo fisiológico de regular calor e energia no corpo, com o propósito de proteger o organismo";

Domínio 12 - Conforto: "Sensação de bem-estar ou conforto mental, físico ou social' (NANDA, 2005 - 2006, p.270).

Classe 1 - Conforto Físico: "sensação de bem-estar ou conforto";

Classe 2 - Conforto Ambiental: "sensação de bem-estar ou conforto no ou com o ambiente em que está a pessoa";

Classe 3 - Conforto Social: "sensação de bem-estar ou conforto da pessoa com as suas situações sociais".

Domínio 13 - Crescimento / Desenvolvimento: "aumentos apropriados para a idade nas dimensões físicas e nos sistemas orgânicos e/ou a consecução de estágios de desenvolvimento" (NANDA, 2005 - 2006, p.270).

Classe 1 - Crescimento: "aumentos nas dimensões físicas ou maturidade sistemas orgânicos";

Classe 2 - Desenvolvimento: "consecução, falta de consecução ou perda de estágios de desenvolvimento". 


\section{PERGUNTAS:}

1) Em qual padrão funcional de saúde você considera pertinente a inclusão do diagnóstico de enfermagem Desobstrução ineficaz de vias aéreas:
( ) promoção de saúde
( ) nutrição
( ) eliminação
( ) atividade / repouso
( ) percepção / cognição
( ) auto percepção
( ) relacionamentos de papel
( )sexualidade
( ) enfrentamento / tolerância ao estresse
( ) princípios de vida
( ) segurança / proteção
( ) conforto
( ) crescimento / desenvolvimento

Comentários:

2) Você considera o rótulo (ou título) Desobstrução ineficaz de vias aéreas adequado à definição apresentada pela NANDA?
( ) Adequada
( ) Pouco adequada
( ) Nada adequada

Comentários:

No seguinte passo, você deverá assinalar, com base em sua experiência profissional e conhecimentos, sua opinião quanto à pertinência de cada característica definidora para o diagnóstico Desobstrução ineficaz de vias aéreas. Assinale apenas uma possibilidade de pertinência para cada característica definidora.

No final, no item SUGESTÕES, você poderá acrescentar novas características definidoras para o referido diagnóstico de enfermagem, colocando sua pertinência logo em seguida e sua definição operacional. Obrigado! 
Parte C - Desobstrução Ineficaz de Vias Aéreas: "incapacidade de eliminar secreções ou obstruções do trato respiratório pra manter uma via aérea desobstruída" (NANDA, 2005 - 2006, p.84).

\begin{tabular}{|c|c|c|c|c|c|}
\hline Característica Definidora e Definição: & $\begin{array}{l}\text { Não } \\
\text { Característica }\end{array}$ & $\begin{array}{l}\text { Muito Pouco } \\
\text { Característica }\end{array}$ & $\begin{array}{l}\text { De algum modo } \\
\text { Característica }\end{array}$ & $\begin{array}{l}\text { Muito } \\
\text { Característica }\end{array}$ & $\begin{array}{l}\text { Muitíssimo } \\
\text { Característica }\end{array}$ \\
\hline $\begin{array}{l}\text { DISPNÉIA } \\
\text { É a dificuldade para respirar (TARANTINO, 2001). }\end{array}$ & & & & & \\
\hline $\begin{array}{l}\text { MURMURIOS VESICULARES DIMINUÍDOS } \\
\text { Murmúrio vesicular é o ruído respiratório produzido pela } \\
\text { turbulência do ar circulante ao chocar-se com as saliências das } \\
\text { bifurcações brônquicas, ao passar por cavidades de tamanhos } \\
\text { diferentes, tais como os bronquíolos para os alvéolos, e vice } \\
\text { versa (TARANTINO, 2001). } \\
\text { Murmúrios vesiculares diminuídos é a redução do sons } \\
\text { respiratórios. }\end{array}$ & & & & & \\
\hline $\begin{array}{l}\text { ORTOPNÉIA } \\
\text { É a dispnéia que impede o paciente de ficar deitado e o obriga a } \\
\text { assentar-se ou a ficar de pé para obter algum alívio } \\
\text { (TARANTINO, 2001). }\end{array}$ & & & & & \\
\hline $\begin{array}{l}\text { RUÍDOS ADVENTÍCIOS (ESTERTORES, CREPTAÇÕES, } \\
\text { RONCOS, SIBILOS) } \\
\text { Estertores: sons anormais descontínuos. São ruídos audíveis na } \\
\text { inspiração ou na expiração, superpondo-se aos sons respiratórios } \\
\text { normais (TARANTINO, 2001). } \\
\text { Crepitação ou estertores crepitantes: são ruídos audíveis no final } \\
\text { da inspiração e têm freqüência alta, isto é, são agudos e de curta } \\
\text { duração. Não se modificam com a tosse. Podem ser comparados } \\
\text { ao ruído produzido pelo atrito de um punhado de cabelos junto ao } \\
\text { ouvido ou a som percebido ao se fechar ou abrir um fecho tipo } \\
\text { velcro (TARANTINO, 2001). }\end{array}$ & & & & & \\
\hline
\end{tabular}


Desobstrução Ineficaz de Vias Aéreas: "incapacidade de eliminar secreções ou obstruções do trato respiratório pra manter uma via aérea desobstruída" (NANDA, 2005 - 2006, p.84).

\begin{tabular}{|c|c|c|c|c|c|}
\hline Característica Definidora e Definição: & $\begin{array}{l}\text { Não } \\
\text { Característica }\end{array}$ & $\begin{array}{l}\text { Muito Pouco } \\
\text { Característica }\end{array}$ & $\begin{array}{l}\text { De algum modo } \\
\text { Característica }\end{array}$ & $\begin{array}{l}\text { Muito } \\
\text { Característica }\end{array}$ & $\begin{array}{l}\text { Muitíssimo } \\
\text { Característica }\end{array}$ \\
\hline $\begin{array}{l}\text { RUÍDOS ADVENTÍCIOS (cont.) Roncos: sons graves, de baixa } \\
\text { freqüência. Originam-se nas vibrações das paredes brônquicas e do } \\
\text { conteúdo gasoso quando há estreitamento destes ductos. Aparecem } \\
\text { na inspiração como na expiração, mas predominantemente na } \\
\text { expiração. São fugazes, mutáveis, surgindo e desaparecendo em } \\
\text { curto período de tempo (Tarantino, 2001). Sibilos: sons agudos. } \\
\text { Também se originam nas vibrações das paredes brônquicas e do } \\
\text { conteúdo gasoso e aparecem na inspiração como na expiração. Em } \\
\text { geral são múltiplos e disseminados por todo o tórax (TARANTINO, } \\
\text { 2001). }\end{array}$ & & & & & \\
\hline $\begin{array}{l}\text { FREQÜÊNCIA URINÁRIA AUMENTADA } \\
\text { Necessidade de urinar repetidas vezes, com curto intervalo entre as } \\
\text { micções, inferior a duas horas, sem que haja aumento do volume } \\
\text { urinário (PORTO, 2005). }\end{array}$ & & & & & \\
\hline $\begin{array}{l}\text { TOSSE INEFICAZ } \\
\text { Tosse: é um mecanismo de defesa das vias respiratórias, as quais } \\
\text { reagem aos irritantes ou procuram eliminar secreções anormais, } \\
\text { sempre com o objetivo de se manter as VAS pérveas. A tosse } \\
\text { consiste numa inspiração rápida e profunda, seguida de fechamento } \\
\text { da glote, contração dos músculos expiratórios, principalmente o } \\
\text { diafragma, terminando com uma expiração forçada, após a abertura } \\
\text { súbita da glote. A ultima parte da tosse, a expiração forçada, } \\
\text { constitui um mecanismo expulsivo de grande importância para as } \\
\text { vias aéreas (TARANTINO, 2001). } \\
\text { Ineficaz: que não produz efeito; que não dá resultado; impróprio, }\end{array}$ & & & & & \\
\hline
\end{tabular}


Desobstrução Ineficaz de Vias Aéreas: "incapacidade de eliminar secreções ou obstruções do trato respiratório pra manter uma via aérea desobstruída" (NANDA, 2005 - 2006, p.84).

\begin{tabular}{|c|c|c|c|c|c|}
\hline Característica Definidora e Definição & $\begin{array}{l}\text { Não } \\
\text { Característica }\end{array}$ & $\begin{array}{l}\text { Muito Pouco } \\
\text { Característica }\end{array}$ & $\begin{array}{l}\text { De algum modo } \\
\text { Característica }\end{array}$ & $\begin{array}{l}\text { Muito } \\
\text { Característica }\end{array}$ & $\begin{array}{l}\text { Muitíssimo } \\
\text { Característica }\end{array}$ \\
\hline \multicolumn{6}{|l|}{ inconveniente (Dicionário MICHAELIS, 2005). } \\
\hline \multicolumn{6}{|l|}{$\begin{array}{l}\text { TOSSE AUSENTE } \\
\text { A tosse é um mecanismo de defesa das vias respiratórias, as quais } \\
\text { reagem aos irritantes ou procuram eliminar secreções anormais, } \\
\text { sempre com o objetivo de se manter as VAS pérveas. A tosse } \\
\text { consiste numa inspiração rápida e profunda, seguida de } \\
\text { fechamento da glote, contração dos músculos expiratórios, } \\
\text { principalmente o diafragma, terminando com uma expiração } \\
\text { forçada, após a abertura súbita da glote. A última parte da tosse, a } \\
\text { expiração forçada, constitui um mecanismo expulsivo de grande } \\
\text { importância para as vias aéreas (TARANTINO, 2001). } \\
\text { Ausente: que não está presente (Dicionário MICHAELIS,2005). }\end{array}$} \\
\hline \multicolumn{6}{|l|}{$\begin{array}{l}\text { EXPECTORAÇÃO } \\
\text { É o ato de expectorar } \\
\text { Expectorar é expelir, lançar do peito, escarrar (Dicionário } \\
\text { MICHAELIS, 2005). } \\
\text { Costuma ser a conseqüência da tosse (TARANTINO, 2001). }\end{array}$} \\
\hline $\begin{array}{l}\text { CIANOSE } \\
\text { É a coloração azulada da pele. } \\
\text { Para ser considerada cianose o paciente tem que estar, com pelo } \\
\text { menos } 5 \% \text { da hemoglobina reduzida (TARANTINO, 2001). }\end{array}$ & & & & & \\
\hline $\begin{array}{l}\text { ESQUECIMENTO } \\
\text { Ato de esquecer; falta de memória, lembrança; distração (PORTO, } \\
\text { 2005). }\end{array}$ & & & & & \\
\hline
\end{tabular}


Desobstrução Ineficaz de Vias Aéreas: "incapacidade de eliminar secreções ou obstruções do trato respiratório pra manter uma via aérea desobstruída" (NANDA, 2005 - 2006, p.84).

\begin{tabular}{|c|c|c|c|c|c|}
\hline Característica Definidora e Definição & $\begin{array}{l}\text { Não } \\
\text { Característica }\end{array}$ & $\begin{array}{l}\text { Muito Pouco } \\
\text { Característica }\end{array}$ & $\begin{array}{l}\text { De algum modo } \\
\text { Característica }\end{array}$ & $\begin{array}{l}\text { Muito } \\
\text { Característica }\end{array}$ & $\begin{array}{l}\text { Muitíssimo } \\
\text { Característica }\end{array}$ \\
\hline $\begin{array}{l}\text { VOCALIZAÇÃO DIFICULTADA } \\
\text { É a alteração da voz, como disfonias, rouquidão e a afonia, que } \\
\text { são observáveis nos casos de laringites crônicas, presentes } \\
\text { nos casos de neoplasias, nas paralisias das cordas vocais, } \\
\text { entre outras (HUNGRIA, 2001). } \\
\text { Mudanças no timbre da voz ou rouquidão são alterações na } \\
\text { dinâmica das cordas vocais (TARANTINO, 2001). }\end{array}$ & & & & & \\
\hline $\begin{array}{l}\text { OLHOS ARREGALADOS } \\
\text { Olhos: órgão da visão, formado pelos globos oculares e seus } \\
\text { anexos (Dicionário MICHAELIS,2005).. } \\
\text { Arregalado: muito aberto, esbugalhado. Adjetivo do verbo } \\
\text { arregalar que significa abrir muito por espanto ou satisfação } \\
\text { (Dicionário MICHAELIS,2005). }\end{array}$ & & & & & \\
\hline $\begin{array}{l}\text { MUDANÇAS NO RITMO RESPIRATÓRIO } \\
\text { É a alteração a para mais ou menos na amplitude da } \\
\text { respiração. Normalmente a inspiração dura quase o mesmo } \\
\text { tempo que a expiração, sucedendo-se os dois movimentos } \\
\text { com a mesma amplitude, intercalados por leve pausa. Quando } \\
\text { uma dessas características se modifica, surgem os ritmos } \\
\text { respiratórios anormais (TARANTINO, 2001). }\end{array}$ & & & & & \\
\hline
\end{tabular}


Desobstrução Ineficaz de Vias Aéreas: "incapacidade de eliminar secreções ou obstruções do trato respiratório pra manter uma via aérea desobstruída" (NANDA, 2005 - 2006, p.84).

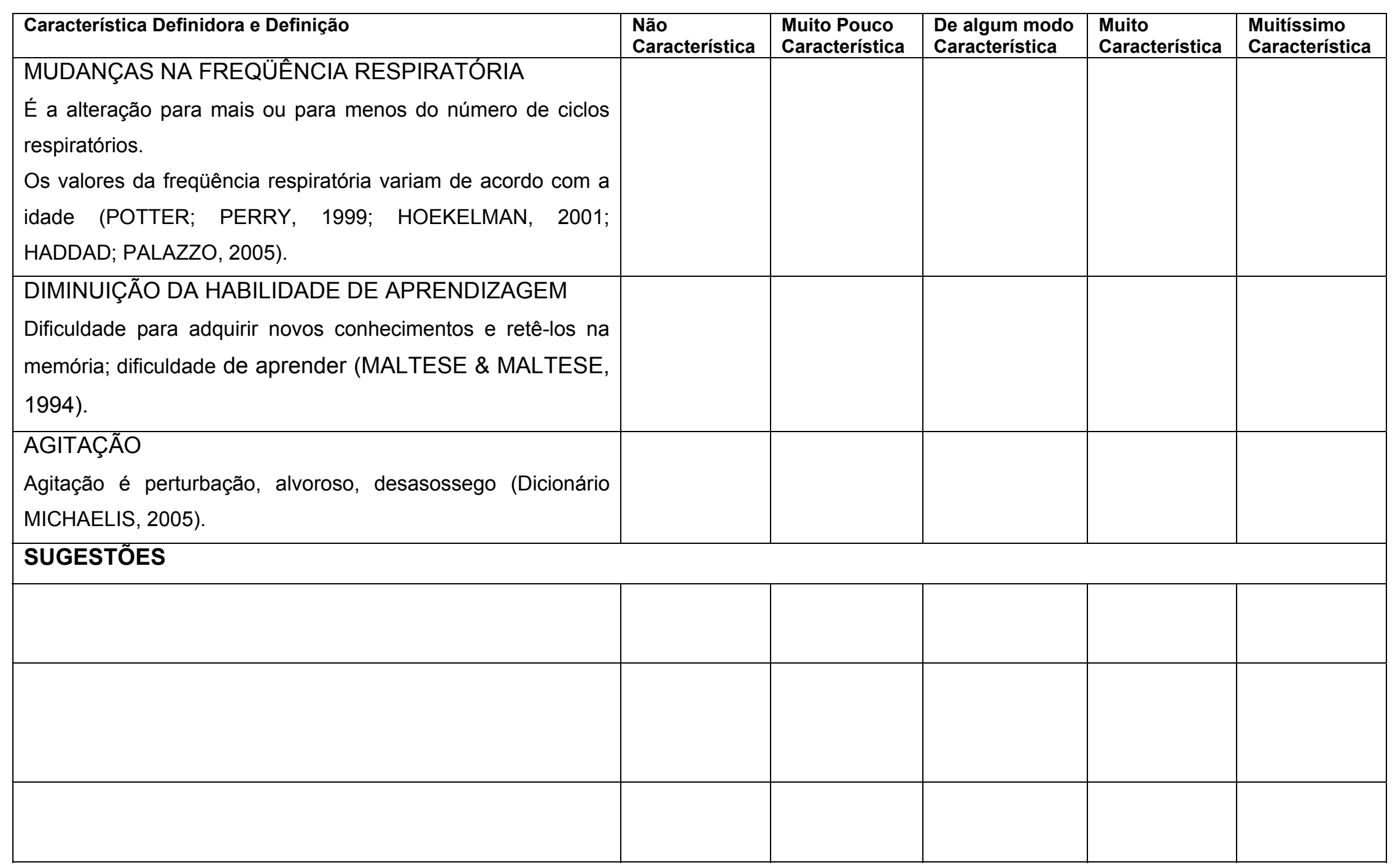




\section{APÊNDICE B - Termo de consentimento livre e esclarecido \\ ETAPA DE VALIDAÇÃO POR ESPECIALISTA}

Prezado Colega (enfermeiro),

Sou aluna do curso de pós-graduação do Programa de Enfermagem Fundamental da Escola de Enfermagem de Ribeirão Preto da Universidade de São Paulo.

Vimos através desta pedir sua colaboração para responder o instrumento em anexo, para ser integrante do projeto de pesquisa intitulada "Validação do Diagnóstico de Enfermagem Desobstrução Ineficaz de Vias Aéreas de Crianças submetidas à correção cirúrgica de Cardiopatia Congênita".

Sua participação é importantíssima neste estudo, pois são poucos os enfermeiros que trabalham com esta temática. Gostaríamos de esclarecer que asseguramos total sigilo sobre sua identidade. Você poderá deixar de participar do estudo, em qualquer momento, sem que isso traga prejuízo para você. Poderá solicitar esclarecimento quando sentir necessidade e em qualquer momento da pesquisa. Asseguramos também que os dados coletados serão utilizados para fins de trabalhos científicos e informamos que você não terá despesas nenhuma com o estudo.

Pedimos sua colaboração para que nos envie a resposta o mais rápido possível, pois estes resultados nortearão a fase seguinte da coleta de dados deste trabalho que será realizada com o cliente (Validação Clínica).

Caso concorde em participar deste estudo, solicitamos preencher os dados abaixo:

Eu, ,RG

enfermeira especialista, recebi todas as informações acima e ciente dos meus direitos, concordo em participar da pesquisa intitulada "Validação do Diagnóstico de Enfermagem Desobstrução Ineficaz de Vias Aéreas de Crianças submetidas a correção cirúrgica de cardiopatia congênita"

Local, Data

Local, Data
Assinatura 


\section{APÊNDICE C - Termo de consentimento livre e esclarecido \\ ETAPA DA VALIDAÇÃO CLÍNICA}

Prezado Colega (enfermeiro)

Sou aluna do curso de pós-graduação do Programa de Enfermagem Fundamental da Escola de Enfermagem de Ribeirão Preto da Universidade de São Paulo.

Vimos através desta pedir sua colaboração para responder o instrumento em anexo, para ser integrante do projeto de pesquisa intitulada "Validação do Diagnóstico de Enfermagem Desobstrução Ineficaz de Vias Aéreas de Crianças submetidas à correção cirúrgica de Cardiopatia Congênita".

Precisamos de sua atuação para participar da etapa de verificação das incidências clínicas, que será realizada através de um exame clínico, na criança portadora de cardiopatia congênita, internada no Centro de Terapia Intensiva pediátrico e que foi submetida à correção cirúrgica. Este exame clínico deverá ocorrer no pós-operatório imediato. Deverá ser estabelecido ou não a presença do diagnóstico de "Desobstrução Ineficaz de Vias Aéreas" e suas características definidoras.

A coleta de dados será realizada no próprio impresso da unidade e será realizada no período de janeiro a abril de 2007.

Sua participação é importantíssima neste estudo, pois são poucos os enfermeiros que trabalham com esta temática. Gostaríamos de esclarecer que asseguramos total sigilo sobre sua identidade. Você poderá deixar de participar do estudo, em qualquer momento, sem que isso traga prejuízo para você. Poderá solicitar esclarecimento quando sentir necessidade e em qualquer momento da pesquisa. Asseguramos também que os dados coletados serão utilizados para fins de trabalhos científicos e informamos que você não terá despesas nenhuma com o estudo. Informamos ainda que a coleta de dados será combinada previamente, conforme sua disponibilidade de dia e horário.

Caso concorde em participar deste estudo, solicitamos preencher os dados abaixo:

$\mathrm{Eu}$, ,RG

enfermeira especialista, recebi todas as informações acima e ciente dos meus direitos, concordo em participar da pesquisa intitulada "Validação do Diagnóstico de Enfermagem Desobstrução Ineficaz de Vias Aéreas de Crianças submetidas a correção cirúrgica de cardiopatia congênita"

Local, Data

Local, Data
Assinatura

Pesquisadora: Simone de Oliveira Pileggi

Mestranda da pós graduação da EERP.

End. Rua Itapura, 1068 - Jd. Paulistano

Cep. - 14.090-080 Ribeirão Preto - SP

F. (16) 3602-2577 


\title{
APÊNDICE D - Termo de consentimento livre e esclarecido
}

\section{ETAPA DA VALIDAČ̃̃ CLÍNICA}

\author{
VALIDACÃ̃O DO INSTRUMENTO DE COLETA DE DADOS
}

Prezado Colega (enfermeiro)

Sou aluna do curso de pós-graduação do Programa de Enfermagem Fundamental da Escola de Enfermagem de Ribeirão Preto da Universidade de São Paulo.

Vimos através desta pedir sua colaboração para participar do processo de validação do instrumento de coleta de dados do projeto de pesquisa intitulada "Validação do Diagnóstico de Enfermagem Desobstrução Ineficaz de Vias Aéreas de Crianças submetidas à correção cirúrgica de Cardiopatia Congênita".

A validação do instrumento de coleta de dados é uma das fases, da etapa de verificação das incidências clínicas, onde utilizaremos o instrumento de coleta de dados do Centro de Terapia Intensiva Pediátrica (CTIP), do Hospital onde será realizado este estudo, pois ele foi elaborado no modelo conceitual de Horta (1979) à luz das necessidades humanas básicas. O instrumento servirá de guia para identificar as características definidoras do diagnóstico de enfermagem em estudo.

O instrumento de coleta de dados do CTIP do HCFMRP - USP foi elaborado para atender a criança e o adolescente gravemente enfermo, incluindo a clientela portadora de cardiopatia congênita. Esse instrumento de avaliação compreende as seguintes etapas: identificação (nome, registro, data de internação, diagnóstico e cirurgia realizada), fichas de avaliação das necessidades psicobiológicas: oxigenação / respiração, circulação, termorregulação, integridade tecidual, motilidade, percepção sensorial, alimentação / hidratação e eliminação, sono e repouso; ficha de necessidade psicossociais (comunicação interação).

Este instrumento deverá ser submetido a uma validação aparente e de conteúdo e deverá ser submetido a um teste piloto, para complementar a validação do instrumento, nas crianças internadas no CTIP em pós-operatório imediato de cirurgia cardíaca para correção de cardiopatia congênita.

Gostaríamos de esclarecer que asseguramos total sigilo sobre sua identidade. Você poderá deixar de participar do estudo, em qualquer momento, sem que isso traga prejuízo para você. Poderá solicitar esclarecimento quando sentir necessidade e em qualquer momento da pesquisa. Asseguramos também que os dados coletados serão utilizados para fins de trabalhos científicos e informamos que você não terá despesas nenhuma com o estudo. Informamos ainda que a coleta de dados será combinada previamente, conforme sua disponibilidade de dia e horário.

Caso concorde em participar deste estudo, solicitamos preencher os dados abaixo:

Eu, ,RG

enfermeira especialista, recebi todas as informações acima e ciente dos meus direitos, concordo em participar da pesquisa intitulada "Validação do Diagnóstico de Enfermagem Desobstrução Ineficaz de Vias Aéreas de Crianças submetidas a correção cirúrgica de cardiopatia congênita" 

Mestranda da pós graduação da EERP. End. Rua Itapura, 1068 - Jd. Paulistano Cep. - 14.090-080 Ribeirão Preto - SP F. (16) 3602-2577 


\section{APÊNDICE E - Termo de consentimento livre e esclarecido}

\section{Prezados Pais ou Responsável}

Sou aluna do curso de pós-graduação do Programa de Enfermagem Fundamental da Escola de Enfermagem de Ribeirão Preto da Universidade de São Paulo.

Estamos realizando um estudo intitulado "Validação do Diagnóstico de Enfermagem Desobstrução Ineficaz de Vias Aéreas de Crianças submetidas à correção cirúrgica de Cardiopatia Congênita" para identificar a possível presença do diagnóstico de enfermagem "desobstrução ineficaz de vias aéreas", no primeiro dia de cirurgia que o seu filho será submetido. A identificação deste diagnóstico possibilitará um cuidado de enfermagem mais rápido e eficiente, e ajudará na recuperação de crianças que forem submetidas à correção cirúrgica de cardiopatia congênita.

Será realizado no seu filho um exame físico nas primeiras $24 \mathrm{hs}$ em que ele permanecer dentro do Centro de Terapia Intensivo Pediátrico - Campus. Esse exame físico será realizado por mim e por enfermeiras especialistas.

Gostaríamos de esclarecer que asseguramos total sigilo sobre a identidade de seu filho, que poderá deixar de participar do estudo, em qualquer momento, sem que isso traga prejuízo para ele e para você. Poderá solicitar esclarecimento quando sentir necessidade e em qualquer momento da pesquisa. Asseguramos também que os dados coletados serão utilizados para fins de trabalhos científicos e informamos que você e seu filho não terão despesas nenhuma com o estudo.

Caso concorde em participar deste estudo, solicitamos preencher os dados abaixo:

Eu, ,RG

responsável do paciente, recebi todas as informações acima e ciente dos meus direitos, concordo em participar da pesquisa intitulado "Validação do Diagnóstico de Enfermagem Desobstrução Ineficaz de Vias Aéreas de Crianças submetidas a correção cirúrgica de cardiopatia congênita"

\author{
Local, Data
}

\author{
Assinatura do responsável
}

Local, Data
Pesquisadora: Simone de Oliveira Pileggi Mestranda da pós graduação da EERP. End. Rua Itapura, 1068 - Jd. Paulistano Cep. - 14.090-080 Ribeirão Preto - SP F. (16) 3602-2577




\section{APÊNDICE F - Validação de aparência e conteúdo}

Por gentileza, gostaria de solicitar a você que realizasse a validação de aparência e conteúdo do instrumento que pretendo utilizar em meu projeto de mestrado intitulado "Validação do Diagnóstico de Enfermagem Desobstrução Ineficaz de Vias Aéreas de Crianças e Adolescente Submetidas à Correção Cirúrgica de Cardiopatia Congênita" que tem como objetivos: Validar clinicamente o diagnóstico de Enfermagem da NANDA (2002) "Desobstrução Ineficaz de Vias Aéreas", analisar o conceito do diagnóstico de enfermagem "Desobstrução Ineficaz de Vias Aéreas", identificando na literatura, as possíveis características definidoras; realizar a validação por especialista do diagnóstico de enfermagem Desobstrução Ineficaz de Vias Aéreas e verificar a incidência das características definidoras do diagnóstico estudado, no pósoperatório imediato de cirurgia cardíaca para correção de cardiopatia congênita.

Por favor, responda as seguintes questões:

1) Os itens agrupados no instrumento por necessidades são suficientes para identificar alterações nas necessidades nas quais estão inseridas?

2) Em sua opinião há repetição de questões nas diferentes necessidades?

3) O instrumento favorece a formulação do diagnóstico de enfermagem em estudo, considerando o objetivo do estudo?

4) Alguma alteração deve ser feita para melhorar o instrumento?

5) Expresse a sua opinião quanto à forma de apresentação e conteúdo do instrumento.

\section{Observações:}

- o instrumento de coleta formulado foi baseado no modelo conceitual de Wanda Aguiar Horta;

- as respostas aos questionamentos acima podem ser realizadas no verso desta folha;

- as alterações necessárias, segundo sua opinião, podem ser feitas no próprio instrumento.

Obrigada pela sua colaboração, 
APËNDICE G - $\quad$ NECESSIDADES PSICOBIOLÓGICAS - CTI PEDIÁTRICO - CAMPUS

Data de internação no CTIP

Hora PO: $\quad$ Diagnóstico:

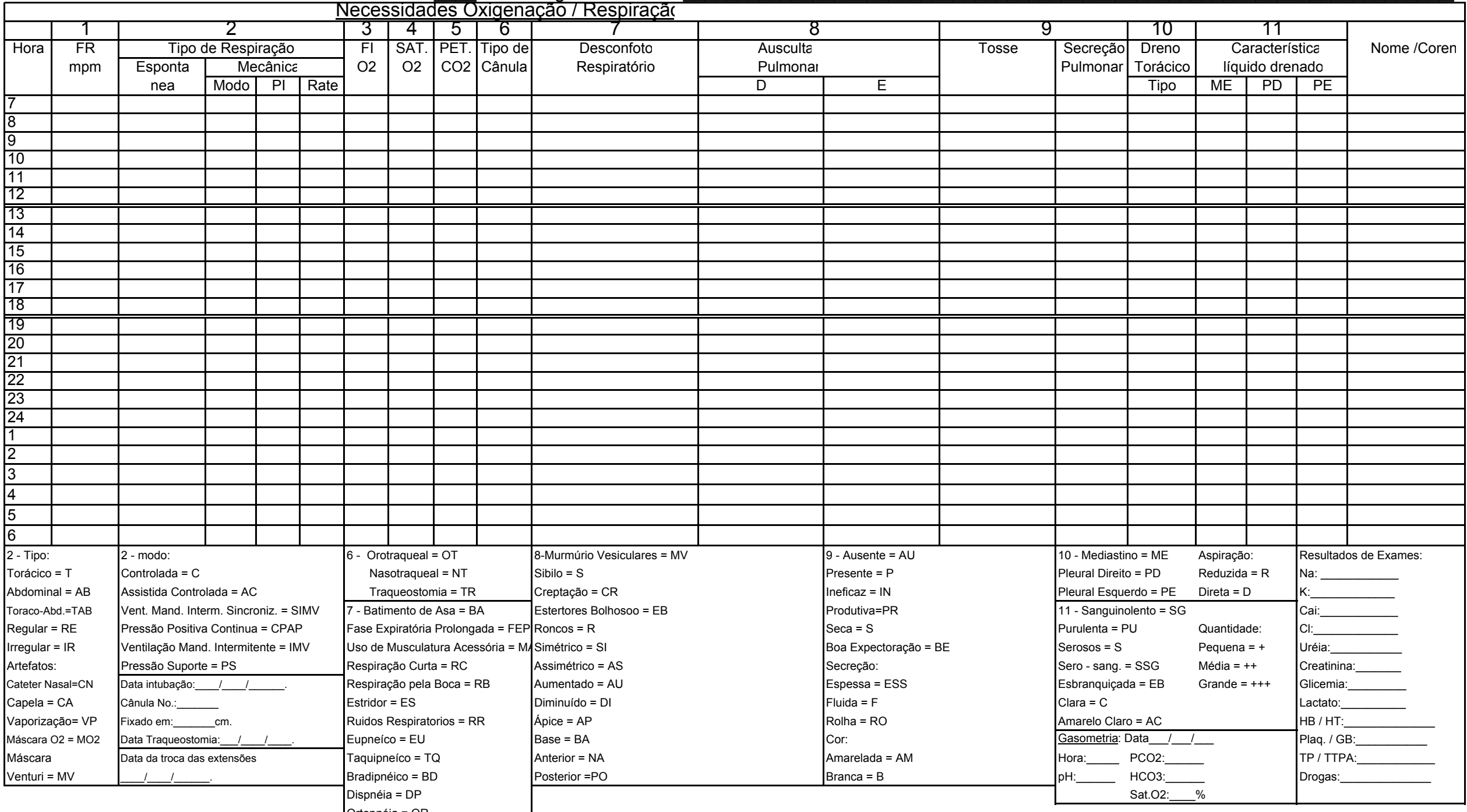

Dispneia $=\mathrm{DP}$

Olhos Arregalados $=\mathrm{OA}$

Agitação $=$ AG

Vocalização Dificultada $=$ VD

Cianose $=\mathrm{Cl}$ 
NECESSIDADES PSICOLOGICAS

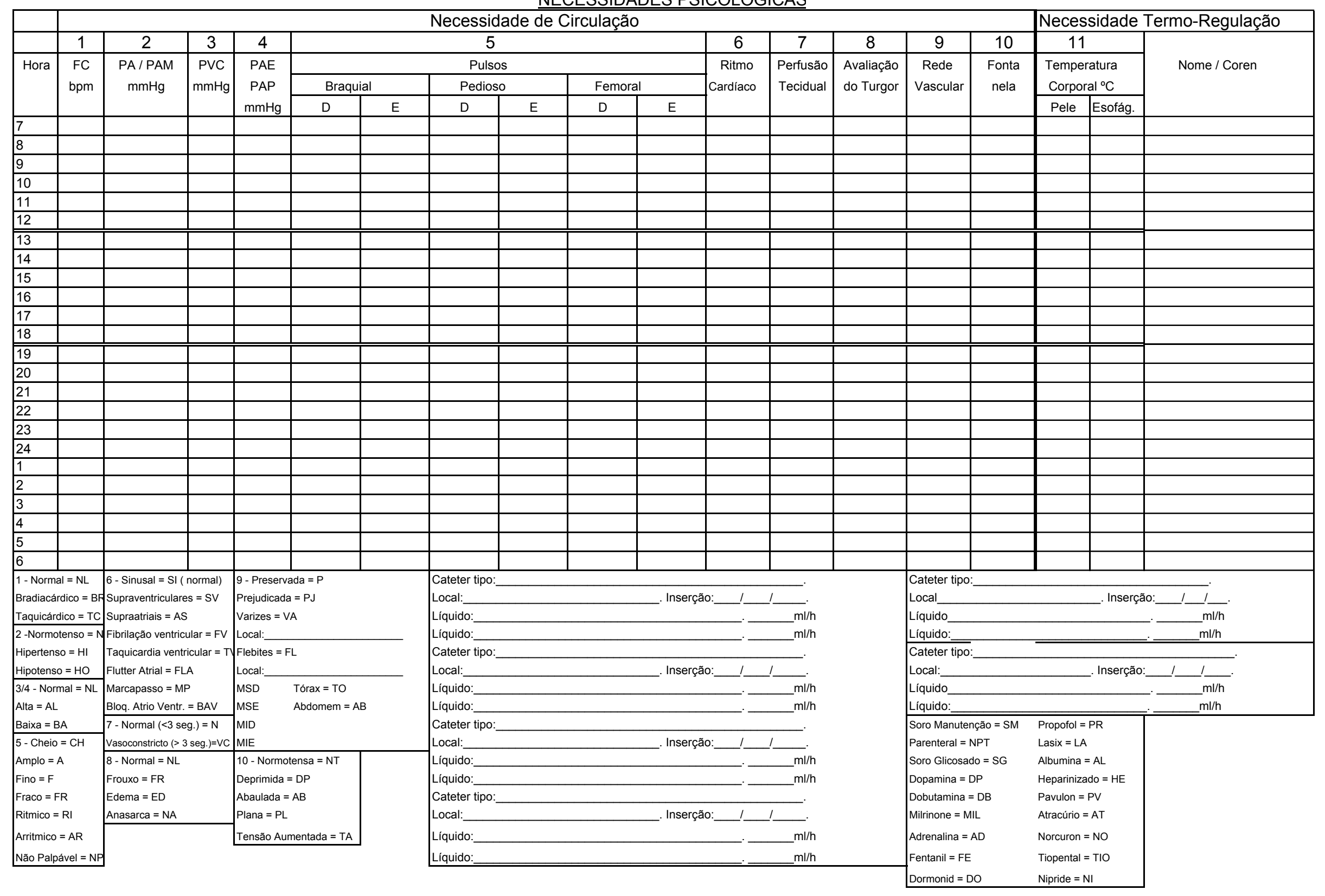


NECESSIDADES PSICOBIOLÓGICAS - CTI PEDIÁTRICO - CAMPUS

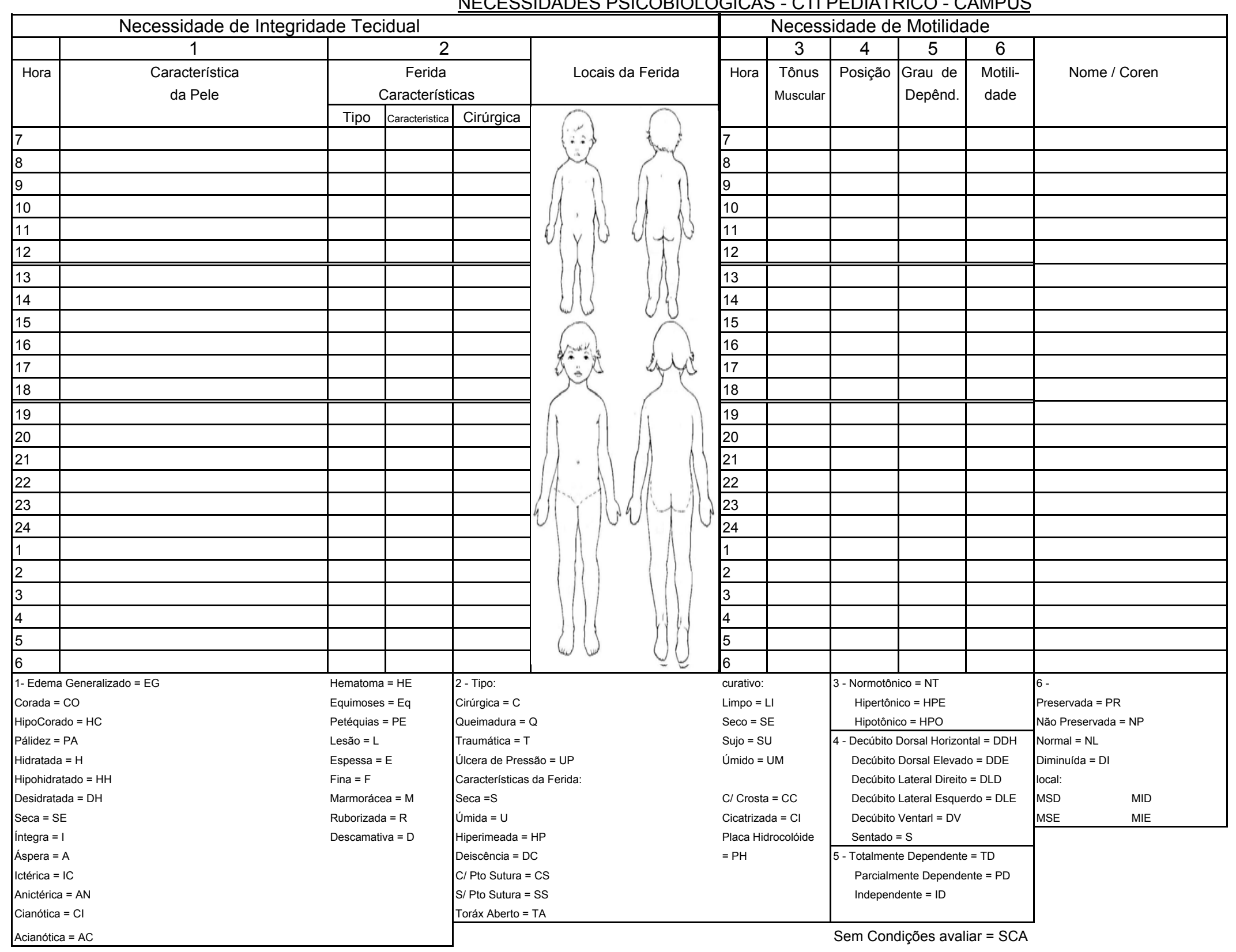


NECESSIDADE PSICOBIOLÓGICAS

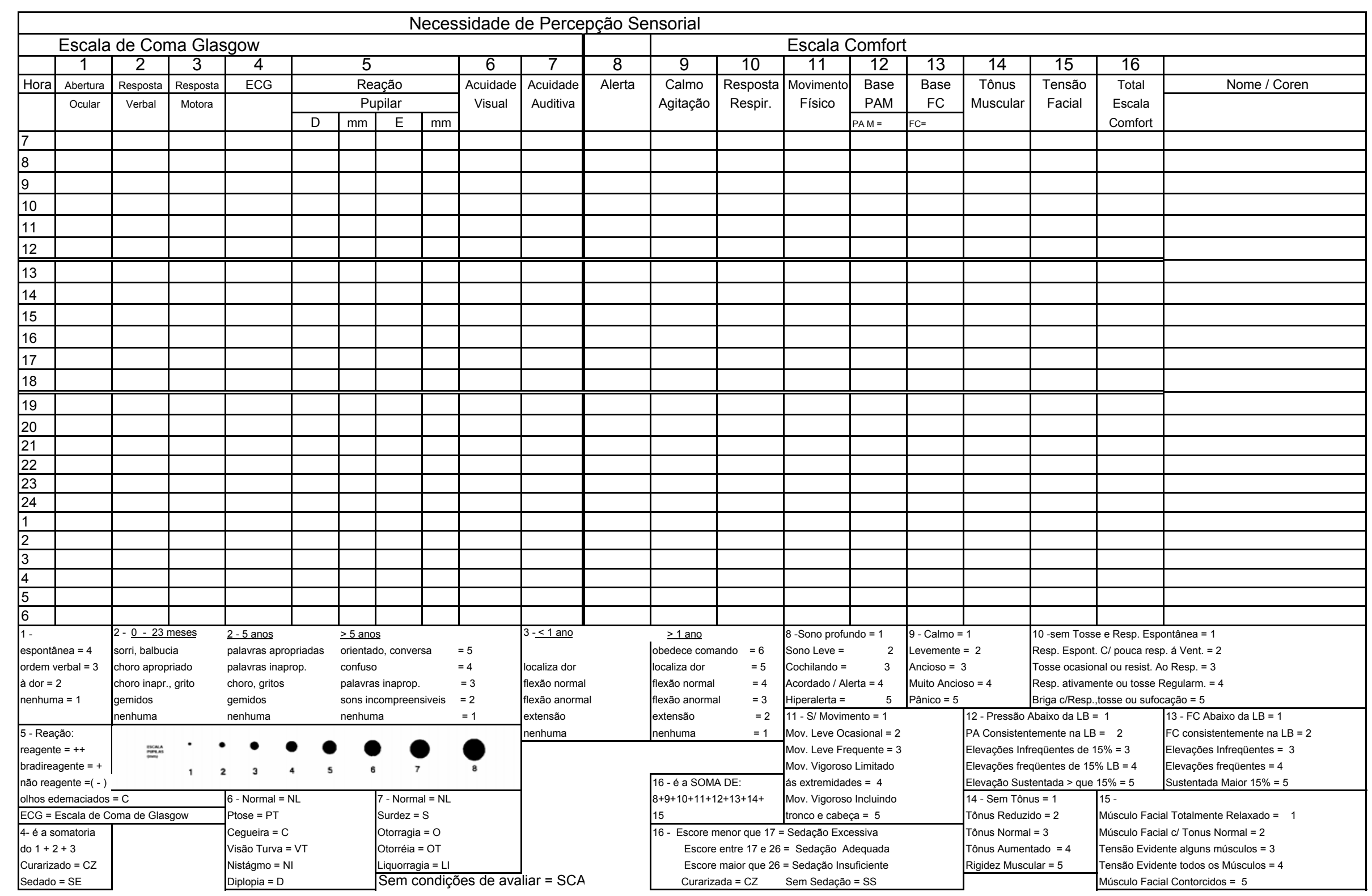




\begin{tabular}{|c|c|c|c|c|c|c|c|c|c|c|c|c|c|c|c|c|c|}
\hline \multicolumn{6}{|c|}{ Necessidade de Alimentação } & \multicolumn{12}{|c|}{ Necessidade de Eliminação Intestinal e Urinária } \\
\hline & 1 & \multicolumn{2}{|c|}{2} & 3 & 4 & 5 & 6 & \multirow{2}{*}{\multicolumn{5}{|c|}{$\begin{array}{c}7 \\
\text { Característica das Fezes }\end{array}$}} & & 8 & 9 & 10 & \multirow{3}{*}{ Nome / Coren } \\
\hline \multirow[t]{2}{*}{ Hora } & \multirow{2}{*}{$\begin{array}{c}\text { Tipo de } \\
\text { Alimentação }\end{array}$} & \multirow[t]{2}{*}{ Abdome } & \multirow{2}{*}{$\begin{array}{c}\text { Figado } \\
\mathrm{cm}\end{array}$} & \multirow{2}{*}{\begin{tabular}{|c|} 
Ruídos \\
Hidro \\
aéreos
\end{tabular}} & \multirow{2}{*}{$\begin{array}{l}\text { Teste } \\
\text { SNG } \\
\text { SNE }\end{array}$} & \multirow{2}{*}{$\begin{array}{l}\text { Secreção } \\
\text { Gástrica }\end{array}$} & \multirow{2}{*}{$\begin{array}{l}\text { Secreção } \\
\text { Ostomias }\end{array}$} & & & & & & \multicolumn{2}{|c|}{ Débito Úrinário } & \multirow{2}{*}{\begin{tabular}{|l|} 
Coloração \\
da Urina \\
\end{tabular}} & pensidade & \\
\hline & & & & & & & & \multicolumn{2}{|c|}{\begin{tabular}{|l|l}
\multicolumn{2}{|c}{ Caract } \\
Colo & Odor \\
\end{tabular}} & $\begin{array}{l}\text { Consis } \\
\text { tência }\end{array}$ & \multirow[t]{2}{*}{$\begin{array}{l}\text { Quanti } \\
\text { dade }\end{array}$} & outros & Tipo & Volume & & Urinária & \\
\hline 7 & & & & & & & & & & & & & & & & & \\
\hline 8 & & & & & & & & & & & & & & & & & \\
\hline 9 & & & & & & & & & & & & & & & & & \\
\hline 10 & & & & & & & & & & & & & & & & & \\
\hline 11 & & & & & & & & & & & & & & & & & \\
\hline 12 & & & & & & & & & & & & & & & & & \\
\hline 13 & & & & & & & & & & & & & & & & & \\
\hline 14 & & & & & & & & & & & & & & & & & \\
\hline 15 & & & & & & & & & & & & & & & & & \\
\hline 16 & & & & & & & & & & & & & & & & & \\
\hline 17 & & & & & & & & & & & & & & & & & \\
\hline 18 & & & & & & & & & & & & & & & & & \\
\hline 19 & & & & & & & & & & & & & & & & & \\
\hline 20 & & & & & & & & & & & & & & & & & \\
\hline 21 & & & & & & & & & & & & & & & & & \\
\hline 22 & & & & & & & & & & & & & & & & & \\
\hline 23 & & & & & & & & & & & & & & & & & \\
\hline 24 & & & & & & & & & & & & & & & & & \\
\hline 1 & & & & & & & & & & & & & & & & & \\
\hline 2 & & & & & & & & & & & & & & & & & \\
\hline 3 & & & & & & & & & & & & & & & & & \\
\hline 4 & & & & & & & & & & & & & & & & & \\
\hline 5 & & & & & & & & & & & & & & & & & \\
\hline 6 & & & & & & & & & & & & & & & & & \\
\hline $\begin{array}{l}\text { - Jeju } \\
\text { Via Ora }\end{array}$ & $\begin{array}{l}m=J \\
I=V O\end{array}$ & $\begin{array}{l}2-\text { Massa Palpável = } \\
\text { Plano }=\mathrm{P}\end{array}$ & & Rigido RI & & \begin{tabular}{|l|} 
- Posicional \\
Medida Exter
\end{tabular} & mento Correto: & & $\begin{array}{l}7 \text { - Color } \\
\text { Marrom }=\end{array}$ & $\begin{array}{l}\text { ação: } \\
=M\end{array}$ & $\begin{array}{l}\text { Consistên } \\
\text { Pastosa }\end{array}$ & $\begin{array}{l}\text { ncia: } \\
=\mathrm{P}\end{array}$ & & $\begin{array}{l}\text { 8- Tipo: } \\
\text { micção espontâne: }\end{array}$ & ME & $\begin{array}{l}\text { Sonda Ve } \\
\text { cateteriza }\end{array}$ & âa em: emo. \\
\hline $\begin{array}{l}\text { SNG } \\
\text { SOG }\end{array}$ & & $\begin{array}{l}\text { Globoso = GL } \\
\text { Semi Glob. }=\text { SG }\end{array}$ & & Timpánico & $\begin{array}{l}0=\mathrm{TI} \\
\text { Ascite }=\mathrm{A}\end{array}$ & \begin{tabular}{|l} 
Teste de Refl \\
Teste de Refl
\end{tabular} & fluxo Positivo = & & Melena $=$ & $=\mathrm{ME}$ & Semi Pas & stosa $=\mathrm{SP}$ & & sonda vesical dem & $\begin{aligned} \mathrm{ra}=S V D \\
A S\end{aligned}$ & SNG / SN & no. \\
\hline $\begin{array}{l}\text { SOG } \\
\text { SNE }\end{array}$ & & $\begin{array}{l}\text { Semi Glob. = SG } \\
\text { Flácido = FL }\end{array}$ & & & $\begin{array}{l}\text { Ascite }=9 \\
\text { Incisões }=\end{array}$ & Ausculta Car & raxo Negegativo $=$ & & Amerelac & $\begin{array}{l}a d a=E S V \\
d a=A M\end{array}$ & $\begin{array}{l}\text { Formada } \\
\text { Liquida }=\end{array}$ & $\begin{array}{l}=\mathrm{F} \\
=\mathrm{LI}\end{array}$ & & $\begin{array}{l}\text { Sondagem allivio }= \\
\text { cistostomia }=\mathrm{CIS}\end{array}$ & & & $\mathrm{cm}$. \\
\hline Soro $\mathrm{M}_{\mathrm{z}}$ & lanutenção= SM & Tenso $=\mathrm{TS}$ & & & Ostomias $=$ & & 2- Figado & & Mecônio & & Semi-Liqu & uida = SL & & com estímulo $=\mathrm{CE}$ & & & \\
\hline Parente & eral $=N P T$ & Distendido = DI & & & Drenos $=\mathrm{D}$ & & Reboerdo Cost & & Odor: & & ${ }_{\text {Endurecic }}$ & ida $=E M$ & & sem estimulo $=\mathrm{SE}$ & & amarelo clar & $=\mathrm{AC}$ \\
\hline $\begin{array}{l}\text { Drenag } \\
\text { Gastros }\end{array}$ & $\begin{array}{l}\text { yem }=D R \\
\text { stomia }=G\end{array}$ & $\begin{array}{l}\text { Normotenso }=\mathrm{NT} \\
\text { Fecaloma }=\mathrm{FE}\end{array}$ & & & Tenkoff $=\mathrm{T}$ & & RBC & & $\begin{array}{l}\text { Caracter } \\
\text { Fétido }=\end{array}$ & $\begin{array}{l}\text { istico }=\mathrm{C} \\
\mathrm{F}\end{array}$ & $\begin{array}{l}\text { Quantidac } \\
\text { Pequena }\end{array}$ & $\begin{array}{l}\overline{l i d e:} \\
=(+)\end{array}$ & & $\begin{array}{l}\text { Volume: } \\
\text { Normal = N }\end{array}$ & & $\begin{array}{l}\text { amarelo For } \\
\text { amarronzad }\end{array}$ & $\begin{array}{l}=A F \\
=A R\end{array}$ \\
\hline $\begin{array}{l}\text { Com Di } \\
\text { Clampa }\end{array}$ & $\begin{array}{l}\text { ieta }=C D \\
a d a=C l\end{array}$ & 5/6 - Sanguinolenta = & & & Amarela $=$ & $\begin{array}{l}=A M \\
=A M\end{array}$ & & & Outros: & $\overline{-s e}$ & $=$ média $=($ & $(++)$ & & anúria = AN & & hematúrica & $\mathrm{HE}$ \\
\hline $3-$ Norn & moativo $=\mathrm{NA}$ & Borra de Café $=\mathrm{BC}$ & & & Clara $=\mathrm{CL}$ & & & & $\begin{array}{l}\text { Restos A } \\
\text { Reste }\end{array}$ & limentares & $=$ RA & & & disúria = DI & & & \\
\hline Hiperati & ivo $=\mathrm{HI}$ & Acastanhada $=\mathrm{AC}$ & & & Vômito $=\mathrm{V}$ & & & & Corpos E & Estranhos $=$ & & & & oligúria $=\mathrm{OL}$ & & limpida $=\mathrm{L}$ & \\
\hline $\begin{array}{l}\text { Hipoativ } \\
\text { Ausente }\end{array}$ & $\begin{array}{l}v_{0}=H O \\
e=A U\end{array}$ & $\begin{array}{l}\text { Esbranquiçada = EB } \\
\text { Restos Alimentares }\end{array}$ & & & & & & & $\begin{array}{l}\text { Parasitas } \\
\text { pus = PU }\end{array}$ & & & & & & & $\begin{array}{l}\text { concentrada } \\
\text { com sedime }\end{array}$ & $\begin{array}{l}=C \\
\text { tos }=c s\end{array}$ \\
\hline
\end{tabular}


NECESSIDADES PSICOSSOCIAIS - CTI PEDIÁTRICO - CAMPUS

\begin{tabular}{|c|c|c|c|c|c|c|}
\hline \multicolumn{2}{|c|}{$\begin{array}{l}\text { Necessidade } \\
\text { Sono/Repouso }\end{array}$} & \multicolumn{5}{|c|}{ Necessidade de comunicação/Interação } \\
\hline & 1 & 2 & 3 & 4 & 5 & \multirow[b]{2}{*}{ Nome / Coren } \\
\hline Hora & $\begin{array}{l}\text { Padrões do } \\
\text { Sono }\end{array}$ & $\begin{array}{c}\text { Aspectos } \\
\text { Emocionais }\end{array}$ & $\begin{array}{l}\text { Comuni } \\
\text { cação }\end{array}$ & \begin{tabular}{|c|} 
Estratégia de \\
Resoluçăo Individua
\end{tabular} & \begin{tabular}{|c|} 
Relacionamente \\
Social
\end{tabular} & \\
\hline \multicolumn{7}{|l|}{7} \\
\hline \multicolumn{7}{|l|}{8} \\
\hline \multicolumn{7}{|l|}{9} \\
\hline \multicolumn{7}{|l|}{10} \\
\hline \multicolumn{7}{|l|}{11} \\
\hline \multicolumn{7}{|l|}{12} \\
\hline \multicolumn{7}{|l|}{13} \\
\hline \multicolumn{7}{|l|}{14} \\
\hline \multicolumn{7}{|l|}{15} \\
\hline \multicolumn{7}{|l|}{16} \\
\hline \multicolumn{7}{|l|}{17} \\
\hline \multicolumn{7}{|l|}{18} \\
\hline \multicolumn{7}{|l|}{19} \\
\hline \multicolumn{7}{|l|}{20} \\
\hline \multicolumn{7}{|l|}{21} \\
\hline \multicolumn{7}{|l|}{22} \\
\hline \multicolumn{7}{|l|}{23} \\
\hline \multicolumn{7}{|l|}{24} \\
\hline \multicolumn{7}{|l|}{1} \\
\hline \multicolumn{7}{|l|}{2} \\
\hline \multicolumn{7}{|l|}{3} \\
\hline 4 & & & & & & \\
\hline 5 & & & & & & \\
\hline 6 & & & & & & \\
\hline $1-\mathrm{Acc}$ & rdado $=$ AC & & $2-$ Tenso $=T$ & Irritado $=I R$ & & \\
\hline \begin{tabular}{|l} 
Dificuld \\
Dificuld
\end{tabular} & $\begin{array}{l}\text { ade } p / \text { Dormir }=D I D \\
\text { ade } p / \text { Permanecer }\end{array}$ & ormindo = DPD & $\begin{array}{l}\text { Aprensivo }=A \\
\text { Medo }=M\end{array}$ & $\begin{array}{l}\text { A Depressivo = DE } \\
\text { Apático }=\mathrm{AT}\end{array}$ & $\begin{array}{l}\text { Presente }=\mathrm{PE} \\
\text { Ausente }=\mathrm{AU}\end{array}$ & \\
\hline Agitaça & $0=A G$ & & Triste = TR & Humorado $=\mathrm{HU}$ & Visita: & \\
\hline Alteraç & âo de Humor = AH & & Ancioso $=\mathrm{NA}$ & $A$ Agressivo $=A G$ & Regularmente $=\mathrm{R}$ & \\
\hline Sonolê & ncia Diurna = SD & & Choroso $=\mathrm{Cr}$ & $F$ Impaciente = IM & Eventualmente $=\mathrm{E}$ & \\
\hline Dormi & $\mathrm{em}=\mathrm{DB}$ & & Tranquilo $=\mathrm{T}$ & & Esporadicamente = & \\
\hline Dormin & do no Momento = DN & & Sedado $=S E$ & & Reação da Criançaa & \\
\hline Sedadc & & & Outros $=\mathrm{OU}$ & (especificar) & Tremores $=\mathrm{TR}$ & \\
\hline Curariz & $\mathrm{ado}=\mathrm{Cz}$ & & 4 - Hostilidade & $\mathrm{le}=\mathrm{HO}$ & Suspiros = SU & \\
\hline & unicativo $=\mathrm{C}$ & & Afeto Triste = & & Hipertonicidade $=$ & \\
\hline Năo Cc c & municativo = NC & & Solidão $=$ so & & Agitaçăo = AG & \\
\hline $\begin{array}{l}\text { Dificuld } \\
\text { Afonia }\end{array}$ & ade de Manter a Cor & nunicaçăo = DC & Rejeiçăo = RJ & & Choro Intenso $=\mathrm{Cl}$ & \\
\hline Afonia & $=A$ & & Outros $=\mathrm{OU}$ & J (especificar) & $\begin{array}{l}\text { Acalma c/ Mãe = Al } \\
\text { Outros = OU (espe }\end{array}$ & \\
\hline Disartri & & & cond & dições de a & $=\mathrm{SCA}$ & \\
\hline
\end{tabular}


Oficio $\mathrm{n}^{\circ} 1061 / 2006$

$\mathrm{CEP} / \mathrm{SPC}$

Prezada Senhora:

O trabalho intitulado "VALIDAÇÃO DO DIAGNÓSTICO DE ENFERMAGEM DESOBSTRUÇÃO INEFICAZ DE VIAS AÉREAS DE CRIANÇAS SUBMETIDAS À CORREÇÃO CIRÚRGICA DE CARDIOPATIA CONGÊNITA", foi analisado pelo Comitê de Ética em Pesquisa, em sua $223^{a}$ Reunião Ordinária realizada em 17/04/2006, e enquadrado na categoria: APROVADO, bem como os Termos de Consentimento Livre e Esclarecido, de acordo com o Processo HCRP n $3229 / 2006$.

Aproveito a oportunidade para-apresentar a Vossa Senhoria protestos de estima e consideração.

Coordenador do Comite de Ética em Pesquisa do HCRP e da FMRP-USP

Ilustríssima Senhora

SIMONE DE OLIVEIRA PILEGGI

PROF $^{a}$ DR $^{\mathrm{a}}$ MARIA CÉLIA BARCELLOS DALRI (Orientadora)

Escola de Enfermagem de Ribeirão Preto-USP

Em mãos 